Institut of Animal Physiology and Animal Nutrition

Georg August University of Göttingen

\title{
POSSIBILITIES AND LIMITATIONS OF \\ FEEDING RAPESEED MEAL TO \\ BROILER CHICKS
}

\author{
Doctoral Dissertation \\ submitted for the degree of Doctor Agricultural Sciences \\ of the Faculty of Agricultural Sciences \\ Georg-August University Göttingen
}

by

AURANG ZEB

(born in Pakistan)

Göttingen, 1998

GEORG-AUGUST UNIVERSITY GÖTTINGEN 
Adviser : Prof. Dr. Udo ter Meulen

Co Adviser : Dr. Abdus Sattar 


\section{LIST OF ABBREVIATIONS}

$\begin{array}{ll}\text { AME } & \text { Apparant Metabolizable Energy } \\ \text { GIT } & \text { Gastro Intestinal Tract } \\ \text { HG } & \text { High Glucosinolate } \\ \text { LG } & \text { Low Glucosinolate } \\ \text { LH } & \text { Liver Haemorrhage } \\ \text { ME } & \text { Metabolizable Energy } \\ \text { OZT } & \text { Oxazolidinthione } \\ \text { PA } & \text { Phytic Acid } \\ \text { RSM } & \text { Rapeseed Meal } \\ \text { SBM } & \text { Soybean Meal } \\ \text { T3 } & \text { Triiodothyronine } \\ \text { T4 } & \text { Thyroxine } \\ \text { TMA } & \text { Trimethylamine } \\ \text { TMAO } & \text { Trimethylamine-Oxidase } \\ \text { TME } & \text { True Metabolizable Energy } \\ \text { TSH } & \text { Thyroid Stimulating Hormone } \\ \text { kGy } & \text { kilo Grey } \\ \text { GSL } & \text { Glucosinolates }\end{array}$




\section{INTRODUCTION}

\section{CONTENTS}

\section{REVIEW OF LITERATURE}

\subsection{NUTRIENTS}

2.1.1. Protein

2.1.1.1. Content of protein in rapeseed meal

2.1.1.2. Quality of rapeseed protein

2.1.1.3. In Vitro protein digestibility

2.1.2. Amino acids

2.1.3. Amino acid availability

\subsection{ANITNUTRIENTS}

2.2.1. Glucosinolates

2.2.1.1. General

2.2.1.2. Glucosinolates in rapeseed meal

2.2.1.3. Myrosinase and hydrolysis of glucosinolates

2.2.1.4. Effects of glucosinolates

\subsection{Goitroginicity}

2.2.1.4.2. Effects of glucosinolates on feed consumption

2.2.1.4.3. Effects of glucosinolates on liver in poultry

2.2.1.5. Treatment effect

\subsubsection{Sinapine}

2.2.2.1. General

2.2.2.2. Sinapine in rapeseed meal

2.2.2.3. Treatment effects

2.2.3. Phytic acid

2.2.3.1. General

2.2.3.2. Phytates in rapeseed meal

2.2.3.3. Treatment effects

\subsection{FEEDING TRIALS}

\subsubsection{General}

2.3.2. Experiments with HG-rapeseed meal

2.3.2.1. Performance

2.3.2.2. Sensory qualities

2.3.3. Experiments with LG-rapeseed meal

2.3.3.1. Performance

2.3.3.2. Sensory qualities

2.3.4. Comparative studies with LG- and HG-rapeseed meal

2.3.5. Treatment effects

\section{MATERIALS AND METHODS}

\subsection{Materials}




\subsection{Processing}

3.2.1. Control samples

3.2.2. Dry heat treatment

3.2.3. Autoclaving treatment

3.2.4. Irradiation treatment

3.2.5. Dehulling treatment

\subsection{Biochemical Analysis}

3.3.1. Determination of total glucosinolates

3.3.2. Determination of phenolics

3.3.2.1. Total Phenols

3.3.2.2. Sinapine

\subsubsection{Phytic acid}

3.3.4. Determination of crude protein in feed and feed ingredients

3.3.5. Amino acid analysis

3.3.6. In-vitro protein digestibility

\subsection{Chick Bioassays}

3.4.1. Experiment

1.

3.4.2. Experiment

2.

3.4.3. Experiment

3.

3.4.4. Experiment

4.

3.4.5. Experiment

5.

3.4.6. Experiment

6.

3.4.7. Experiment

7.
Effect of feeding different levels of rapeseed meal on the performance of broiler chicks

Effects of irradiation on the nutritional value of rapeseed meal for broiler chicks

Effect of dry heating and dehulling on the nutritional value of rapeseed meal for broiler chicks Effect of autoclaving time on the nutritional value of rapeseed meal for broiler chicks

Effect of pre- and post-extraction autoclaving on the nutritional value of rapeseed meal for broiler chicks Effect of feeding increased levels of heat processed rapeseed meal on the performance of broiler chicks Effect of feeding increased levels of irradiated rapeseed meal on the performance of broiler chicks

\subsection{Blood serum thyroid hormones analysis}

3.5.1. Determination of Triiodothyronine $\left(\mathrm{T}_{3}\right)$ in blood serum

3.5.2. Determination of Thyroxine $\left(\mathrm{T}_{4}\right)$ in blood serum

\subsection{Statistical Analysis.}

\section{RESULTS}

\subsection{BIOCHEMICAL ANALYSIS}

4.1.1. Phytic acid

4.1.2. Total phenols and sinapine

4.1.2.1. Effect of heating at temperatures for 30 minutes

4.1.2.2. Effect of autoclaving time

4.1.2.3. Effect of time of dry heating

4.1.3. Total glucosinolates

4.1.4. In-vitro protein digestibility

4.1.4.1. Effect of autoclaving

4.1.4.2. Effect of dry heating

4.4.4.3. Effect of irradiation and combination treatments 
4.1.5. Amino acid profile

4.1.5.1 Dry heating effect

4.1.5.2. Autoclaving effect

4.1.5.3. Irradiation effect

\subsection{FEEDING TRIALS WITH BROILER CHICKS}

4.2.1. Effect of feeding different levels of rapeseed meal on the performance of broiler chicks

4.2.2. Effects of irradiation on the nutritional value of rapeseed meal for broiler chicks

4.2.3. Effect of dry heating and dehulling on the nutritional value of rapeseed meal for broiler chicks

4.2.4. Effect of autoclaving time on the nutritional value of rapeseed meal for broiler chicks

4.2.5. Effect of pre- and post-extraction autoclaving on the nutritional value of rapeseed meal for broiler chicks

4.2.6. Effect of feeding increased levels of heat processed rapeseed meal on the performance of broiler chicks

4.2.7. Effect of feeding increased levels of irradiated rapeseed meal on the performance of broiler chicks

\section{DISCUSSION}

5.1. BIOCHEMOCAL ANALYSIS

5.1.1. Phytic acid

5.1.2. Phenolics

5.1.3. Glucosinolates

5.1.4. In-vitro protein digestibility

5.1.5. Amino acids

\subsection{CHICK BIOASSAY}

5.2.1. Effect of feeding different levels of rapeseed meal on the performance of broiler chicks

5.2.2. Effects of irradiation on the nutritional value of rapeseed meal for broiler chicks

5.2.3. Effect of dry heating and dehulling on the nutritional value of rapeseed meal for broiler chicks

5.2.4. Effect of autoclaving time on the nutritional value of rapeseed meal for broiler chicks

5.2.5. Effect of pre- and post-extraction autoclaving on the nutritional value of rapeseed meal for broiler chicks

5.2.6. Effect of feeding increased levels of heat processed rapeseed meal on the performance of broiler chicks

5.2.7. Effect of feeding increased levels of irradiated rapeseed meal on the performance of broiler chicks

\section{SUMMAY}

\section{ZUSAMMENFASSUNG}

\section{REFERENCES}




\section{LIST OF TABLES}

TABLE NO.

Title

PAGE

1

2

3

4

5

6

7

8

9

10

11

12

13

14

15

16

17

18

Area and production of different oilseed crops in Pakistan during 1995-96

Important Brassica species, their common names and countries where they make bulk of the rapeseed production.

Amino acids in rapeseed meal

Major glucosinolates in rapeseed meal

Composition of the Vitamin-mineral premix

Composition of the Experimental Diets used in experiment no. 1

Composition of the experimental Diets used in experiment no. 2

Composition (\%) of experimental Diet used in experiment No. 3

Composition of the experimental Diets Diets used in experiment no. 4

Composition of the experimental Diets Diets used in experiment no. 5

Composition of the experimental Diets Diets used in experiment no. 6

Some calculated analysis of the experimental diets

Composition of the experimental Diets Diets used in experiment no. 7

Some calculated analysis of the experimental diets

Effects of dry heat treatment time on the Phytic acid content (\%) in rapeseed meal

Effects of autoclaving time on the Phytic acid content (\%) in rapeseed meal

Effects of irradiation dose on the Phytic acid content (\%) in rapeseed meal

Effect of temperature of dry heat treatment for 30 minutes on sinapine and total phenol contents in rapeseed

Effect of time of autoclaving treatment $(103.5 \mathrm{kPa})$ on sinapine and total phenol contents in rapeseed

Effect of time dry heat treatment $\left(100^{\circ} \mathrm{C}\right)$ on sinapine and total phenol contents of rapeseed

Total glucosinolate content of control and processed rapeseed meal

Effect of autoclaving on in-vitro digestibility of rapeseed protein

Effect of dry heat treatment $\left(121^{\circ} \mathrm{C}\right)$ on in-vitro digestibility of rapeseed protein 
Effect of irradiation and combination methods on in-vitro digestibility of rapeseed protein

Effect of Heat treatments on the amino acid contents (\%) of rapeseed meal

Effects of autoclaving treatments $121^{\circ} \mathrm{C}$ at $15 \mathrm{psi}(103.5 \mathrm{kPa})$ on the amino acid contents (\%) of rapeseed meal

27 Effects of irradiation treatments on the amino acid contents (\%) of rapeseed meal

Effect of feeding different levels of rapeseed meal to broiler chicks on their biological performance

Performance of broiler chicks fed on diets containing irradiated rapeseed meal

30 Organ weights (\% of body weight) of broiler chicks fed on diets containing irradiated rapeseed meal

31 Performance of broiler chicks as influenced by feeding diets containing processed rapeseed meal

32 Effect of time of autoclaving $121^{\circ} \mathrm{C}$ at $15 \mathrm{psi}(103.5 \mathrm{kPa})$ on the nutritional value of rapeseed meal for broiler chicks

33 Performance of broiler chicks fed on diets containing autoclaved rapeseed meal

34 Organ weights ( $\mathrm{g} / 100$ body weight) as influenced by different treatments

35 Effects of feeding different levels of heat processed and control rapeseed meal on the performance of broiler chicks

36 Effects of feeding different levels of heat processed and control rapeseed meal on the dressing percentage and organ weights ( $\%$ of body weight) of broiler chicks

37 Effects of feeding different levels of irradiated and control rapeseed meal on the performance of broiler chicks

38 Effects of feeding different levels of irradiated and control rapeseed meal on the dressing percentage and organ weights (\% of body weight) of broiler chicks

Effects of feeding different levels of irradiated and control rapeseed meal on the thyroid hormone levels of broiler chicks 


\section{LIST OF FIGURES}

TABLE NO.

TITLE

PAGE

1

2

3

4

5

6

7

8

9

10

11

12

13

14

Structure of glucosinolates.

Some enzymatic hydrolysis products of glucosinolates

Structure of sinapine.

Structure of phytic acid and its possible interactions with minerals, proteins and starch.

Percent reduction in phytic acid content of RSM with dry heat treatment.

Percent changes in phytic acid content of RSM with autoclaving treatments.

Percent reduction in sinapine and total phenols due to different heating temperatures.

Percent reduction in total phenols and sinapine contents of RSM due to autoclaving time.

Percent reduction in sinapine and total phenol content of RSM due to different times of heating.

Percent reduction in glucosinolates content of RSM due to different treatments.

Percent increase in the in-vitro digestibility of rapeseed protein with autoclaving treatments.

Percent change in the in-vitro digestibility of rapeseed protein with heat treatments.

Percent change in feed consumption and weight gain of broiler chicks due to different levels of RSM in the diet.

Percent change in feed consumption and weight gain of broiler chicks due to control and irradiated RSM in the diet.

Percent change in feed consumption and weight gain of broiler chicks due to feeding heated and dehulled RSM in the diet.

Percent change in feed consumption and weight gain of broiler chicks due to control and autoclaved RSM in the diet.

Percent change in feed consumption and weight gain of broiler chicks due to differently autoclaved RSM in the diet.

Percent change in feed consumption and weight gain of broiler chicks fed higher levels of control and heated RSM in the diet.

Percent change in feed consumption and weight gain of broiler chicks due to higher levels of control and irradiated RSM in the diet. 
Effect of glucosinolates content in the feed on the weight gain of broiler chicks - linear relationship.

21. Effect of glucosinolates content in the feed on the weight gain of broiler chicks - curvi-linear relationship. 


\section{INTRODUCTION}

About $70 \%$ of the expenditures involved in poultry raising are feeding expenses. The higher the cost of feed, the more difficult it will be to raise poultry birds. The non availability of locally produced soybean (Table 1) and soybean meal in substantial amounts and with cheaper rates, compels the local poultry feed producers to use combinations of different feed concentrates as protein source. These commonly include fish meal, meat meal, blood meal, corn gluten of different protein concentrations etc. They are not only very costly, resulting in an overall increase in the cost of production of feed, but also the protein concentrates from animal source are generally highly infested and carry heavy microbial loads. Another reservation against these meals is that they are heavily salted at the time of processing, which can adversely affect the ion ratios in the resultant feed. Some of the reports in this field have also suggested that fish meal is a rich source of methyl- groups (SALMON et al., 1984); this can result in the production of fishy odour in the eggs of layers with brown shelled eggs. The preceding discussion suggests a search for cheaper protein concentrates which can be easily available in the local market, and will be nutritionally safe.

Rapeseed as an oilseed crop with a total area of 0.6 million ha. and total production of 0.5 million tones ranks first in area and production among other oilseed crops in Pakistan (Table 1). It ranks third in the world production of other oilseed crops (SHAHIDI, 1990). As an agricultural product rapeseed is important for its oil and protein contents. The seeds contain about $40 \%$ oil and on extraction of oil yield a meal with about 38 to $43 \%$ protein. The protein of rapeseed has a well balanced amino acid profile and in terms of several essential amino acids supplements favourably the protein from cereals.

The word "rape" in rapeseed finds its origin in the Latin word rapum which means turnips. Today the name rapeseed applies to the oilseeds of several species of the genus Brassica. The most important species contributing to rapeseed, their common names and the countries where they constitute the bulk of rapeseed production are listed in Table 2.

Table 1. Area and production of different oilseed crops in Pakistan during 1995-96

\begin{tabular}{|c|c|c|c|}
\hline S. No. & Oilseed crop & $\begin{array}{c}\text { Area } \\
\text { (\% of total area } \\
\text { under all oilseed } \\
\text { crops })\end{array}$ & $\begin{array}{c}\text { Production } \\
(\% \text { of total oilseeds } \\
\text { produced })\end{array}$ \\
\hline
\end{tabular}




\begin{tabular}{llcc}
1 & Rapeseed & 53.58 & 49.95 \\
2 & Ground nut & 17.15 & 22.14 \\
3 & Sunflower & 13.73 & 19.49 \\
4 & Sesamum & 14.99 & 7.73 \\
5 & Soybean & 0.35 & 0.53 \\
6 & Safflower & 0.20 & 0.16 \\
\hline
\end{tabular}

(Source. Federal Bureau of Statistics, Statistics Division, Government of Pakistan, Islamabad.)

Contributions of plants from the genus Brassica towards man's diet date back to immemorial times. There are indications that rapeseed was cultivated over three thousand years ago in India, from where it was introduced to China and Japan. It is however not clear when oil became a part of human diet apart from its use as fuel for lighting. Besides other vegetables of the genus Brassica use of rapeseed in Europe before the Christian era has been reported by Greek writers (BELL, 1982). Its regular field scale cultivation in Europe, however, began in the thirteenth century (DOWNEY, 1983).

Despite the significant amounts of the highly valued nutrients, use of rapeseed in human diets or in animal feeding has been limited, mainly because both oil and protein in rapeseed are accompanied by certain anti-nutritional factors. Oil from the traditional varieties of rapeseed contains some $22-60 \%$ erucic acid, a mono-unsaturated C 22 fatty acid. Feeding experiments have revealed that its inclusion in the diet of the experimental animals leads to the deposition of fat in the heart tissue and eventually to myocardial lesions (CORNER et al., 1985). Although reports of such experiments with human beings are lacking, results from animal trials have discouraged its large scale use in human diets (FENWICK and CURTIS, 1980).

Rapeseed meal is a by-product of the oil industry, and is the material left after the extraction of oil from rapeseed. If the extraction is carried only through pressing the seeds, the material left is some times referred to as rapeseed cakes or expeller. In common industrial processing, the oil is extracted using an additional extraction with an organic solvent (hexane) to affect a maximum extraction. The meal left after this process is generally called rapeseed meal (SHAHIDI, 1990). In this manuscript the term rapeseed meal will be applied to this latter product unless otherwise mentioned.

Table 2 : Important Brassica species, their common names and countries where they make bulk of the rapeseed production.*

\begin{tabular}{|c|c|c|c|}
\hline Species & Common Name & Country & Other names \\
\hline B. napus & Rape & Canada & Rapeseed \\
\hline
\end{tabular}




$\begin{array}{ll}\text { Europe } & \text { Oil Rape } \\ & \text { Oilseed Rape } \\ & \text { Swede Rape } \\ & \text { Winter Rape } \\ & \text { Argentine Rape } \\ & \text { Rapeseed } \\ \text { Canada } & \text { Oil Turnip } \\ \text { Europe } & \text { Polish Rape } \\ \text { India } & \\ \text { China } & \text { Rapeseed } \\ \text { India } & \text { Brown Mustard } \\ \text { China } & \text { Indian Mustard } \\ & \text { Oriental Mustard }\end{array}$

(Table adapted from SHAHIDI, 1990)

The meal left after the extraction of oil has a protein content of up to $50 \%$. Its use is however complicated by several anti-nutrients, the most prominent of them being the glucosinolates. These are sulphur rich compounds found in all members of the cruciferae family. Their hydrolysis products hamper the normal functioning of thyroid gland, resulting among other effects, in decreased levels of thyroid hormones production. These hormones are required to control the normal running of metabolism.

According to BELL, (1984) rapeseed would have been the most unlikely plant to be used for food supply, if its toxic factors were known before. It is to the credit of Canadian researchers in this field that the first low erucic acid variety was developed in 1968 and the first double low variety was released in 1974. The terms "double low" or "double zero" refer to low levels of erucic acid and glucosinolates. Some of the varieties are even called triple zero due to further improvement through reducing the fibre content (PUSZTAI, 1989) The name canola was adopted for the double low varieties of rapeseed in 1979. By definition Canola seeds contain less than $2 \%$ erucic acid and less than $30 \mu$ moles glucosinolates in its defatted meal. Although the United States Department of Food and Drug Administration recognised Canola as a separate species, in the scientific writings the names canola and double low or double zero-rapeseed are used interchangeably.

Although genetic manipulations have introduced much changes in the chemical composition of rapeseed through reduction in erucic acid and glucosinolates, these antinutrients have not yet been totally removed. These are, also, not the only factors detracting from the nutritional worth of rapeseed. The carbohydrates in the meal, which 
are mostly pectins, cellulose and amyloids, are not regarded as readily digestible, leading to low metabolizable energy content. Phytates present in the rapeseed meal cause the binding of divalent minerals and some proteins. The phenolic compounds have their own effects, the most prominent and thoroughly investigated being the egg taint or the fishy odour in the eggs of brown-shelled-egg-layers.

Reduction in the glucosinolate content in rapeseed through quality breeding and other techniques has been limited only to alkenyl-glucosinolates. Almost half of the remaining glucosinolates in the double improved varieties are the indolyl glucosinolates. Seen from a purely genetic point of view, it would not, theoretically, be possible to bring the glucosinolate content in rapeseed meal to zero. This means they will continue to pose problems if other methods could not be devised to remove them from the rapeseed meal. Situation in Pakistan in this regards is different. Bulk of the rapeseed and hence of rapeseed meal is that of high glucosinolate-varieties. And we will have to wait for quite a long time till the meal of the Canola type rapeseed varieties is available in some mentionable quantities.

A possible alternative to the breeding approach can be a technological processing method capable of removing the glucosinolates from rapeseed meal. Several methods have been proposed in this connection e. g. ammoniation, autoclaving, changes in desolventisation conditions, dehulling etc. each with its merits and demerits. The situation necessitates search for a suitable method which can also be adopted on commercial scale. Due to these and several other problems, which will be discussed in some detail in this study, a lot of research activity throughout the world is still dedicated to the feeding of rapeseed meal to different animals and poultry (JAMROZ, 1991).

Present work is focused on the possibilities and limitations of including rapeseed meal in the broiler ration under the feeding system prevalent in Pakistan, and to study the effects of different processing techniques on the nutritional value of rapeseed meal for broiler chicks. 


\section{CHAPTER 2}

\section{REVIEW OF LITERATURE}

Rapeseed and its meal has been the subject of numerous works published during the last 2-3 decades. Very conflicting views are found about its use as an ingredient in poultry rations. Where some reports advocate its use upto quite high levels, others deem it to be a forbidden fruit. The big breeding breakthrough in finding low glucosinolates character and subsequent breeding of LG-RSM varieties has paved the way to its use in substantial amounts. Meal from canola varieties is now recommended upto $20 \%$ in broiler's ration. The controversy, however, does not seem to have come to an end. Reports, criticising rapeseed meal as a poultry feed ingredient, are still coming every now and then. On the other extreme are those reports which recommend relatively higher levels of even HG-RSM on the basis of better amino acid balance. There is little possibility that the conflict will acquire political dimensions, because rapeseed meal is not a competitor for soybean. Instead, it is claimed, that soybean as the sole source of dietary protein does not yield satisfactory results; and if supplemented with rapeseed meal, the former can give higher growth performances in broiler chicks (SUMMERS and LEESON, 1978). The reason of this diversity of opinions, therefore, has to been searched within the technicalities involved. The experimental conditions, the breed of broiler chicks used in the study, the type of ration (practical type or otherwise), the duration of rapeseed meal feeding, the chemical composition of rapeseed meal used particularly the glucosinolate contents of rapeseed meal and of ultimate feed, and other ingredients of the ration used in such feeding trials have to be compared. The following review discusses some of these points in relatively larger detail.

\subsection{NUTRIENTS}

\subsubsection{PROTEIN}

\subsubsection{CONTENT OF PROTEIN IN RAPESEED MEAL}

Rapeseed meal serves as a protein supplement in the poultry rations. Rapeseed protein has been rated to be of high quality (SANDMANN and SCHÖNE, 1987). Numerous workers have reported the protein content of rapeseed meal belonging to different varieties of various rapeseed species. Table 1 shows some of the reported results of proximate analysis of rapeseed meal. An absolute value in this regard would rather seem to be unrealistic, as the variation in its content is considerably 
large. This variation is logical, as it is largely dependent on the variety from which the rapeseed meal has been prepared. According to BECKER and NEHRING, (1965), this variation is even stronger by the agro-climatic conditions than the genotype. Although the inter-specific differences in respect to the protein content are quite high, there seem to have been hardly any effect of the recent quality improvements brought about by genetic manipulations in the direction of reducing the erucic acid and/or glucosinolates (HENKLE and MOSENTHIN, 1989).

According to CLANDININ and ROBBLEE, (1983) the protein content of rapeseed meal from B. napus is higher (38-39\%) than that from B. compestris (35\%), whereas the commercial rapeseed meal (with unknown or mixed genetic origin) contains on the average $36-37 \%$ protein. These specific differences in the content of protein are supported by the findings of DURRANI and KHALIL, (1990) who reported a crude protein value of $41.5 \%$ for $B$. juncea, $37.6 \%$ for B. napus and 35,8\% for B. carinat. BLAIR et al., (1986a) have reported protein contents of 46.9,42.9 and $41.0 \%$ for varieties Triton, Westar, and commercial canola, respectively.CLANDININ et al., (1986) have reported an average value of $37-38 \%$ for the low glucosinolates (canola) varieties, whereas BELL, (1984) has reported an average value of crude protein $(\mathrm{N} \mathrm{x}$ $6.25) \%$ to be 42.8. Instead of giving a single average value, HENKLE and MOSENTHIN, (1989) have divided them in to low (36.3\%), middle (39.8\%) and high $(43.7 \%)$ protein contents.

Crude protein is calculated by multiplying the total nitrogen content with a factor of 6.25. This is based on the assumption that all proteins contain on the average $16 \%$ nitrogen. TKACHUK, (1969) and FINLAYSON, (1974) have reported that variation in the amino acid composition of protein and amounts of non protein nitrogen render the $\% \mathrm{~N}$ x 6.25 inappropriate for estimating the true protein in most cereal grains and oil seeds. According to BELL, (1984) the correct factor for converting nitrogen to true protein is about 5.53. HENKLE and MOSENTHIN, (1989) on the other hand have reported $17.5 \%$ nitrogen in rapeseed protein, leading to a conversion factor of 5.7 which is the same as for soybean.

\subsubsection{QUALITY OF RAPESEED PROTEIN}

Results regarding the quality of rapeseed meal protein are rather contradictory.LO and HILL, (1971) graded the rapeseed protein to be equal in quality to casein on the basis of protein efficiency ratio and net protein utilisation data in rats.OLIVER et al., (1971) on the other hand found that only the low glucosinolates rapeseed meal resulted in a nitrogen retention equivalent to that of casein.GRUEHN and ZANDER, 
(1989) reported a crude protein digestibility value of $81.9-82.6 \%$ for different rapeseed meals and 79.4-82.2\% for expeller (cakes).BJÖRKLUND et al., (1990) on the other hand reported a value of $77 \%$ for the rapeseed meal protein digestibility. Protein digestibility in rapeseed meal is influenced to a large extent by the presence of relatively disproportionate amounts of hulls. Dehulling of the rapeseeds resulted in meals with 7 to $11 \%$ higher digestibility in different low and high glucosinolates rapeseed meal (LESSIRE and BAUDET, 1986). In broiler chickens the true digestibility of crude protein and amino acids has been reported to decrease with age from 3 to 6 week of age. Digestibility of these nutrients was reported to be higher in males as compared to females chicks (ZUPRIZAL and CHEGNEAU, (1991).

KEITH and BELL, (1984) did not find significant differences in weight gain of rats fed heated $\left(105^{\circ} \mathrm{C}\right)$, steamed or ammoniated rapeseed meal. They concluded that while ammoniation is effective in reducing the glucosinolate concentrations of rapeseed meal, this processing step has an adverse effect on the protein quality, particularly lysine availability, of the meal thereby decreasing its nutritional value.

GRALA et al., (1994) reported that increasing the toasting temperature from $90^{\circ} \mathrm{C}$ to $95^{\circ} \mathrm{C}$ and $100^{\circ} \mathrm{C}$ decreased total and available lysine contents $(5.20,4.85,4.33$ and $4.28,3.84,3.00 \mathrm{~g} / 16 \mathrm{~g} \mathrm{~N}$, respectively). It was concluded that protein value of RSM obtained from Polish oil factories using solvent extraction, is highly dependent on the toasting temperature. But other parameters of rapeseed processing such as moisture and duration of heating may also affect the nutritional value of RSM.

\subsubsection{IN-VITRO PROTEIN DIGESTIBILITY}

It seems that very little work on the in-vitro protein digestibility of rapeseed meal has been conducted, particularly on the effects of different processing techniques. However effects of various treatments on thein-vitro protein digestibility in different legumes have been frequently reported. KOHNHORST et al., (1990) reported that protein concentrates and protein isolates from common dry beans had lowin-vitro protein digestibility, which was improved by heating, with moist heat being more effective than dry heat.

LIN and LAKIN, (1990) studied thermal denaturation of soy proteins as related to their dye binding characteristics and functionality and reported that unheated soy meal was found to have rather poorin-vitro protein digestibility, which was gradually improved by heat treatment (steaming under atmospheric pressure) up to 40 minutes, where the in-vitro protein digestibility was maximum using single enzyme (pronase) 
system. The digestibility of the samples heated for more than 40 minutes then fell slowly as the heating time increased. The explanation given by these authors is an interesting. The effect of heating on the in-vitro protein digestibility is two fold. Heat inactivates protease inhibitors and cause conformational changes of the proteins. The latter effect is important because peptide bonds become more accessible to enzymes. Native proteins are resistant to hydrolysis by proteases owing to their fairly compact structures in which most of the peptide linkages are buried inside the molecules. Consequently of the closely packed peptide chains are partially unfolded upon denaturation, hydrolysis would be facilitated and in-vitro protein digestibility improved. However, excessive heating causes a reduction in in-vitro protein digestibility. Thus, changes in digestibility are not necessarily proportional to the degree of protein denaturation. With prolonged heating the conformations of the protein may refold to give new, enzyme resistant structures, possibly stabilized by S$\mathrm{S}$ polymerization. Spraying acid solutions $(2.5$ and $5 \% \mathrm{~V} / \mathrm{W}$ of $\mathrm{HCl}$, acetic acid, formic acid and propionic acid) reduced the in vitro digestibility of rapeseed meal (KHORASSANI et al., 1989).

ROGULSKI, (1989a) determined the non-protein nitrogen from rapeseed meal. The NPN from post-extraction rapeseed meal (toasted and untoasted) contained mainly $\mathrm{N}$ of low-molecular peptides (rich in asparagine, glutamine and basic amino-acids), glucosinolates and free amino acids. The NPN fraction of untoasted rapeseed meal contained peptide-N (about 60\%), glucosinolate-N (19\%) and free NPN (21\%); that of toasted rapeseed meal contained 62, 7 and $31 \%$, respectively. About $30 \%$ of NPN in toasted rapeseed meal (including peptides and glucosinolates) were insoluble in water and 80\%-ethanol. ROGULSKI, (1989b) in another study determined the nutritive value of non-protein nitrogen fraction extracted from toasted and untoasted rapeseed meal on the basis of feed intake, digestibility, nitrogen utilization and body weight gain in rats. As compared with soybean and rapeseed meal as well as with other products obtained from toasted and non-toasted rapeseed meal the NPN nutritive value was very low. Nutritive value was reduced with increasing amounts of NPN fractions in the diet. The nutritive value of rapeseed residues, particularly nontoasted ones, compared with the NPN fraction was reasonably high.

FERNANDEZ et al., (1993) determined the protein solubility in oilseed meals using Comassie blue dye binding. Protein solubility decreased as autoclaving time increased for all oilseed meals, with the response being greatest for soybean meal. JENSEN et al., (1995) studied the effect of heat treatment on glucosinolates and nutritional value of rapeseed meal in rats. Samples of rapeseed meal were toasted at $100^{\circ} \mathrm{C}$ for $0,15,30,60$ or 120 minutes, air dried and analysed for protein solubility, 
amino acids, carbohydrates and nitrogen utilization in rats. Four commercial rapeseed meal samples (extracted meal and press cake from Denmark, extracted meal from Germany and extracted meal from China) were also analysed. Protein solubility decreased linearly from 85 to $81,61,52$ and $40 \%$ after the respective toasting times. True digestibilities of rapeseed were 77.0, 73.9, 72.1, 72.9 and 71.2\% after $0,15,30$, 60 and $120 \mathrm{~min}$ toasting, respectively.

\subsubsection{AMINO ACIDS}

Although the correct conversion factor of nitrogen to protein value, can have important nutritional implications in terms of protein quality, digestibility and nitrogen utilisation, it remains most meaningful to concentrate on amino acids and their physiological availability along with crude protein BELL, 1984). Rapeseed meal has a physiologically suitable amino acid combination HANKEL and MOSENTHIN, 1989). Table 3 summarises some of the reported data on the amino acid profile of rapeseed meal. Large variations in the contents of different amino acids of rapeseed meal cane be noted. These variations can be explained on the basis of differences in genetic background, agroclimatic conditions, procedures adopted for oil extraction and analytical techniques (FENWICK and CURTIS, 1980).

Attempts to improve the nutritional quality of rapeseed meal include, among others, to treat rapeseed meal with ammoniated methanol. This is aimed at reducing the glucosinolates and other aninutrients in rapeseed meal. SHAHIDI et al., (1992) determined the impact of this treatment on the essential amino acid contents of rapeseed meal from four different varieties and failed to record any adverse effect with respect to these amino acids. Heat treatments of proteins have been reported to result in losses in the lysine content. Heating the protein with steam and under atmospheric pressure resulted in lysine losses only when the heating time was longer than 40 minutes. During heat treatment the e-amino group of the reactive lysine may react with reducing surgars (Maillard reaction). Alternatively, dehydroalanine (a decomposition product of cystine or serine) may react with the free amino group of lysine to form lysino-alanine. A third possible reaction is that between amide group of glutamine and free amino group of lysine to form a peptide type linkage with the release of ammonia. Any one or all of these reactions could cause significant loss of available lysine.(LIN and LAKIN, 1990)

JENSEN et al., (1995) studied the effect of heat treatment $\left(100^{\circ} \mathrm{C}\right)$ on glucosinolates and nutritional value of rapeseed meal. Total lysine content dropped from 5.93 to 5.72 and $4.91 \mathrm{~g} / 16 \mathrm{~g} \mathrm{~N}$ after 30 and 120 minutes toasting, respectively. The content of all other amino acids remained unchanged except cystine which decreased by $12 \%$ 
after 120 minutes toasting. NASI and SILJANDER, (1991) conducted research on the effects of thermal processing on digestibility and protein utilization of rapeseed meal of medium $(25-55 \mu \mathrm{g} / \mathrm{g}$ defatted meal $)$ and low $(<25 \mu \mathrm{g} / \mathrm{g})$ glucosinolate type in diets for growing pigs. The various cultivars or differently processed RSMs were similar in

proximate 
Amino Acids Table 
composition. However, thermal treated 0-RSM had a slightly reduced lysine content compared to untreated meal.

\subsubsection{AMINO ACID AVAILABILITY}

The availability for the essential amino acids lysine, histidine, arginine, threonine, valine, cystine, methionine, leucine, isoleucine, and phenylalanine ranged from 75 to 94,84 to 92,73 to 96,78 to 91,73 to 91,69 to 93,75 to 92,79 to 93,86 to 92 and 80 to 95\%, respectively (BARBOUR and SIM, 1991, SALMON et al. 1991, MUZTAR et al. 1980, MUZTAR and SLINGER, 1980, NWOKOLO et al., 1976b). MEEROV and GRIGOR'EVA (1988) reported an overall $90 \%$ availability value for all amino acids in rapeseed meal for chicks.

LESLIE and SUMMERS, (1975a) conducted studies on the amino acids balance of rapeseed meal. In a series of experiments using $15 \%$ protein semipurified diet containing rapeseed meal as the sole source of protein they observed that addition of lysine significantly reduced growth rate in chickens. Addition of arginine or methionine alone gave little response, but the combination of these amino acids significantly improved the performance. The reported antagonism LEVIS et al., 1963, JONNES et al., 1966, DEAN and SCOTT, 1968) between lysine and arginine in the case of casein (lysine : arginine $=2: 1$ ) was not considered to be working in the case of rapeseed meal, which has a lysine to arginine ratio of about 1:1. It was postulated that since rapeseed meal contains 3\% tannins and arginine may play a role in the excretion of tannins in addition to its normal metabolic functions FULLER et al., 1967), arginine may be required in higher amounts.

Similar lysine-arginine relationship in rapeseed meal has also been reported by other workers in chicks (OLOMU et al., 1974) and rats (GORRIL et al., 1974). It was suggested that interference with arginine metabolism is likely to be at the metabolic level, because no differences in the digestion or absorption of arginine from rapeseed meal and soybean meal were found (CHO and BALLY, 1970, TAO et al., 1971).

The view that part of the absorbed arginine from rapeseed meal may be utilised by the chicks to take part in the tannins excretion was further substantiated byLESLIE et al., (1976). They observed that addition of tannic acid to soybean meal result in severe growth depression which was partly corrected by supplemental arginine. They concluded that the response of birds to added arginine decreased with increased age. It was suggested that, although there does not seem to be an amino acid imbalance in the content, it is possible that part of the arginine is being utilised for metabolic 
functions other than anabolic processes, such as tannic acid metabolism, thus creating a deficiency per se.

The lysine-arginine imbalances, however, were observed by SUMMERS and LEESON, (1978) only when rapeseed meal was used as the sole source of dietary protein in chickens ration and associated with supplemental lysine, arginine and methionine. With practical type diets no growth depression was observed. It appeared that the amino acid balance of rapeseed meal was more favourable in practical type diets in which part of the protein came from soybean meal and corn, than that of rapeseed meal alone. Hence a synergistic balancing effect was observed among the three proteins.

SUMMERS and LEESON, (1986) reported that lysine in canola meal was $90 \%$ as available as that in soybean meal, while methionine availability was estimated to be similar in both meals, based on gain and feed : gain response in chicks. They also concluded that leucine and isoleucine were not likely to be limiting in canola with respect to chicks requirements. In further studies (1989) they observed that methionine in canola/ rapeseed meal is not limiting and that excess methionine can depress performance when added to canola meal. They suspected that methionine toxicity may be at work in studies when it is fed in higher amounts as an attempt of supplementation; and where no additional glycine is added to alleviate the toxic effects of excessive methionine.

SUMMERS et al., (1990a) conducted experiments to study the influence of Ca and/or S supplementation of rapeseed meal based diets on the performance of broiler chicks. They found a significant cystine x $\mathrm{Ca}$ interaction. Calcium supplementation resulted in significant improvement in the performance; the reverse was true for supplemental cystine. This led to a reduced response in performance caused by $\mathrm{Ca}$ supplementation. Higher levels of Ca supplementation could nullify this adverse effect of cystine. These authors explained the phenomenon on the basis of the fact that feeding $S$ as $S$ salt or as sulphur amino acids increases acid excretion, which is accompanied by an increase in urinary calcium excretion (WHITING and DRAPER, 1980, 1981, WHITING and COLE, 1986). In another study SUMMERS et al., (1990b) confirmed the existence of the above mentioned interaction between $\mathrm{Ca}$ and $\mathrm{S}$ in rapeseed meal feeding to poultry. They also observed no alterations in the liver weight due to these interactions, suggesting little or no liver involvement in the reduced performance (caused by high levels of dietary sulphur). Similar mineral imbalances were reported from another study conducted by the same author (SUMMERS et al., 1992). Proteins and amino acids in rapeseed hulls have been reported to have lower digestibility and contribute to the lower digestibility values of 
rapeseed meal protein and amino acids (BELL, 1984). ZURIPAL and CHEGNEAU, (1992) reported that true digestibility of amino acids in whole and dehulled rapeseed meals were 80.1 and $86.0 \%$, respectively, as compared to $88.9 \%$ in soybean meal. Lysine availability was 76.9 and $81.4 \%$ in the whole and dehulled rapeseed meals, respectively, in chicks. The respective values were 72.8 and $78.3 \%$ in another experiment by the same authors.

GRALA et al., (1994) studied the effect of stages in the oil plant and of toasting in laboratory conditions on the protein value of double-low rapeseed products.. In whole rapeseed, toasting significantly decreased total and available lysine and glucosinolates compared with untreated seeds. Increasing temperature and time of laboratory heating resulted in a linear decrease $(\mathrm{P}<0.001)$ in lysine, available lysine and protein value of defatted rapeseed cake in rats. The decrease in lysine content depended more on the increase of temperature than heating time.

\subsection{ANTINUTRIENTS}

\subsubsection{GLUCOSINOLATES}

\subsubsection{GENERAL}

Glucosinolates, commonly referred to as goitrogens, are uniform class of naturally occurring compounds found exclusively in the plant kingdom, and only in limited number of dicotyledonous families (UNDERHILL, 1980). All members of the cruciferae family, including rapeseed, contain glucosinolates FENWICK and CURTIS, 1980). About 100 glucosinolates have been so far identified SÖRENSEN, 1990, FENWICK and HEANY, 1983). They are all characterised (UNDERHILL, 1980) by:

a: A general structural skeleton (Fig.1); different glucosinolates differing only with respect to their side chains $-\mathrm{R}$.

b: Their ability to be hydrolysed by the enzyme myrosinase to yield glucose and a labile aglucone, which spontaneously rearranges.

Essentially the basic structure of all glucosinolates is more or less the same, with a side chain (-R group) and beta-D-thioglucose attached to carbon atom number 0 $(\mathrm{C}=\mathrm{N})$. It has been established through $\mathrm{X}$-ray crystallography that the configuration around the $=\mathrm{N}$ is with the side chain $-\mathrm{R}$ anti to sulphate $\mathrm{WASER}$ and WATSON, 1963, OLSEN and SÖRENSON, 1981).

Differences in the chemical nature of the side chain $-\mathrm{R}$ lead to the differences between glucosinolates and also in the ultimate hydrolysis end products. On the basis of structure of side chain glucosinolates are classified into alkenyl-glucosinolates, 
having an open chain - $\mathrm{R}$ group and indolyl-glucosinolates, having a hetrocyclic $-\mathrm{R}$ group (HENKEL and MOSENTHIN, 1989).

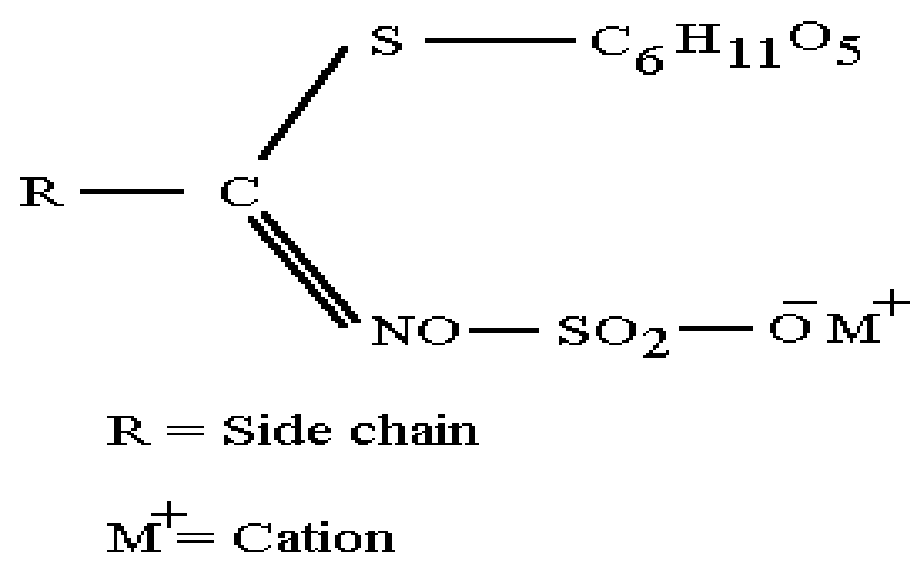

Fig. 1. Structure of Glucosinolate

\subsubsection{GLUCOSINOLATES IN RAPESEED MEAL}

Rapeseed does not contain all known glucosinolates. Only 27 have been identified in rapeseed (JERG and SÖRENSEN, 1986). Out of these only six (Table 10) are present in significant quantities in rapeseed (HENKEL and MOSENTHIN, 1989, BELL, 1984). The dominant glucosinolates of B. napus and B. oleifera are progoitrin and gluconapin, where as in $B$. campestris the dominant glucosinolates are gluconapin and glucobrassicanapin (HENKEL and MOSENTHIN, 1989). Quantitatively, $B$. napus varieties were found to contain double the amount of total glucosinolates found in B. campestris (APPELQUIST, 1972, BLAIR and SCOUGAL, 1975).

Table 4. Major glucosinolates in rapeseed meal

\begin{tabular}{lll}
\hline Glucosinolates & \multicolumn{1}{c}{$\begin{array}{c}\text { Semi-systematic } \\
\text { Name }\end{array}$} & \multicolumn{1}{c}{ R - Group } \\
\hline Progoitrin & 2-OH-3-butenyl & $\mathrm{CH}_{2}=\mathrm{CH} . \mathrm{CHOH}$. $\mathrm{CH}_{3}$ \\
Gluconapin & 3 - butenyl & $\mathrm{CH} 2=\mathrm{CH} \cdot\left(\mathrm{CH}_{2}\right)_{2}$ \\
Glucobrassicanapin & 4 - pentenyl- & $\mathrm{CH}_{2}=\mathrm{CH}\left(\mathrm{CH}_{2}\right)_{3}$ \\
Napoleiferin & 2 - OH - 4 - pentenyl- & $\mathrm{CH}_{2}=\mathrm{CH} \cdot \mathrm{CH}_{2} \mathrm{CH} . \mathrm{CH}_{2}$ \\
& & $\mathrm{OH}$
\end{tabular}




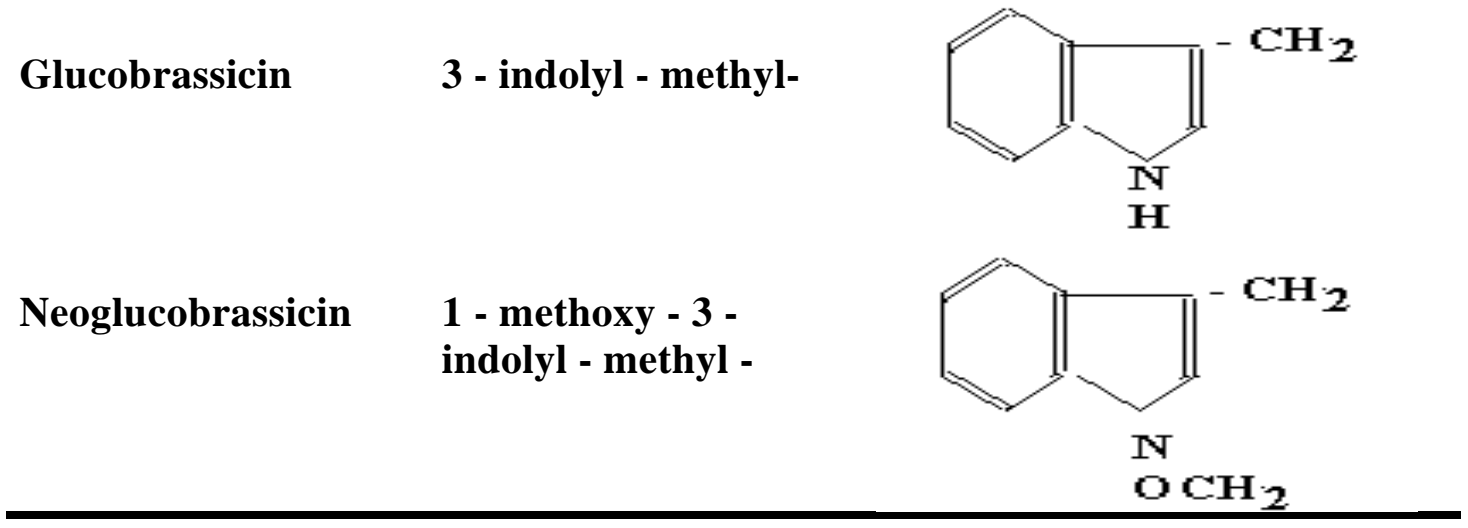


Practically all glucosinolates present in seeds are concentrated in the meal of rapeseed after the extraction of oil. In case of $B$. napus varieties they make up to $8 \%$ of the weight of meal and the meal of $B$. campestris they may amount 3 to $4 \%$ of the weight (APPELQUIST, 1972).

The low glucosinolate character in B. napus cultivar Bronowski was discovered in 1967. It was a major breakthrough which was utilised to breed the so called low glucosinolates rapeseed cultivars. Tower and Erglu varieties, which have been developed from crosses with Bronowski have been reported to contain less than on tenth the glucosinolates level of normal rapeseed cultivars FINLAYSON et al., 1973, STEFANSSON and KONDRA, 1975, and RÖBBELEN, 1976). The name canola was adopted in Canada for such varieties which contained low levels of glucosinolates and erucic acid. By definition from Canola Council of Canada, Canola varieties are required to contain less than $30 \mu$ moles/g of one or any combination of the four known aliphatic glucosinolates, i e gluconapin, progoitrin, glucobrassicanapin, and napoleiferin, in its defatted meal (SHAHIDI, 1990). It is however noteworthy that the reduction achieved through genetic manipulations in glucosinolates contents was limited only to the glucosinolates having butenyl- and pentenyl sides chains. The contents of indolyl glucosinolates, which also occur in significant quantities in rapeseed meal remained unchanged. These glucosinolates, which yield isothiocyanates as their hydrolysis products, make up almost half of the total glucosinolates in the low glucosinolates rapeseed meal MCGREGOR, 1978, SLOMINSKI and CAMPBELL, 1989)

\subsubsection{MYROSINASE AND HYDROLYSIS OF GLUCOSINOLATES}

Glucosinolates as such are considered to be non toxic. It is, rather, their hydrolytic products which are associated with diverse antinutritional effects TAPPER and TERRY, 1973, BENN, 1977). Hydrolysis of glucosinolates is by the enzyme myrosinase (Thioglycoside glycohydrolase). Myrosinases as mixture of isoenzymes (BUCKWALDT et al., 1986)) have been found to occur in tissue of all plants containing glucosinolates. They are, however, separated from each other in the intact tissues. The cellular disruption, which is necessary for effective oil extraction from rapeseeds, results in the release of myrosinases which leads to the hydrolysis of glucosinolates .Figure 2 (UNDERHILL, 1980) gives schematic representation of

glucosinolates hydrolysis caused by myrosinase. The glucosinolates molecule breaks to yield D-glucose and an aglucone. In neutral $\mathrm{pH}$ the aglucone releases a sulphate (ion) and rearranges to an isothiocyanate. In weak acidic medium the result is the 
formation of a nitrile with the release of elemental sulphur. Beta hydroxyl bearing isothiocyanates cycles to give oxazolidin-2-thione (UNDERHILL, 1980, LARSEN, 1981).

Like other enzymes myrosinase is heat labile. Efforts have been made to inactivate it before processing. Microwave inactivation of myrosinase has been successfully accomplished, this however, was dependent on moisture content and variety of the sample (YAW et al., 1991). Thermal processing of rapeseeds prior to oil extraction results in inactivation of myrosinase (KOZLOWSKA and NOWAK, 1982, CAMPBELL et al., 1987) and hence the bulk of glucosinolates found in such meals are of intact glucosinolates. However CAMPBELL et al., (1980) have shown that some glucosinolates hydrolysis takes place during the commercial processing.

Myrosinase activity has also been observed in gastro- intestinal bacteria of several animal species and poultry (MARANGOS and HILL, 1974, BOUGON et al., 1988). SLOMINSKI et al., (1988) reported the results of a 24 hours glucosinolates balance trial on laying hens. They reported low recovery of intact glucosinolates in excreta and low absorption of intact glucosinolates, assessed from blood analysis. These results suggested glucosinolates hydrolytic activity in the gastro-intestinal tract. They noted that contents from ceaca or ceaca plus colon were the major source of hydrolytic activity responsible for decomposition of intact glucosinolates in the GIT of laying hens. They observed increase in the content of free thiocyanate ions over those in the diet. Similar findings had already been reported byCAMPBELL and SLOMINSKI, (1987). SMITH and CAMPBELL, (1976) observed that when progoitrin is hydrolysed under the conditions existing in the digestive tract of laying hens, nitrils are the predominant product. SLOMINSKI and CAMPBELL, (1985) reported that hydrolysis of indolyl-glucosinolates in the hind gut of hens fed canola meal in the diet was a source of significant portion of SCN-present in the excreta of poultry. CAMPBELL and SLOMINSKI, (1989) supported this and noted a low production of SCN- in the hind gut of hens fed on rapeseed meal. They, however, noted that this is readily excreted by the hens. SLOMINSKI et al., (1983) observed that recovery of intact glucosinolates in faeces of cecactomised hens was significantly higher than in intact hens, indicating that most of the hydrolytic activity came from cecum.

Ability of poultry birds to absorb the ingested intact glucosinolates from the gastrointestinal tract as such is limited. Only the hydrolytic breakdown products are absorbed in physiologically significant amounts. FREIG et al., (1987) observed in three glucosinolates balance trials that although poultry birds were capable of 
absorbing glucosinolates in intact form, the extent of tissue deposition of these compounds was small. PAIK et al., (1984) found higher levels of SCN- in the blood plasma of hens fed 10-20\% rapeseed meal in their diets. These were 4-5 times higher than in soybean meal fed birds. Eggs from rapeseed meal fed hens contained higher levels of SCN- in their ovalbumin.

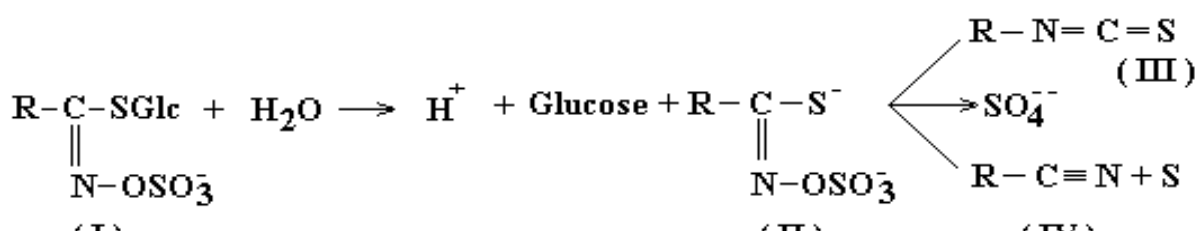<smiles>[R]C(O)CN=CSC</smiles>

( $v$ )<smiles>[R]C1CNC(=S)O1</smiles>

(VI)

Fig. 2: Some enzymatic hydrolysis products of glucosinolates.

\subsubsection{EFFECTS OF GLUCOSINOLATES}

\subsection{Goitroginicity}

Goitrogenic properties of rapeseed in rats have long been known (KENNEDY and PURVES, 1941). Presence of glucosinolates in the diets leads to hyperthyroidism in animals and poultry. It also reduces the level of circulating thyroid hormones and alters the ratio between T3 and T4 in blood. Enlarged thyroid size,increased thyroid stimulating hormones levels and reduced thyroid hormones in the blood of poultry with rapeseed meal feeding has been widely reported CLANDNIN et al., 1966, BELL and BELZILE, 1965, MATSUMOTO et al., 1968, JACKSON, 1969 ,CHIASSON and SHARP, 1979, GOH et al., 1985, NASSAR and ARSCOT, 1986a, b).

These effects have been attributed to the glucosinolates hydrolysis products. The glucosinolate progoitrin (2-hydroxy,3-butenyl-glucosinolate) yields on hydrolysis as 
end product a cyclic compound 5-venyl,2-thio oxazolidinthione, called goitrin due to its strong goitrogenic effects (KJAER, 1960). Most of the other glucosinolates hydrolysis products have also been frequently reported to be implicated in the anti thyroidal activity, differing only in the degree of severity and mode of action BELL, 1984).

T3 and T4 can be synthesised by the thyroid gland only when sufficient iodine is supplied in the diet. Iodine ions are removed from the blood against a concentration gradient, oxidised to elemental iodine and inserted into a tyrosine radical (KARLSON, 1969). Isothiocyanates block iodine transport from the blood into the thyroid (KARLSON, 1969, CLANDININ et al., 1966). ANKE, (1980) reported that isothiocyanates compete for the available iodine at the site of thyroxin formation in thyroid gland, resulting in a decreased synthesis of thyroxin. Goitrin has been shown to hinder the iodide oxidation, resulting in its decreased availability for organification (binding) to the aromatic ring of tyrosine which serves as the basic structural nucleus for thyroxin formation (GMELIN, 1969, BERGNER and SCHMIDT, 1972). CLANDININ et al., (1966) included $0.15 \%$ of 5-venyl,2-oxazolidinthione in the diet of chicks and observed depression in growth rate and thyroid enlargement. Initially decreased radio iodine uptake and increased excretion by the thyroid gland was noted. However, a physiological equilibrium was reached after 3-4 weeks.

The reduced synthesis of thyroid hormones which control, through a negative feed back relationship with pituitary, the production of thyroid stimulating hormones (TSH), results in enhanced production of the later ANKE et al., (1980). The increased physiological activity resulting from competition for iodine leads to increased thyroid size, also to alteration in the ratio of triiodothyronine to thyroxin (T3 : T4) and thyroid histology (LO and HILL, 1971, BELL et al., 1972, BURGNER and SCHMIDT, 1972, LEUNG and MARCH, 1976, NISHI and DAXENBICHLER, 1980). Supplemental dietary iodine in rapeseed meal containing poultry diets has been reported to reduce the thyroid size (NASSAR and ARSCOTT, 1986a).

Feeding of rapeseed meal was shown to cause slight depression in T4 levels of blood, but a significant depression was noted in the level of T3 concentrations in broiler chickens between 3 and 5 weeks of age (CHIASSON et al., 1979). Dietary supplementation of thyroxin in the rapeseed meal including broilers diet did not have any beneficial effects on growth (SUMMERS and LEESON, 1977a).

ROTKIEWICZ and KOZLOWSKI, (1984) studied the morphology of the thyroid gland of broiler ducks fed an all-mash diet supplemented with rapeseed meal. 
Ducklings were reared on diets containing 5 or $10 \%$ rapeseed meal until slaughter at 2 months of age. The lower concentration of rapeseed meal had little or no effect on the thyroid, but various pathological changes were produced by the higher concentration. It was reported by BAO et al., (1996) that the amount of damage to the thyroid was related to the content of OZT and ITC in the feed of broiler chicks. Hyperplasia of epithelial cells and haemorrhage or hyperaemia of the thyroid developed when OTZ + ITC were greater than $2700 \mathrm{mg} / \mathrm{kg}$.

\subsection{Effects of glucosinolates on feed consumption}

Reduced feed intake in poultry birds with diets containing rapeseed meal has been frequently reported (SUMMERS et al., 1967, 1969, 1978, SLINGER et al., 1978a, b). Although rapeseed meal contains substantial concentrations of phenolic compounds, which reportedly impart bitter taste and astringency to the diet containing them (SHAHIDI and NACZK, 1992), the behaviour of reduced feed intake by poultry birds with rapeseed meal inclusion in their diet can at least partly be explained on the basis of glucosinolate contents of rapeseed meal.

According to HENKEL and KALLWEIT, (1989) broilers kept on rapeseed meal containing diets consumed much less diets as compared to controls. Reduction in feed uptake was dependent on the amount of glucosinolates in the rapeseed meal. The broilers given diets containing the highest $(12209 \mu$ moles $)$ glucosinolates refused to eat after a few days of the start of the experiment. LESLIE and SUMMERS ,(1972) observed reduced feed intake in laying hens with inclusion of rapeseed meal in the diets. LEE et al. (1984) noted substantial reduction in feed intake of pigs and attributed it to the levels of glucosinolates in the meals. SUMMERS et al., (1985) suggested that while the glucosinolates levels in canola rapeseed meals have been substantially reduced, there is still a small percentage in the meal and hence may account, among other effects, for lower feed intake.

These observations find further support from the work by HULAN and PROUDFOOT, (1980) who, while comparing the performance of broiler chickens with rapeseed meals, noted that the low feed consumption effect observed with high glucosinolate rapeseed meal were not there in the case of low glucosinolate rapeseed meal. LEESON et al., (1987) also reported no effect of canola (low glucosinolates rapeseed) meal on feed intake of broilers and layers at a level of 25 and 38\% inclusion in the diets. However LESLIE and SUMMERS, (1972) and CLANDININ and ROBBLEE, (1983) have reported substantial reduction in the feed intake of diets 
containing various rapeseed meal in chickens, presumably due to high levels of glucosinolates. 


\subsection{Effects of glucosinolates on liver in poultry}

Increase in liver weight relative to body weight with glucosinolates rapeseed meal has been frequently reported . KORELESKI et al., (1987) reported liver weights of $1.82,2.26$, and $2.47 \mathrm{~g} / \mathrm{kg}$ body weight in broilers fed soybean meal, low glucosinolates rapeseed meal and high glucosinolates rapeseed meal, respectively. ROTKIEWICKZ et al., (1988) observed increased liver weights (20.7 to $25 \mathrm{~g}$ ) in broilers with $6 \%$ rapeseed meal feeding in the diets. Increase in the liver weight of rats due to feeding on 00-rapeseed meal containing diets has also been reported by BILLE et al., (1983). CAMPBELL, (1987a) observed a low but consistent LH in birds fed canola rapeseed meal, however, he could not establish a relationship between liver weight and haemorrhage liver in birds fed canola rapeseed meal. It was concluded that while the incidence of LH varied with dietary level of intact glucosinolates, the effects was related more to total intact glucosinolates than to specific glucosinolates, such as progoitrin. MARCH et al., (1978) observed haemorrhage lesions not only in liver but also in other tissue of the birds fed rapeseed meal and suggested the presence of an agent affecting the integrity of the vascular system.

GRIFFITHS et al., (1980) observed that the inclusion of $10 \%$ rapeseed meal in broiler diets did not cause severe liver haemorrhage, however, it did produce a significant enlargement of liver; and changes of plasma enzyme activities indicative of damage to the bilary system of the chicks. They suspected rapeseed meal to possess some hepatotoxic factors. Higher Levels of bile acids in rapeseed meal fed hens than controls was also reported by BROMIDGE et al., (1985), however, these were not found to be related to the severity of LH lesions.

PEARSON et al., (1983b) noted increased activities of asparate transaminase, lactate dehydrogenase and alkaline dehydrogenase in the plasma of layers and broilers fed rapeseed meal $(500 \mathrm{~g} / \mathrm{kg})$ in the diets. These were suggested to be indicative of liver damage. Oxazolidinethione was thought to be the causative agent.TREFNY et al., (1989) observed significant increases in the liver and slight increase in thyroid weight. These changes, however, had no effects on their physiological functions, and on broiler productivity. Rapeseed meal was found to have no effect on serum enzymes activities.

MARTLAND et al., (1984) observed liver haemorrhage (LH) in birds fed high or low glucosinolates rapeseed meal $(200 \mathrm{~g} / \mathrm{kg})$ in the feed. However, there were no histological differences in the livers of the two groups. Haemorrhages emanated from intrahepatic portal veins, capillaries and sinusoids, and were associated with 
degenerative changes in vessel walls. Increased asparate transaminase activities in plasma indicated necroses. They also observed hyperglycaemia and reduced triglycerides in blood. Glucosinolates could not be held responsible as the sole agent for these effects as the addition of myrosinase to the diet did not increase its hepatotoxicity, inspite of the reducing effects on productive performance ( reduced egg production).

These results were supported by those of KONCICKI et al., (1991) who fed 26-30\% rapeseed meal to broilers for the total fattening period and noted lesions in liver cells, reflected by increased activities of alanine and asparate transaminases and alkaline phosphatase. An increase cholesterol content in the blood was also noted. Contradicting these results SZYMKIEWICZ et al., (1988) did not find any effect of feeding rapeseed meal on the activities of blood serum transaminases and alkaline phosphatase. They also noted no change in the level of blood cholesterol.WIGHT et $a l .$, (1986) studied liver haemorrhages induced by rapeseed meal. Adult cockerels of a commercial egg-producing strain did not develop liver haemorrhages when maintained for 12 weeks on a diet containing rapeseed meal $400 \mathrm{~g} / \mathrm{kg}$ food.

BROMIDGE et al., (1985) studied the bile acids in the plasma of laying hens fed rapeseed meal. Laying hens fed a diet containing rapeseed meal (RSM; $400 \mathrm{~g} / \mathrm{kg}$ ) for 12 weeks had higher bile acid levels $(154 \mu \mathrm{mol} / \mathrm{litre})$ than hens fed a control soybean diet $(116 \mu \mathrm{mol} /$ litre). The incidence of liver haemorrhages was higher (34.8\%) in RSM-fed hens than in controls $(21 \%)$, but the severity of the lesions did not correlate with the bile acid concentration in affected birds. Livers of RSM-fed birds showed no hepatocyte degeneration outside the immediate vicinity of the haemorrhage. Canalicular bile plugs were never seen. The incidence of liver haemorrhages (13\%) and plasma bile acids ( $85 \mu \mathrm{mol} / \mathrm{litre})$ were lower in hens fed a diet containing betaaminopropionitrile $(0.5 \mathrm{~g} / \mathrm{kg})$, a known lathyrogen. Administration of the hepatotoxin alpha-naphthyl isothiocyanate over 4 days induced necrosis of hepatocytes and resulted in elevated bile acid concentrations $(262 \mu \mathrm{mol} / \mathrm{litre})$. It was concluded that laying hens fed high levels of RSM develop cholestasis but the toxic principle is not known. BAO et al., (1996) reported that nitrile was more toxic to liver than OZT and ITC and caused plasma protein to solidify. Hyalin thrombi appeared in liver or kidney capillaries when nitril was $2350 \mathrm{mg} / \mathrm{kg}$.

\subsubsection{TREATMENT EFFECT}


Works dealing with the effects of different processing techniques on the nutrients and antinutrients are relatively fewer . Exposure of desolventized meal to toasting (90 $120{ }^{\circ} \mathrm{C}$ for 3540 minutes) is considered necessary for glucosinolates degradation and partial removal of their breakdown products. The same is true for the conditioning of rapeseeds prior to oil extraction, the aim of which is, among others, to inactivate native enzymes including myrosinase. Myrosinase has been reported to have been reduced by over $80 \%$ during the conditioning, pressing, extraction and toasting (MAWSON et al., 1995), while the content of isothiocyanates and oxazolidinethione were reduced over $60 \%$. SIONEK et al., (1994) determined the effect of different stages of processing of improved rapeseed meal on the content of antinutritional substances and its nutritive value. Rapeseed meal was prepared in the laboratory and heated with steam for 30 and $60 \mathrm{~min}$. The results showed that glucosinolate content decreased in proportion to the intensity of heating.GRALA et al., (1994) studied the effect of temperature and heating time in the laboratory $\left(100^{\circ} \mathrm{C}\right.$ and $120^{\circ} \mathrm{C}$ for 10,20 or $30 \mathrm{~min}$ ) on defatted expeller cake. In whole rapeseed, toasting significantly decreased total glucosinolates compared with untreated seeds.

JENSEN et al., (1995) studied the effect of heat treatment on glucosinolates and nutritional value of rapeseed meal in rats. Samples of rapeseed meal were toasted at $100^{\circ} \mathrm{C}$ for $0,15,30,60$ or $120 \mathrm{~min}$, air dried and analysed. The total content of glucosinolates was 16.2, 12.3, 8.7, 4.9 and $0.8 \mu \mathrm{mol} / \mathrm{g}$ DM after 0, 15, 30, 60 and 120 min toasting, respectively. 4-Hydroxy-glucobrassicin was more heat-sensitive than the aliphatic glucosinolates progoitrin and gluconapin.

ROTKIEWICZ et al., (1990) studied the pathomorphology of thyroid glands and liver of broiler chicks fed diets containing rapeseed oil meal of various cultivars. Groups of one-day old Astra B broiler chickens were given complete feeds without rapeseed meal (control) or containing rapeseed oil meal from raw or toasted rapeseeds of various local cultivars: 0 Skrzeszewicki and Beryl, 00 Boh and Jantar and 00 Canadian Canola. Greatest histopathological changes in liver were seen in chickens fed on raw 0 cultivar rapeseed oil meal. Pathomorphological changes in thyroid gland and liver were much less with feeding toasted 0 cultivar rapeseeds. The same authors in another study (ROTKIEWICZ et al., 1993) conducted pathomorphological examination of thyroid glands and livers of broiler chickens fed with diets with maximum content of extracted rapeseed oil meal of the Polish Jantar cultivar and Canadian canola. It was concluded that steaming whole rapeseeds before starting technological processes of fat extraction is useful. 
HEIDENREICH and LOWE, (1993) examined in small-scale experiments effect of hydrothermic and thermic (infrared and hot air) treatment on improvement of fat availability, reduction of glucosinolate, protein solubility in water and pellet stability of 00 rapeseed. and reported that hydrothermic and thermic preconditioning further decreased glucosinolates.

QUINSAC et al., (1994) observed improvement in the nutritive value of high and low glucosinolate rapeseed meal by aqueous extraction. To evaluate the responsibility of glucosinolates in rapeseed meal for metabolic disorders, nutritional trials were carried out on chickens using 2 rapeseed meal fractions obtained by cold aqueous extraction from a dehulled rapeseed meal (Brassica napus). Glucosinolate content was $168.9 \mu \mathrm{mol} / \mathrm{g} \mathrm{DM}$ in the extract and $2.88 \mu \mathrm{mol} / \mathrm{g} \mathrm{DM}$ in the residue. Until 4 weeks old chickens were fed on diets containing $30 \%$ rapeseed meal (reference diet, GSL $15.2 \mu \mathrm{mol} / \mathrm{g}$ diet) or rapeseed meal extract to provide the same amount of GSL as the reference diet, or residue to provide GSL $0.6 \mu \mathrm{mol} / \mathrm{g}$. Diets containing extract significantly reduced body weight $(-14 \%)$ and induced hypertrophy of liver $(+17 \%)$, thyroid $(+154 \%)$ and kidney $(+8.5 \%)$. Similar effects on these organs occurred with the other diets, except for the soybean meal control without rapeseed and that prepared with extract free of GSL. The latter results indicate that cold water extraction can remove toxic factors in rapeseed meal while maintaining high nutritive value. Mean contents of 5-vinyl-1,3-oxazolidine-2-thione (5-VOT) found in liver, thyroid, kidney, muscle and plasma varied in connection with progoitrin amount in diets. However, great variations with individual chickens were seen and no significant correlation was observed between 5-VOT contents and body weight or target organ weight. In spite of an identical glucosinolate content, the diet prepared with extract alone or associated with the residue of extraction was more toxic than the diet prepared with rapeseed meal. GSL content in rapeseed fractions did not seem to be the only factor responsible for toxicity.

Ammonia treatment of rapeseed meal has been frequently tested and recommended for its beneficial effects on its nutritive value for poultry. NACZK and SHAHIDI, (1987) reported a laboratory procedure for methanol-ammonia-water treatment for rapeseed meal. The process included a two-minute blending of ground seed with methanol-ammonia-water followed by a 15 minutes quiescent time. At this time hexane was added and the mixture was stirred vigorously for further two minute period. The meal was then filtered off and the two phases were separated. The process reduced the glucosinolate contents to level below the detection limits. COXWORTH and MCGREGOR, (1980) indicated that ammoniation was effective in 
reducing the content of glucosinolates in mustard meal.GOH et al., (1982) reported its reducing effects on sinapine contents of canola meal.

ARONEN and VANHATALO, (1992) reported that heat-moisture treatment effectively reduced glucosinolate content of rapeseed.KOZLOWSKA et al., (1987) conducted studies on the nutritional value of hydrothermally treated rapeseed meal and reported that this treatment not only resulted in the complete inactivation of myrosinase but also reduced substantially the various glucosinolate derivatives in rapeseed meal. MANSOUR et al., (1993) reported on the effect of processing on the antinutritive factors and nutritive value of rapeseed products. The reductions in antinutritional factors by heat processing ranged from 47 to $94 \%$ for glucosinolates, from 9 to $43 \%$ for phytic acid and from 41 to $67 \%$ for tannic acid after toasting and autoclaving treatments. Rapeseed products have a balanced amino acid composition and their proteins are relatively high in sulphur-containing amino acids and lysine. Chemical score and limiting amino acids of rapeseed products varied considerably, depending on the type of process. Heat treatment improved the digestibility of rapeseed proteins in vitro.

With the inclusion of treated (glucosinolates free) normal rapeseed meal in hens diet at $300 \mathrm{~g} / \mathrm{kg}$ in comparison with a soybean meal diet, the incidence of liver haemorrhage in all rapeseed meal groups was similar and higher than in soybean meal group. Mortality from causes other than LH was higher in all rapeseed meal groups It was suggested that other factors in rapeseed meal alone or in combination in with glucosinolates may be responsible in inducing LH (WIGHT et al., 1987)

Supplemental iodine, however, did not increase the intake of rapeseed meal containing diet by broilers (SCHÖNE et al., 1989). It was also observed that the compounds causing increased liver size were not located in the hulls, as the most profound effects were found when dehulled seeds were fed. Samples with very low myrosinase activity and toasted samples did not affect the liver size, indicating that intact glucosinolates were more harmless than their hydrolytic products. However, increase in the liver size could not be correlated to any histological disorder. Processing designed to reduce tannins (in rapeseed meal) are generally ineffective in reducing rapeseed glucosinolates and, in fact dehulling increases the relative proportion of glucosinolates in the remaining meal (MAWSON et al., 1993).

SCHÖNE et al., (1989) noted in their 7 week feeding trial on broiler chicks that compared with results of soybean meal (SBM) diets, intake of rapeseed diets decreased by $6 \%$; iodine $(1 \mathrm{mg} / \mathrm{kg})$ did not influence feed intake or growth. There was a significant increase in thyroid weight with iodine-free rapeseed diets and iodine- 
free SBM diets, whereas thyroid weight decreased with $\mathrm{Cu}$-treated rapeseed diets, but was still higher than in iodine-free SBM diets. Thyroxine concentration in blood was 12.5 and 20.4, 11.4 and 19.8, and 14.3 and $20.2 \mathrm{nmol} /$ litre for soybean, untreated rapeseed meal, and treated rapeseed meal diets without or with iodine supplement.

SCHÖNE et al., (1993) reported that soaking rapeseed meal in aqueous myrosinase or copper sulphate solution and subsequent drying reduced the content of glucosinolates by more than $90 \%$. Chickens given I-deficient diets with myrosinasetreated RSM showed growth reduction, incomplete feathering, leg injuries and severe goitre. Serum thyroxine (T4) could not be detected. Giving myrosinase-treated RSM plus I, or giving other RSM diets irrespective of I administration, did not reduce growth. RSM diets without I markedly increased thyroid weight: there were no differences between RSM variants. In sera of chickens fed on untreated RSM or RSM treated with $\mathrm{Cu}$, T4 could be detected, suggesting that in I-deficient conditions differences in serum T4 concentration between RSM groups indicate a differing antithyroid activity. With I supplementation, RSM had a significant effect on thyroid weight. Largest thyroids (5-fold heavier) were in chickens given myrosinase-treated cRSM.

SLOMINSKI and CAMPBELL, (1989) traced the thermal degradation products of indole glucosinolates in commercial rapeseed (Brassica napus) meal and found that one of the minor components was identified as 3-indoleacetonitrile (IAN) based on comparisons of gas liquid chromatography retention times and mass spectral data with authentic IAN. The major indole derivative was identified as 4-hydroxy-3indoleacetonitrile by comparison of mass spectral data with that for IAN and by establishing its precursor as 4-hydroxy-3-indolylmethylglucosinolate.

CAMPBELL and SLOMINSKI, (1989) conducted balance trials utilizing intact (control) and caecectomized laying hens to emphasize hindgut fermentation, to investigate the sources of thiocyanate ion $(\mathrm{SCN})$ in the excreta of poultry fed on lowglucosinolate rapeseed meal (LG RSM). Meals varying in amounts of indole glucosinolate degradation products were prepared from defatted low-glucosinolate rapeseed by subjecting this meal to varying degrees of heat treatment and by solvent extraction. Lack of correspondence between indole glucosinolates decomposed and SCN released in hindgut fermentation indicated the presence of an unidentified thermal degradation product(s) of indole glucosinolates in defatted low-glucosinolate rapeseed subjected to prolonged (60 min) heating and in commercial LG RSM. The concentration of the degradation product(s) was 1.4-1.9 $\mu \mathrm{mol} / \mathrm{g}$ in 2 samples of LG RSM. Fractionation experiments showed the compound(s) to be relatively insoluble 
in ethanol when compared with intact indole glucosinolates. Hindgut fermentation of hydroxybenzylglucosinolate resulted in a low production of SCN, and laying hens excreted free SCN readily.

NUGON-BAUDON and co-workers, (1988) studied the production of toxic glucosinolate derivatives from rapeseed meal by intestinal microflora of rat and chicken. Interesting observations were recorded from this work. It was inferred that rat intestinal microflora was responsible for growth depletion, which was suggested to be proportional to the glucosinolates concentration in the diet. In contrast the chicken microflora failed to restrict the growth. An aged dependent sensitivity of the chicken towards glucosinolates was also noted. Sterilization of the RSM diet did not affect the growth of either species, but the weight of the thyroid was significantly higher if the diet was not irradiated. Irradiation caused partial destruction of progoitrin. FENWICK, et al., (1984 b) reported that treatment of high glucosinolate Brassica napus meals with lime, ammonia or by micronisation lowered their tainting potential by reducing their progoitrin, soluble tannin and sinapine contents.

EYRE and ROOKE, (1983) observed the effect of solvent extraction upon the utilisation of rapeseed meal protein by rats. Untreated and formaldehyde-treated rapeseed meals were subjected to a two-stage extraction with aqueous and undiluted acetone. The extraction process significantly reduced the glucosinolate contents of the untreated and treated meals on a proportional basis by about 0.85 and 0.75 , respectively. Formaldehyde-treatment did not affect the true digestibility or biological value of the meal protein. Solvent extraction did not affect true digestibility but increased the biological value of both untreated and treated meals by nearly $20 \%$.

LIU et al., (1993) conducted a survey of nutrients and toxic factors in commercial rapeseed meal in China and evaluation of detoxification by water extraction. The meal contained oxazolidinethione 1.5-1.1 and isothiocyanates $1.4-1.0 \mathrm{mg} / \mathrm{g}$ whereas the cake contained 2.3-2.2 and 2.7-1.8 mg/g, respectively. Tannins 5-6 and phytates $20 \mathrm{~g} / \mathrm{kg}$ were present. Detoxification involving water extraction alongside seed processing was examined on a pilot scale, and the meal was evaluated in feeding trials with pigs, broilers and rabbits. Water extraction removed nearly all glucosinolates and significantly increased crude protein content. Much improvement in animal growth performance was achieved when feeding detoxified meal compared with untreated feed. Treatment rendered the meal suitable for use as a main protein supplement in diets. 


\subsubsection{SINAPINE}

\subsubsection{GENERAL}

Sinapine is the choline ester of 3,5-dimethyl -4 hydroxycinnamic acid (sinapic acid). It is one of the best characterised phenolic compounds in plants. Presence of phenolic compounds in the rapeseed meal may contribute to certain undesirable properties including dark colour, bitter taste, and astringency (KOZLOWSKA et al., 1990). The content of phenolic anti nutritional factors in rapeseed meal and flour has been reported to nearly 30 fold that of soybean meal, however, the data on phenolic compounds and tannins in rapeseed meal are fragmentary and diverse \$HAHIDI and NACZK, 1992).

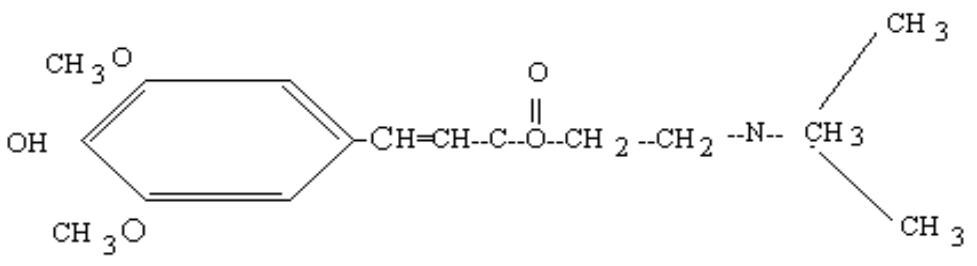

Sinapic Acid

Choline

Fig. 3 . Structure of Sinapine

(Adopted from Hankel and Mosenthin, 1989)

\subsubsection{SINAPINE IN RAPESEED MEAL}

The total content of phenolic compounds in rapeseed meal have been reported to range from $1542 \mathrm{mg}$ to $1837 \mathrm{mg}$ per $100 \mathrm{~g}$ of defatted meal NACZK and SHAHIDI, 1989). Sinapic acid is the predominant phenolic acid in rapeseed meal. It accounts for about $73 \%$ of the total free phenolic acids released from phenolic and glucosidichydrolysis (KRYGIER et al., 1982, DABROWSKI and SOSULSKI, 1984).

Among the phenolic esters sinapine is the most abundant in rapeseed meal (KRYGIER et al., 1982). BILLE et al., (1983) reported investigations of the total 
pool of choline esters isolated from Erglu and Candle seeds and noted that sinapine was the dominant one. The concentration was similar to those of other cultivars. Most of the sinapine was found to be concentrated in cotyledons, and hulls contained only small amounts of choline ester of sinapic acid.NACZK et al., (1992b) reported that sinapic acid accounted for 65 to $85 \%$ of the total free and 71 to $97 \%$ of the estrified phenolic acids in rapeseed meal from four varieties.

Several workers have reported the sinapine content of rapeseed meal from various varieties of compestris and napus species. BLAIR and REICHERT, (1984) reported that the defatted meal from dehulled canola contained $2.85 \%$ sinapine. The respective value for non canola rapeseed meal sample was $2.67 \%$. Rapeseed meal belonging to Brassica napus have been reported higher levels (1.65-2.26\%) of sinapine as compared to those from B. compestris (1.22-1.54\%). FENWICK et al., (1984b) reported a range of 1.17 to $1.83 \%$ of sinapine content on $B$. napus rapeseed meal. According to LAJOLO et al., (1991) the average sinapine content were $3.4 \%$ in rapeseed meal.

VERMOREL et al., (1987) conducted studies on the effects of sinapine and other phenolic compounds on food intake and nutrient utilization in growing rats. Six groups of 10 Sprague-Dawley rats were given diets to appetite for 15 days: control based on wheat starch and fish meal supplemented with methionine; rapeseed oil meal (sinapine $3.80 \mathrm{~g} / \mathrm{kg} \mathrm{DM}$ ); ethanol/water extracted rapeseed oil meal (sinapine $0.48 \mathrm{~g} / \mathrm{kg} \mathrm{DM}$ ); control diet plus $3.74 \mathrm{~g}$ of extracted sinapine; control diet, $3.72 \mathrm{~g}$ sinapine plus other phenolic compounds; or control diet plus the hydrolysis products of sinapine and other phenolic compounds. During the first 8 days the DM intake and live weight gain of the rats were significantly reduced by the intake of sinapine and other phenolic compounds. However, after that adaptation period, feed intake, growth rate and feed efficiency were similar to control values. DM, energy and nitrogen digestibility and protein utilization were not affected by sinapine intake but were slightly reduced with diets containing sinapine and other phenolic compounds.

\subsubsection{TREATMENT EFFECTS}

In addition to the use of various breeding techniques in order to reduce the sinapine contents, several processing methods have been tested to achieve this goal post harvest. Naczk et al., (1992 b) studied the effect of ammonia- methanol treatment of rapeseed meal on the sinapine content. It was found that 41 to $75 \%$ of total, 45 to $79 \%$ of free sinapic acid and 82 to $93 \%$ of total estrified phenols reduced as a result of this treatment. Treatment of seeds with methanol-ammonia or gaseous ammonia 
has been shown to remove up to $94 \%$ of sinapine from mustard meal. This treatment has been reported to have beneficial effects in terms of, among others, reducing the fishy odour in eggs of brown egg layer chickens (GOH et al., 1987).

FENWICK et al., (1984 b) treated rapeseed meal with lime, ammonia and micronization ( in which the meal was subjected to radiant heat produced by ceramic bodies) and studied the effect of these treatments on tainting potentials of rapeseed meal when fed to laying hens. Although these treatments lowered the progoitrin, soluble tannins, and sinapine contents, these effects were not sufficient to prevent inhibition of trimethylamine oxidation and subsequent rise in egg trimethylamine levels beyond tainting threshold. It was suggested that removal of the genetic defect from poultry stock was the only realistic approach to deal the problem.

FENWICK et al. (1984 a) observed significantly higher egg trimethylamine with dehulled rapeseed meal as compared to whole rapeseed meal, reflecting the higher sinapine content of cotyledons. These workers also included neomycin in the drinking water of experimental hens, with the idea to reduce intestinal/caecal micro flora and thereby reducing the possible hydrolysis of sinapine and progoitrin. This, however, did not work and tainting of eggs still occurred. It was concluded that antibiotics have little role in this regard. It was suggested that breed of hens was the most practical way to combat the egg taint problem.

TAYARANIAN and HENKEL, (1991) reported that processing of rapeseed meal under standardised conditions $\left(4 \% \mathrm{Na}_{2} \mathrm{CO}_{3}\right.$, pressure of 30 bar and for a time of 45 min.) resulted in complete reduction in the content of sinapine and glucosinolates which, in turn, resulted in a significant reduction of fishy taint in eggs of tainter hens.

\subsubsection{PHYTIC ACID}

\subsubsection{GENERAL}

Phytic acid is myo-inositol-1,2,3,4,5,6-hexakis-dihydrogen phosphate with the chemical structure given below. In most seeds it serves as primary phosphorus and myo-inositol reserve. It also stores other cations and energy COSGROVE, 1980, GREENWOOD, 1990). Generally one or two phosphate groups of the same phytic acid or belonging to different phytic acid molecules form complex with a cation (GOSSELIN and COGHLAN, 1953). A mixed salt of phytic acid is one in which more than one cations bind with the same phytic acid molecule. The binding of phytic acid with minerals is $\mathrm{pH}$ dependent and complexes with different cations have 
varying solubilities. Phytic acid also bind protein molecules SCHWENKE et al., 1986, MOTHES et al., 1987). Protein-phytic acid complex is insoluble but may become soluble when the $\mathrm{pH}$ decreases below 3 (CHERYON, 1980).

The complexing of protein molecule with phytic acid in the intermediate $\mathrm{pH}$ range is mainly mediated through multivalent cations. these may dissociate at higher $\mathrm{pH}$ values to insoluble phytates and soluble sodium-proteinate (THOMPSON and CHO, 1984a, b, THOMPSON, 1987). Whether directly complexed with phytic acid or through cations, the very phenomenon of protein binding leads to decreased solubility, functionality and digestibility of proteins (MAGA, 1982).Binding of minerals with phytic acid also results in their reduced physiological availability (COSGROVE, 1980).

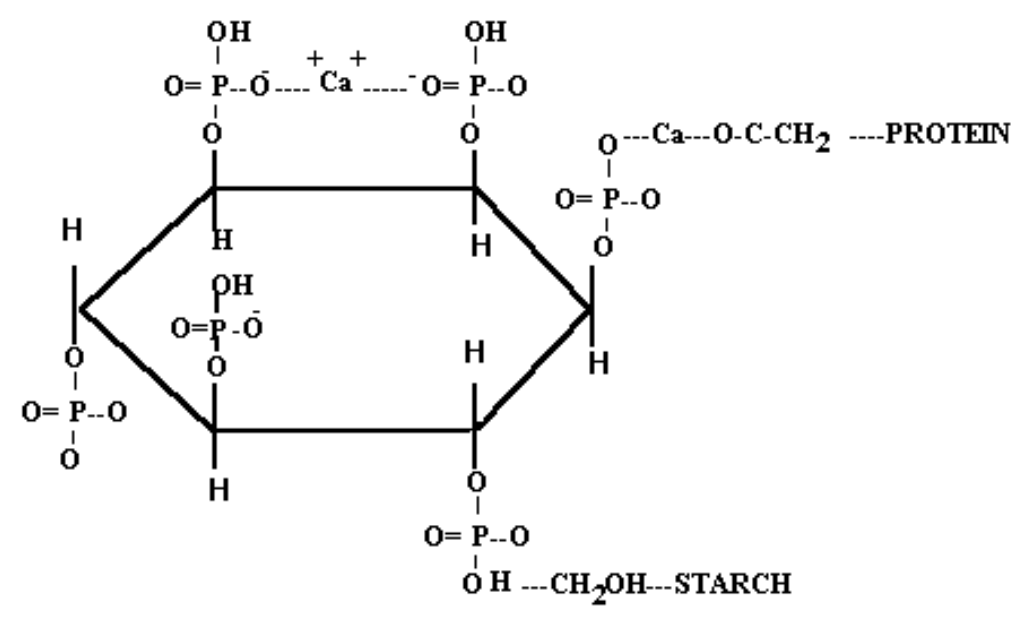

Fig. 4 : Structure of Phytic Acid and its possible interactions with Minerals, Proteins and starch.

(Adopted from Thompson 1986)

\subsubsection{PHYTATES IN RAPESEED MEAL}

According to ANJU, (1977) the average phytic acid content of different rapeseed meals was $4.4 \%$ in the dry matter. About 60 to $70 \%$ of total $\mathrm{P}$ was bound by phytic acid. The content of phytic acid in whole rapeseed ranged from 2-4\% according to REDDY et al., 1982). The value for oil free rapeseed meal varied from 2 to 5\% according workers (NWOKOLO and BRAGG, 1977, TZENG, 1987, TZENG et al., $1988 \mathrm{a}, \mathrm{b})$. 
Phytic acid has been reported to typically exist as salt of $\mathrm{Ca}, \mathrm{Mg}$, and K MILLS and CHONG, 1977, YIU et al., 1982). LOTT, (1985) reported the presence of naturally occurring protein-phytic acid complexes and suggested that further complex formation may take place during oil extraction from the seeds. ALI and HOUDE, (1987) also reported that phytates in intact rapeseed are bound to protein molecules.

Reports are available which confirm reduced availability of $\mathrm{P}, \mathrm{Ca}, \mathrm{Mg}$ and $\mathrm{Zn}$ from rapeseed meal due mainly to phytic acid (MARCH 1987). In a comparative study on the availability of minerals in four protein supplements ( rapeseed meal, soybean meal, palm kernel oil meal, and cotton seed cake)NWOKOLO and BRAGG, (1976 a) observed that the availabilities of $\mathrm{P}, \mathrm{Ca}, \mathrm{Mg}$, and $\mathrm{Zn}$ were inversely related to the phytate contents. Since there was also a negative correlation between mineral availablities and fibre contents, they suggested that phytic acid may not be the only factor influencing the mineral availability in rapeseed meal and other oilseed meals.

SETH et al., (1975) studied the binding of Zn-65 by rapeseed meal and soybean meal and found that rapeseed meal binds twice as much $\mathrm{Zn}$ as soybean meal. However they failed to explained this $\mathrm{Zn}$ binding behaviour of rapeseed meal only on the basis of tannin contents and suggested that some other factor/s may also be additionally involved in the phenomenon. SUMMERS and LEESON, (1985 c) were, however, of the view that inspite of the higher content of phytic acid and lower availability, presumably due to the phytate binding in rapeseed meal there was little likelihood of $\mathrm{Zn}$ deficiency being precipitated when rapeseed meal is used in commercial broiler rations. SUMMERS et al., (1985 a) supplemented canola rapeseed meal containing diets of laying hens with $2 \%$ phytic acid and noted poorer shell quality of eggs, indicating effects of phytic acid on Ca availability.

\subsubsection{TREATMENT EFFECT}

Techniques have been developed for the removal of phytic acid from rapeseed, particularly during the preparation of protein isolates and concentrates. Approaches include the use of differential solubility between protein and phytic acid, membrane separation, enzyme treatment and ion exchange resin. But while phytic acid may be reduced during the preparation of protein isolates and concentrates, a better approach to the utilization of rapeseed may be the reduction of phytic acid in the seed before processing and consumption. (THOMPSON, 1990)

Very little work has been done on the effect of the common processing methods such as cooking, autoclaving, microwave etc. on phytic acid in rapeseed probably due to 
the fact that rapeseed is not normally eaten as the whole seed. However, studies on legumes, cereals and other oilseeds showed that phytic acid is generally stable under ordinary processing conditions (THOMPSON, 1990).

Pure phytic acid is in aqueous solution at pH 6.0 was lost (about 50\%) after 1 hour autoclaving (DE BOLAND et al. 1975), but in biological systems e.g. in cereals and oilseeds less than $10 \%$ loss was observed autoclaving for 0.5 - 2.0 hours (Lease, 1966, DE BOLAND et al., 1975). Boiling of legumes also did not result in a significant breakdown of their phytic acid content (KUMAR et al., 1978, Reddy et al., 1978). OLOGHOBO AND FETUGA, (1984) also could not record a significant reduction in phytic acid of soybean due to cooking, autoclaving and soaking. Microwave heating of soybean caused a $23 \%$ phytic acid reduction after 9 minutes and $46 \%$ after 15 minutes, while gamma irradiation ( $1 \mathrm{kGy})$ reduced the phytic acid content of soybean by only 4\% (HAFIZ et al., 1989).

Most of the phytate and tannins are concentrated in the seed- coat (hull) and measures aimed at reducing these compounds have included breeding for reduced seed coat thickness or mechanically removing the seed coat (dehulling). The latter process has been profitably used in France where the hulls may be fed to rabbits (CHONE et al., 1986)

\section{3 : FEEDING TRIALS}

\subsubsection{GENERAL}

Numerous experiments have been conducted and reported on the use of rapeseed meal as a source of supplementary protein in poultry rations. While the data appearing up to the early years of the seventies was mostly on the use of high glucosinolates rapeseed meal, the tendency in the later years has been more towards the use of rapeseed meal from varieties low in erucic acid and glucosinolates. And although the 00-cultivars have, to a large extent, brought new prospects, questions still arise from some corners regarding its suitability for inclusion in poultry feeding programmes. Reports on the rapeseed meal feeding to poultry are so diverse, with respect to the various experimental conditions like the type and strain of birds, type and levels of rapeseed meal fed, environments of the experiments, levels of different nutrients and antinutrients in the test diets, etc. that it would be rather difficult to make generalisations from any few studies reported. More stress, however, has been given to emphasise the differences in the nutritional potentials of low and highglucosinolate rapeseed meals. It, therefore, seems imperative to discuss some of the 
important studies in a way that will clearly differentiate the effects of low and high contents of glucosinolates in the poultry diets, instead of taking simply the chronological order, to have a broader view of the genesis of the problem, rather of the proposed solutions to the problem, through the last two-three decades. This will, no doubt, pin point the limitations and potentials of rapeseed meal as a candidate for inclusion in poultry feedings.

\subsubsection{EXPERIMENTS WITH HG-RAPESEED MEAL}

\subsubsection{PERFORMANCE}

Depression in weight gain in broilers has been frequently reported with rapeseed meal inclusion in the diet. Many workers have related it to the presence and concentrations of glucosinolates. CLANDININ et al., (1966) studied the effect of goitrin at $0.15 \%$ in the diet of broiler chicks on the growth rate, and observed a depression in performance and thyroid enlargement.MATSUMOTO et al., (1968) on the other hand confirmed the effects of goitrin on thyroid but failed to record any depression in the weight gain of broiler chickens when goitrin was included in their diet at $0.05 \%$ level. VOGT and SCHUBERT, (1969) conducted a series of experiments on feeding rapeseed meal to poultry. In one of their experiments on broilers they fed rapeseed meal up to $35 \%$ of the diet for different lengths of times and noted that negative influence of rapeseed meal increased corresponding to the period of its feeding. Weight gain was slightly reduced but feed to gain ratio was increased from 1.85 in control group to 3.40 in group fed rapeseed meal for 8 weeks.

Most of the reports in the literature which describe a depression in the broiler performance due to rapeseed meal feeding relate it to glucosinolates; however, only a few workers have tried to quantify the effect of glucosinolates on performance. VOGT and STUTE (1974) reported that broiler chicks could tolerate oxazolidinethion (OZT) level 700 to $1500 \mathrm{ppm}(5.4-11.6 \mu \mathrm{mol} / \mathrm{g})$. Several reports (LEESON et al., 1987, ROBBLEE et al., 1978) appearing latter on are consistent with the recommended levels of glucosinolates in the feed, proposed by these authors.

ANWAR et al., (1971) reported that when the same levels of energy and gross protein values were fed to broilers from 6 day age onwards, soybean meal and rapeseed meal as protein sources produced similar results in weight gains.LESLIE $e t$ al., (1976) demonstrated that when fortified with arginine and methionine, rapeseed meal can be fed to broilers at a level of $40 \%$ to supply the entire protein requirements without any adverse effects on growth. 
In an earlier experiment the same authors, (1973) studied the effect of colour on consumption of broiler diets containing rapeseed meal and rapeseed. No significant effect of colour or diet combination on feed consumption during the starter period was noted. Colouring, however, reduced the feed intake during the grower period. In this phase of feeding soybean meal containing diet was preferred over the rapeseed or rapeseed meal diets. Weight gain was also highest with soybean meal diet. It was noted that changes in feed consumption due to colour were not followed by proportionate changes in weight gain, indicating that the level of consumption was not a major factor in the utilisation of diets containing rapeseed meal. It was suggested that some toxic factor/s or amino acid imbalances were responsible for the depression in performance.

LEESON and SUMMERS, (1976) recorded significantly lower final weight in broiler chicks fed $11 \%$ rapeseed meal from variety Span than soybean meal. The depression in weight gain was found to be associated with reduced feed intake and an increased feed : gain ratio. Compared to soybean meal fed birds, rapeseed meal fed birds had significantly fewer grade A scores for fleshing and breast and back finish.

SUMMERS and LEESON, (1977a) studied the effects of feeding up to $31 \%$ Span rapeseed meal to broilers on their performance. Significantly $(\mathrm{P}<0.05)$ lower weight gains with rapeseed meal than soybean meal (194 vs. 214g) were noted. Addition of choline and iodine did not affect the performance. Feed intake was not affected but feed : Gain ratio was increased with rapeseed meal. Addition of thyroxin to the diet did not correct this effect. They rejected the idea that the growth depression in rapeseed meal fed birds was solely due to classical hypothyrotic condition. It was suggested that although rapeseed meal fed birds were abnormal with respect to their thyroid activity, it seems probable that factors other than a simple reduction in serum thyroxin concentrations are responsible for the growth depression. It was suggested by HULAN and PROUDFOOT, (1978) that in combination with a complementary protein source, such as fish meal, rapeseed meal can replace all of the soybean meal in practical type broiler diets.

THOMAS et al., (1983) fed expeller extracted rapeseed meal at 25 and $50 \%$ replacement levels of soybean meal to broilers. Feed consumption g/chick/day and weight gain g/chick were 65.97 and 37.60 , respectively, with soybean meal. These values were reduced to 52.76 and 30.00 , respectively with $25 \%$ rapeseed meal inclusion and to 37.93 and 18.50 , respectively, with $50 \%$ rapeseed meal. Reduction in these values with rapeseed meal at both levels were statistically significant 
$(\mathrm{P}<0.01)$. The rapeseed meal used had 78.3umol glucosinolates/g. Reduction in the broilers performance was related to the intake of glucosinolates. At $25 \%$ replacement of soybean meal, the rapeseed meal made up $13.95 \%$ of the total diet. On the basis of these results the idea of using high rapeseed meal in poultry rations was rejected and the need for low glucosinolates rapeseed meal was emphasised. On the other hand PEARSON et al., (1983a) reported from a study involving four different broiler strains, that the growth rate with feeding high glucosinolates rapeseed meal was reduced only in one broiler strain although hypertrophic effects in all strain was evident.

POKNIAK et al., (1985) evaluated rapeseed meal at three different levels of inclusion $(0,8$ and $14 \%$ in the broiler diets and concluded that it was safe to add $14 \%$ rapeseed meal in the broiler starter rations. ARENA and PENZ, (1988) recorded reduced weight gains but high feed conversions in broilers with rapeseed meal at 22.5 or $30 \%$ inclusion level in their diet. KARUNAJEWA et al., (1990) reported a linear reduction in broiler weight gain when the level of inclusion of rapeseed meal increased from 0 to $298 \mathrm{~g} / \mathrm{kg}$ in the diet. Thyroid, liver and heart weight increased due to increased proportion of rapeseed meal in the diet. Even at $149 \mathrm{~g}$ rapeseed meal per $\mathrm{kg}$ diet there was significantly higher mortality due to high liver and heart weight.

Studies conducted on turkey broilers have not been very frequent, however it would not be without interest to make a mention of them.SLINGER, (1977) fed meal from Brassica napus variety Tower to turkey broilers to 16 weeks of age at a level of $250 \mathrm{~g} / \mathrm{kg}$ of the diet and noted that gain in weight was equal to corn soybean meal diet

REDDY and REDDY, (1987) reported work on utilization of turnip (Brassica campestris) meal in the ration of White Leghorn chicks. Male White Leghorn chickens were given to age 3 weeks a control diet containing maize 45 , rice polish 6.5 , groundnut cake 26 , fish meal 10 and wheat bran $10 \%$ or with turnip meal $(14.1 \%$ crude protein) replacing $25,50,75$ or $100 \%$ of bran. Turnip meal up to $75 \%$ replacement did not affect weight gain and feed efficiency but values were poorer with $100 \%$ replacement.

KINAL et al., (1990) studied the possibilities of including rape seeds, partly defatted seeds and rapeseed oil meal from var. Jantar in the feed of broilers. Groups of 2381 day-old Astra B chickens were fed on concentrate diets without (control) or containing 4 or $6 \%$ rapeseed (RSM), 4 or $8 \%$ partially defatted rapeseeds (PDRS) or 10 or $15 \%$ rapeseed meal (RSM). The lower levels of supplementation were fed from 0 to 3 weeks old, and the higher levels from 3 to 8 weeks old. After 3 weeks the body 
weights of the chickens fed on $10 \%$ RSM were from 8 to $15 \%$ lower than the other groups $(\mathrm{P}<0.01)$ but after 8 weeks they were similar to the control group. After 8 weeks the RS and PDRS supplements gave the best performance especially for feed utilization $(\mathrm{P}<0.01)$. Compared with the control group the chickens on the different rape diets had 35-90\% thyroid hypertrophy. Differences in the lengths of the small intestines, colon and caecum were also observed in the latter groups. The quality and sensory characteristics of the breast muscle meat was not significantly different.

TREFNY et al., (1990) studied the possibility of influencing the strumigenic action of rapeseed meal in fattened chickens and turkey poults by adding iodine and zinc to their diets. Rapeseed meal containing glucosinolates 53.4 and $20.5 \mu \mathrm{mol} / \mathrm{g}$ was included at $8-9 \%$ in starter diets for fowls and at $15 \%$ in diets for turkey poults. Iodine $0.5 \mathrm{mg} / \mathrm{kg}$ or zinc $150 \mathrm{mg} / \mathrm{kg}$ or both were added to the rapeseed meal. Diets without rapeseed meal (controls) and without iodine or zinc supplements were also given. At the end of finishing thyroid weights of both fowls and turkeys were increased with rapeseed meal diets and iodine and zinc supplements had no effect. In fowls rapeseed meal decreased blood thyroxine compared with controls but overall had no effect on growth rate. Iodine and zinc supplements had no effect on body weight changes. In turkey poults blood triiodothyronine increased with $\mathrm{Zn}+\mathrm{I}$ and $\mathrm{Zn}$ alone and thyroxine increased with $\mathrm{Zn}+\mathrm{I}$.

KOSHELEVA and VERESHCHAK, (1986) published findings on rapeseed meal as a component of a feed mixture. Rapeseed meal and oil meal could be used for feeding poultry, but the disadvantage is that rapeseed feeds are low in energy, high in fibre and glucosinolates and deficient in some essential amino acids. The amount to be added to poultry diets should be up to $5 \%$ of rapeseed oil meal high in erucic acid, or up to $8 \%$ of rapeseed oil meal low in erucic acid.

TIMMS, (1983) studied the forms of leg abnormality observed in male broilers fed on a diet containing 12.5 per cent rapeseed meal. The incidence of leg abnormalities was studied in 216 male Ross I broilers, fed for 10 weeks on a diet containing $12.5 \%$ rapeseed meal . Regular serological examination showed that the birds remained free from Mycoplasma gallisepticum, Mycoplasma synoviae and avian reovirus. Post mortem and radiographic examination were performed when birds were culled because of leg deformities or at the end of the experiment. Leg abnormalities were seen in $19.4 \%$ of the birds, which is a higher rate than currently occurs in commercial flocks. They consisted of a large range of skeletal deformities including valgus and varus deformities, dyschondroplasia, slipped gastrocnemius tendons, dislocated condyles, rotation and penetration of the distal tibiotarsus and fractured fibulas. 
PROUDFOOT et al., (1983)conducted studies on the effect of feeding poultry diets supplemented with rapeseed meal as a primary protein source to juvenile and adult meat breeder genotypes. A factorial experiment was conducted, with 3168 chickens from 4 commercial meat parent genotypes, to study the cumulative effects of soy bean meal (SM) and rapeseed meal (RSM) as protein sources in both juvenile and adult breeder diets. General performance was equivalent for all combinations of SM and RSM in the juvenile and adult diets although there was some evidence of 2nd order interactions involving genotypes with juvenile and adult dietary combinations. These interactions affected egg production and related traits such as feed efficiency. It was concluded that some genotypes exhibit a greater response to RSM diets than others and that juvenile and adult diets, using a combination of different sources of dietary protein, supported equal or better performance than the same dietary protein source used throughout both periods.

\subsubsection{SENSORY QUALITIES}

YULE and MCBRIDE, (1976) observed that feeding greater than 5\% rapeseed meal to broilers could produce off flavours in chickens meat. STEEDMANN et al., (1979a) studied the influence of feeding 15\% Span rapeseed meal on the eating quality of broiler chickens. Results indicated that overall acceptability of dark meat was significantly lower with rapeseed meal than with soybean meal, whereas for light coloured meat there was no difference in the overall acceptability scores. Objective measurement showed no effect of protein source on shear force and water holding capacity of the meats.

These results were confirmed in a subsequent study by the same workers, (1979b). It was noted that although palatability scores for chickens fed span rapeseed meal at $15 \%$ level of inclusion in the diet were slightly lower than comparable scores given to the soybean meal-control chickens, the consumers panel rated the rapeseed mealgroup as acceptable in quality. With $10 \%$ high glucosinolates rapeseed meal in the diet, (GRIFFITHS et al., 1980) noted no effect on the flavour of the chickens meat.

\subsubsection{EXPERIMENTS WITH LG-RAPESEED MEALS}

\subsubsection{PERFORMANCE}


Reports regarding the feeding of even the LG-RSM to broiler chicks are diverse. Some authors have recommended higher levels, while other are of the view that with low levels in the diet, canola meal can produce negative results. Some have reported that canola meal is better than soybean meal, while others concluded the other way round.

The meal from double low variety Tower was compared with soybean meal for its effects on broiler chickens by SLINGER et al., (1978a). Although not significant, Tower rapeseed meal upto $30 \%$ in one experiment and $20 \%$ in four experiments gave higher weight gains than soy-maize diets. Feed to gain ratio was significantly lower with $20 \%$ rapeseed meal than soybean meal in one experiment, and was similar for both meals in three other experiments. While the nutritive value of soybean meal increased with steam pelleting, there was no influence on rapeseed meal diets. These results were in accordance with previous work of the same authors, (1977) in which rapeseed meal from two 00 varieties (Candle and Tower) was compared with soybean meal for their effects on broilers performance when fed in mesh form.

SALMON et al., (1981) observed in an experiment on broiler chickens that inclusion of candle rapeseed meal up to $218 \mathrm{~g} / \mathrm{kg}$ diet did not affect the live weights as compared to those chicks fed on soybean meal. Feed efficiency was also not influenced by rapeseed meal. Efficiency of feed conversion was, however, unchanged only when the TME concentration of the diets was maintained by means of increased dietary fat. Starter and finisher diets required 38 and $15 \mathrm{~g}$ fat $/ \mathrm{kg}$ to maintain the TME levels. It was, however, asserted that, from the stand point of economical production, the greatest possible TME may not always be necessary in practical broiler production.

TREFMY et al., (1986) concluded that 00-rapeseed meal from variety Tandem for broilers was recommendable at 5\% level up to the age of day 22 and $8 \%$ from day 22 to 56. In a later study (1989) the same authors recorded significant increase in the liver and thyroid weight of broilers fed 17 and 34\% of Tandem rapeseed meal. However, these effects did not alter the physiological functions and productivity. An early introduction of rapeseed meal in to the diet provided better chance to the broilers to adjust to rapeseed meal than the later one.

BLAIR et al., (1986a) studied the performance of broiler chickens up to 4 weeks of age with canola rapeseed meal from 3 different varieties i.e. Westar, T.T., and Commercial in comparison with soybean meal, and fed at a level of $20 \%$ of the diet. Final weight at the end of 4th week were 912, 914, 900 and 929 g/chick with 
commercial, T.T. and Westar and soybean meals, respectively. Differences were statistically non significant. Effect on feed consumption was also non significant. Feed efficiency was highest with soybean meal $(\mathrm{P}<0.009)$ but the difference disappeared at the end. The study confirmed the $20 \%$ level of inclusion of canola meal in the diet of broilers recommended by the Canola Council of Canada, (1984). On the other hand there are reports which have recommended $10 \%$ ( BANASZKIEWICZ, 1996) and 15\% (GAO et al., 1996) of 00-RSM for broiler chicks feeding.

LEESON et al., (1987) replaced 0 to $100 \%$ of soybean meal with canola rapeseed meal in the broiler chickens diets to see the effect on performance and nutrient retention. At the highest level of rapeseed meal inclusion, replacing all the dietary soybean meal, canola meal accounted for $38 \%$ of the broiler diet. The performance of all groups irrespective of dietary protein source or level of rapeseed meal inclusion was similar. Daily feed intake, body weight gain and feed : gain ratio ranged from 38.5 to $41.1 \mathrm{~g} / \mathrm{bird}, 505.8$ to $520.0 \mathrm{~g} / \mathrm{bird}$ and 1.59 to $1.68 \mathrm{~g} / \mathrm{bird}$, respectively, and the differences were statistically non significant. Effect on nutrient retention and metabolizable energy were also non significant. Retention of $\mathrm{N}, \mathrm{Ca}, \mathrm{P}, \mathrm{Mg}$, and fat ranged from 54.7 to $57.9,54.8$ to $58.7,37.5$ to $40.1,25.9$ to 28.2 and 76.7 to $80.3 \%$ ,respectively. Metabolizable energy content ranged from 12.92 to $13.12 \mathrm{MJ} / \mathrm{kg}$ of the diet among various diets. It was concluded that canola meal can replace dietary soybean meal entirely without any detrimental effects on performance and nutrient retention.

These results ,however, could not be supported by those obtained in a similar study by WÜRZNER et al. (1989), who studied the effect of replacing soybean meal with rapeseed meal from low glucosinolates rapeseed meal in the diet of broiler chickens on their performance. With complete replacement of soybean meal the content of rapeseed meal in the diet accounted for $30 \%$. Final weight and feed intake were significantly $(\mathrm{P}<0.01)$ lowered with the inclusion of rapeseed meal in the diet. Feed efficiency (gain/feed) was not influenced up to $24 \%$ of inclusion; but with $30 \%$ rapeseed meal it was significantly reduced. A maximum of $20 \%$ rapeseed meal was recommended by these workers

CHRAPPA et al., (1989) fed rapeseed meal from 00-cultivars of Czhekoslovakia of Polish origin to broilers in a 7 weeks performance trial. At $50 \%$ level of replacement both meals gave comparable values for final weights and feed intake/kg gain. Significant reduction in final weight and increase in feed : gain ratio was observed with full replacement of soybean meal with rapeseed meal.FRITZ et al., (1989) 
studied the nutritive value of new 00-rapeseed meal for broilers. With 15 and $13 \%$ replacements of soybean meal with rapeseed meal in the starter and finisher rations ,respectively, there was no significant difference in body weights of broilers kept on rapeseed meal or soybean meal diets. HEINZ et al., (1987) did not observe any difference in the weight gain, and feed intake of broilers up to 42 days when rapeseed meal from a 00 variety (DDR-Neuzüchtung) was included in their diet up to $18 \%$ at the expense of soybean meal. KOZLOWSKI et al., (1987) on the other hand recommended a level of 10\% 00-rapeseed meal inclusion in the diet of broilers up to the age of 21 days and $15 \%$ from 21 to 56 days of age. A level of $17.5 \%$ rapeseed meal from 00-variety Janter was recommended for inclusion in the broilers ration by KORELESKI and RYS, (1987). SCHADEREIT et al., (1987) included 10, 12 and $15 \%$ 00-rapeseed meal in broiler rations and detected no adverse effects on weight gain, feed consumption and feed conversion. Increase in thyroid weight was up to $352 \%$ with rapeseed meal feeding but effect on liver weight was not significant.

WETSCHEREK et al., (1990) included rapeseed meal from a 00-rapeseed cultivar into the diet of broiler chickens at 5,10, and 20\% level and studied the influence on fattening, carcass characteristics and chemical composition of the meat. Weight gain ( $100 \%$ for control) was 102,103 , and $101 \%$ with 5,10 and $20 \%$ rapeseed meal fed groups ,respectively. Inclusion of rapeseed meal up to $20 \%$ level in the chicks diet had no significant effect on any of the measured parameters; and this level of inclusion was recommended.

CLASSEN et al., (1991) studied the nutritional value of very low glucosinolate rapeseed meal (cv. Tobin) and normal canola rapeseed meals for broiler chickens. The apparent metabolizable energy values were 2130 and $1837 \mathrm{kcal} / \mathrm{kg}$ for the two rapeseed meals, respectively, as compared to $2575 \mathrm{kcal} / \mathrm{kg}$ for soybean meal. Weight gain was decreased in a linear fashion, when the level of rapeseed meal was increased from 15, 30 and 45\%. This effect ,however, was moderate when diets isonitrogenous and isocaloric were used The degree of effect was less severe with Tobin rapeseed meal as compared with the normal low glucosinolates canola rapeseed meal. Feed to gain ratio followed the same pattern. These results were confirmed in a second experiment.

SALMON, (1979) fed rapeseed meal of low glucosinolates cultivars Tower and Candle and a high glucosinolates cultivar Midas at $0,75,150,225$, and $300 \mathrm{~g} / \mathrm{kg}$ of diet to broiler turkeys from 6 to 56 day of age. The live final weight were similar with soybean meal and rapeseed meal diets. Variety Midas, however, resulted in significantly lower weight than other rapeseed meals ( $2.34 \mathrm{~kg}$ vs. 2.43 and $2.5 \mathrm{Kg}$ ). 
Feed efficiency ratio was also significantly lower with Midas-rapeseed meal as compared to tower and candle meals. Thyroid size was also the largest (8.18 $\mathrm{mg} / 100 \mathrm{~g}$ body weight) with this rapeseed meal. Candle rapeseed meal gave marginally higher feed consumption and weight gain values. This was attributed to slightly lower isothiocyanates and oxazolidinethion (1.2 vs. $1.5 \mathrm{mg} / \mathrm{g})$ or to substantially lower levels of indolyle glucosinolates in candle rapeseed meal (0.8 vs. $1.4 \mathrm{mg} / \mathrm{g}$ ). It was also concluded from the results that turkeys are able to tolerate the goitroginicity remaining in the improved varieties.

No weight gain differences in turkey broilers were observed bySALMON et al., (1979) when fed on diets containing soybean meal or candle rapeseed meal (up to $225 \mathrm{~g} / \mathrm{kg}$ ) to 63 days of age. However, gain was much faster with soybean meal containing diet between 63 and 98 days, resulting in a significant difference in the final weights. The feed utilisation efficiency (growth/feed) were similar with both types of vegetable protein supplements. There was no effect on the mortality.

HULAN et al., (1980) also studied the effect of inclusion of rapeseed meal from varieties Candle and Tower or in combination of the two meals in the turkey broilers diet at 0,10 or $20 \%$ levels. Higher mortality was recorded in control group than rapeseed meal groups $(16.6 \%-11.3 \%$ in soybean meal group as compared to 2.6$10.3 \%$ in different rapeseed meal fed groups). Live weights were also higher for all rapeseed meal groups than soybean meal group at 42,63, and 97 days of age for both sexes. Feed : gain ratio was better with Candle rapeseed meal alone (2.28) and Candle + Tower rapeseed meal (2.31) than control (2.34). More grade A carcasses were produced in both sexes with diets containing rapeseed meal (44.7 to $63.0 \%$ ) than soybean meal (36.9 to $38.2 \%$ ). Monetary returns were also higher with rapeseed meal (1.31-1.37\$) than with soybean meal (1.07\$). In another experiment the same authors (1980) reported improved growth and growth efficiency when turkey broilers were fed starter, grower and finisher diets containing 10, 20 and 30\% canola rapeseed meal, respectively, replacing soybean meal in the diets that also contained fish meal. The authors attributed the superior performance to the complementary amino acid balance of canola and fish meal.

SALMON, (1982) incorporated candle rapeseed meal in the starter diets of large white female turkey broilers at dietary levels of $0,150,300$, and $450 \mathrm{~g} / \mathrm{kg}$ in combination with 0,60 , and $120 \mathrm{~g}$ fish meal. Replacement of soybean meal with rapeseed meal had no effect on weight gain from 7 to 42 days. Additional increase of $5.3 \%$ was noted with the addition of fish meal. Rapeseed meal feeding led to slightly reduced feed efficiency ( 0.656 to 0.626$)$ whereas fish meal enhanced it from 0.639 
(with no fish meal in the diet) to 0.654 (with $120 \mathrm{~g}$ fish meal). Interaction of the two variants was statistically non significant, indicating lack of any synergism between the two protein sources for their effect on growth. WAIBLE et al., (1990) studied the effect of inclusion of canola meal in turkey broiler diets on growth performance and inferred that rapeseed meal up to $26 \%$ level of inclusion in the diet at the expense of soybean meal had no significant effect on body weight (19 weeks).

VALDERRABAN and URIARTE, (1988) studied the effect of fish meal supplement on the intake and performance of lactating ewes fed on turnips (Brassica campestris var. rapa). Ewes given fish meal supplements had increased organic matter intake compared with unsupplemented ewes (106 vs. $75 \mathrm{~g} / \mathrm{kg} 0.75$ ) but there were no significant differences between the different levels of fish meal supplementation. Estimated mean daily milk yield increased with increasing level of fish meal supplementation.

GAWECKI et al., (1983) reported their studies on oil meal from low-glucosinolate rapeseed Start 00 to replace soybean meal in diets for broilers. Cornish $\mathrm{X}$ White Rock chickens, equal proportion of either sex, in groups of 40 were fed from hatch to 49 days old on starting and finishing feeds with the low-glucosinolate, low-erucic acid Start 00 rapeseed oil meal (RSM), 10 and 8; 15 and 12, and 20 and 16\% of the diet replacing equivalent amounts of soybean oil meal. Live weight gain, without or with increasing amount of RSM was 1320, 1441, 1369 and $1369 \mathrm{~g}$. Feed intake per $\mathrm{kg}$ gain was 2604, 2403, 2441 and $2403 \mathrm{~g}$. In a similar experiment with 2 groups of 180 chickens the diet had Start 00 RSM 35 and 26\% in starting and finishing feeds. Live weight gain was 1565 and $1481 \mathrm{~g}$ and feed intake/kg gain without or with RSM 2057 and $2243 \mathrm{~g}$.

KIISKINEN, (1983a) experimented on the effect of diets supplemented with Regent rapeseed meal on performance of broiler chicks. Rapeseed oil meal (RSM) from the low-glucosinolate cultivar Regent was given as $0,8,16$ and $22 \%$ of a broiler diet at 2 energy levels (11.2 and 12.1 MJ ME/kg). RSM replaced soybean oil meal (SBM). The inclusion of RSM in the diet decreased by about $15 \mathrm{~g}(\mathrm{P}<0.01)$ the body weights of the broilers at the age of 2.5 weeks. The weight gain between 2.5 and 6 weeks did not, on the whole, differ between the RSM groups and the SBM controls. Growth rate and feed efficiency were better $(\mathrm{P}<0.01)$ with $\mathrm{ME}$ at $12.1 \mathrm{MJ}$ than at 11.2 $\mathrm{MJ} / \mathrm{kg}$. Mortality was not significantly affected by dietary treatment. The relative weight of the thyroid gland increased by an average of $80 \%$ when RSM was included in the diets $(\mathrm{P}<0.001)$. Enlargement of the liver was also found in the RSM groups. Giving RSM to chickens was not found to affect the acceptability of their meat. 
KIISKINEN, (1983b) reported on the use of Tower rapeseed meal separately and together with pea meal to replace fish and soybean meal in layers' diet at varying protein concentrations. Rapeseed oil meal (RSM) from the low-glucosinolate cultivar Tower was given in 2 trials with laying hens, as a replacement for fish meal and soybean oil meal in diets with protein $13.5,14.8$ or $16.2 \%$. In the first experiment RSM comprised about $50 \%$ of supplementary protein $(5,8$ and $11 \%$ in diet) and in the second experiment both RSM and pea meal (PM) were included at 4, 8 and $12 \%$, replacing all fish meal and soybean oil meal. No significant differences in egg production, egg weight or mortality could be ascertained between the supplementary protein groups and protein levels in each experiment. Because the diets were not isocaloric, feed consumption by the RSM-PM groups was significantly higher (P $<0.01)$ than that by the control groups and the feed conversion efficiency of the test protein groups was inferior (though not significantly) to the control groups in each experiment. The final body weight of the hens in the RSM-PM groups was significantly ( $\mathrm{P}<0.001)$ lower than that of the control groups. Tower RSM caused an average thyroid enlargement of 30 and $60 \%(\mathrm{P}<0.001)$ in experiments 1 and 2 , respectively.

\subsubsection{SENSORY QUALITIES}

HAWRYSH et al., (1980a) determined the effects of inclusion in the diet of tower rapeseed meal $(20 \%)$ on the sensory qualities of chicken meat. Rapeseed meal did not affect the eating quality of chicken meat. Odour, flavour juiciness, tenderness and overall acceptability scores were similar for soybean meal and rapeseed meal fed birds. Additional methyl groups in the form of choline or methionine in the diet resulted in inferior organoleptic quality. The same authors in a subsequent study, (1980b) obtained similar results and suggested that rapeseed meal from variety Tower can be safely included in broiler diet without affecting the consumers preference. Later on the same workers, (1980c) recommended the use of Tower rapeseed meal at $10 \%$ level in the diet of broilers in order to avoid deterioration in the organoleptic attributes of the chickens meat. The average overall acceptability scores for rapeseed meal fed broilers was 4.8 as compared to 5.1 for soybean meal. The difference was statistically non significant. Further studies by the same group, (1980d) confirmed these results. Additionally, they failed to record any effect of rapeseed screening on the organoleptic data obtained from 110 consumer penalists.

SALMON et al., (1981) reported that intensity of chicken flavour decreased and frequency of off-flavour increased when diets containing $281 \mathrm{~g}$ rapeseed meal/ $\mathrm{kg}$ in 
the starter and $121 \mathrm{~g} / \mathrm{kg}$ in finisher. But with $210 \mathrm{~g}$ rapeseed meal per $\mathrm{kg}$ in the starter and $90 \mathrm{~g} / \mathrm{kg}$ in finisher ration no adverse organoleptic effects were found.

In continuation of their studies on the influences of feeding rapeseed meal on the sensory characteristics of the resulting meat, HAWRYSH et al., (1982) studied the comparative effects of Regent and Candle rapeseed meal. These were included in the chicks diets alternatively at $20 \%$ level. Other variants included in the study were 0.1 and $0.01 \%$ DL-methionine and 0.5 and $0.05 \%$ choline chlorides. The results revealed that while there were effects of the additional methyl groups on some of the objective measurements like trimmed raw weight, thaw losses and $\mathrm{pH}$ of the dark meat, rapeseed meal from both the varieties had no effect on these attributes. The organoleptic qualities like odour, flavour, juiciness, tenderness and overall acceptability, chickeny odour and chickeny and other than chickeny flavour were all similar and acceptable for meats belonging to rapeseed meal of soybean meal fed groups. Shear force and water holding capacity were also similar in all groups. The recommended level of $20 \%$ rapeseed meal for inclusion in broilers rations was confirmed. It also appeared from the results that the level of sinapine in rapeseed meal plus the supplementary amounts of methionine and choline did not promote the production and accumulation of trimethylamine or that the trimethylamine produced was converted to the essentially odourless trimethylamine oxide and excreted.

SALMON et al., (1984) determined the effect of feeding canola meal (150 or 300 $\mathrm{g} / \mathrm{kg}$ ) and herring fish meal ( 0 or $50 \mathrm{~g} / \mathrm{kg}$ ) on the sensory quality of broiler chickens. supplemental methionine ( 0 or $1 \mathrm{~g}$ ) and choline chloride $(0$ or $0.5 \mathrm{~g}$ ) were the other dietary variants. Results failed to reveal any significant differences on the intensity of flavour, juiciness, or tenderness in either breast or thigh meat due to the inclusion of up to $300 \mathrm{~g}$ rapeseed meal $/ \mathrm{kg}$ diet. The inclusion of fish meal or other methyl donors (mthionine or choline chloride) alone also failed to adversely affect these parameters. However, combination of these three supplements led to an increase in the frequency of off flavours in thigh $(\mathrm{P}<0.05)$ but not in breast meat. It was suggested that production of off flavour in groups fed methionine+choline + fish meal cannot be solely due to the accumulation of trimethylamine in the tissue, because off flavour due to fish meal has been associated with accumulation in the tissue of polyenoic marine fatty acids (MILLER et al., 1969, OPSTVEDT, 1974). WÜRZNER et al., (1989) recommended $20 \%$ level of low glucosinolates rapeseed meal for inclusion in the broilers diets after finding no effect of this level of rapeseed meal on the sensory and carcass characteristics in broilers. KOZLOWSKI et al., (1989) on the other hand reported lower sensory quality of chickens meat due to rapeseed meal feeding at $15 \%$ level of the diet. 
Not much work has been reported on the effects of feeding of rapeseed meal on the organoleptic qualities of turkey meat.LARMOND et al., (1980) failed to record any off flavour in the meat of turkey broilers due to feeding of candle rapeseed meal in the diets up to $22.5 \%$ of the diet. With 10, 20 and $26 \%$ inclusion of canola rapeseed meal in the diet of turkey broilers WAIBEL et al., (1990) found no effect on parts yield, and taste preference of breast meat. Canola meal was rated as an acceptable alternate protein source in turkey diets that does not impart any adverse sensory problem. WAIBEL et al., (1992) reported that taste panel findings showed no preference among breast meat samples, but thigh meat from birds fed on $20 \%$ canola meal was preferred over that of the control.

\subsubsection{COMPARATIVE STUDIES WITH LG- AND HG-RAPESEED MEALS}

BOGEDANOV and ROBAKO, (1986) studied the comparative effects of low and high glucosinolates rapeseed meal on broiler performance at $20 \%$ level of inclusion. High glucosinolates rapeseed meal feeding resulted in a depression in growth, however feeding low glucosinolates rapeseed meal in the diet at this level did not exert such effect. BOUGON et al., (1988) on the other hand recorded a linear reduction in weight gain, feed intake and feed conversion with increasing levels $(0,5$, $10,15 \%)$ of 00 -rapeseed meal inclusion in the diet of broilers.

FARUGA et al., (1987) fed at 6\% level of diet meal from a traditional HG- rapeseed variety and 6 to $15 \%$ from a 00 rapeseed variety to broilers and observed no differences in the performance. Thyroid weights were generally higher in rapeseed meal fed birds as compared to soybean meal group, however, liver weight was not significantly affected.

GAO et al., (1988) studied the impact of level of glucosinolates in rapeseed meal on the broilers when fed to them in diets at $20 \%$ level. Total glucosinolates in 4 rapeseed meal samples were $13.44,1.82,11.05$ and $3.64 \mu \mathrm{mol} / \mathrm{g}$. In a 28 days experiment the high glucosinolates rapeseed meal feeding resulted in reduced body weight gain and feed efficiency and highest enlargement of liver and thyroid. However, these values for low glucosinolates rapeseed meal fed groups were similar to those of soybean meal fed group.

SCHÖNE et al., (1990) conducted feeding trials with broiler chickens using conventional (high glucosinolates) and new (low glucosinolates) rapeseed meal. 
Soybean meal was replaced (16\%) with rapeseed meal. Results showed similar weight gains with control and both rapeseed meal diets; but there were health abnormalities with high glucosinolates rapeseed meal feeding, whereas with low glucosinolates rapeseed meal in the diet there was hypothyroidism without growth depression. No difference in the weight gain and feed conversion efficiency was observed in the broilers when rapeseed meal from a conventional variety and a LGrapeseed variety Start was included in their diets (HANCZAKOWSKI and FRAS, 1983).

VERMOREL and BAUDET, (1987) studied the nutritive value of high or lowglucosinolate varieties and effect of dehulling. Dehusking the seeds significantly increased the energy and protein digestibility of the RSM and the utilization of digestible protein in an indirect nitrogen balance trial. In the feeding trial the feed efficiency of the dehusked RSM diets was lower than that of the untreated RSM diets. Dehusking the Tandem rapeseed reduced lysine content and availability. Expressed per $100 \mathrm{~g}$ of empty body weight the liver weight of rats receiving RSM was significantly higher than that of controls. ELWINGER and SATERBY, (1986) conducted a series of experiments with rapeseed meal of a Swedish low glucosinolate type fed to growing broiler chickens. The results of all experiments confirmed that LG-RSM, with the maximum levels tested in these trials (12-20\%), did not adversely affect performance and health. However, the presence of off-flavours in the chicken meat, especially with the addition of fish meal, will limit the recommended maximum level for practical diets to about $12 \%$. The weight of thyroid glands increased with increasing LG-RSM levels. In one experiment performance of chickens fed on highglucosinolate winter and summer RSM did not differ significantly from the control or LG-RSM diets.

PLONKA et al., (1985) gave recommendations for the use of rapeseed oil meal (RSM) in diets for different farm animals. For broiler chickens RSM should not exceed 3 and $5 \%$ in starting and finishing feeds; if RSM from "00" (low glucosinolate, low erucic acid) varieties are used the proportion can be increased to 5 and $10 \%$, the latter also in diets for laying hens and fattening geese.

\subsubsection{TREATMENT EFFECTS}

BLAIR, (1984) conducted studies on the nutritional evaluation of ammoniated mustard meal. Commercial canola meal (believed to consist of $80 \%$ Tower and $20 \%$ Candle meal) was used in the experiments. In the first experiment only up to $10 \%$ of treated or untreated meal could be successfully incorporated into the broiler diets. 
With the inclusion of $20 \%$ treated or untreated meal in diet, there was significant $(\mathrm{P}<0.01)$ reduction in the live weights at 2 and 4 weeks of age. However, feed consumption and gain : feed ratio was unaltered due to various treatments. In the second experiment $20 \%$ ammonia treated canola rapeseed meal could be successfully included in the diet, when supplemented with 0.15 or $0.3 \%$ lysine. Supplementation of diet with lysine at $0.3 \%$ level gave significant increase in live weight at 4 weeks of age. Feed intake was not affected by dietary treatments. A level of $15 \%$ of mustard meal treated with ammonia and corrected for lysine deficiency was recommended for inclusion in the broiler ration.

PAIK, (1991) studied the influence of ammoniation (0 to 6\%) on the nutritional worth of rapeseed meal. In several experiments it was observed that ammoniation of rapeseed meal increased its true metabolizable energy value up to $4 \%$ level of ammoniation. The same level of ammoniation also resulted in highest availability of crude protein, dry matter and crude ash. Ammoniation at $6 \%$ level tended to reduce these values. The response of broiler chickens fed these treated rapeseed meal at $20 \%$ levels of inclusion was not significant, ,however, numerically $1.5 \%$ ammonia treated rapeseed meal gave better results than other treatments in respect of weight gain and feed conversion efficiency. In another experiment the broiler chicks fed 3 or $6 \%$ ammoniate rapeseed meal gained significantly less weight than those fed untreated rapeseed meal. Feed consumption was also significantly lowered with ammoniation . Ammoniation did not exert effect on goitrogen level, but level of isothiocyanates increased with the increased level of ammoniation. This effect was also depicted in the feeding trial in which it was observed that increased level of rapeseed meal ammoniation tended to increase thyroid weight of the chickens. Since the birds fed $1.5 \%$ ammoniated rapeseed meal diet weighed less up to 4 week of age but weighed more than other groups after 5 weeks of age, it was suggested that lysine availability of rapeseed meal was reduced by ammoniation. This conclusion was based on the fact that lysine requirement of broilers decreased sharply after 4 weeks of age. Increased thyroid weight with ammoniation was explained on the basis of thiourea derivatives formation as a result of $\mathrm{NH}_{3}$ to isothiocyanate combination. This hypertrophy in thyroid was held responsible for the poor performance of the birds fed diets with high levels of ammonia. Ammoniation of rapeseed meal at 3\% level and above was not recommended on the basis of these results.AN and PAIK, (1989) had already reported from a similar study that ammoniation of rapeseed meal at $1.5 \%$ $\mathrm{NH}_{3}$ level increased weight gains in broilers but the influence disappeared at 6 weeks of age. This treatment improved the nutrients availabilities. 
ANDERSON-HAEFERMANN et al., (1993) studied the influence of autoclaving (0$60 \mathrm{~min}$.) on the nutritional and functional properties of rapeseed meal. Results indicated that autoclaving of rapeseed meal at $121 \mathrm{C}$ for $30 \mathrm{~min}$ led to significantly $(<\mathrm{P} 0.05)$ reduced protein solubility and weight gain, gain to feed ratio in broilers when this rapeseed meal was included in broiler ration at about $44 \%$. Chicks fed on corn soybean meal diet performed significantly better than any of the rapeseed meal fed groups. Protein solubility was also significantly higher for corn-soybean meal diet in $0.2 \% \mathrm{KOH}$ solution than all rapeseed meal diets ( $84 \%$ vs. 22 to $40 \%$ ). In a second experiment it was noted that although there were reductions in weight gain and gain to feed ratio due to autoclaving of rapeseed meal, these effects were significant only with $10 \mathrm{~min}$. and above autoclaving. Protein solubility in $0.2 \% \mathrm{KOH}$ solution was not significantly reduced with the treatment. The reduced growth performance of chicks fed on autoclaved rapeseed meal was related to the decreased digestibility of amino acids, which in turn was attributed to Maillard reaction during autoclaving. An autoclaving time of 10 minutes was found most suitable byGRAY et al., (1958). Longer times of autoclaving was found to reduce the nutritive value of rapeseed meal for chickens. KOZLOWSKA et al., (1987) fed rapeseed meal prepared from hydrothermally treated seeds to broilers and noted improvements in the body weights of broilers over those fed on control rapeseed meal diets. The effect of steaming was far more evident in hg-rapeseed meal than in LG-rapeseed meal.

The influence of desolventization conditions ( evaporation at $25{ }^{\circ} \mathrm{C}$ or heating to 100 ${ }^{\circ} \mathrm{C}$ with and without the addition of live steam) and removal of fibrous material ( by grinding and screening) on the nutritive value of hexane-extracted canola rapeseed meal for broiler chickens was determined bySHIRES et al., (1983) .It was noted that birds fed rapeseed meal desolventized at $100{ }^{\circ} \mathrm{C}$ consumed $6 \%$ more feed $(\mathrm{P}<0.01)$ and grew $5 \%$ faster $(\mathrm{P}<0.01)$ than birds fed desolventized at $25{ }^{\circ} \mathrm{C}$. This was attributed to the inactivation of myrosinase with $100^{\circ} \mathrm{C}$ treatment for desolventization. This process ,however, had no effect on feed : gain ratio. The performance of the birds fed normal or screened (low fibre) rapeseed meal was similar at 10, 20\% level of the diet. It was calculated that substitution of normal fibre rapeseed meal with low fibre rapeseed meal increased the metabolizable energy content of the diet by $76 \mathrm{kcal} / \mathrm{kg}$ at $20 \%$ level of inclusion. This was $2.5 \%$ of the total dietary calories. This difference was considered small and difficult to measure in terms of growth rate and efficiency of feed utilisation.

LIU et al., (1993) carried out a survey of nutrients and toxic factors in commercial rapeseed meal in China and evaluation of detoxification by water extraction. Detoxification involving water extraction alongside seed processing (for oil extraction) was examined on a pilot scale, and the meal was evaluated in feeding 
trials with pigs, broilers and rabbits. Water extraction removed nearly all glucosinolates and significantly increased crude protein content. Much improvement in animal growth performance was achieved when feeding detoxified meal compared with untreated feed. Treatment rendered the meal suitable for use as a main protein supplement in diets. LEE et al., (1991) reported from their studies on live performance, carcass yield, protein and energy retention of broiler chickens fed canola and flax full-fat seeds and the restored mixtures of meal and oil Heat treatment did not significantly affect performance. DM and protein retention, and bird mortality were not influenced by diet.

KOZLOWSKI AND FARUGA, (1989) fed Peking ducklings on a diet containing 10 and $15 \%$ rapeseed meal (RSM) in starter and finisher diets, respectively in place of soybean meal (SBM). RSM had been steamed at $90{ }^{\circ} \mathrm{C}$ for $90 \mathrm{~min}$, at $105{ }^{\circ} \mathrm{C}$ for 90 min or at $95{ }^{\circ} \mathrm{C}$ for $60 \mathrm{~min}$. Live weight and feed intake/kg were similar in different dietary treatment groups. 


\section{MATERIALS AND METHODS}

\subsection{MATERIALS}

Rapeseed of commercial high glucosinolate $(60.85 \mu \mathrm{mol} / \mathrm{g})$ variety Pakcheen was obtained from the Mutation Breeding section of the Nuclear Agriculture Division of Nuclear Institute for Food and Agriculture (NIFA) Peshawar.

\subsection{PROCESSING}

\subsubsection{CONTROL SAMPLES}

Crushing and extraction of oil was conducted according to the standard procedures (SHAHIDI, 1990). The seeds were crushed to fracture their fibrous coat and rupture the oil cells. The crushed seeds were then prepressed to reduce the oil content from above $40 \%$ to about $23 \%$ and compress the material into large cake fragments. These fragments were then broken by hand and extracted with petroleum ether (b.p. $40^{\circ} \mathrm{C}$ ) to remove the residual oil. The cooking of the crushed seeds was omitted in the control samples since it was an experimental variant.

\subsubsection{DRY HEAT TREATMENT}

The seeds of rapeseed were given dry heat $\left(121^{\circ} \mathrm{C}\right)$ treatment in an oven for $10,20,30,40,50$ or 60 minutes prior to crushing and then extracted as discussed in control samples.

\subsubsection{AUTOCLAVING TREATMENT}

The seeds were autoclaved at $121^{\circ} \mathrm{C}$ under $15 \mathrm{psi}(103.5 \mathrm{kPa})$ for $10,20,30,40,50$, and 60 minutes. The rest of the extraction procedure was the same as presented in case of control samples.

\subsubsection{IRRADIATION TREATMENT}

The seeds were given gamma irradiation treatment $(1.0,2.5,5.0,7.5$ and $10.0 \mathrm{kGy}$ doses) in a research irradiator (Issledovatel, USSR) at Nuclear Institute for Food and Agriculture, Peshawar. The dose rate of the radiation source at the time of irradiation was $1.0 \mathrm{kGy}$ per hour. The seeds were then extracted using the normal procedure as mentioned for control samples. 


\subsubsection{DEHULLING TREATMENT}

The seeds were given dry heat treatment at $105^{\circ} \mathrm{C}$ for 15 minutes and then rubbed between two wooden plates with slight pressure. The heat treatment rendered the seedcoat brittle and rubbing separated it easily. The separated seedcoats were then removed by blowing air. However, the dehulling could not be completely achieved.

\subsection{BIOCHEMICAL ANALYSIS}

The samples of rapeseed meal prepared using the above mentioned procedures were all or selectively analyzed for the following constituents :,

1. Total glucosinolates

2. Sinapine

3. Total phenols

4. Phytic acid

5. Protein content

6. Amino acids

7. In-Vitro Protein Digestibility

All the analysis were carried in triplicate except for total glucosinolate contents which were analysed in duplicate and for amino acids which were analysed one sample per treatment. The amino acid content are being given relative to control sample to visualise the percent changes caused by different treatments.

\subsubsection{DETERMINATION OF TOTAL GLUCOSINOLATES}

Assay for total glucosinolates was carried out according to the method of DECLERCQ AND DAUN, (1989).

\section{Reagents}

1. Pyridine acetate solution $0.5 \mathrm{M}$.

2. Barium/lead acetate solution $0.5 \mathrm{M}$

3. Sodium hydroxide solution $0.5 \mathrm{~N}$

4. Formic acid solution $30 \%$.

5. Potassium sulphate solution $0.3 \mathrm{M}$

6. Sulphuric acid $80 \%$.

7. Thymol in ethanol solution $1 \%$.

8. Sinigrin standard solution $0.3 \mu \mathrm{mol} / \mathrm{ml}$.

\section{Procedure}

\section{Sample extraction}

Defatted sample $(100 \mathrm{mg})$ was weighed into a 16 x $75 \mathrm{~mm}$ Pyrex tube and placed in a heating block at $95^{\circ} \mathrm{C}$ for 15 minutes. Four $\mathrm{ml}$ boiling water was added and the tube was fitted with a PTFF lined screw cap and mixed quickly on a vortex mixer to reduce cooling. The tube was returned to the heating block and heated at $95{ }^{\circ} \mathrm{C}$ for three minutes. After cooling and centrifugation at $600 \mathrm{xg}$, the supernatant solution was transferred 
to a $10-\mathrm{ml}$ graduated centrifuge tube containing $150 \mu 1$ of $0.5 \mathrm{M}$ barium/lead acetate solution. The resulting pellet was extracted with an additional $4 \mathrm{ml}$ of boiling water for three minutes at $95{ }^{\circ} \mathrm{C}$. After cooling and centrifuging, the supernatant from the second extraction was added to the first, and the total volume was adjusted to $10 \mathrm{ml}$.

\section{Preparation of Sephadex pyridine-acetate columns:-}

Dry DEAE -Sephadex A -25 (25 mg) was weighed into clean 0.8 x 4 cm Econo-Columns (Bio-Rad Labs) and was allowed to swell with deionized water while being stirred to remove air bubbles. The bed volume of the columns was $15 \times 8 \mathrm{~mm}$ leaving 10-ml reservoir at the top for rinsing and sample application. Prior to sample application, five $\mathrm{ml}$ of $0.5 \mathrm{~N}$ sodium hydroxide was passed through the columns, followed by $10 \mathrm{ml}$ water to remove the excess sodium hydroxide. The eluate was monitored to ensure that the $\mathrm{p}^{\mathrm{H}}$ was neutral. Columns were changed to acetate form by addition of $5 \mathrm{ml}$ of $0.5 \mathrm{M}$ pyridine acetate solution and then 10 $\mathrm{ml}$ of water leaving a meniscus of water on the top of the column for sample application.

\section{Sample application}

An aliquot $(3.0 \mathrm{ml})$ of the total sample extract was added to the columns. The columns were then washed with $2 \times 2 \mathrm{ml}$ water, discarding the eluate each time. Glucosinolates were eluted with $2 \times 4.75 \mathrm{ml}$ of $0.3 \mathrm{M}$ potassium sulphate and adjusted to $10.0 \mathrm{ml}$.

\section{Measurement of glucosinolates}

Aliquots of $1 \mathrm{ml}$ of the sample eluate were taken into test tubes and $7.0 \mathrm{ml}$ of $80 \%$ sulphuric acid followed by $1.0 \mathrm{ml}$ of $1 \%$ thymole solution were added. The tubes were screw capped, thoroughly mixed, placed in a heating block at $100{ }^{\circ} \mathrm{C}$ for 60 minutes, cooled under tap water, and mixed again. Absorbance was measured against 0.3M potassium sulphate as blank at $505 \mathrm{~nm}$ using Shimadzu-21 spectrophotometer.

5. Calculation of total glucosinolates

The concentration of glucosinolates in the samples was calculated from the absorbance readings using the absorbance of sinigrin standard solution. The micro molar concentrations of glucosinolates in the samples were calculated as :,

$$
=\mathrm{A}_{\mathrm{X}} / \mathrm{K} \times \mathrm{DF} / \mathrm{W}
$$

Where :,

$$
\begin{aligned}
& \mathrm{A}_{\mathrm{X}}=\text { absorbance of the sample. } \\
& \mathrm{K} \quad=\text { absorbance factor (absorbance /concentration of standard) } \\
& \mathrm{DF}=\text { dilution factor } \\
& \mathrm{W}=\text { Weight of the sample taken. }
\end{aligned}
$$

\subsubsection{DETERMINATION OF PHENOLICS}




\section{Extraction}

The treated and control seeds of rapeseed were dried to a moisture level of about $7 \%$, cleaned from dust, dirt and other undesirable matter, and ground to pass through $0.4 \mathrm{~mm}$ sieve. The samples were extracted with methanol and $1 \%$ acidic methanol (RAMAMURTHI et al., 1985).

\subsubsection{TOTAL PHENOLS}

\section{Principle}

Analysis of the extracts was carried out for extractable total phenols by the method of TITTO, (1985) using Folin - Ciocalteu-phenol reagent which contained sodium molybdate and sodium tungstate, 2.5 and 10\%, respectively. This reagent like others is non-specific for any phenolic and the colour yield depends on hydroxyl groups and their place in the molecules.

\section{Procedure}

A certain amount (50 to $100 \mu \mathrm{l}$ ) of the extract was diluted with distilled water to $2 \mathrm{ml}$ in a measuring flask. One $\mathrm{ml}$ of Folin-Ciocalteu phenol reagent was added and the flask vigorously shaken. Immediately $5 \mathrm{ml}$ of $20 \%$ sodium carbonate solution was pipetted and the mixture made up to $10 \mathrm{ml}$, shaking thoroughly again. After 20 minutes the OD was taken at $720 \mathrm{~nm}$ without background measurements. The spectrophotometer was set to zero against air. For calculation standard curve was prepared using tannic acid and the total phenolics were expressed as tannic acid equivalent.

3.3.2.2. SINAPINE

The methanol and acidic methanol extracts of the samples prepared for the determination of total phenols were assayed for sinapine content using spectrophotometery by the procedure of BLAIR et al., (1984). The concentration of sinapine in the methanol extract was calculated using the formula $\mathrm{C}=\mathrm{A} / \mathrm{El}$, where $\mathrm{C}=$ concentration in mol/l, $\mathrm{A}=$ absorbance at $330 \mathrm{~nm}, \mathrm{E}=$ extinction coefficient $(21390)$ at $330 \mathrm{~nm}$ and $1=$ pathlength of the spectroscopic cell. The sinapine content determined by this method includes all sinapic acid esters plus free sinapic acid.

\subsubsection{PHYTIC ACID}

Effects of different treatments was studied on phytic acid content in the resultant defatted meal. The sensitive method of HAUG AND LANTZSCH, (1983) was adapted for the determination of phytates in the rapeseed meal samples.

\section{Principle}


The sample extract (with $0.2 \mathrm{~N} \mathrm{HCl}$ ) was heated with an acidic Iron III solution of known iron content. The decrease in iron content (determined colorimetrically with 2,2-bipyridine) in the supernatant was the measure of the phytate phosphorus .

\section{Reagents}

1. Phytate reference solution. Sodium salt of phytic acid (Sigma Chemicals, USA) was used for reference. Stock solution was prepared which contained $0.15 \mathrm{~g}$ sodium phytate in $100 \mathrm{ml}$ distilled water. The reference solutions were prepared by diluting the stock solution with $\mathrm{HCl}$ in a range from 3 to $30 \mu \mathrm{g} / \mathrm{ml}$ phytate phosphorus.

2. Ferric solution. Ammonium Iron (III)sulphate. $12 \mathrm{H}_{2} \mathrm{O}(0.2 \mathrm{~g})$ was dissolved in $100 \mathrm{ml} 2 \mathrm{~N} \mathrm{HCl}$ and was made up to $1000 \mathrm{ml}$ with distilled water.

3. Bipyridine solution. Ten $\mathrm{g}$ of 2,2 bipyridine and $10 \mathrm{ml}$ of thioglycolic acid was dissolved in distilled water and the volume was made up to $1000 \mathrm{ml}$.

\section{Procedure}

The defatted and finely ground rapeseed meal sample $(0.5 \mathrm{~g})$ was extracted with $10 \mathrm{ml}$ of $0.2 \mathrm{~N} \mathrm{HCl}$ for 1 hour. From this extract, $0.5 \mathrm{ml}$ was taken into a stoppered test tube. Solution $2(1 \mathrm{ml})$ was added to this and covered with the stopper. These tubes were heated in a boiling water bath for 30 minutes and allowed to cool to room temperature. Solution $3(2 \mathrm{ml})$ was added to this and mixed. The absorbance was measured within 1 minute. A standard calibration curve was prepared using the same procedure with the standard solutions of known concentration of sodium phytate. Using the standard curve the concentration of phytic acid in the sample was calculated.

\subsubsection{DETERMINATION OF PROTEIN IN FEED AND FEED INGREDIENTS}

Reagents

1. Boric Acid 4\% Solution :- Weighed $40 \mathrm{~g}$ of Boric and poured it in a beaker. Dissolved it by stirring on a hot plate. The volume was made upto one litre with addition of $5 \mathrm{ml}$ mixed indicator.

2. $\mathrm{NaOH} 40 \%$ : Weighed $400 \mathrm{~g}$ of $\mathrm{NaOH}$ in a beaker, dissolved it and poured it in a flask making volume to 1 litre.

3. Digestion Mixture: The digestion mixture was made in the following ratios:

$\begin{array}{ll}\mathrm{K}_{2} \mathrm{SO}_{4} & 10 \mathrm{~g} \\ \mathrm{CuSO}_{4} & 1 \mathrm{~g}\end{array}$

Selenium powder $\quad 0.1 \mathrm{~g}$

4 Mixed indicator:- Weighed $0.5 \mathrm{~g}$ of Bromocresol green indicator and dissolved it in $100 \mathrm{ml}$ ethanol. Then weighed $0.1 \mathrm{~g}$ of Methyl Red indicator and dissolved it in $100 \mathrm{ml}$ ethanol. The two solutions were mixed in a beaker and the $\mathrm{pH}$ was adjusted to 4.5 .

Procedure (Digestion) 
The sample was weighed $(0.3$ to $0.5 \mathrm{~g})$ on a filter paper and then put it in the digestion tube. Then $2-3 \mathrm{~g}$ of digestion mixture and $7 \mathrm{ml}$ of concentration $\mathrm{H}_{2} \mathrm{SO}_{4}$ was added to each digestion tube. The samples were put in the Tecator digestion system at an initial temp. of $100 \mathrm{C}$ for about one and a half hour. The temperature was increased to $150,200,250,300$ and $350{ }^{\circ} \mathrm{C}$ at regular intervals of $30-45$ minutes until the digested samples became clear.

\section{Distillation}

After digestion, process of distillation was started. In which $4 \%$ boric acid and $40 \% \mathrm{NaOH}$ are used. The sample was poured into the upper flask of distillation apparatus and some distilled water was added. $\mathrm{NaOH}$ $40 \%$ was added into the upper flask to make the medium alkaline. The distillate was received in a conical flask containing $75 \mathrm{ml}$ of $4 \%$ boric acid solution. The sample was distilled until the volume of the distillate in the flask reached to $120-125 \mathrm{ml}$. The contents of this flask were titerated against standard $\mathrm{H}_{2} \mathrm{SO}_{4}$ solution i.e. $(0.01 \mathrm{~N})$, until the original colour of boric acid reappeared. Formlula for Protein: $\quad 0.01 \times 0.014 \times 100 \times 6.25 \times$ volume of acid used wt. of sample taken.

\subsubsection{AMINO ACID ANALYSIS}

The control and variously treated rapeseed meal samples were analysed for their amino acid contents using the LKB 4101 (Biochem, UK) amino acid analyser.

\section{Principle}

The amino acids are separated on a cation exchange resin with buffers of carefully defined salt concentrations and $\mathrm{pH}$. The resin on which the ion exchange takes place, consists of small spherical beads of polystyrene, sulphonated to provide an electrical charge and reacted with divinylbenzene to achieve the required degree of cross linkage between the polymerised chains of styrene. The 3-Sodium buffer system was used for this particular analysis. The eluate from the ion exchange column is passed through a Teflon coil placed in boiling water bath. Before entering the coil the column effluent is mixed with an acetate buffer containing the reduced ninhydrin. This compound reacts with amino acids forming a dye complex. The absorption is measured at 440 and $570 \mathrm{~nm}$ in a flow photometer and registered on the chart of a recorder. The area under the peaks corresponds to the amounts of amino acids present in the sample.

\section{Reagents}

1. Buffer $\mathrm{A}=$ Sodium citrate buffer $(\mathrm{pH}=3.25)$

2. Buffer $\mathrm{B}=$ Sodium citrate buffer $(\mathrm{pH}=4.25)$

3. Buffer $\mathrm{C}=$ Sodium citrate buffer $(\mathrm{pH}=6.45)$

4. Regeneration of resin with $0.4 \mathrm{~N}$. NaOH.

5. Loading buffer $=$ Sodium citrate buffer $(\mathrm{pH}=2.25)$

6. Calibration Mixture $=$ Standard amino acid solution containing $2.5 \mu \mathrm{mol}$ of each amino acid in one $\mathrm{ml}$ was prepared. One $\mathrm{ml}$ of this mixture was diluted to $50 \mathrm{ml}$ with loading buffer.

\section{Hydrolysis}


The samples were hydrolysed prior to analysis. About 20 to $25 \mathrm{mg}$ of sample was weighed in to a test tube and 5 to $6 \mathrm{ml}$ of $6 \mathrm{~N} \mathrm{HCl}$ was added to it. The tube was sealed under vacuum and place in an oven at $104^{\circ} \mathrm{C}$ for 24 hours after which the tube was taken out of the oven and cooled to room temperature, unsealed and the contents were concentrated on a rotary vacuum evaporator. Three subsequent washings with distilled water were given and evaporated to remove excessive acid. The dried hydrolysate was redissolved in loading buffer and the volume made to $10 \mathrm{ml}$.

\section{Procedure}

The sample loop was washed by injecting a few $\mathrm{ml}$ of the loading buffer. The knob was set at load position. Two $\mathrm{ml}$ of the hydrolysate were injected into the sample loop. Only $0.5 \mathrm{ml}$ of this was retained by the loop, while the rest was drained out. The sample load knob was turned to "Auto" position; and the analyzer was turned to "Analyze" position. The run time of different buffers was set as follows:,

$$
\begin{aligned}
& \text { Buffer } \mathrm{A}=24 \text { minutes } \\
& \text { Buffer } \mathrm{B}=45 \text { minutes } \\
& \text { Buffer } \mathrm{C}=75 \text { minutes } \\
& \text { Regeneration with } \mathrm{NaOH}=10 \text { minutes } \\
& \text { Equilibration with buffer } \mathrm{A}=45 \text { minutes }
\end{aligned}
$$

T1 (temperature 1) i.e. $45^{\circ} \mathrm{C}$ was maintained for the initial 30 minutes of the run

$\mathrm{T} 2$ (temperature 2) i.e. $70^{\circ} \mathrm{C}$ was maintained for the rest of the time.

\section{Calculation}

The recorder was set at a speed of 12 inches per hour. Area of the peaks corresponding to different amino acids was calculated as follows:,
a. The baseline was read
b. Peak height was read
c. Height $(\mathrm{H})$ was calculated $(\mathrm{H}=\mathrm{a}-\mathrm{b})$
d. Half height was calculated (half height $=\mathrm{H} / 2+$ baseline) and marked on the peak.
e. Width (W) was measured at this point of the peak.
f. Area of the peak was calculated (Area $=\mathrm{H} x \mathrm{~W}$ ).

The concentration of different amino acids was calculated using the standard aminogram developed for the calibration mixture with known concentrations of different amino acids.

\subsubsection{IN VITRO PROTEIN DIGESTIBILITY}

The multienzyme technique of HSU et al., (1977) was used for determining the in-vitro protein digestibility of different rapeseed meal samples. 


\section{Reagents}

1. Multienzyme solution containing per $\mathrm{ml} 1.6 \mathrm{mg}$ trypsin (Porcine pancreatic, type IX, Sigma) $3.1 \mathrm{mg}$ Chymotrypsin (Bovine pancrearic, type II, Sigma) and $1.3 \mathrm{mg}$ Peptidase (porcine intestinal grade III, Sigma) was maintained in an ice bath and adjusted to $\mathrm{pH} 8$ with $0.1 \mathrm{~N} \mathrm{HCl}$ and /or $\mathrm{NaOH}$.

\section{Sample}

Sample was suspended in distilled water to contain $6.25 \mathrm{mg}$ of protein / $\mathrm{ml}$ and adjusted to $\mathrm{pH} 8$ in a water bath set at $37^{\circ} \mathrm{C}$.

\section{Procedure}

Fifty $\mathrm{ml}$ of the sample suspension were taken and $5 \mathrm{ml}$ of the multienzyme solution added to it while $\mathrm{pH}$ electrode was inserted into the stirring suspension. $\mathrm{pH}$ dropped immediately due to the freeing of $>\mathrm{COOH}$ groups of the amino acids from the protein chain by the proteolytic enzymes. Exactly after 10 minutes the $\mathrm{pH}$ was noted and the protein digestibility was calculated using the following regression equation:-

$\mathrm{Y}=210.46-18.10 \mathrm{X}$

\section{Whereas}

$\mathrm{Y}=$ Protein digestibility and

$\mathrm{X}=\mathrm{pH}$ at 10 minutes

\subsection{CHICK BIOASSAYS}

The biological experiments were conducted using rapeseed meal as a component of the diet. A computer spread-sheet (for Excel-5) was developed for the formulation of experimental diets so as to prepare iso- or near to iso-nitrogenous and iso-caloric diets in all the experiments. These experiments were conducted in the poultry shed of Nuclear Institute for Food and Agriculture (NIFA), Peshawar. Unless otherwise stated the group size was 8 birds per group and in all the experiments replicated at least three times. Cages constructed for this purpose were ( $\mathrm{L} x \mathrm{~W}$ x H) 120 x 60 x $60 \mathrm{~cm}$, with wooden floor and steel wire walls.Day old broiler chicks were procured from MS. Big Bird (private) Ltd. Lahore through an agent in Peshawar. The chicks belong to the Hubbard breed and are marketed under the trade name of Big Bird. Temperature and lighting were maintained and altered according to the recommendations of the supplier of the broiler chicks. Saw-dust was used as litre in all the experiments. Table 5 gives the composition of the vitamin-mineral premix used in these experiments.

\section{Experiments Conducted}

1. Effect of feeding different levels of rapeseed meal on the performance of broiler chicks. 
2. Effect of irradiation on the nutritional value of rapeseed meal for broiler chicks.

3. Effect of dry heating and dehulling on the nutritional value of rapeseed meal for broiler chicks.

4. Effect of autoclaving time on the nutritional value of rapeseed meal for broiler chicks.

5. Effect of pre- and post-extraction autoclaving on the nutritional value of rapeseed meal for broiler chicks.

6. Effect of feeding increased levels of heat processed rapeseed meal on the performance of broiler chicks.

7. Effect of feeding increased levels of irradiated rapeseed meal on the performance of broiler chicks. 
Table 5. Composition of the Vitamin-mineral premix

Vitamins
A (IU)
D3 (IU)
E (IU)
$\mathrm{K}$ (mg)

Thiamine (mg)

Riboflavin (mg)

Pantothenic acid (mg)

Nicotinic acid (mg)

Pyridoxine $(\mathrm{mg})$

Folic acid (mg)

Biotin (mg)

Choline (mg)

Vitamin B12 (mg)

Inorganic elements

Calcium $(\%)$

Phosphorus available

Sodium (\%)

Potassium (\%)

Chloride (\%)

Manganese (mg)

Magnesium (mg)

Iron (mg)

Copper (mg)

Zinc (mg)

Selenium (mg)

Iodine (mg)
Units/g of premix

4409

440

4.4

0.9

0.9

1.8

5.7

13

1.8

0.5

0.1

529

0.0

0.9

0.4

0.1

0.4

0.1

22.0

220

35

4.4

17.6

0.1

0.1

\subsubsection{EXPERIMENT 1. EFFECT OF FEEDING DIFFERENT LEVELS OF RAPESEED MEAL ON THE PERFORMANCE OF BROILER CHICKS.}

An experiment was conducted to study the effect of different levels of rapeseed meal in the diet on the biological performance of broiler chicks. Rapeseed meal was included at $0,5,10,15,20$ or $25 \%$ in the diet (Table 6). Diets were formulated using computer. Rapeseed meal was included in the diet at the expense of other protein concentrates. Protein and energy of the diet ranged from 21.31 to $22.62 \%$ and 3404 to 3472 
$\mathrm{Kcal} / \mathrm{kg}$, respectively. Three replicate cages were assigned to each dietary treatment. Feed and water was supplied ad-libitum during the entire trial period. Chicks were divided into groups of 8 chicks and housed in separate cages. Chicks were sexed prior to grouping and put into groups so that each group consisted 4 birds from either sex.

Table 6. Composition of the Experimental Diets used in experiment no. 1

\begin{tabular}{|c|c|c|c|c|c|c|}
\hline Ingredients & \multicolumn{6}{|c|}{ Experimental Diets } \\
\hline$(\%)$ & $\begin{array}{c}\text { 0\% } \\
\text { RSM } \\
\end{array}$ & $\begin{array}{c}5 \% \\
\text { RSM } \\
\end{array}$ & $\begin{array}{l}10 \% \\
\text { RSM } \\
\end{array}$ & $\begin{array}{l}15 \% \\
\text { RSM } \\
\end{array}$ & $\begin{array}{l}20 \% \\
\text { RSM } \\
\end{array}$ & $\begin{array}{l}25 \% \\
\text { RSM } \\
\end{array}$ \\
\hline Wheat & 28 & 28 & 28 & 30 & 30 & 29 \\
\hline Maize & 25 & 25 & 25 & 28 & 27 & 27 \\
\hline Rice polishings & 5 & 5 & 5 & 0 & 0 & 0 \\
\hline Wheat bran & 5 & 5 & 5 & 0 & 0 & 0 \\
\hline Fish meal & 7 & 7 & 6 & 6 & 6 & 4 \\
\hline Blood meal & 3 & 3 & 3 & 3 & 2 & 2 \\
\hline Cotton seed cake & 8 & 8 & 0 & 0 & 0 & 0 \\
\hline Corn gluten & 8 & 3 & 6 & 6 & 4 & 3 \\
\hline Meat meal & 3 & 3 & 5 & 5 & 4 & 3 \\
\hline RSM (rapeseed meal) & 0 & 5 & 10 & 15 & 20 & 25 \\
\hline Molasses & 6 & 6 & 5 & 5 & 5 & 5 \\
\hline Dicalcium phosphate & 1 & 1 & 1 & 1 & 1 & 1 \\
\hline Lime stone & 1 & 1 & 1 & 1 & 1 & 1 \\
\hline Total & 100 & 100 & 100 & 100 & 100 & 100 \\
\hline \multirow[t]{2}{*}{ Vita.-minerals Premix* } & $12.5 \mathrm{~g} / 5 \mathrm{k}$ & $12.5 \mathrm{~g} / 5 \mathrm{k}$ & $12.5 \mathrm{~g} / 5 \mathrm{k}$ & $12.5 \mathrm{~g} / 5 \mathrm{~kg}$ & $12.5 \mathrm{~g} / 5 \mathrm{~kg}$ & $12.5 \mathrm{~g} / 5 \mathrm{~kg}$ \\
\hline & $\mathrm{g}$ & $\mathrm{g}$ & $\mathrm{g}$ & & & \\
\hline Protein \% & 21.31 & 22.62 & 21.51 & 22.62 & 22.00 & 22.10 \\
\hline \multicolumn{7}{|l|}{ Calculated Analysis } \\
\hline ME Kcal $/ \mathrm{kg}$ & 3419 & 3404 & 3409 & 3462 & 3455 & 3472 \\
\hline Lysine \% & 1.08 & 1.15 & 1.14 & 1.21 & 1.11 & 1.07 \\
\hline Methionine \% & 0.51 & 0.45 & 0.48 & 0.50 & 0.45 & 0.45 \\
\hline Calcium \% & 1.24 & 1.28 & 1.42 & 1.46 & 1.35 & 1.31 \\
\hline Phosphorous\% & 0.94 & 0.98 & 1.02 & 0.97 & 0.93 & 0.91 \\
\hline Available P \% & 0.64 & 0.64 & 0.69 & 0.70 & 0.61 & 0.60 \\
\hline Glucosinolates $\mu \mathrm{g} / \mathrm{g}$ & 0.00 & 3.04 & 6.08 & 9.12 & 12.16 & 15.20 \\
\hline
\end{tabular}

* The composition of the Vitamin-mineral mixture is given in Table No. 5

**ME Metabolizable energy

This experiment was of 5 weeks duration. Data on feed consumption and weight gain were recorded weekly. At the end of 5-week experimental period, the chicks were slaughtered and dressed weights were 
determined and reported as percentage of the live weight. Dressing percentage was determined according to the method reported by PAIK, (1991) except that skin was removed.

\subsubsection{EXPERIMENT 2. EFFECTS OF IRRADIATION ON THE NUTRITIONAL VALUE OF RAPESEED MEAL FOR BROILER CHICKS.}

An experiment was undertaken on day old broiler chicks using irradiated rapeseed meal (RSM). This experiment was of 5 weeks duration. The chicks were divided into 12 groups each having 8 chicks. There were four treatments in this study, each replicated three times. The treatments were;

1). Standard, having no rapeseed meal,

2). Control, having $10 \%$ untreated rapeseed meal in the diet,

3). rapeseed meal irradiated at $5 \mathrm{kGy}$ dose and included in the diet at $10 \%$ level, and

4). rapeseed meal irradiated at $10 \mathrm{kGy}$ dose and included at $10 \%$ level in the diet.

Since the irradiation treatments ( 5 and 10kGy) did not change the Kjeldahl nitrogen content, all RSM-diets would have the same composition as shown in the relevant column of the Table 7. Rapeseed meal was included in the diet at the expense of other protein concentrates. Irradiation of the samples was carried out on a gamma irradiation Co-60 source. All diets were adjusted to provide almost similar protein and energy. Data for weight record, feed consumption and weight gain were noted weekly for a duration of 5 weeks and calculated to per chick. Feed to gain ratio and weekly gain in weight were calculated from these data. At the end of the experiment the chicks were slaughtered and dressed and their weight was taken to calculate dressing percentage in each group. In addition to this, organ weights (liver, heart and gizzard) were also recorded and reported as $\mathrm{g} / 100 \mathrm{~g}$ of body weight.

\subsubsection{EXPERIMENT 3. EFFECT OF DRY HEATING AND DEHULLING ON THE NUTRITIONAL VALUE OF RAPESEED MEAL FOR BROILER CHICKS.}

In this experiment the effect of including rapeseed meal (processed in different ways) in the diet of broiler chicks on their biological performance was studied. Rapeseed meal was prepared in three different ways:

1. Normal procedure was adopted,

2. Seeds were given dry heat $\left(80^{\circ} \mathrm{C}\right)$ treatment for 60 minutes and then extracted in the normal way

3. Seeds were dehulled and the remaining cotyledon part of the seeds was extracted.

Table 7. Composition of the experimental Diets used in experiment no. 2

\begin{tabular}{lcc}
\hline Ingredients & \multicolumn{2}{c}{ Experimental Diets } \\
\cline { 2 - 3 }$(\%)$ & $\begin{array}{c}\text { Standard diet } \\
\text { (Without RSM) }\end{array}$ & $\begin{array}{c}\text { RSM- diet } \\
\text { (Control and irradiated) }\end{array}$ \\
\hline Wheat & 28 & 30 \\
Maize & 25 & 22 \\
Rice polishings & 5 & 5 \\
Wheat bran & 5 & 5
\end{tabular}


Fish meal

Blood meal

Cotton seed cake

Corn gluten

Meat Meal

RSM (rapeseed meal)

Molasses

Dicalcium phosphate

Lime stone

Total

Vitamin-minerals Premix *

Protein \% (assayed)

ME Kcal/kg (calculated)

Calcium \%

Phosphorous \%
0

6

1

1

100

$12.5 \mathrm{~g} / 5 \mathrm{~kg}$

21.31

3419

1.24

0.94

0.64
6

3

0

7

5

10

5

1

1

100

$12.5 \mathrm{~g} / 5 \mathrm{~kg}$

21.51

3409

1.42

1.02

0.70

Available Phosphorous \%

The composition of the Vitamin-mineral mixture is given in Table No. 5

$* *$ Metabolizable energy

$* * *$ Glucosinolates $\mu \mathrm{g} / \mathrm{g}$ content of the feeds (calculated) were Control $=6.08$, Irradiated $5 \mathrm{kGy}=5.59$ and Irradiated $10 \mathrm{kGy}=3.91$.

$* * * *$ The calculated lysine and methionine contents of standard, control, 5kGy diet and $10 \mathrm{kGy}$ diet were 1.08 and $0.51,1.16$ and $0.50,1.04$ and 0.48 , and 1.13 and $0.49 \%$, respectively. 
These meals were included at a level in the diet so as to provide $25 \%$ of the total dietary protein as rapeseed meal protein (Table 8). Rapeseed meal was included in the diet at the expense of other protein concentrates. Protein and energy of the diets ranged from 21.75 to 21.98 and 3520 to $3559 \mathrm{Kcal} / \mathrm{kg}$, respectively. Three replicate cages were assigned to each dietary treatment. Feed and water were supplied ad-libitum during the entire trial period. Chicks were divided into groups of 8 chicks and housed in separate cages. Chicks were sexed prior to grouping and put into groups so that each group consisted 4 birds from either sex. This experiment was of 5 week duration. Data on feed consumption and weight gain was recorded weekly.

Table 8. Composition (\%) of experimental Diet used in experiment No. 3

\begin{tabular}{|c|c|c|c|c|}
\hline \multirow{2}{*}{$\begin{array}{l}\text { Ingredients } \\
\qquad(\%)\end{array}$} & \multicolumn{4}{|c|}{ Experimental Diets } \\
\hline & Standard & $\begin{array}{c}\text { RSM } \\
\text { Control } \\
\end{array}$ & $\begin{array}{c}\text { RSM } \\
\text { Heated }\end{array}$ & $\begin{array}{c}\text { RSM } \\
\text { Dehulled }\end{array}$ \\
\hline Wheat & 60.00 & 58.00 & 58.00 & 60.00 \\
\hline Wheat bran & 8.00 & 8.00 & 8.00 & 8.00 \\
\hline Corn & 2.00 & 6.30 & 6.30 & 8.50 \\
\hline Rapeseed meal & 00 & 16.67 & 16.67 & 11.06 \\
\hline Cotton seed cake & 8.00 & 00 & 00 & 00 \\
\hline Corn gluten (60) & 8.00 & 3.00 & 3.00 & 5.94 \\
\hline Blood Meal & 6.00 & 6.00 & 6.00 & 4.50 \\
\hline DCP(Dicalcium Phos) & 1.00 & 1.00 & 1.00 & 1.00 \\
\hline Lime stone & 1.00 & 1.00 & 1.00 & 1.00 \\
\hline Total & 100 & 100 & 100 & 100 \\
\hline Vitamin Mineral & $12.5 \mathrm{~g} / 5 \mathrm{~kg}$ & $12.5 \mathrm{~g} / 5 \mathrm{~kg}$ & $12.5 \mathrm{~g} / 5 \mathrm{~kg}$ & $12.5 \mathrm{~g} / 5 \mathrm{~kg}$ \\
\hline \multicolumn{5}{|l|}{ Premix } \\
\hline $\begin{array}{l}\text { Glucosinolates } \boldsymbol{\mu m o l} / \mathbf{g} \\
\text { (Calculated) }\end{array}$ & 0.00 & 10.14 & 9.37 & nd \\
\hline $\begin{array}{l}\text { Protein \% } \\
\text { (assayed) }\end{array}$ & 21.89 & 21.98 & 21.98 & 21.75 \\
\hline ME Kcal/kg (calculated) & 3520 & 3547 & 3547 & 3557 \\
\hline $\begin{array}{l}* \\
* * \\
n d\end{array}$ & $\begin{array}{l}\text { mposition } \\
\text { olizable en } \\
\text { termined. }\end{array}$ & Vitamin-mi & ixture is $g$ & Table No. 5 \\
\hline
\end{tabular}

\subsubsection{EXPERIMENT 4. EFFECT OF AUTOCLAVING TIME ON THE NUTRITIONAL VALUE OF RAPESEED MEAL FOR BROILER CHICKS.}

An experiment was conducted to investigate the effects of autoclaving time on the nutritional value of high glucosinolate-RSM. Rapeseed of commercial variety Pakcheen (double high) was obtained from the 
Mutation Breeding section of the Nuclear Agriculture Division of Nuclear Institute for Food and Agriculture (NIFA) Peshawar. Crushing and extraction of oil was conducted according to the standard procedures except that the seeds were autoclaved at $121^{\circ} \mathrm{C} 15 \mathrm{PSi}(103.5 \mathrm{kPa})$ for $0,10,15,20,25$ and 30 minutes before crushing and extraction.

Table 9. Composition of the experimental diets used in experiment no. 4

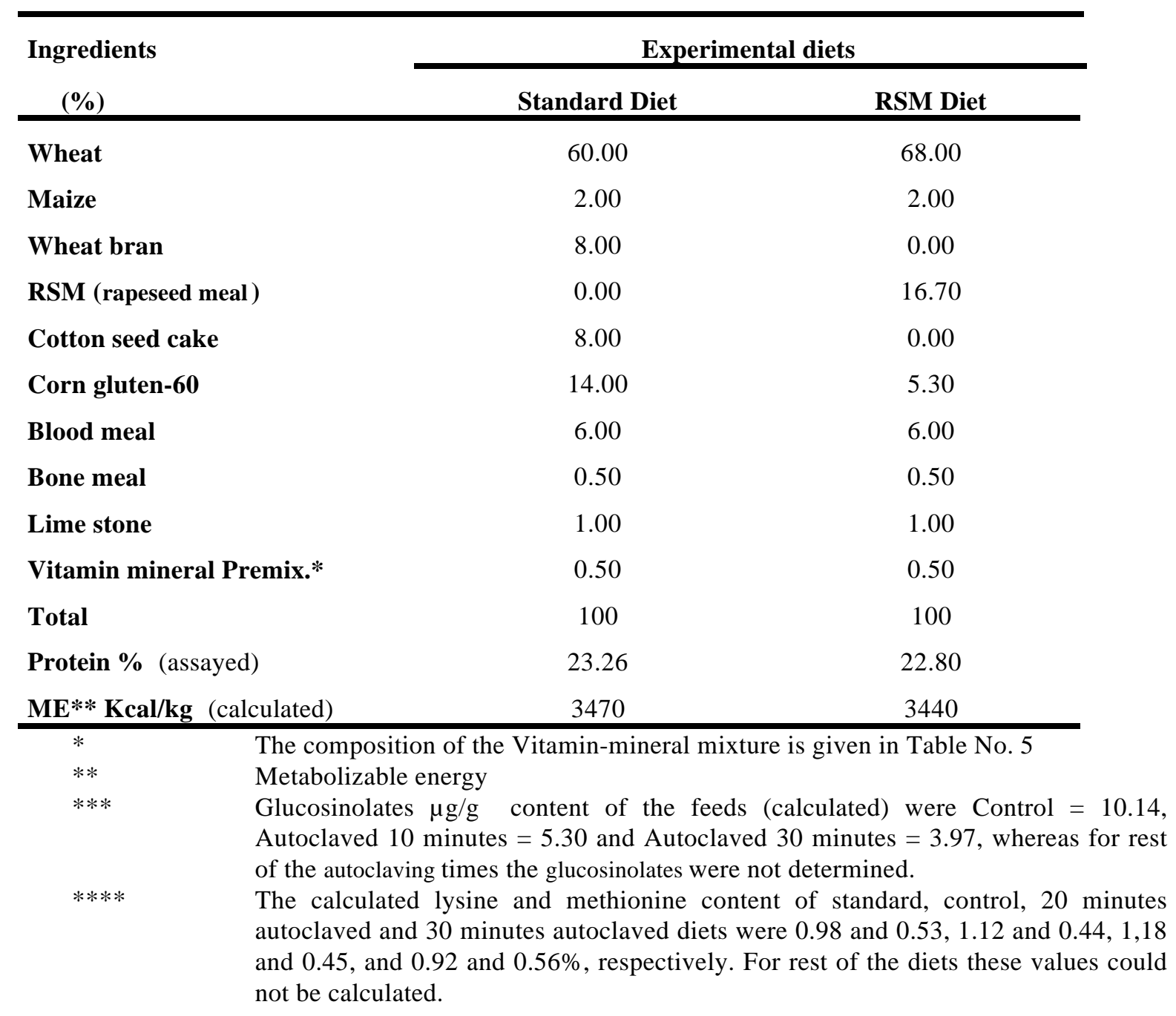

Rapeseed meal was included into the broiler`s ration at a level so as to provide $25 \%$ of the dietary protein from rapeseed meal. One group was fed on standard commercial formula diet without rapeseed meal while the other groups were given diets containing rapeseed meal (control and autoclaved for different times). Rapeseed meal was incorporated into the diet at the expense of cotton seed meal and a part of corn gluten meal. Since the autoclaving treatments ( 0 to 30 minutes) did not change the Kjeldahl nitrogen content, all RSM-diets would have the same composition as shown in the relevant column of the Table 9. Protein and energy of the diet ranged from 22.8 to $23.26 \%$ and 3440 to $3470 \mathrm{Kcal} / \mathrm{kg}$, respectively. Three replicate cages were assigned to each dietary treatment. Feed and water were supplied ad-libitum during the entire trial period. Chicks were divided into groups of 8 chicks and housed in separate cages. Chicks were sexed prior to grouping and put into groups so that each group consisted 4 birds from either sex.This experiment 
was of 8 weeks duration and the data on feed consumption and weight gain were recorded weekly during the experiment. Feed to gain ratio was calculated at the end.

\subsubsection{EXPERIMENT 5. EFFECT OF PRE- AND POST-EXTRACTION AUTOCLAVING ON THE NUTRITIONAL VALUE OF RAPESEED MEAL FOR BROILER CHICKS.}

A 5 week experiment was conducted using 200 broiler chicks. Treatments included autoclaving of rapeseed for 15 and 30 minutes (15psi or $103.5 \mathrm{kPa}$ at $121 \mathrm{C}$ ). Same treatments were given to two other lots but after the oil was extracted. These four variants of rapeseed meal were included in the feed of different groups at $10 \%$ level, replacing $8 \%$ Cotton seed cake and $2 \%$ corn gluten in the standard diet. Since the autoclaving treatments (15 and 30 minutes) did not change the Kjeldahl nitrogen content, all RSM-diets would have the same composition as shown in the relevant column of the Table 10.

These diets were fed to groups of chicks, each containing 8 chicks and replicated 4 times. Feed and water were provided ad-libitum and this experiment was of 5 weeks duration. Data were recorded weekly on weight gain and feed consumption. The chicks were slaughtered at the end of fifth week and data on dressed weight, weights of heart, liver, gizzard and spleen were also noted. 
Table 10. Composition of the experimental diets used in experiment no. 5

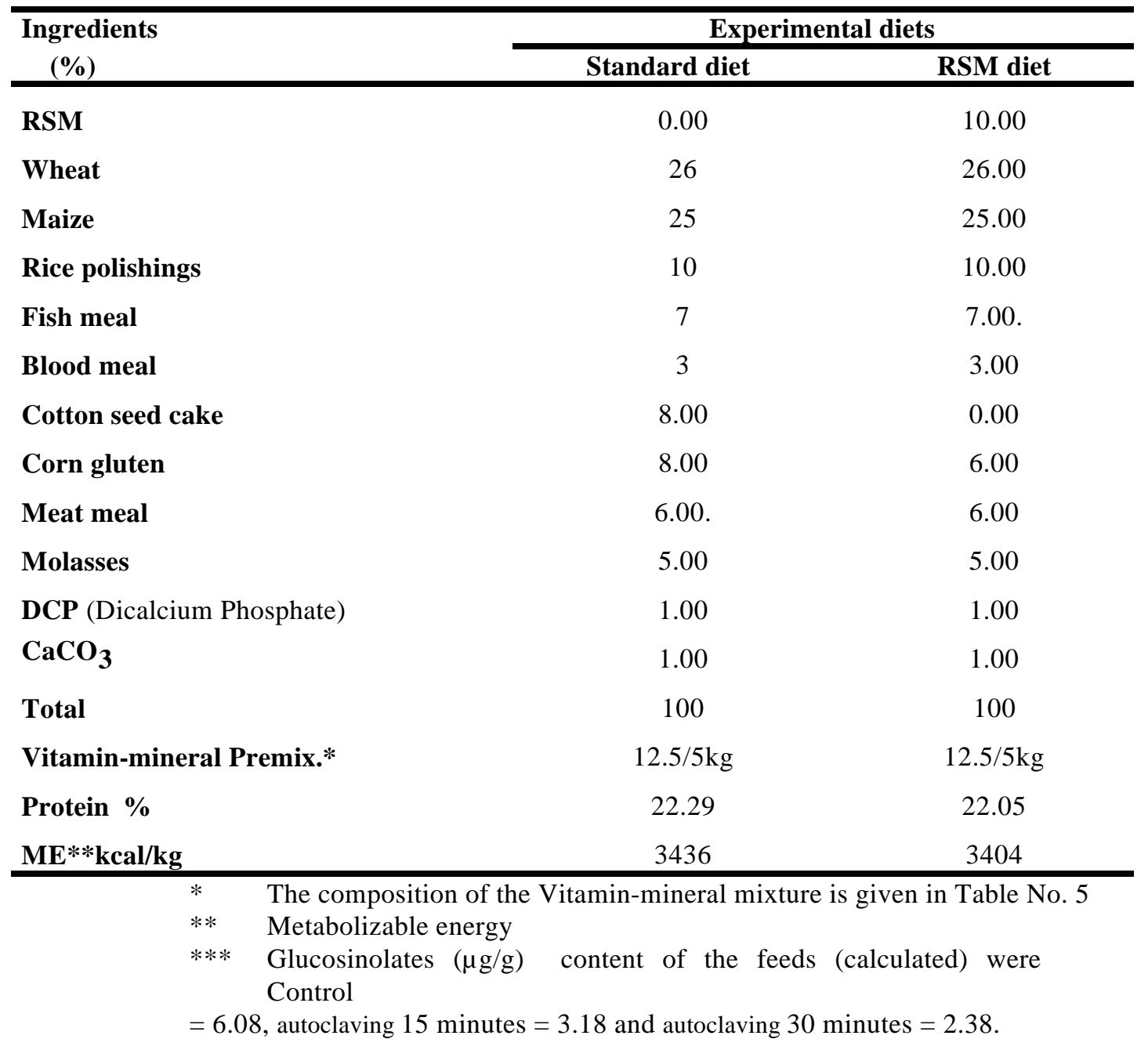

\subsubsection{EXPERIMENT 6. EFFECT OF FEEDING INCREASED LEVELS OF HEAT PROCESSED RAPESEED MEAL ON THE PERFORMANCE OF BROILER CHICKS.}

Male day-old broiler chicks were divided into seven groups, each replicated three times. Eight chicks were included in every group. One group was fed on standard commercial formula diet without rapeseed meal, three groups were given diets containing 15, 20, and 25\% rapeseed meal while another three groups were fed on diets containing 15, 20 and $25 \%$ rapeseed meal that was prepared from heat treated (105 ${ }^{\circ} \mathrm{C} / 15$ minutes) rapeseed. Rapeseed meal was incorporated into the diet at the expense of other protein concentrates. Since the heat treatment did not change the Kjeldahl nitrogen content, feeds with heat treated RSM would have the same composition as its respective control. Therefore the columns for 15, 20 and $25 \%$ RSM-diets also represent the diet with 15, 20 and 25\% heated RSM, respectively, (Table 11). Feed and water were given ad-libitum throughout the experimental period. Data on feed consumption and weight gain were recorded weekly. The experiment was of 6 week duration at the end of which the chicks were slaughtered and dressed. Dressing percentage was determined according to the method reported by PAIK, (1991) except that skin was removed. 
Table 11. Composition of the experimental diets used in experiment no. 6

\begin{tabular}{|c|c|c|c|c|}
\hline \multirow[t]{2}{*}{ INGREDIENTS - (\%) } & \multicolumn{4}{|c|}{ Experimental dies } \\
\hline & STANDARD & $15 \%$ RSM & $20 \%$ RSM & $25 \%$ RSM \\
\hline RSM & 0 & 15 & 20 & 25 \\
\hline Wheat & 26 & 30 & 30 & 29 \\
\hline Maize & 25 & 28 & 27 & 27 \\
\hline Rice polishings & 10 & 0 & 0 & 0 \\
\hline Fish meal & 7 & 6 & 6 & 4 \\
\hline Blood meal & 3 & 3 & 2 & 2 \\
\hline Cotton seed Cake & 8 & 0 & 0 & 0 \\
\hline Corn gluten & 8 & 6 & 4 & 3 \\
\hline Meat meal & 6 & 5 & 4 & 3 \\
\hline Molasses & 5 & 5 & 5 & 5 \\
\hline $\begin{array}{l}\text { DCP } \\
\text { (Dicalcium Phosphate) }\end{array}$ & 1 & 1 & 1 & 1 \\
\hline Limestone & 1 & 1 & 1 & 1 \\
\hline Total & 100 & 100 & 100 & 100 \\
\hline Vita-mineral Premix.* & $12.5 / 5 \mathrm{~kg}$ & $12.5 / 5 \mathrm{~kg}$ & $12.5 / 5 \mathrm{~kg}$ & $12.5 / 5 \mathrm{~kg}$ \\
\hline Protein \% & 22.29 & 22.62 & 22.00 & 22.10 \\
\hline $\mathrm{ME}^{* *} \mathrm{kcal} / \mathrm{kg}$ & 3426 & 3462 & 3455 & 3472 \\
\hline
\end{tabular}

* The composition of the Vitamin-mineral mixture is given in Table No. 5

** Metabolizable energy 
Table 12. Some calculated analysis of the experimental diets

\begin{tabular}{|c|c|c|c|c|c|c|c|}
\hline \multirow[t]{3}{*}{ Calculated analysis } & \multicolumn{7}{|c|}{ Experimental Diets } \\
\hline & Standard & RSM & RSM & RSM & H-RSM & H-RSM & H-RSM \\
\hline & & 15 & 20 & 25 & 15 & 20 & 25 \\
\hline Lysine \% & 1.16 & 1.21 & 1.11 & 1.07 & 1.05 & 0.90 & 0.92 \\
\hline Methionine \% & 0.52 & 0.50 & 0.45 & 0.45 & 0.48 & 0.42 & 0.42 \\
\hline Calcium \% & 1.46 & 1.46 & 1.35 & 1.31 & - & - & - \\
\hline Phosphorous \% & 1.07 & 0.96 & 0.93 & 0.91 & - & - & - \\
\hline Available P \% & 0.75 & 0.70 & 0.16 & 0.60 & - & - & - \\
\hline Glucosinolates $\mu \mathrm{g} / \mathrm{g}$ & 0.00 & 9.12 & 12.16 & 15.20 & 8.42 & 11.23 & 14.04 \\
\hline
\end{tabular}

\subsubsection{EXPERIMENT 7. EFFECT OF FEEDING INCREASED LEVELS OF IRRADIATED RAPESEED MEAL ON THE PERFORMANCE OF BROILER CHICKS.}

An experiment was carried out to study the effects of feeding higher levels of irradiation processed rapeseed meal on the performance of broiler chicks. Male day-old broiler chicks were divided into seven groups, each replicated three times. Eight chicks were included in every group. One group was fed on standard commercial formula diet without rapeseed meal, three groups were given diets containing 15,20 , and $25 \%$ rapeseed meal, while another three separate groups were fed on diets containing 15, 20 and $25 \%$ irradiated (5 kGy) rapeseed meal. Rapeseed meal was incorporated into the diet at the expense of other protein concentrates. Since the irradiation treatment did not change the Kjeldahl nitrogen content, feeds with irradiation treated RSM would have the same composition as its respective control. Therefore the columns for 15, 20 and 25\%RSM-diets also represent the diet with 15, 20 and 25\% irradiated RSM, respectively, (Table 13). Feed and water were given ad-libitum throughout the experimental period. Data on feed consumption and weight gain were recorded weekly. The experiment was of 6 week duration at the end of which the chicks were slaughtered and dressed. Dressing percentage was determined according to the method reported by PAIK, (1991) except that skin was removed. 
Table 13. Composition of the experimental Diets used in experiment no. 7

\begin{tabular}{|c|c|c|c|c|}
\hline \multirow{2}{*}{$\begin{array}{l}\text { INGREDIENTS } \\
(\%)\end{array}$} & \multicolumn{4}{|c|}{ Experimental dies } \\
\hline & STANDARD & $15 \%$ RSM & $20 \%$ RSM & $25 \%$ RSM \\
\hline RSM & 0 & 15 & 20 & 25 \\
\hline Wheat & 26 & 30 & 30 & 29 \\
\hline Maize & 25 & 28 & 27 & 27 \\
\hline Rice polishings & 10 & 0 & 0 & 0 \\
\hline Fish meal & 7 & 6 & 6 & 4 \\
\hline Blood meal & 3 & 3 & 2 & 2 \\
\hline Cotton seed Cake & 8 & 0 & 0 & 0 \\
\hline Corn gluten & 8 & 6 & 4 & 3 \\
\hline Meat meal & 6 & 5 & 4 & 3 \\
\hline Molasses & 5 & 5 & 5 & 5 \\
\hline DCP (Dicalcium & 1 & 1 & 1 & 1 \\
\hline \multicolumn{5}{|l|}{ Phosphate) } \\
\hline Limestone & 1 & 1 & 1 & 1 \\
\hline Total & 100 & 100 & 100 & 100 \\
\hline Vita. mineral Premix.* & $12.5 / 5 \mathrm{~kg}$ & $12.5 / 5 \mathrm{~kg}$ & $12.5 / 5 \mathrm{~kg}$ & $12.5 / 5 \mathrm{~kg}$ \\
\hline Protein \% & 22.29 & 22.62 & 22.00 & 22.10 \\
\hline ME** Kcal/kg & 3426 & 3462 & 3455 & 3472 \\
\hline $\begin{array}{ll}* & \text { The comp } \\
* * & \text { Metaboliz }\end{array}$ & $\begin{array}{l}\text { of the Vitan } \\
\text { lergy }\end{array}$ & 10 & $\cdot \quad \cdot$ & .5 \\
\hline
\end{tabular}

Table 14. Some calculated analysis of the experimental diets

\begin{tabular}{llllcccc}
\hline Calculated analysis & \multicolumn{7}{c}{ Experimental Diets } \\
\cline { 2 - 8 } & Standard & $\begin{array}{c}\text { RSM } \\
\mathbf{1 5}\end{array}$ & $\begin{array}{c}\text { RSM } \\
\mathbf{2 0}\end{array}$ & $\begin{array}{c}\text { RSM } \\
\mathbf{2 5}\end{array}$ & $\begin{array}{c}\text { R-RSM } \\
\mathbf{1 5}\end{array}$ & $\begin{array}{c}\text { R-RSM } \\
\mathbf{2 0}\end{array}$ & $\begin{array}{c}\text { R-RSM } \\
\mathbf{2 5}\end{array}$ \\
\hline Lysine \% & 1.16 & 1.21 & 1.11 & 1.07 & 1.04 & 0.84 & 0.90 \\
Methionine \% & 0.52 & 0.50 & 0.45 & 0.45 & 0.47 & 0.41 & 0.41 \\
Calcium \% & 1.46 & 1.46 & 1.35 & 1.31 & - & - & - \\
Phosphorous \% & 1.07 & 0.96 & 0.93 & 0.91 & - & - & - \\
Available P \% & 0.75 & 0.70 & 0.16 & 0.60 & - & - & - \\
Glucosinolates $\boldsymbol{\mu g} / \mathbf{g}$ & 0.00 & 9.12 & 12.16 & 15.20 & 8.38 & 11.18 & 13.98 \\
\hline
\end{tabular}

- not calculated

\subsection{BLOOD SERUM THYROID HORMONES ANALYSIS}

The blood sample from chicks of experiment on "Effects of feeding increased levels of irradiated rapeseed meal on the performance of broiler chicks" were analysed for thyroid hormones concentration using radioimmunoassay techniques. 


\subsubsection{DETERMINATION OF TRIIODOTHYRONINE (T3) IN BLOOD SERUM}

The radioimmunoassay for the determination of thyroid hormones was carried out in the RIA-lab of Institute for Radiotheraphy and Nuclear Medicine (IRNUM) Peshawar. Triiodothyronine was determined using the Amerlex-M T3 RIA kit of Amersham International, Amersham, UK.

\section{Principal}

The radioimmunoassay (RIA) method depends on the comparison between T3 in the serum and ${ }^{125} \mathrm{I}-\mathrm{T} 3$ for a limited number of binding sites on a T3 specific antibody. The proportion of ${ }^{125} \mathrm{I}-\mathrm{T} 3$ bound to the antibody is inversely related to the concentration of the T3 present in the serum. The antibody suspension in the kit contains antibody that is bound to magnetisable polymer particles. Separation of the antibody-bound fraction is affected by magnetic separation of the suspension, followed by decantation of the supernatant. By measuring the proportion of ${ }^{125} \mathrm{I}-\mathrm{T} 3$ bound in the presence of reference standard sera containing various known amounts of $\mathrm{T} 3$, the concentration of $\mathrm{T} 3$ present in the unknown can be calculated.

\section{Reagents}

1. ${ }^{125} \mathrm{I}-\mathrm{T} 3$ solution in barbitone buffer $(50 \mathrm{mM})$ with antimicrobial agent.

2. T3-Antibody suspension with antimicrobial agent.

3. T3 standards in serum with $0,0.5,1.5,3.0,6.0$, and $12.0 \mathrm{nmol} \mathrm{T3/1}$.

4. Amerlex-M NSB reagent for the determination of nonspecific binding with antimicrobial agent.

\section{Procedure}

Assay tubes were labelled and arranged in the tube rack. Aliquots $(50 \mu 1)$ of the standards and unknown specimens were pipetted in to the respective tubes. To each tube $500 \mu$ l of labelled ( ${ }^{125} \mathrm{I}$ ) T3 solution was dispensed. The non specific binding (NSB) reagent was $(500 \mu 1)$ dispensed into the appropriate tube. All tubes were vortex mixed and incubated at $37^{\circ} \mathrm{C}$ for 60 minutes. The rack was attached to the separator base and ensured that all the tubes were in contact with the base plate. It was left for 15 minutes. After separation all supernatant liquid were poured off and discarded without removing the rack from the separator base. All tubes were counted in gamma counter for the time required to accumulate at least 20,000 counts in the zero standard tubes. Count rates of standards were plotted against their respective concentration and a standard curve was drawn. The T3 concentration for the unknown samples were read off from the standard curve.

\subsubsection{DETERMINATION OF THYROXIN (T4) IN BLOOD SERUM}

\section{Principal}

The radioimmunoassay (RIA) method depends on the comparison between T4 in the serum and ${ }^{125} \mathrm{I}-\mathrm{T} 4$ for a limited number of binding sites on a T4 specific antibody. The proportion of $125 \mathrm{I}-\mathrm{T} 4$ bound to the antibody is inversely related to the concentration of the $\mathrm{T}_{4}$ present in the serum. The antibody suspension in the kit contains antibody that is bound to magnetisable polymer particles. Separation of the antibody-bound fraction is affected by magnetic separation of the suspension, followed by decantation of the supernatant. By measuring the proportion of ${ }^{125} \mathrm{I}-\mathrm{T} 4$ bound in the presence of reference standard sera containing various known amounts of $\mathrm{T} 4$, the concentration of $\mathrm{T} 4$ present in the unknown can be calculated. 


\section{Reagents}

1. ${ }^{125} \mathrm{I}-\mathrm{T} 4$ solution in barbitone buffer $(50 \mathrm{mM})$ with antimicrobial agent.

2. T4-Antibody suspension with antimicrobial agent.

3. T4 standards in serum with $0,30,60,120,200$, and $320 \mathrm{nmol} \mathrm{T} 4 / 1$.

4. Amerlex-M NSB reagent for the determination of nonspecific binding with antimicrobial agent.

\section{Procedure}

Assay tubes were labelled and arranged in the tube rack. Aliquots $(50 \mu \mathrm{l})$ of the standards and unknown specimens were pipetted in to the respective tubes. To each tube $500 \mu \mathrm{l}$ of labelled (125I) T3 solution was dispensed. The NSB reagent was $(500 \mu \mathrm{l})$ dispensed into the appropriate tube. All tubes were vortex mixed and incubated at room temperature $\left(18-28{ }^{\circ} \mathrm{C}\right)$ for 45 minutes. The rack was attached to the separator base and ensured that all the tubes were in contact with the base plate. It was left for 15 minutes. After separation all supernatant liquid were poured off and discarded without removing the rack from the separator base. All tubes were counted in gamma counter for the time required to accumulate at least 20,000 counts in the zero standard tubes. Count rates of standards were plotted against their respective concentration and a standard curve was drawn. The T4 concentration for the unknown samples were read off from the standard curve.

\subsection{STATISTICAL ANALYSIS}

Analysis of Variance for all the data were determined using Co-Stat package and means were separated using DNMRT. 


\section{RESULTS}

\subsection{BIOCHEMICAL ANALYSIS}

\subsubsection{PHYTIC ACID}

Data regarding the effects of different heat treatments on phytic acid content are given in Tables 15-17. Effect of dry heating for different times on the phytic acid content in rapeseed meal was non significant. The phytic acid content of control sample was 4.23\%, and ranged between 3.59 (10 minutes) to $4.8 \%$ (40 minutes) for different heat treated samples. Effect of autoclaving treatment for 10, 20, and 30 minutes was also non-significant on the content of phytic acid in rapeseed meal (Table 15) and the values ranged between 4.23 (control) to $4.53 \%$ (30 minutes autoclaved). Effect of different irradiation doses on the phytic acid content was also non significant. The ranged from 3.92 to $4.47 \%$ among different treated and untreated samples (Table 17).

Table 15. Effects of dry heat treatment time on the Phytic acid content (\%) in rapeseed meal

\begin{tabular}{cc}
\hline $\begin{array}{c}\text { Heating Time } \\
\text { (Minutes) }\end{array}$ & Phytic acid \\
\hline $\mathbf{0}$-Unheated & 4.23 \\
\hline $\mathbf{1 0}$ & 3.59 \\
$\mathbf{2 0}$ & 4.29 \\
$\mathbf{3 0}$ & 3.96 \\
$\mathbf{4 0}$ & 4.83 \\
$\mathbf{5 0}$ & 4.00 \\
$\mathbf{6 0}$ & 4.15 \\
$\mathbf{C V}$ & 8.45 \\
\hline
\end{tabular}

Table 16. Effects of autoclaving time on the Phytic acid content (\%)

in rapeseed meal 


\begin{tabular}{cc}
\hline $\begin{array}{c}\text { Autoclaving Time } \\
\text { (Minutes) }\end{array}$ & $\begin{array}{c}\text { Phytic acid } \\
(\%)\end{array}$ \\
\hline $\mathbf{0 - \text { Untreated }}$ & 4.23 \\
$\mathbf{1 0}$ & 4.35 \\
$\mathbf{3 0}$ & 4.25 \\
$\mathbf{C V}$ & 4.53 \\
\hline
\end{tabular}

Table 17. Effects of irradiation dose on the Phytic acid content (\%) in rapeseed meal

\begin{tabular}{cc}
\hline $\begin{array}{c}\text { Irradiation Dose } \\
(\mathbf{k G y})\end{array}$ & $\begin{array}{c}\text { Phytic acid } \\
(\boldsymbol{\%})\end{array}$ \\
\hline $\mathbf{0 . 0}$ & 4.23 \\
$\mathbf{0 . 5}$ & 3.92 \\
$\mathbf{1 . 0}$ & 4.10 \\
$\mathbf{2 . 5}$ & 4.09 \\
$\mathbf{5 . 0}$ & 4.10 \\
$\mathbf{1 0 . 0}$ & 4.47 \\
& \\
$\mathbf{C V}$ & 4.06 \\
\hline
\end{tabular}

\subsubsection{TOTAL PHENOLS AND SINAPINE}

\subsubsection{EFFECT OF HEATING AT DIFFERENT TEMPERATURES FOR 30 MINUTES}

Effects of heating for 30 minutes at different temperatures on the total phenols and sinapine content is shown in Table 18, while the percent reduction in these phenolics due to these treatments is given in Figure 
5. Total phenols were reduced to the minimum value $(0.71 \%)$ with $200^{\circ} \mathrm{C}$ treatment, however, the value obtained with $150^{\circ} \mathrm{C}$ treatment $(0.72 \%)$ was not much different from this. Reduction in the sinapine content, however, was continuous with increasing temperatures. It can be judged from the Figure 5 that the reduction was less with $100^{\circ} \mathrm{C}$, but the slope increased sharply after that point. More than $63 \%$ of sinapine content was reduced at $250^{\circ} \mathrm{C}$, indicating its susceptibility to higher temperatures.

Table 18. Effect of temperature of dry heat treatment for 30 minutes on sinapine and total phenol contents in rapeseed

\begin{tabular}{ccc}
$\begin{array}{c}\text { Heating Temperature } \\
\left({ }^{\circ} \mathbf{C}\right)\end{array}$ & $\begin{array}{c}\text { Total Phenols } \\
(\boldsymbol{\%})\end{array}$ & $\begin{array}{c}\text { Sinapine } \\
(\boldsymbol{\%})\end{array}$ \\
\hline $\mathbf{0}$ & 1.21 & 0.90 \\
$\mathbf{5 0}$ & 0.92 & 0.90 \\
$\mathbf{1 0 0}$ & 0.76 & 0.84 \\
$\mathbf{1 5 0}$ & 0.72 & 0.60 \\
$\mathbf{2 0 0}$ & 0.71 & 0.46 \\
$\mathbf{2 5 0}$ & 0.75 & 0.33 \\
$\mathbf{C V}$ & 21.0 & 33.2 \\
\hline
\end{tabular}

$\%$ Reduction

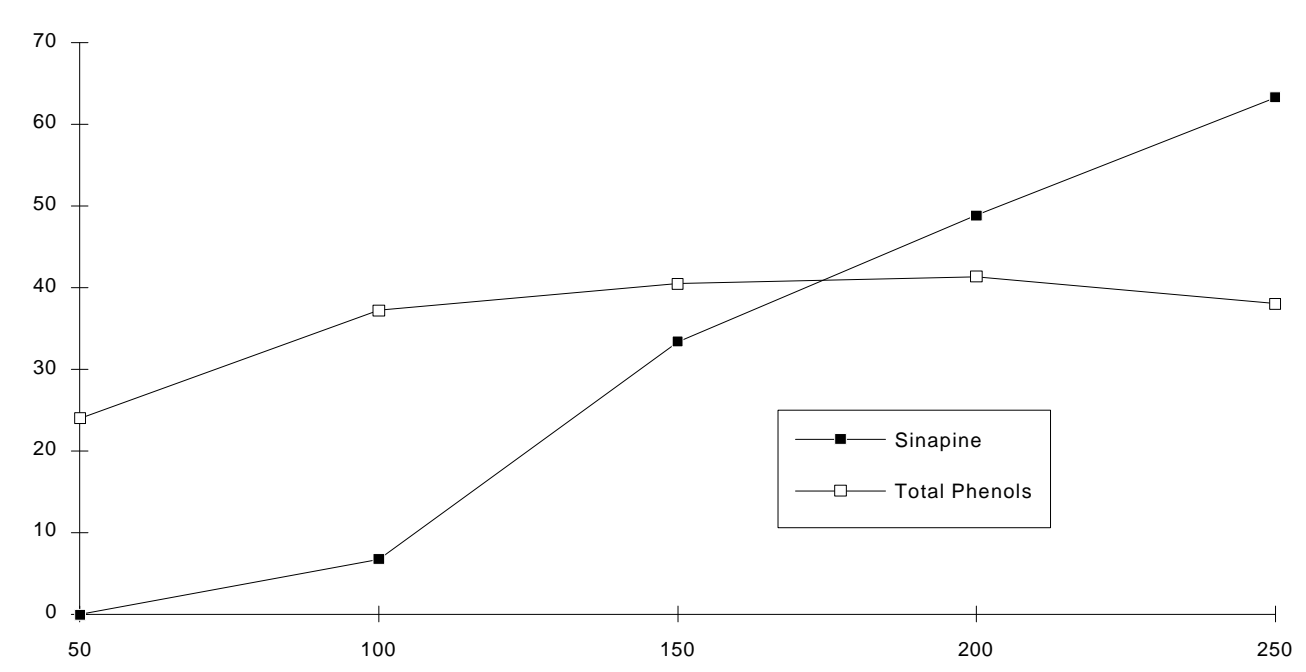

Heating Temperatures $\left({ }^{\circ} \mathrm{C}\right)$

Fig. 5 . Percent reduction of sinapine and total phenol concentration due to different heating temperatures

\subsubsection{EFFECTS OF AUTOCLAVING TIME}

The total phenol content in the untreated rapeseed were $1.21 \%$ and a significant reduction in this was observed with autoclaving (Table 19). The longest treatment time (60 min.) resulted in the maximum 
reduction $(56.2 \%)$ in total phenol content. Sinapine was also influenced in a similar pattern, however the maximum reduction $(62.2 \%)$ in this case was achieved with a treatment time of 30 minutes.

Table 19. Effect of time of autoclaving treatment $(103.5 \mathrm{kPa})$ on sinapine and total phenol contents in rapeseed

\begin{tabular}{ccc}
\hline $\begin{array}{c}\text { Autoclaving Time } \\
\text { (Minutes) }\end{array}$ & Total Phenols & Sinapine \\
\hline $\mathbf{0}$ & \% & \% \\
\hline $\mathbf{1 5}$ & 1.21 & 0.90 \\
$\mathbf{3 0}$ & 0.84 & 0.53 \\
$\mathbf{4 5}$ & 0.63 & 0.34 \\
$\mathbf{6 0}$ & 0.61 & 0.45 \\
$\mathbf{C V}$ & 0.53 & 0.36 \\
\hline
\end{tabular}

Fig. 6. Percent reduction in total phenols and sinapine content of RSM due to autoclaving treatment

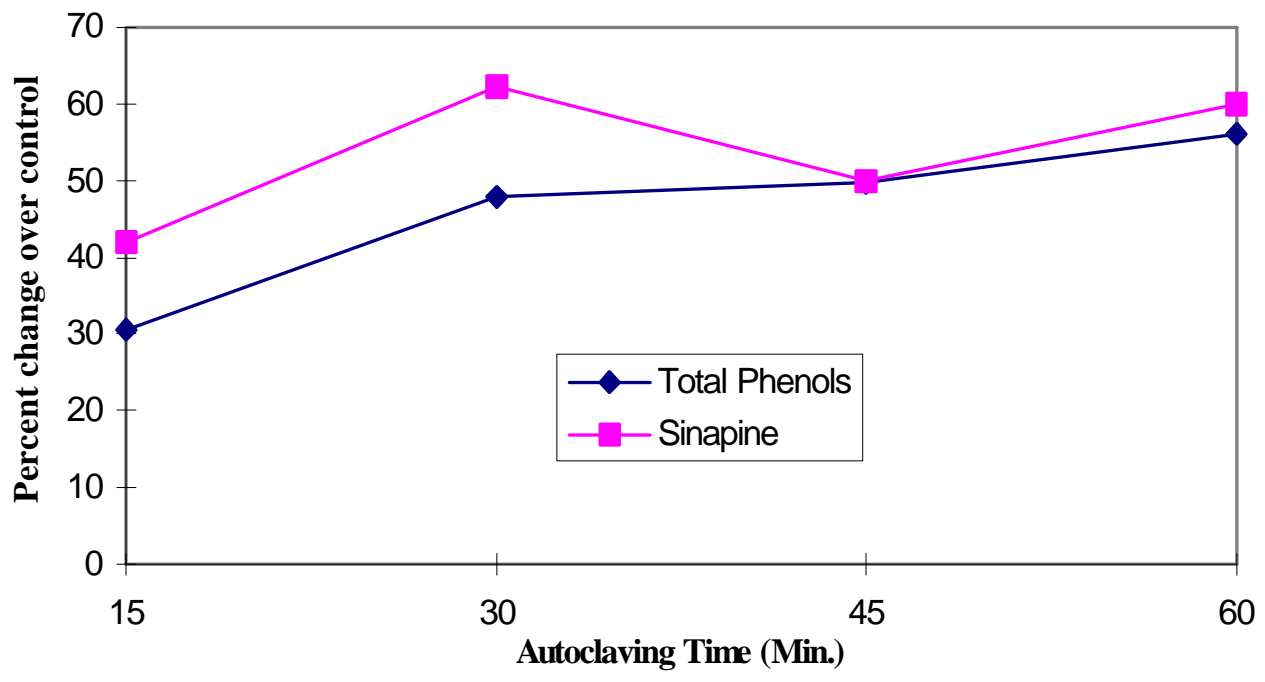

\subsubsection{EFFECTS OF TIME OF DRY HEATING}

Dry heating of rapeseed resulted in reduction of total phenols. Most of the reduction (41.3\%) was achieved with 20 minutes of treatment. Beyond this point further reduction was nominal. With 60 minutes heating the total reduction in total phenols was $45.5 \%$. In case of sinapine, most of the reduction $(23.3 \%)$ was achieved with 5 minutes heating. Further heating did not cause any mentionable reduction (Table 20).

Table 20. Effect of time dry heat treatment $\left(100^{\circ} \mathrm{C}\right)$ on sinapine and total phenol contents of rapeseed 


\begin{tabular}{ccc}
\hline $\begin{array}{c}\text { Heating Time } \\
\text { (Minutes) }\end{array}$ & $\begin{array}{c}\text { Total Phenols } \\
\text { Sinapine }\end{array}$ & \% \\
\hline $\mathbf{0}$ & 1.21 & 0.9 \\
$\mathbf{5}$ & 1.02 & 0.69 \\
$\mathbf{1 0}$ & 0.89 & 0.7 \\
$\mathbf{2 0}$ & 0.71 & 0.71 \\
$\mathbf{4 0}$ & 0.68 & 0.67 \\
$\mathbf{6 0}$ & 0.66 & 0.68 \\
$\mathbf{C V}$ & 23.4 & 10.9 \\
\hline
\end{tabular}

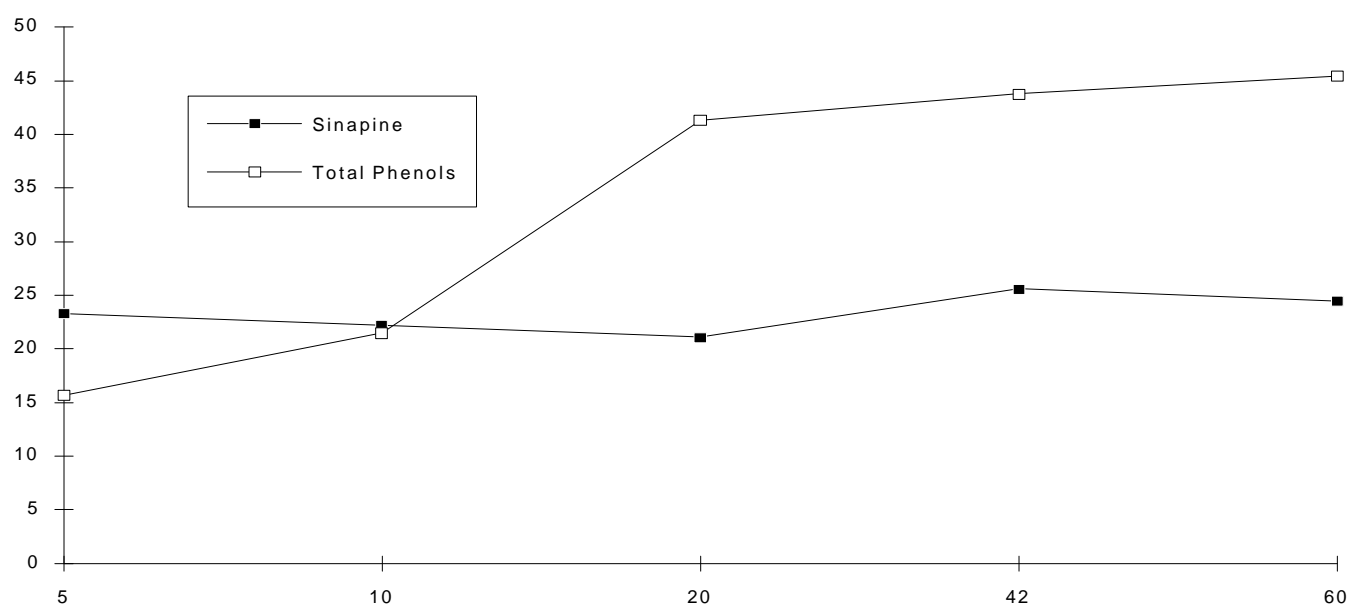

Heating Times (Min.)

Fig. 7. Percent reduction in sinapine and total phenol contents of RSM due to different times of heating

\subsubsection{TOTAL GLUCLSINOLATE}

Table 21 shows the influence of different treatments on the total glucosinolate content of rapeseed meal. The control sample had a glucosinolates content of $60.8 \mu \mathrm{mol} / \mathrm{g}$. Heat treatments did not cause much changes and the value was $56.2 \mu \mathrm{mol} / \mathrm{g}$ in 60 minutes heat treated sample. Autoclaving $(103.5 \mathrm{kPa})$ of rapeseed on the other hand drastically reduced its glucosinolate content and was 48 and $61 \%$ reduced in 10 and 30 minutes treated rapeseed meal samples, respectively. Irradiation treatment did not reduce much the glucosinolates up to $5 \mathrm{kGy}$ dose but with $10 \mathrm{kGy}$ dose their content were $36 \%$ reduced.

Table 21. Total glucosinolate content of control and processed rapeseed meal

Treatment
Total Glucosinolates

$(\mu \mathrm{mol} / \mathrm{g})$
Reduction

(\%) 


\begin{tabular}{lcc} 
Control - untreated & 60.8 & 0.0 \\
Heating - 20 min. & 59.4 & 2.4 \\
Heating 60 min. & 56.2 & 7.6 \\
Autoclaving 10 min. & 31.8 & 47.8 \\
Autoclaving 30 min. & 23.8 & 60.8 \\
Irradiation-5 kGy & 55.9 & 8.1 \\
Irradiation-10kGy & 39.13 & 35.6 \\
CV $\quad 29.6$ & --- \\
\hline \multicolumn{2}{c}{$\begin{array}{l}a \text { Expressed as sinigrin equivalent } \\
b \text { Dry heat treatment at } 121^{\circ} \mathrm{C}\end{array}$} \\
$\quad c \quad$ Autoclaving at $121^{\circ} \mathrm{C}$ under 15 psi pressure (103.5kPa)
\end{tabular}

Fig. 8. Percent reduction in glucosinolate content of RSM due to different treatments

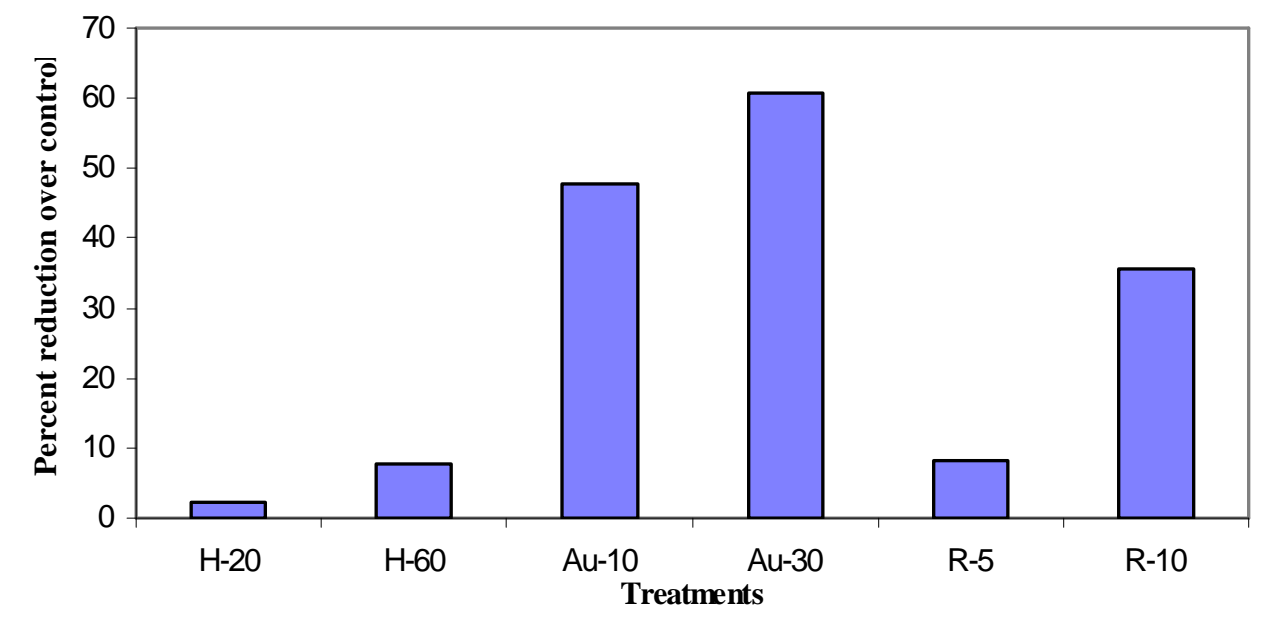

\subsubsection{IN-VITRO PROTEIN DIGESTIBILITY}

\subsubsection{EFFECT OF AUTOCLAVING}

Effect of autoclaving was significant on the in-vitro digestibility of rapeseed protein (Table 22). The control sample had an in-vitro protein digestibility of $85.7 \%$ and with 15 minutes of autoclaving the digestibility rose to $90.1 \%$. This was significantly $(\mathrm{p}<0.05)$ higher than the control samples. Longer heating times did not cause further improvement in the in-vitro protein digestibility. In fact heating beyond 20 minutes caused reduction in the in-vitro protein digestibility of rapeseed protein.

Table 22 Effect of autoclaving on in-vitro digestibility of rapeseed protein

\begin{tabular}{cc}
$\begin{array}{c}\text { Autoclaving Time } \\
\text { (Minutes) }\end{array}$ & $\begin{array}{c}\text { Digestibility } \\
(\%)\end{array}$ \\
\hline $\mathbf{0}$ & $85.7^{\mathrm{bc}}$ \\
$\mathbf{5}$ & $88.0^{\mathrm{ab}}$ \\
$\mathbf{1 0}$ & $88.5^{\mathrm{ab}}$
\end{tabular}


$a$ Values with different superscripts in the same column are significantly different $(\mathrm{P}<0.05)$.

b Autoclaving $-121^{\circ} \mathrm{C}$ at $15 \mathrm{psi}(103.5 \mathrm{kPa})$ for 30 minutes

\section{Fig. 9. Percent increase in the in vitro digestibility of rapeseed protein with autoclaving treatments}

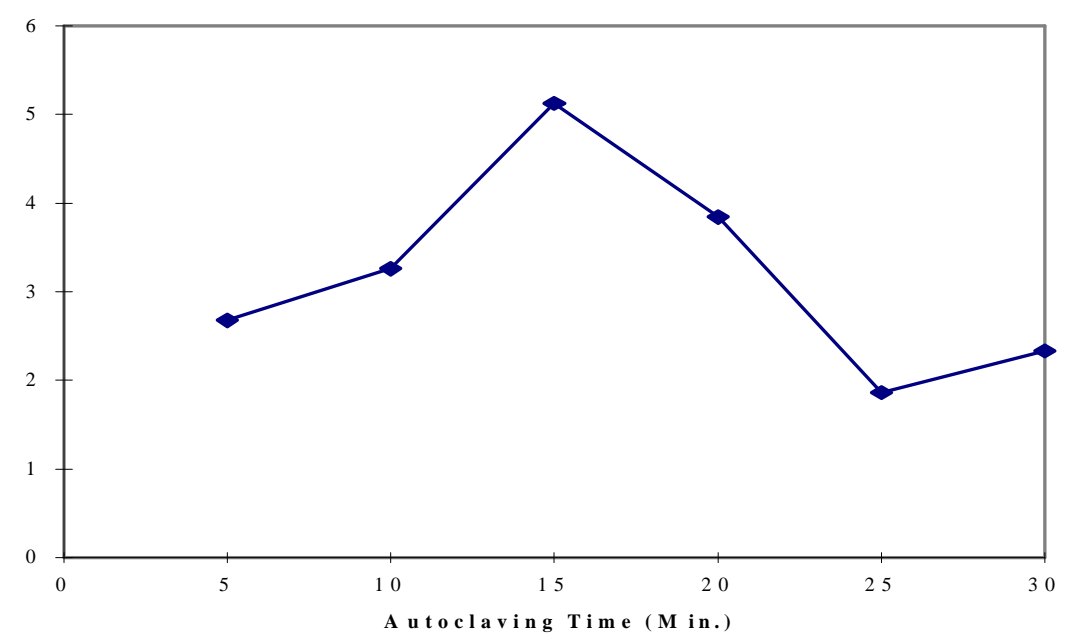

\subsubsection{EFFECT OF DRY HEATING}

Dry heating of the rapeseed also caused improvement in the in-vitro protein digestibility, and the effect again was statistically significant $(\mathrm{p}<0.05)$. The highest value $(91.8 \%)$ in case of dry heating, was achieved with a treatment time of 60 minutes. However the digestibility value attained with 20 minutes treatment $(90$ $\%$ ) was not significantly different from that obtained with 60 minutes treatment (Table 23).

Table 23. Effect of dry heat treatment $\left(121^{\circ} \mathrm{C}\right)$ on in-vitro digestibility

of rapeseed protein

\section{Heating time}

(Minutes)

0

5

10

15

20

25

30
Digestibility*

(\%)

$85.7^{\mathrm{c}}$

$87.0^{\mathrm{C}}$

$86.6^{\mathrm{C}}$

$85.2^{\mathrm{C}}$

$90.0^{\mathrm{ab}}$

$90.4^{\mathrm{ab}}$

$89.0^{\mathrm{b}}$ 
* Values with different superscripts in the same column are significantly different $(\mathrm{P}<0.05)$.

Fig. 10. Percent changes in the in-vitro digestibility of rapeseed protein with heat treatments

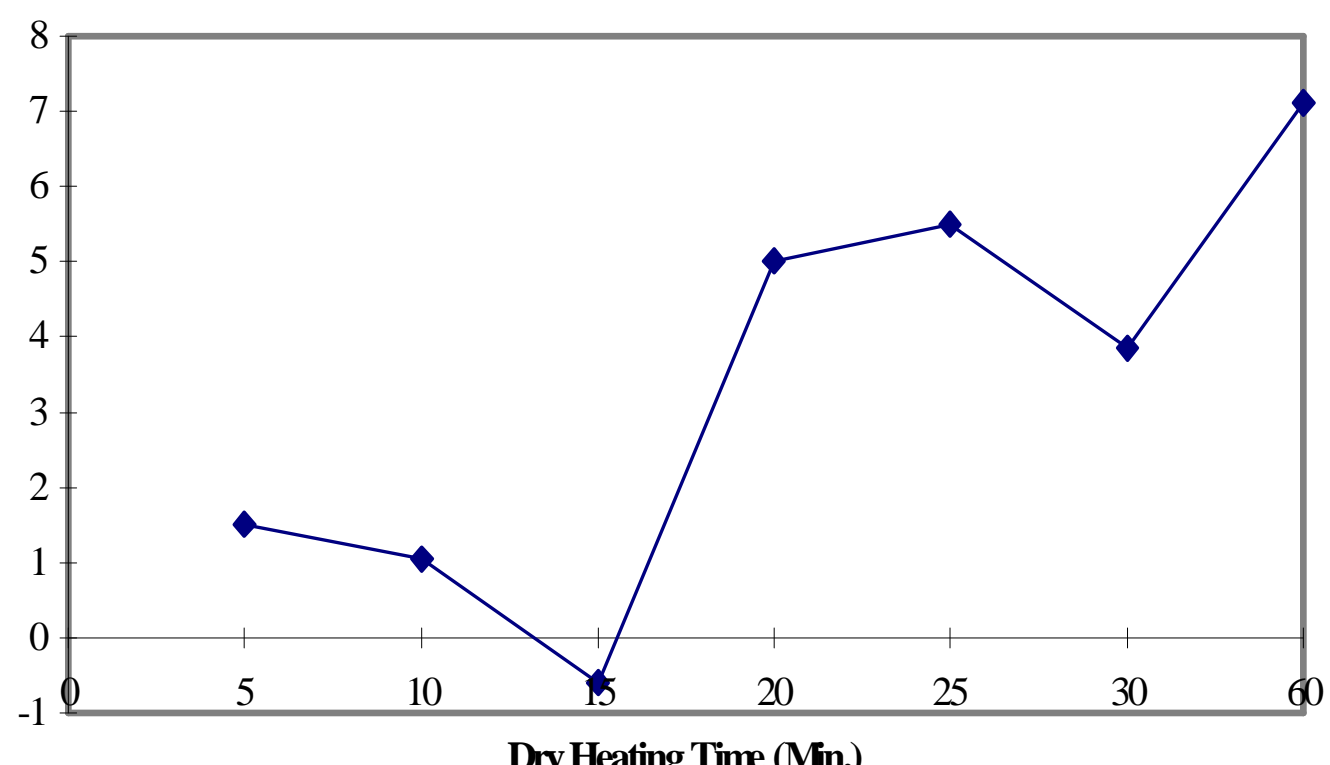

\subsubsection{EFFECT OF IRRADIATION AND COMBINATION TREATMENTS}

Irradiation treatment $(1 \mathrm{kGy})$ did not change significantly the in-vitro protein digestibility of rapeseed (Table 24). However the combination treatments (irradiation and dry heating or irradiation and autoclaving significantly improved the in-vitro protein digestibility of rapeseed. The digestibility increased from $85.7 \%$ (in control sample) to $86.7 \%$ with irradiation + dry heating and to $88.9 \%$ with irradiation + autoclaving combination.

Table 24. Effect of irradiation and combination methods on in-vitro digestibility of rapeseed protein

\begin{tabular}{lc}
\hline Treatment & $\begin{array}{c}\text { In-Vitro protein digestibility } \\
\%\end{array}$ \\
\hline Control & $85.7^{\mathrm{bc}}$ \\
Irradiation $^{* *}$ & $85.4^{\mathrm{c}}$ \\
Irradiation + Heat $* * *$ & $86.7^{\mathrm{b}}$ \\
Irradiation + autoclaving **** $\quad 88.9^{\mathrm{a}}$ \\
$* \quad \quad$ Values with different superscripts in the same column are significantly different $(\mathrm{P}<0.05)$. \\
Irradiation 1kGy
\end{tabular}


$* * * \quad$ Irradiation + heat $-1 \mathrm{kGy}+121^{\circ} \mathrm{C}$ for 30 minutes

$* * * * \quad$ Irradiation + autoclaving $-1 \mathrm{kGy}+121^{\circ} \mathrm{C}$ at $15 \mathrm{psi}(103.5 \mathrm{kPa})$ for 30 minutes

\subsubsection{AMINO ACID PROFILE}

\subsubsection{DRY HEATING EFFECT}

The amino acid profile of heat treated rapeseed meal relative to that of the untreated control rapeseed meal is given in Tables 25. The amino acids were variously influenced by different heat treatments. The amino acids of special interest in connection with poultry feeding are methionine, lysine and arginine. Methionine content were reduced to 80 and $83 \%$ in the 30 and 60 minutes heated meal samples, respectively. Lysine content was also decreased to 53 and $48 \%$ of the original concentration with these treatments, respectively. Effect of heat treatment on arginine, however was inconsistent. The original arginine content increased to $145 \%$ with 30 minutes treatment but decreased to $87 \%$ with 60 minutes treatment time. 
Table 25. Effect of Heat treatments on the amino acid contents (expressed as \% of control sample) in rapeseed meal

\begin{tabular}{|c|c|c|c|}
\hline AMINO ACID & CONTROL & $\begin{array}{c}\text { HEATING } \\
\text { 30MIN }\end{array}$ & $\begin{array}{c}\text { HEATING } \\
\text { 60MIN }\end{array}$ \\
\hline Aspartic acid & 100 & 85.9 & 106.1 \\
\hline Threonine & 100 & 93.8 & 96.1 \\
\hline Serine & 100 & 92.3 & 95.8 \\
\hline Glutamic acid & 100 & 102.5 & 103.9 \\
\hline Proline & 100 & 78.6 & 115.7 \\
\hline Glycine & 100 & 137.1 & 148.3 \\
\hline Alanine & 100 & 118.9 & 83.7 \\
\hline Cystine & 100 & 103.1 & 53.1 \\
\hline Valine & 100 & 11.6 & 118.8 \\
\hline Methionine & 100 & 80.00 & 82.9 \\
\hline Isoleucine & 100 & 115.3 & 139.7 \\
\hline Leucine & 100 & 94.9 & 108.6 \\
\hline Tyrosine & 100 & 58.2 & 73.5 \\
\hline Phenylalanine & 100 & 54.0 & 51.0 \\
\hline Histidine & 100 & 111.7 & 32.3 \\
\hline Lysine & 100 & 53.0 & 47.8 \\
\hline Arginine & 100 & 145.1 & 86.9 \\
\hline
\end{tabular}

\subsubsection{AUTOCLAVING EFFECT}

The autoclaving treatment has more drastically influenced the amino acid profile of rapeseed meal (Table 26). The percentage of cystine relative to that in the control sample was reduced from 100 to 62.5 with 20 minutes treatment but was increased to 131 with 30 minutes autoclaving. Similarly methionine (107\%) remained almost unchanged with 20 minutes treatment but increased to almost double with 30 minutes autoclaving treatment. This trend was reversed with lysine content, which, although, was not much affected with the first treatment (93.5\%), decreased to $47 \%$ with 30 minutes autoclaving. Arginin on the other hand 
was reduced to $72 \%$ with 20 minutes but longer treatment showed practically an increase in its content $(112.6 \%)$.

Table 26. Effects of autoclaving treatments $121^{\circ} \mathrm{C}$ at $15 \mathrm{psi}(103.5 \mathrm{kPa})$ on the amino acid contents (expressed as \% of control sample) in rapeseed meal

\begin{tabular}{|c|c|c|c|}
\hline Amino Acid & Control & $\begin{array}{c}\text { Autoclaving } \\
\text { 20min }\end{array}$ & $\begin{array}{c}\text { Autoclaving } \\
\text { 30min }\end{array}$ \\
\hline Aspartic acid & 100 & 88.8 & 87.2 \\
\hline Threonine & 100 & 121.7 & 93.8 \\
\hline Serine & 100 & 138.5 & 93.0 \\
\hline Glutamic acid & 100 & 125.1 & 103.9 \\
\hline Proline & 100 & 108.3 & 98.6 \\
\hline Glycine & 100 & 144.9 & 144.9 \\
\hline Alanine & 100 & 134.0 & 101.3 \\
\hline Cystine & 100 & 62.5 & 131.3 \\
\hline Valine & 100 & 125.4 & 103.6 \\
\hline Methionine & 100 & 107.1 & 204.3 \\
\hline Isoleucine & 100 & 119.8 & 97.7 \\
\hline Leucine & 100 & 116.1 & 87.5 \\
\hline Tyrosine & 100 & 100.5 & 66.3 \\
\hline Phenylalanine & 100 & 64.6 & 72.2 \\
\hline Histidine & 100 & 37.0 & 53.5 \\
\hline Lysine & 100 & 93.5 & 47.4 \\
\hline Arginine & 100 & 72.1 & 112.6 \\
\hline
\end{tabular}

\subsubsection{IRRADIATION EFFECT}

Effect of irradiation doses on different amino acids in rapeseed meal is shown in Table 27. The sulphur containing amino acids (cystine and methionine) were reduced with both the irradiation doses. Lysine also showed a reduction with irradiation but arginine was increased due to irradiation treatments.

Table 27. Effects of irradiation treatments on the amino acid contents

(expressed as \% of control sample) in rapeseed meal 


\begin{tabular}{|c|c|c|c|}
\hline Amino Acid & Control & $\begin{array}{c}\text { Irradiation } \\
5 \mathrm{kGy} \\
\end{array}$ & $\begin{array}{c}\text { Irradiation } \\
10 \mathrm{kGy}\end{array}$ \\
\hline Aspartic acid & 100 & 83.3 & 77.2 \\
\hline Threonine & 100 & 104.7 & 90.7 \\
\hline Serine & 100 & 104.2 & 50.3 \\
\hline Glutamic acid & 100 & 100.0 & 88.7 \\
\hline Proline & 100 & 70.1 & 61.3 \\
\hline Glycine & 100 & 134.3 & 109.0 \\
\hline Alanine & 100 & 139.9 & 95.4 \\
\hline Cystine & 100 & 71.9 & 65.6 \\
\hline Valine & 100 & 115.2 & 121.0 \\
\hline Methionine & 100 & 71.4 & 92.9 \\
\hline Isoleucine & 100 & 153.4 & 129.0 \\
\hline Leucine & 100 & 121.2 & 93.3 \\
\hline Tyrosine & 100 & 61.2 & 70.9 \\
\hline Phenylalanine & 100 & 98.0 & 62.6 \\
\hline Histidine & 100 & 44.0 & 87.3 \\
\hline Lysine & 100 & 50.4 & 87.4 \\
\hline Arginine & 100 & 132.0 & 121.6 \\
\hline
\end{tabular}




\subsection{FEEDING TRIALS WITH BROILER CHICKS}

The following biological experiments were conducted using rapeseed meal as a component of the diet

1. Effect of feeding different levels of rapeseed meal on the performance of broiler chicks.

2. Effect of irradiation on the nutritional value of rapeseed meal for broiler chicks.

3. Effect of dry heating and dehulling on the nutritional value of rapeseed meal for broiler chicks.

4. Effect of autoclaving time on the nutritional value of rapeseed meal for broiler chicks.

5. Effect of pre- and post-extraction autoclaving on the nutritional value of rapeseed meal for broiler chicks.

6. Effect of feeding increased levels of heat processed rapeseed meal on the performance of broiler chicks.

7. Effect of feeding increased levels of irradiated rapeseed meal on the performance of broiler chicks.

\subsubsection{EFFECT OF FEEDING DIFFERENT LEVELS OF RAPESEED MEAL ON THE PERFORMANCE OF BROILER CHICKS.}

Results regarding the effect of feeding rapeseed meal at various levels in the diet on the growth performance of broiler chicks are given in Table 28. Minimum feed intake (2109g chick $\left.{ }^{-1}\right)$ was recorded in group fed $5 \%$ rapeseed meal in the diet, whereas maximum feed intake $\left(3151 \mathrm{~g} \mathrm{chick}^{-1)}\right.$ was noted for $25 \%$ rapeseed meal fed group. The feed intake for standard group was $2730 \mathrm{~g} \mathrm{chick}^{-1}$. Weight gain chick $^{-1}$ was not significantly reduced up to $15 \%$ rapeseed meal feeding and ranged from 930 to $966 \mathrm{~g} \mathrm{chick}^{-1}$, however, increasing the rapeseed meal upto $25 \%$ in the diet significantly $(\mathrm{p}<0.01)$ reduced the weight gain chick ${ }^{-1}$. The gain in weight chick $^{-1}$ was maximum with $15 \%$ rapeseed meal feeding (966 g) followed by 5\% rapeseed meal diet $(962 \mathrm{~g})$. Final weight chick $^{-1}$ followed the same pattern. The feed to gain ratio was lowest (2.19) in 5\% rapeseed meal group followed by 10 and $15 \%$ rapeseed meal groups. Dressing percentage ranged from 54.28 to 56.19 among different groups and was not significantly affected by any treatment.

The same data presented in terms of percentage increase or decrease (Figure. 11) give an interesting view. Feed intake was over $20 \%$ lower than standard group with 5\% inclusion of rapeseed meal. Increasing the levels of rapeseed meal in the diet increased this and at $15 \%$ level the feed intake was equal to that in standard group. Further increase in the rapeseed meal inclusion resulted in better feed intake than standard group. Gain in weight, on the other hand, did not follow this pattern. Weight gain was similar to that of standard group up to $15 \%$ rapeseed meal inclusion, and dropped below the standard group with further increasing rapeseed meal in the diet. It can be noted that both the feed intake and weight gain were equal or better than standard diet at $15 \%$ rapeseed meal.

Table 28. Effect of feeding different levels of rapeseed meal to broiler chicks on their biological performance 


\begin{tabular}{lccccc}
\hline Groups & $\begin{array}{c}\text { Feed intake** } \\
\left(\mathbf{g ~ C h i c k}^{-1}\right)\end{array}$ & $\begin{array}{c}\text { Final Weight } \\
\left(\mathbf{g ~ C h i c k}^{-1}\right)\end{array}$ & $\begin{array}{c}\text { Weight Gain * } \\
\left(\text { g Chick }^{-1}\right)\end{array}$ & $\begin{array}{c}\text { Feed : Gain } \\
\text { Ratio }\end{array}$ & $\begin{array}{c}\text { Dressing } \\
\text { Percentage }\end{array}$ \\
\hline RSM-0 & $2730^{\mathrm{abc}}$ & 1000 & $952^{\mathrm{a}}$ & 2.87 & 56.2 \\
RSM-5 & $2109^{\mathrm{c}}$ & 1010 & $962^{\mathrm{a}}$ & 2.19 & 55.5 \\
$\mathbf{R S M - 1 0}$ & $2410^{\mathrm{bc}}$ & 975 & $930^{\mathrm{a}}$ & 2.59 & 56.0 \\
RSM-15 & $2726^{\mathrm{abc}}$ & 1015 & $966^{\mathrm{a}}$ & 2.82 & 56.00 \\
RSM-20 & $2985^{\mathrm{ab}}$ & 950 & $900^{\mathrm{b}}$ & 3.32 & 55.2 \\
RSM-25 & $3151^{\mathrm{a}}$ & 905 & $857^{\mathrm{bc}}$ & 3.68 & 54.3 \\
CV & 14.12 & 4.34 & 4.6 & 18.2 & 1.3 \\
\hline
\end{tabular}

Values with different superscripts in the same column are significantly different at $\mathrm{P}<0.01(* *)$ or $\mathrm{P}<0.05(*)$.

Fig. 11. Percent change in feed consumption and weight gain of broiler chicks due to different levels of

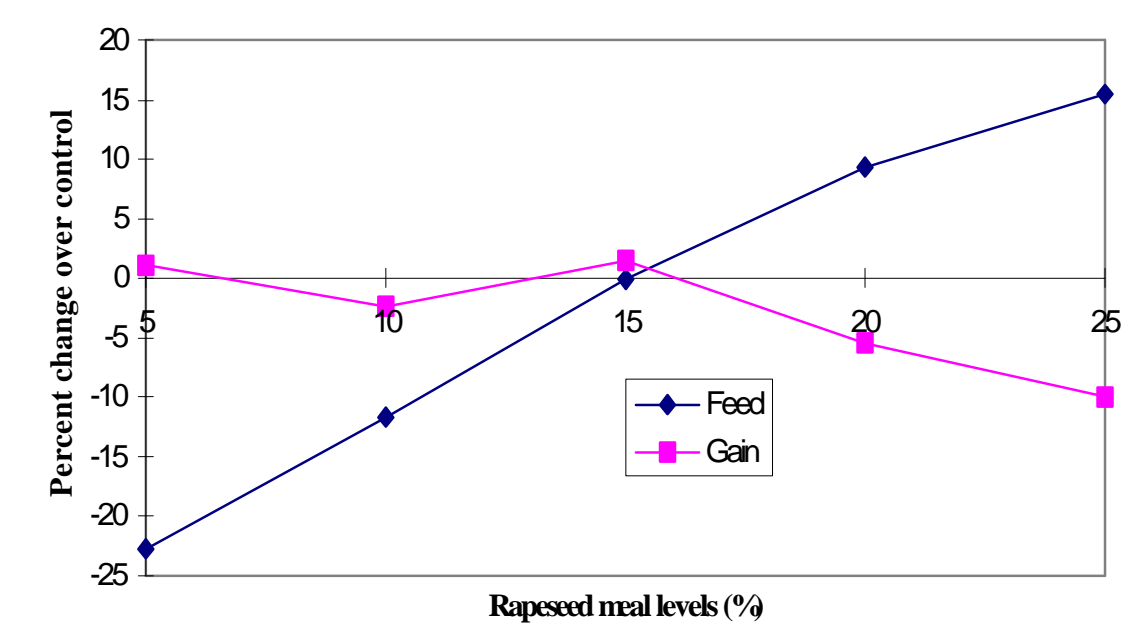

RSM in diet

\subsubsection{EFFECT OF IRRADIATION ON THE NUTRITIONAL VALUE OF RAPESEED MEAL FOR BROILER CHICKS.}

Differences among different groups regarding total feed intake, total weight gain and final weight were statistically non-significant (Table 29). However it is clear from the results that feed consumption was maximum in 5 and $10 \mathrm{kGy}$ groups, indicating some taste improvement, which, however, was not paralleled by a concomitant increase in weight gain and the feed to gain ratio was maximum with $5 \mathrm{kGy}$ diet. Data regarding dressing percentage showed minimum value for $10 \mathrm{kGy}$ group, while values observed for control, $5 \mathrm{kGy}$ and standard group were comparable to each other ( 56 to $57 \%$ ). 
As can be seen from Figure 12, feed intake per chick as well as weight gain in control group were lower than standard group. Feed intake improved with 5kGy irradiation and did not improve with higher dose. Gain in weight on the contrary was highest with $10 \mathrm{kGy}$ dose. Variation in organ weights (Table 16) were negligible. Values noted for heart ranged from $0.58 \mathrm{~g} / 100 \mathrm{~g}$ body weight (10kGy group) to $0.67 \mathrm{~g} / 100 \mathrm{~g}$ body weight (5kGy group), Liver weight ranged from $2.09 \mathrm{~g} / 100 \mathrm{~g}$ body weight (control and $10 \mathrm{kGy}$ group) to $2.44 \mathrm{~g} / 100 \mathrm{~g}$ body weight (5 kGy group) and gizzard weight ranged from $1.31 \mathrm{~g} / 100 \mathrm{~g}$ body weight (10 kGy group) to $1.61 \mathrm{~g} / 100 \mathrm{~g}$ body weight ( $5 \mathrm{kGy}$ group).

Table 29. Performance of broiler chicks fed on diets containing irradiated rapeseed meal

\begin{tabular}{lccccc}
\hline Groups & $\begin{array}{c}\text { Feed Intake } \\
\left(\text { g Chick }^{-1}\right)\end{array}$ & $\begin{array}{c}\text { Weight Gain } \\
\left(\text { g Chick }^{-1}\right)\end{array}$ & $\begin{array}{c}\text { Final Weight } \\
\left(\mathrm{g} \mathrm{Chick}^{-1}\right)\end{array}$ & $\begin{array}{c}\text { Feed : Gain } \\
\text { Ratio }\end{array}$ & $\begin{array}{c}\text { Dressing } \\
\text { Percentage }\end{array}$ \\
\hline Standard & 2566 & 1174 & 1251 & 2.19 & 57.5 \\
Control & 2392 & 1145 & 1224 & 2.09 & 57.6 \\
$\mathbf{5}$ kGy & 2630 & 1108 & 1187 & 2.38 & 56.3 \\
$\mathbf{1 0}$ kGy & 2628 & 1241 & 1318 & 2.12 & 47.1 \\
$\mathbf{C V}$ & 4.39 & 4.82 & 4.44 & 5.93 & 9.25 \\
\hline
\end{tabular}

Fig. 12. Percent changes in feed consumption and weight gain per chick due to control and irradiated RSM in the diet 


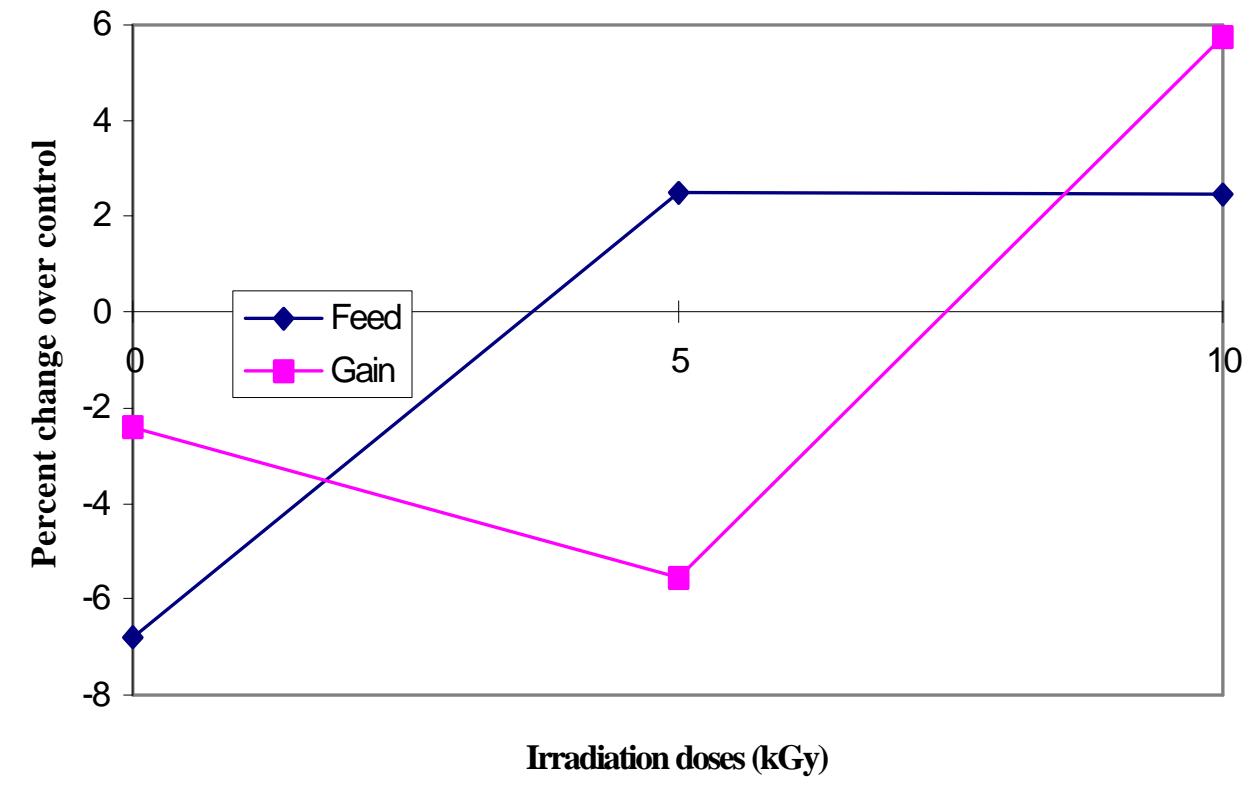

Table 30: Organ weights (\% of body weight) of broiler chicks fed on diets containing irradiated rapeseed meal

\begin{tabular}{lccc}
\hline Groups & Heart & Liver & Gizzard \\
\hline Standard & 0.61 & 2.18 & 1.49 \\
Control & 0.64 & 2.09 & 1.43 \\
$\mathbf{5}$ kGy & 0.67 & 2.44 & 1.61 \\
$\mathbf{1 0 k G y}$ & 0.58 & & 1.31 \\
$\mathbf{C V}$ & 6.20 & 2.09 & 8.55 \\
\hline
\end{tabular}

\subsubsection{EFFECTS OF DRY HEATING AND DEHULLING ON THE NUTRITIONAL VALUE OF RAPESEED MEAL FOR BROILER CHICKS.}

Data regarding the effects of heating and dehulling on the nutritional quality of rapeseed meal for broiler chicks are presented in Table 31. As can be noted from the data, all rapeseed meal fed groups consumed significantly $(\mathrm{P}<0.05)$ more feed than the standard diet with no rapeseed meal. Among the rapeseed meal groups heat treated resulted in the highest feed intake $\left(2081 \mathrm{~g} \mathrm{chick}{ }^{-1}\right)$ followed by control $\left(1940 \mathrm{chick}^{-1}\right)$ 
and dehulled rapeseed meal (1915g chick $\left.{ }^{-1}\right)$. This trend was paralleled by gain in weight and maximum gain was recorded in the case of heat treated rapeseed meal fed group, whereas minimum weight gain (637.60 $\left.\mathrm{g} \mathrm{chick}^{-1}\right)$ was noted in control group without rapeseed meal. This was significantly $(\mathrm{p}<0.05)$ lower than all rapeseed meal groups. Feed to gain ratio ranged from 2.49 to 2.72 among different groups.

Table 31. Performance of broiler chicks as influenced by feeding diets containing processed rapeseed meal

\begin{tabular}{lcccc}
\hline Groups & $\begin{array}{c}\text { Feed intake } \\
\left(\text { g Chick }^{-1}\right)^{*}\end{array}$ & $\begin{array}{c}\text { Final Weight } \\
\left(\text { g Chick }^{-1}\right)\end{array}$ & $\begin{array}{c}\text { Weight Gain } \\
\left(\text { g Chick-1 }^{-*}\right.\end{array}$ & $\begin{array}{c}\text { Feed : Gain } \\
\text { Ratio }\end{array}$ \\
\hline Standard & $1710^{\mathrm{b}}$ & 704 & $638^{\mathrm{b}}$ & 2.68 \\
Control & $1940^{\mathrm{a}}$ & 783 & $713^{\mathrm{a}}$ & 2.72 \\
Heated & $2081^{\mathrm{a}}$ & 855 & $788^{\mathrm{a}}$ & 2.64 \\
Dehulled & $1915^{\mathrm{a}}$ & 833 & $769^{\mathrm{a}}$ & 2.49 \\
& & & & \\
CV & 8.00 & 8.44 & 9.26 & 3.82 \\
\hline
\end{tabular}

* Values with different superscripts in the same column are significantly different at $\mathrm{P}<0.05$. 


\section{Fig. 13. Percent changes in feed intake and weight gain of}

broiler chicks due to feeding heated and dehulled RSM in the diet

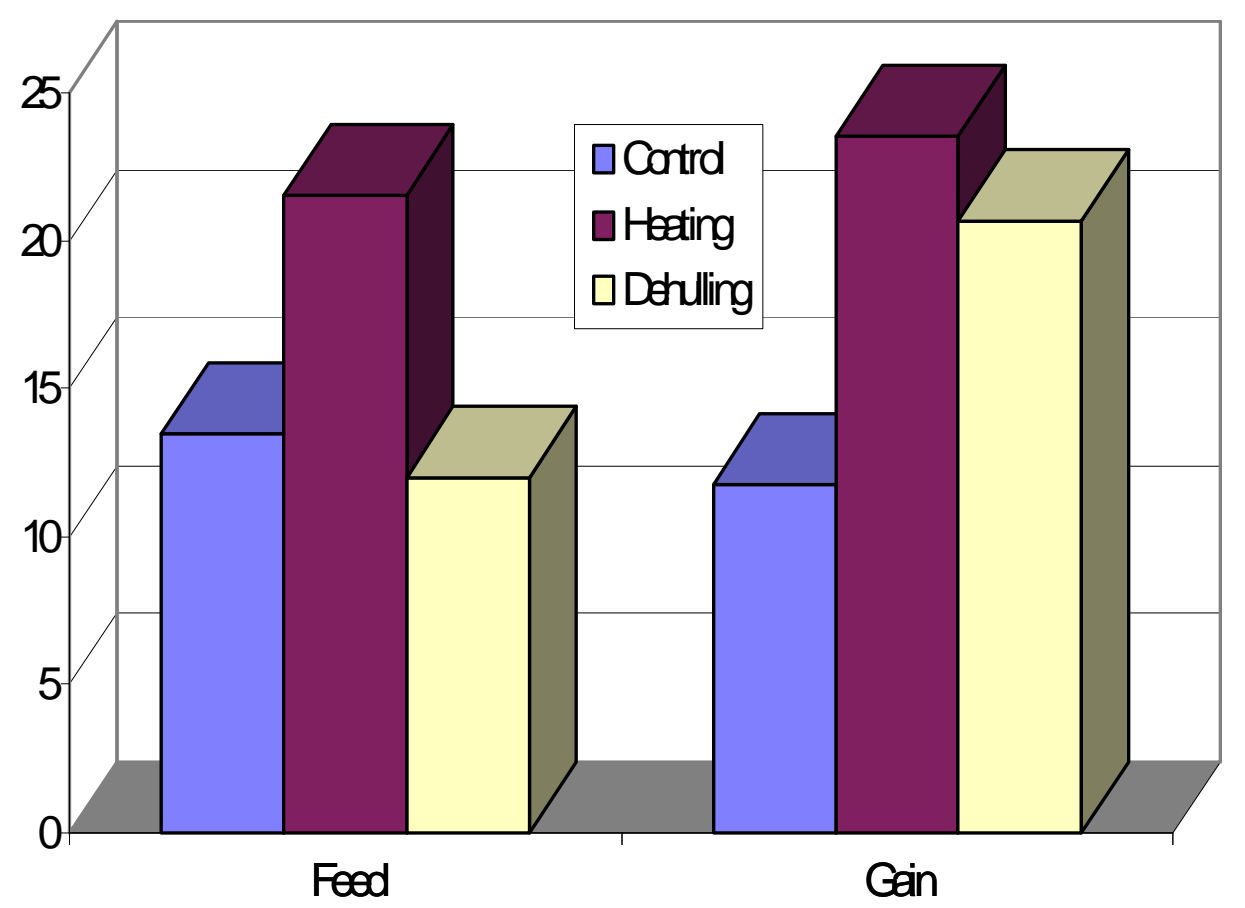

\subsubsection{EFFECTS OF AUTOCLAVING TIME ON THE NUTRITIONAL VALUE OF RAPESEED MEAL FOR BROILER CHICKS.}

Data on the effects of feeding autoclaved rapeseed meal in the diet on the biological performance of broiler chicks are shown in Table 32. Significant $(\mathrm{P}<0.05)$ differences were observed in the values regarding feed intake, total weight gain and feed to gain ratio among different groups (treatments). Feed intake was highest (2120 $\mathrm{g} \mathrm{chick}^{-1}$ ) in the group fed on untreated rapeseed meal followed by 25 minutes treated rapeseed meal group $\left(1982 \mathrm{~g} \mathrm{chick}^{-1}\right)$. Almost similar feed intake was recorded in standard $\left(1740 \mathrm{~g} \mathrm{chick}^{-1)}\right.$ and 30 minutes treatment group $\left(1704 \mathrm{~g} \mathrm{chick}^{-1}\right)$. Weight gain was maximum ( $\left.1162 \mathrm{~g} \mathrm{chick}^{-1}\right)$ with 30 minutes treatment and minimum ( $\left.898 \mathrm{~g} \mathrm{chick}^{-1}\right)$ in group fed on untreated rapeseed meal in the diet. Weight gain for standard group was $1055 \mathrm{~g} \mathrm{chick}^{-1}$. Feed to gain ratio was lowest (1.47) in 30 minutes treatment and was comparable with the value recorded for standard group (1.65); whereas highest (2.36) feed to gain ratio was recorded in untreated control group, indicating poor feed efficiency of feed containing untreated rapeseed meal. 
Table 32. Effect of time of autoclaving $121^{\circ} \mathrm{C}$ at $15 \mathrm{psi}(103.5 \mathrm{kPa})$ on the nutritional value of rapeseed meal for broiler chicks

\begin{tabular}{|c|c|c|c|c|}
\hline Group & $\begin{array}{l}\text { Feed intake } \\
\left(\text { g Chick }^{-1}\right)^{*}\end{array}$ & $\begin{array}{l}\text { Final Weight } \\
\left(\text { g Chick }^{-1}\right)\end{array}$ & $\begin{array}{l}\text { Weight Gain } \\
\left(\text { g Chick }^{-1}\right)^{*}\end{array}$ & $\begin{array}{c}\text { Feed : Gain } \\
\text { Ratio }\end{array}$ \\
\hline Standard & $1740^{\mathrm{d}}$ & 1099 & $1055^{b}$ & 1,65 \\
\hline Autoclaving - & $2120^{\mathrm{a}}$ & 940 & $898^{\mathrm{c}}$ & 2,36 \\
\hline \multicolumn{5}{|l|}{0 min.** } \\
\hline Autoclaving - & $1572^{e}$ & 1100 & $1058^{b}$ & 1,49 \\
\hline \multicolumn{5}{|l|}{$10 \mathrm{~min}}$. \\
\hline Autoclaving - & $1888^{\mathrm{c}}$ & 1000 & $956^{\mathrm{bc}}$ & 1,97 \\
\hline \multicolumn{5}{|l|}{$15 \mathrm{~min}}$. \\
\hline Autoclaving - & $1872^{c}$ & 953 & $909^{c}$ & 2,06 \\
\hline \multicolumn{5}{|l|}{20 min. } \\
\hline Autoclaving - & $1982^{b}$ & 1092 & $1046^{b}$ & 1,89 \\
\hline \multicolumn{5}{|l|}{25 min. } \\
\hline Autoclaving - & $1704^{d}$ & 1200 & $1162^{\mathrm{a}}$ & 1,47 \\
\hline \multicolumn{5}{|l|}{$30 \mathrm{~min}$. } \\
\hline $\mathrm{CV}$ & 10.5 & 9.6 & 10.2 & 18.4 \\
\hline
\end{tabular}

\section{Fig. 14. Percent changes in feed intake and weight gain of broilers} due to control and autoclaved RSM in the diet

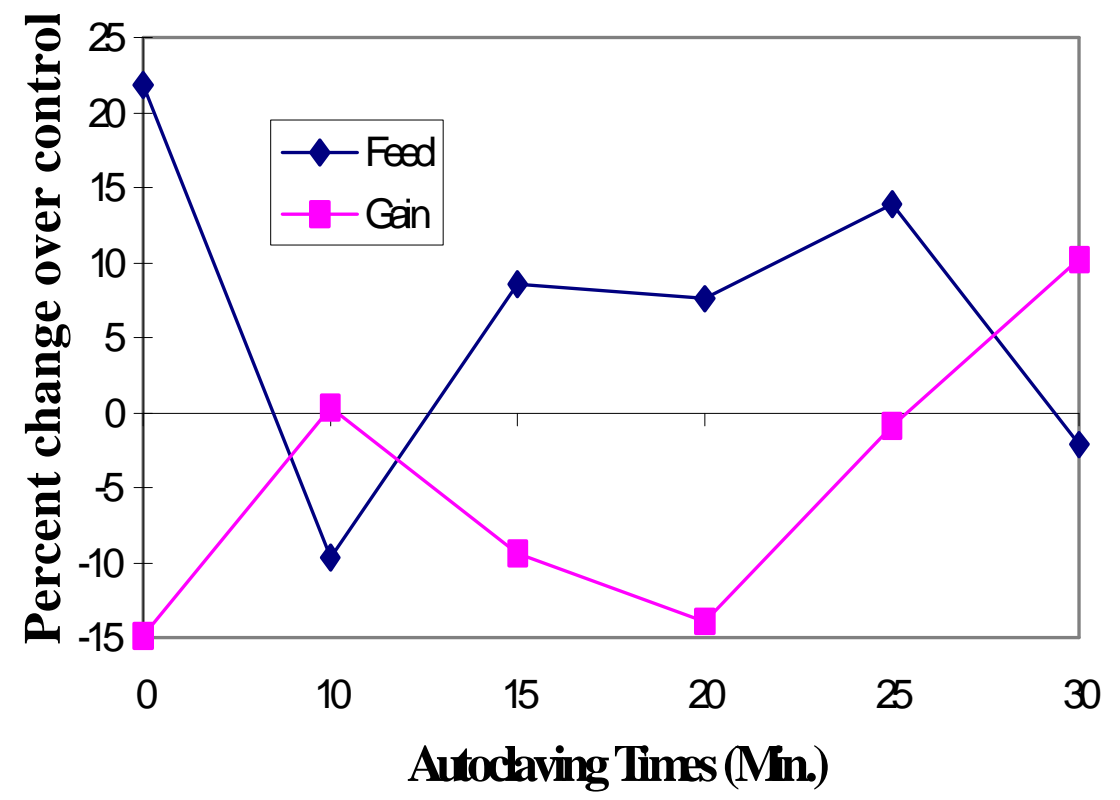




\subsubsection{EFFECTS OF PRE- AND POST-EXTRACTION AUTOCLAVING ON THE NUTRITIONAL VALUE OF RAPESEED MEAL FOR BROILER CHICKS}

Autoclaving of different seed grains has been reported to have beneficial effects on the nutritive value of their protein. In case of rapeseed it was reported to exhibit the additional benefit of deactivating myrosinases in the seed to avoid the hydrolysis of glucosinolates. It was, therefore, considered important to study the effects of autoclaving rapeseed before and after extraction of oil and for different times on the nutritional quality of the resultant meal for broiler chicks.

Data on feed consumption in $\mathrm{g} /$ chick as influenced by different treatments are presented in Table 33. The differences in the feed consumption were statistically non-significant, indicating that at this level (10\%) of incorporation of rapeseed meal in the diet for broilers did not affect the feed intake. It can, however, be noted from the data that feed intake in general was better in the case of pre-extraction autoclaving. This demonstrates that both the functions of inactivating of myrosinases and improvement in the proteins are at work. However, since the level of inclusion of rapeseed meal in the chick diet was relatively low (10\%), these effects could not be very clearly demonstrated.

In case of weight gain again the differences were statistically non-significant. Maximum total weight gain per chick (952.3g), however, was recorded with seed autoclaved for 30 minutes (SA-30), followed by control $(950 \mathrm{~g})$. It is clear that all the rapeseed meal diets gave better results as compared to standard diet. Feed to gain ratio obtained by different groups was also not significantly different; and ranged from 1.94 (control) to 2.08 (SA-30). Dressing percentage of different groups ranged from 51.4 ( standard) to 53.49 ( MA-30), and the differences again were not significant.

Among the organ weights, expressed as percent of total body weight (Table 34), none was influenced significantly by any treatments at this level of inclusion of rapeseed meal in the chicks diet. Weights of heart, liver, spleen and gizzard (g/100 g body weight) ranged among different groups from 0.84 to 0.95 , 2.89 to $3.13,0.85$ to 1.93 and 1.47 to 1.89 , respectively. 
Table 33. Performance of broiler chicks fed on diets containing autoclaved * rapeseed meal

\begin{tabular}{lccccc}
\hline Groups & $\begin{array}{c}\text { Feed Intake } \\
\left(\mathrm{g} \mathrm{Chick}^{-1}\right)\end{array}$ & $\begin{array}{c}\text { Weight Gain } \\
\left(\mathrm{g} \mathrm{Chick}^{-1}\right)\end{array}$ & $\begin{array}{c}\text { Final Weight } \\
\left(\mathrm{g} \mathrm{Chick}^{-1}\right)\end{array}$ & $\begin{array}{c}\text { Feed/Gain } \\
\text { ratio }\end{array}$ & $\begin{array}{c}\text { Dressing } \\
\text { Percentage }\end{array}$ \\
\hline Standard & 1942 & 866 & 916 & 2.07 & 51.6 \\
Control & 1878 & 951 & 1002 & 1.94 & 51.4 \\
SA-15 & 1957 & 904 & 953 & 2.08 & 52.9 \\
SA-30 & 1941 & 952 & 1003 & 2.00 & 53.1 \\
MA-15 & 1738 & 932 & 983 & 1.99 & 51.6 \\
MA-30 & 1865 & 876 & 926 & 2.01 & 53.5 \\
CV & 4.34 & 4.09 & 3.94 & 2.6 & 1.75 \\
\hline
\end{tabular}

$*=1$. SA15:- Seed autoclaving (15Min) and then extraction. 2. SA30:- Seed autoclaving (30Min) and then extraction. 3. MA15:- Oil extraction and then autoclaving (15Min). 4. MA30 :- Oil extraction and then autoclaving (30Min). 5. Control :- Oil extraction and inclusion in the diet as such. 6. Standard :-Standard (commercial) feed Formula

Fig. 15. Percent changes in feed intake and weight gain of broilers due to differently autoclaved RSM in the diet

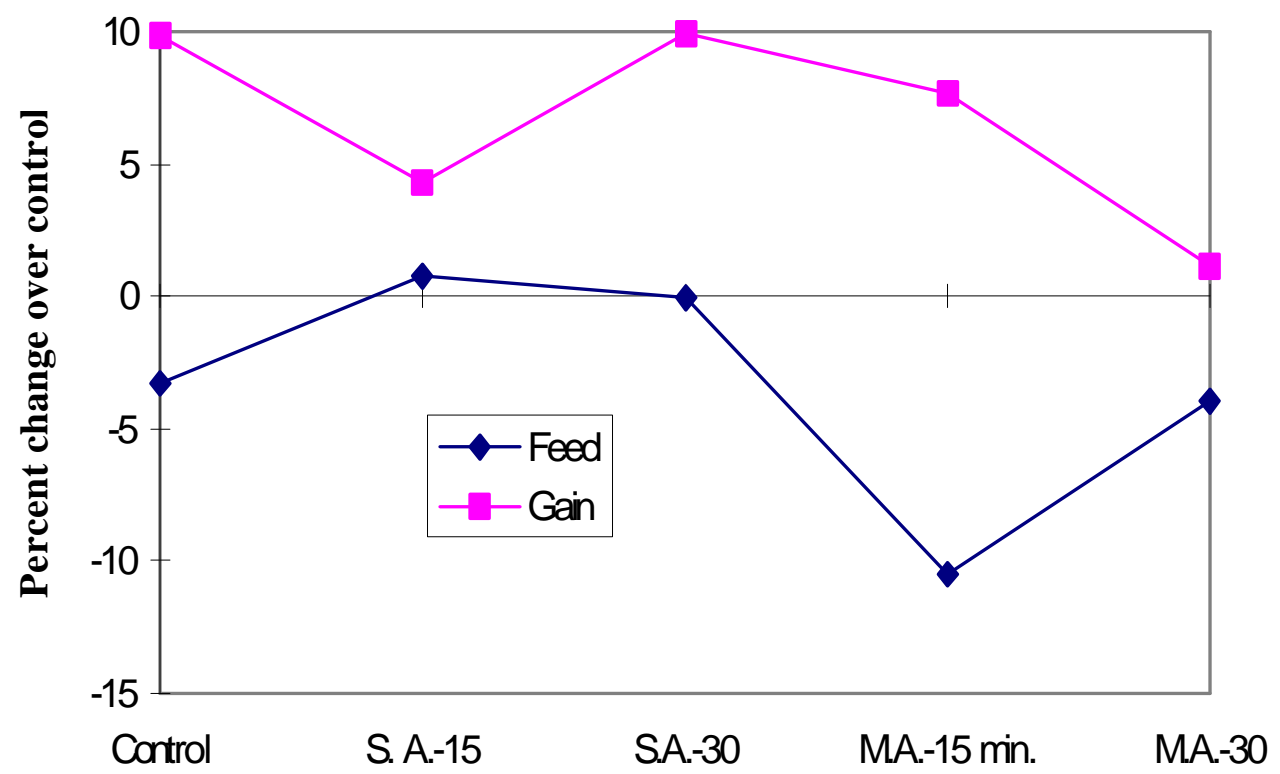

Table 34. Organ weights (g/100 body weight) as influenced by different treatments* 


\begin{tabular}{lcccc}
\hline Groups & Heart & Liver & Spleen & Gizzard \\
\hline Standard & 0.88 & 3.13 & 1.93 & 1.56 \\
Control & 0.87 & 3.01 & 1.49 & 1.47 \\
SA-15 & 0.84 & 3.07 & 1.92 & 1.54 \\
SA-30 & 0.91 & 3.06 & 1.47 & 1.72 \\
MA-15 & 0.86 & & & 1.66 \\
MA-30 & 0.95 & 2.89 & 1.44 & 1.89 \\
CV & 4.45 & 3.05 & 0.85 & 9.23 \\
\hline
\end{tabular}

$*=1$. SA-15:- Seed autoclaving (15Min) and then extraction. 2. SA-30:- Seed autoclaving (30Min) and then extraction. 3. MA15:- Oil extraction and then autoclaving (15Min). 4. MA30 :- Oil extraction and then autoclaving (30Min). 5. Control :- Oil extraction and inclusion in the diet as such. 6. Standard :-Standard (commercial) feed Formula

\subsubsection{EFFECTS OF FEEDING INCREASED LEVELS OF HEAT PROCESSED RAPESEED MEAL ON THE PERFORMANCE OF BROILER CHICKS.}

Table 35 presents the data on the effects of feeding different levels of heat processed and unprocessed rapeseed meal on the performance of broiler chicks. Effect of all dietary treatments was non significant on the feed consumption, which ranged from $1895 \mathrm{~g} /$ chick (20\% heat treated RSM) to $2343 \mathrm{~g} /$ chick (standard diet group). Gain in weight was significantly $(\mathrm{P}<0.01)$ influenced by different treatments. Highest gain (1298.33g) in weight was recorded in standard diet group. This however, was not significantly different from weight gains in $15 \%$ untreated RSM fed groups (1247.67g). Among the RSM fed groups the highest weight gain per chick was noted for 15\% RSM group followed by $15 \%$ treated RSM fed groups (1165g). Lowest gain in weight (1130g) was recorded in group fed on 25\% untreated RSM diet.

Feed to gain ratio was not influenced significantly by various dietary treatments. The feed economy was also highest in $20 \%$ treated RSM diet group which consumed $1.7 \mathrm{~kg}$ of feed per $\mathrm{kg}$ of weight gain. This was followed by the 15\% treated RSM fed group (1.77). Dressing percentage (Table 36) was not influenced by different treatments. The value ranged from 54.22 (standard diet) to 58.38 (15\% RSM). The differences, however, were not statistically significant. Similarly values for liver, gizzard and heart weights ranged from 3.03 to $3.59,1.75$ to 1.98 and 0.73 to $0.99 \mathrm{~g} / 100 \mathrm{~g}$ body weight, respectively, and the differences were statistically non-significant. 
Table 35. Effects of feeding different levels of heat processed and control rapeseed meal on the performance of broiler chicks

\begin{tabular}{|c|c|c|c|c|}
\hline Groups & $\begin{array}{l}\text { Feed Intake } \\
\left(\text { g Chick }^{-1}\right)\end{array}$ & $\begin{array}{c}\text { Weight Gain** } \\
\left(\text { g Chick }^{-1}\right)\end{array}$ & $\begin{array}{c}\text { Feed : Gain } \\
\text { Ratio }\end{array}$ & $\begin{array}{l}\text { Final Weight } \\
\left(\text { g Chick }^{-1}\right)\end{array}$ \\
\hline RSM-15 & 2257 & $1248^{\mathrm{ab}}$ & 1.81 & 1302 \\
\hline RSM-20 & 2586 & $1157 \mathrm{bc}$ & 2.18 & 1212 \\
\hline RSM-25 & 2163 & $1133^{\mathrm{c}}$ & 1.91 & 1185 \\
\hline Heated RSM-15 & 2063 & $1165^{b c}$ & 1.71 & 1219 \\
\hline Heated RSM-20 & 1895 & $1143 \mathrm{bc}$ & 1.70 & 1196 \\
\hline Heated RSM-25 & 2322 & $1148^{b c}$ & 2.02 & 1203 \\
\hline Standard & 2343 & $1298^{a}$ & 1.80 & 1350 \\
\hline $\mathrm{CV}$ & 9.9 & 5.31 & 9.31 & 5.05 \\
\hline
\end{tabular}

Fig. 16. Percent changes in feed intake and weight gain of broilers fed higher levels of control and heated RSM in the diet

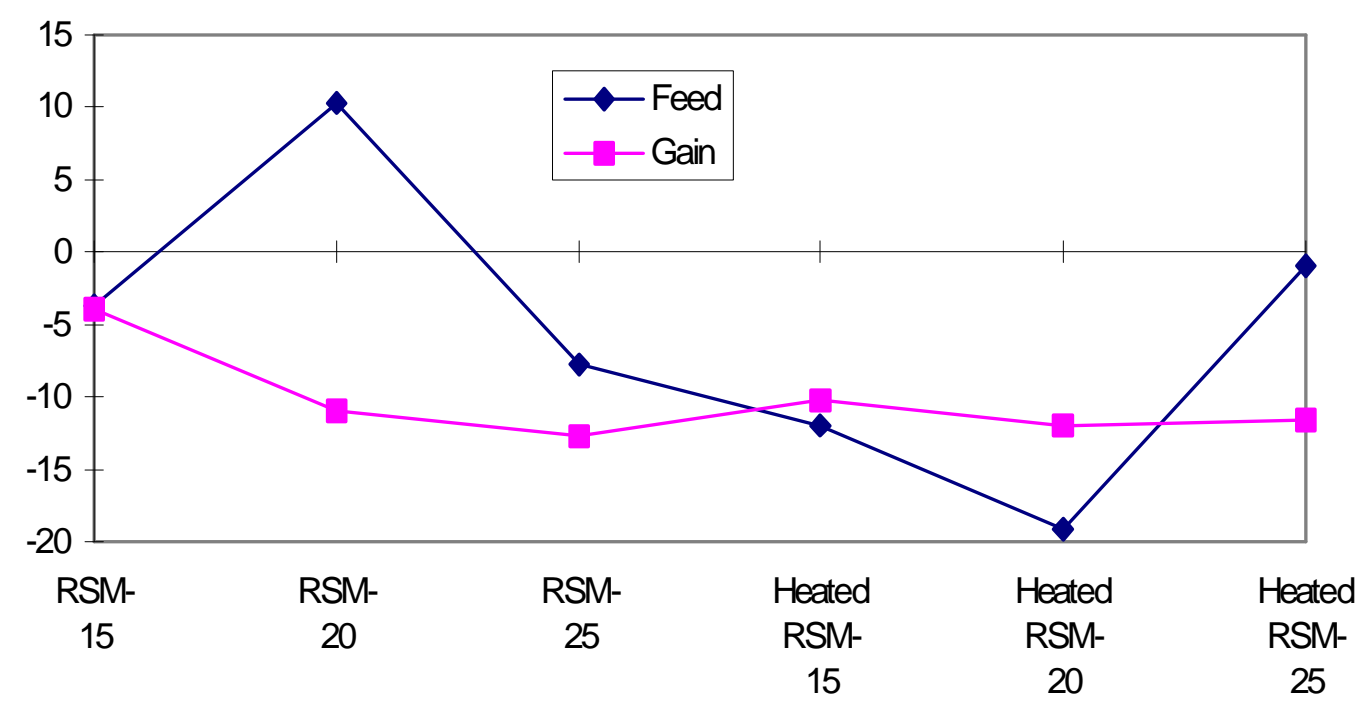

Table 36. Effects of feeding different levels of heat processed and control rapeseed meal on the dressing percentage and organ weights (\% of body weight) of broiler chicks

\begin{tabular}{lcccc}
\hline Groups & Dressing-\% & Liver & Gizzard & Heart \\
\hline RSM-15 & 58.4 & 3.03 & 1.94 & 0.89 \\
RSM-20 & 55.5 & 3.32 & 1.98 & 0.82
\end{tabular}




\begin{tabular}{lcccc} 
RSM-25 & 56.4 & 3.10 & 1.89 & 0.82 \\
Heated RSM-15 & 55.0 & 3.48 & 1.98 & 0.99 \\
Heated RSM-20 & 56.8 & 3.54 & 1.75 & 0.87 \\
Heated RSM-25 & 55.5 & 3.59 & 1.87 & 0.87 \\
Standard & 54.2 & 3.18 & 1.77 & 0.73 \\
CV & & & & \\
\hline
\end{tabular}

\subsubsection{EFFECT OF FEEDING INCREASED LEVELS OF IRRADIATED RAPESEED MEAL ON THE PERFORMANCE OF BROILER CHICKS.}

Results of this experiment are given in Table 37 - 39. It can be seen from the data that feed consumption per chick during the entire period of the experiment ranged from 2682 (RSM-15\%) to 2937g (irradiated RSM$25 \%$ ). Feed consumption for standard group was $2830 \mathrm{~g} / \mathrm{chick}$. Differences in feed consumption of different groups were statistically non-significant, indicating similar taste preference of birds for all the feeds. Weight gain of the birds was significantly $(\mathrm{P}<0.01)$ influenced by different feeds. Gain was maximum with $15 \%$ untreated RSM (1332g/chick) followed by standard diet (1328g/chick) and were not statistically different from each other. Minimum values for weight gain were recorded for 15\% irradiated RSM (1078g/chick) and $25 \%$ untreated RSM diet (1082g/chick). Feed to gain ratio was highest with irradiated 25\% RSM diet (2.57) followed by untreated 25\% RSM diet (2.55). Feed to gain ratio was minimum (2.13) for 15\% RSM diet .

Table 37. Effects of feeding different levels of irradiated and control rapeseed meal on the performance of broiler chicks

\begin{tabular}{lcccc}
\hline Groups & Feed intake & Weight Gain** & Feed : Gain & Final Weight \\
& $\left(\right.$ g Chick $\left.^{-1}\right)$ & $\left(\right.$ g Chick $\left.^{-1}\right)$ & Ratio $^{*}$ & $\left(\right.$ g Chick $\left.^{-1}\right)$ \\
\hline RSM-15 & 2682 & $1332^{\mathrm{a}}$ & $2.02^{\mathrm{b}}$ & $1382^{\mathrm{a}}$ \\
RSM-20 & 2694 & $1138^{\mathrm{ab}}$ & $2.37^{\mathrm{ab}}$ & $1188^{\mathrm{ab}}$ \\
RSM-25 & 2754 & $1082^{\mathrm{b}}$ & $2.55^{\mathrm{a}}$ & $1132^{\mathrm{b}}$ \\
R-RSM-15 & 2732 & $1078^{\mathrm{b}}$ & $2.53^{\mathrm{a}}$ & $1127^{\mathrm{b}}$
\end{tabular}




\begin{tabular}{lcccc} 
R-RSM-20 & 2775 & $1202^{\mathrm{ab}}$ & $2.31^{\mathrm{a}}$ & $1246^{\mathrm{ab}}$ \\
R-RSM-25 & 2937 & $1143^{\mathrm{ab}}$ & $2.57^{\mathrm{ab}}$ & $1192^{\mathrm{ab}}$ \\
Standard & 2830 & $1328^{\mathrm{a}}$ & $2.13^{\mathrm{ab}}$ & $1378^{\mathrm{a}}$ \\
CV & 3.18 & 9.00 & 9.18 & 8.65 \\
\hline
\end{tabular}

R.RSM = irradiated rapeseed meal

Values with different superscripts in the same column are significantly different at $\mathrm{P}<0.01(* *)$ or $\mathrm{P}<0.05(*)$.

\section{Fig. 17. Percent changes in feed intake and weight gain of broilers due to different levels of control and irradiated RSM in the diet}

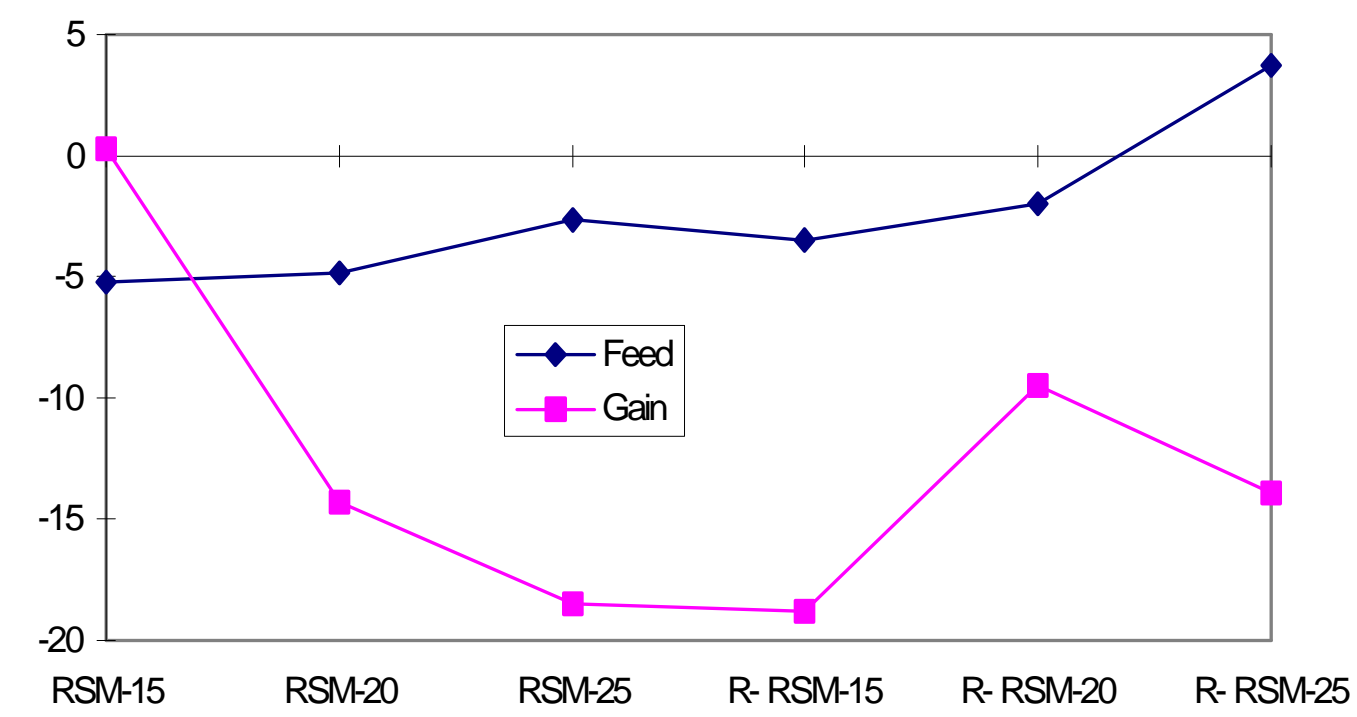

Dressing percentage was minimum with standard diet (45.39) and was significantly $(\mathrm{P}<0.05)$ lower than all RSM fed groups (Table 38). However differences in the dressing percentage of different RSM fed groups were non-significant and ranged from 52.12 to 54.92. The organ (liver, gizzard and heart) weights measured as $\mathrm{g} / 100 \mathrm{~g}$ body weight are given in Table 26 . Liver weight was not influenced by any dietary treatment and ranged from 3.11 to $3.69 \mathrm{~g} / 100 \mathrm{~g}$ body weight. Weight of gizzard was influenced significantly $(\mathrm{p}<0.025)$ by various dietary treatments. It was minimum $(1.30 \mathrm{~g} / 100 \mathrm{~g}$ body weight $)$ with standard diet, and maximum ( $1.70 \mathrm{~g} / 100 \mathrm{~g}$ body weight) with $25 \%$ untreated RSM diet. Heart weight was also significantly $(\mathrm{p}<0.025)$ influenced by the treatments. Minimum value $(0.74 \mathrm{~g} / 100 \mathrm{~g}$ body weight $)$ in this regard was recorded for standard diet group. All RSM fed groups showed hypertrophy to various extents as compared to standard diet group. The maximum heart weight $(0.99 \mathrm{~g} / 100 \mathrm{~g}$ body weight $)$ was noted in group fed on $25 \%$ untreated RSM diet. Blood haemoglobin level was not affected significantly by any dietary treatment.

Table 38. Effects of feeding different levels of irradiated and control rapeseed meal on the dressing percentage and organ weights ( $\%$ of body weight) of broiler chicks 


\begin{tabular}{|c|c|c|c|c|c|}
\hline Groups & Dressing - \% & Liver & $\underset{* *}{\text { Gizzard }}$ & $\begin{array}{c}\text { Heart } \\
* *\end{array}$ & $\begin{array}{c}\text { Blood Hb } \\
\%\end{array}$ \\
\hline RSM-15 & $53.6^{\mathrm{a}}$ & 3.69 & $1.52 \mathrm{bc}$ & $0.81 \mathrm{bc}$ & 9.89 \\
\hline RSM-20 & $54.9^{\mathrm{a}}$ & 3.44 & $1.60 \mathrm{ab}$ & $0.78 \mathrm{bc}$ & 9.78 \\
\hline RSM-25 & $52.1^{\mathrm{a}}$ & 3.64 & $1.79^{\mathrm{a}}$ & $0.83 \mathrm{bc}$ & 10.82 \\
\hline R-RSM-15 & $53.7^{\mathrm{a}}$ & 3.47 & $1.60^{\mathrm{ab}}$ & $0.99^{\mathrm{a}}$ & 9.69 \\
\hline R-RSM-20 & $53.9^{\mathrm{a}}$ & 3.56 & $1.33^{\mathrm{c}}$ & $0.91 \mathrm{ab}$ & 10.03 \\
\hline R-RSM-25 & $54.8^{\mathrm{a}}$ & 3.64 & $1.60 \mathrm{ab}$ & $0.88^{a b c}$ & 10.68 \\
\hline Standard & $45.4^{b}$ & 3.11 & $1.30^{\mathrm{c}}$ & $0.74^{\mathrm{c}}$ & 10.36 \\
\hline CV & 6.30 & 5.68 & 11.40 & 10.00 & 4.39 \\
\hline
\end{tabular}

R.RSM = irradiated rapeseed meal

Values with different superscripts in the same column are significantly

different at $\mathrm{P}<0.01(* *)$ or $\mathrm{P}<0.05(*)$.

Table 39 shows the effects of feeding different levels of irradiated and control rapeseed meal on the thyroid $\left(\mathrm{T}_{3}, \mathrm{~T}_{4}\right)$ and thyroid stimulating hormone (TSH) levels of broiler chicks. The data revealed that inclusion of RSM in the diet of broiler chicks significantly $(\mathrm{p}<0.01)$ increased the levels of thyroid hormones in the blood. With no RSM in the diet the levels of $\mathrm{T} 3$ and $\mathrm{T} 4$ were 3.23 and $1.37 \eta \mathrm{mol} / \mathrm{L}$, respectively. Excepting the $15 \%$ irradiated RSM group, all other RSM fed groups had significantly $(\mathrm{P}<0.025)$ higher levels of T3 in the blood. In the case of T4 increasing levels of RSM in the diet was paralleled by a concomitant increase in the blood $\mathrm{T} 4$ levels. The ratio of $\mathrm{T} 3$ to $\mathrm{T} 4$ followed the same trend, with maximum values recorded for highest $(25 \%)$ RSM in the diet. The concentration of TSH was also significantly ( $\mathrm{p}=$ 0.01 ) influenced by different dietary treatments. However a concrete conclusion can be drawn only from the ratio between T3 and T4 levels. It is clear from the Figure 19 that with increasing levels of (both untreated and irradiated) RSM the ratio T3/T4 fell down. Whereas this ration was 2.4 with standard diet.

Table 39. Effects of feeding different levels of irradiated and control rapeseed meal on the thyroid hormone levels of broiler chicks

\begin{tabular}{lcccc}
\hline Groups & $\begin{array}{c}\mathbf{T 3}^{* *} \\
(\eta \mathrm{mol} / \mathrm{L})\end{array}$ & $\begin{array}{c}\text { T4}^{* *} \\
(\eta \mathrm{mol} / \mathrm{L})\end{array}$ & T3:T4 $^{*}$ & $\begin{array}{c}\text { TSH }^{* *} \\
(\eta \mathrm{mol} / \mathrm{L})\end{array}$ \\
\hline RSM-15 & $6.10^{\mathrm{a}}$ & $2.1^{\mathrm{c}}$ & 2.9 & 0.22 \\
$\mathbf{R S M - 2 0}$ & $6.13^{\mathrm{a}}$ & $3.2^{\mathrm{c}}$ & 1.9 & 0.32 \\
$\mathbf{R S M - 2 5}$ & $6.77^{\mathrm{a}}$ & $13.3^{\mathrm{a}}$ & 0.5 & 0.33
\end{tabular}




\begin{tabular}{lcccc} 
R-RSM-15 & $5.25^{\mathrm{ab}}$ & $3.3^{\mathrm{c}}$ & 1.6 & 0.27 \\
R-RSM-20 & $7.23^{\mathrm{a}}$ & $7.8^{\mathrm{b}}$ & 0.9 & 0.11 \\
R-RSM-25 & $6.70^{\mathrm{a}}$ & $8.6^{\mathrm{b}}$ & 0.8 & 0.17 \\
Standard & $3.23^{\mathrm{b}}$ & $1.4^{\mathrm{c}}$ & 2.4 & 0.27 \\
CV & 22.7 & 77.0 & 56.8 & 33.2 \\
\hline
\end{tabular}

$\mathrm{R}-\mathrm{RSM}=$ irradiated rapeseed meal

Fig. 18. Effects of feeding different levels of irradiated and control rapeseed meal on the thyroid hormone levels of broiler chicks

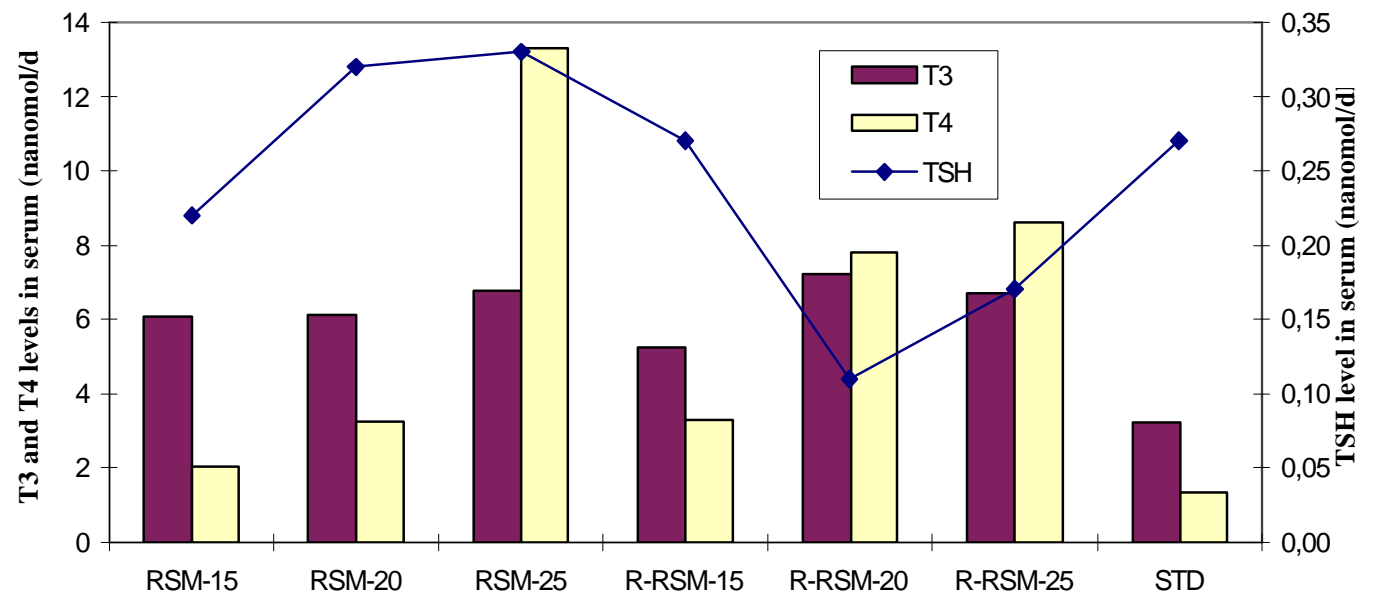

Fig. 19. T3 :T4 ratio in serum of broilers fed on diets containing RSM

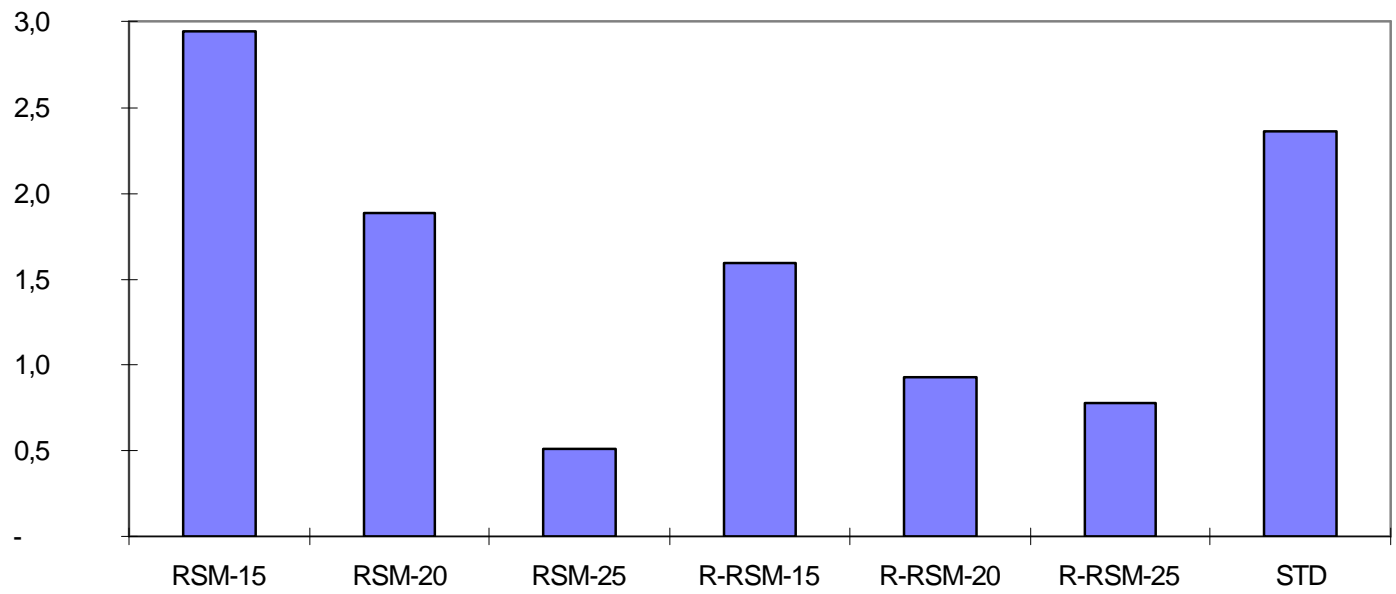




\section{CHAPTER 5}

\section{DISCUSSION}

Rapeseed meal as an ingredient of poultry feed is not a potential competitor for soybean meal or a potential replacement for it. In fact rapeseed meal can complement the later in terms of several essential amino acids and hence can lead to better performances. This is due to its high protein content and quality. Rapeseed meal also provides certain other nutrients like some vitamins and calories. However, the presence of glucosinolates, phenolic compounds phytic acid and proportionately high amounts of fibre leads to nutritional imbalances. Attempts to make use of this high protein feed concentrate have been based on genetic and post harvest technological approaches. In present studies effects of different treatments on some nutrients and antinutrients in rapeseed meal from a medium glucosinolates variety $(60 \mu \mathrm{mol} / \mathrm{g})$ were investigated.

\subsection{CHEMICAL ANALYSIS}

\subsubsection{PHYTIC ACID}

The average phytic acid content of the control rapeseed meal samples was $4.23 \%$. This was well in accordance with the reported value by ANJU, (1977) and NWOKOLO and BRAGG, (1977). Results of the present study indicated that neither the dry nor the moist heat caused any significant reduction in the content of phytates in rapeseed meal. Irradiation treatment also did not significantly reduce the content of phytic acid in rapeseed meal. Similarly OLOGHOBO and FETUGA, (1984) also did not find any significant reduction in phytic acid content with cooking, autoclaving and soaking of soybean. Very little work has been reported on the effect of common processing like cooking, autoclaving and microwave etc. on the phytic acid content in rapeseed meal (THOMPSON, 1990). However, NIAZI et al., (1988) have reported $83.64 \%$ reduction in phytic acid content of mustard seed meal which was leached in $4 \% \mathrm{NaCl}$ solution at $\mathrm{pH}$ 5.0. Present result, however, get support from the fact that the normal oil extraction processing had very little effect on the structural and chemical organization of the storage protein and its phytic acid globoids YIU et al., 1982).

\subsubsection{PHENOLICS}

In a set of three different studies effects of time of dry heating and autoclaving, and effect of dry heating temperature on the content of total phenols and sinapine were 
investigated. All the treatments resulted in substantial reduction of phenolics of rapeseed meal. Maximum reduction in sinapine content was achieved by autoclaving for 30 minutes $(0.90$ to $0.34 \%)$ and dry heating for 40 minutes at $100{ }^{\circ} \mathrm{C}(0.9$ to $0.67 \%$ ). Highest change in total phenols (1.21 to $0.53 \%$ ) occurred during autoclaving for 60 minutes.

Total phenols were reduced to the minimum value $(0.71 \%)$ with $200^{\circ} \mathrm{C}$ treatment, however, the value obtained with $150^{\circ} \mathrm{C}$ treatment $(0.72 \%)$ was not much different from this. Reduction in the sinapine content, however, was continuous with increasing temperatures. The reduction was less with $100^{\circ} \mathrm{C}$, but the slope increased sharply after that point. More than $63 \%$ of sinapine content was reduced at $250^{\circ} \mathrm{C}$, indicating its susceptibility to higher temperatures.

Although the effect of heating on phenolics of rapeseed has not been reported, CHARLENE et al., (1985) found that roasting lowered the total phenolics in mungbean seeds by $16.67 \%$ (roasted seeds contained $3.15 \mathrm{mg}$ of catechin/g of sample as compared to $3.78 \mathrm{mg}$ of catechin/g of sample of the raw sample). The high temperature and dry heat may change the phenolic contents by altering the chemical structure and hence reactivity. BRESSANI et al., (1983) reported an apparent loss of 20 to $39 \%$ from raw to cooked seeds when expressed as tannic acid and 61 to $98 \%$ when expressed as catechin equivalent. Similarly ELIAS et al. (1979) reported that cooking decreased the tannin content in whole seed. LAURENA and co-workers, (1984) showed that cooking of cowpea by roasting and autoclaving was accompanied by removal of polyphenols and an increase in certain assayable phenols could be due to change in their chemical reactivity. It was cited byCHARLENE et al., (1985) that the formation of tannin-protein insoluble complexes and unreactive tannins may also account for the decrease in polyphenol content, however, the significant increase in some treatments may be due to the polymerization of existing phenolic compounds or degradation of high molecular weight insoluble polymers into smaller molecular weight soluble polymers that give colour reaction to the reagent.KHATTAK et al., (1985) reported that the losses of tannins with hot water treatment in persimmon were from 67.6 to $76 \%$ while 32.2 to $54.0 \%$ in the case of dry heat treatment. The loss of tannins and astringency during the thermal treatment of persimmon was also reported by GOLDSTEIN and SWAIN, (1963).

\subsubsection{GLUCOSINOLATES}

The rapeseed meal from the variety under studies (Pakcheen) had a glucosinolates content of $60.8 \mu \mathrm{mol} / \mathrm{g}$ and is, hence, a high glucosinolates (HG-) variety. 
Autoclaving ( $103.5 \mathrm{kPa})$ of rapeseed drastically reduced its glucosinolate content but dry heat treatments did not cause much changes. Irradiation treatment did not reduce much the glucosinolates up to $5 \mathrm{kGy}$ dose but with $10 \mathrm{kGy}$ dose their content were $36 \%$ reduced.

Studies dealing with the effects of different processing techniques on the nutrients and antinutrients are relatively fewer. Reduction in glucosinolates in rapeseed meal with heat treatments has been variously reported GRALA et al., 1994, REBLOVA et al., 1995, ). Exposure of desolventized meal to toasting $\left(90-120^{\circ} \mathrm{C}\right.$ for $35-40$ minutes) is considered necessary for glucosinolates degradation and partial removal of their breakdown products. The same is true for the conditioning of rapeseed prior to oil extraction, the aim of which is, among others, to inactivate native enzymes including myrosinase (MAWSON, et al., 1995). Myrosinase has been reported to have been reduced during the conditioning, pressing, extraction and toasting (YOUNG, 1965), while the content of isothiocyanates and oxazolidinethione were reduced over $60 \%$. Processing techniques designed to reduce tannins (in rapeseed meal) are generally ineffective in reducing rapeseed glucosinolates and, in fact dehulling increases the relative proportion of glucosinolates in the remaining meal (MAWSON et al., 1993).

Reduction in the content of glucosinolates with autoclaving is also supported by the findings of ARONEN and VANHATALO, (1992) who during from their studies on the effect of heat-moisture treatment of rapeseed meal, reported that heat-moisture treatment effectively reduced glucosinolate content of rapeseed.KOZLOWSKA et al., (1987) conducted studies on the nutritional value of hydrothermally treated rapeseed meal and found that this treatment not only resulted in the complete inactivation of myrosinase but also reduced substantially the various glucosinolate derivatives in rapeseed meal. The reductions in glucosinolates by heat processing ranged from 47 to $94 \%$ for toasting and autoclaving treatments MANSOUR et al., 1993). The contents of glucosinolate in rapeseed meal decrease in proportion to the intensity of heating with steam (SIONEK et al., 1994, GRALA et al., 1994, JENSEN et al., 1995, HEIDENREICH and LOWE, 1993).

There have been evidences that heating myrosinase-treated RSM produce antithyroid compounds (SCHÖNE et al., 1993). indol glucosinolates are degraded by heat depending on the degrees of heat treatment. This prolong (60 minutes) heat treatment resulted in the production of unidentified degradation product of indol glucosinolates. Fractionation experiments showed the compound(s) to be relatively 
insoluble in ethanol when compared with intact indol glucosinolates CAMPBELL and SLOMINSKI, 1989).

Although the mechanism of glucosinolates reduction in rapeseed meal with irradiation cannot be fully explained, however, the present findings get support from the results of NUGON-BAUDON and co-workers, (1988) who found that sterilization dose of the RM diet by gamma radiation caused partial destruction of progoitrin.

\subsubsection{IN VITRO PROTEIN DIGESTIBILITY}

Effect of autoclaving was significant on the in-vitro digestibility of rapeseed protein. The control sample had an in-vitro protein digestibility of $85.7 \%$ and with 15 minutes of autoclaving the digestibility rose to $90.1 \%$. Longer heating times beyond 20 minutes caused reduction in the in-vitro protein digestibility of rapeseed protein. Dry heating of the rapeseed also caused significant improvement in thein-vitro protein digestibility. The highest value $(91.8 \%)$ in case of dry heating, was achieved with a treatment time of 60 minutes. However beyond 20 minutes treatment $(90 \%)$ the improvement was nominal. Irradiation treatment $(1 \mathrm{kGy})$ did not change significantly the in-vitro protein digestibility of rapeseed However the combination treatments (irradiation and dry heating or irradiation and autoclaving significantly improved the in-vitro protein digestibility of rapeseed.

It seems that very little work on the in-vitro protein digestibility of rapeseed meal has been conducted, particularly on the effects of different processing techniques. However effects of various treatments on thein-vitro protein digestibility in different legumes have been frequently reported. Protein concentrates and protein isolates from common dry beans have low in-vitro protein digestibility, which is improved by heating, with moist heat being more effective than dry heat KOHNHORST et al., 1990). Protein solubility decreased as autoclaving time increased for all oilseed meals ( FERNANDEZ et al., 1993). Protein solubility of different rapeseed meals decreased linearly from 85 to $81,61,52$ and $40 \%$ after the respective toasting times (at $100^{\circ} \mathrm{C}$ for $0,15,30,60$ or 120 minutes). True digestibilities of rapeseed were $77.0,73.9,72.1,72.9$ and $71.2 \%$ after $0,15,30,60$ and $120 \mathrm{~min}$ toasting, respectively (JENSEN et al., 1995).

True digestibilities of indispensable amino acids decreased $(\mathrm{P}<0.05)$ as autoclaving time increased, with lysine providing the most notable change. The decreased digestibility of lysine was due both to reduced concentration of analysed lysine and 
to reduced digestibility of the analysed lysine remaining after autoclaving. Protein solubility in 0.2 and $0.5 \% \mathrm{KOH}$ decreased as autoclaving time increased (ANDERSON-HAEFERMANN et al., 1993).

Unheated soy meal was found to have rather poorin-vitro protein digestibility, which was gradually improved by heat treatment (steaming under atmospheric pressure) up to 40 minutes The digestibility of the samples heated for more than 40 minutes then fell slowly as the heating time increased. The effect of heating on thein-vitro protein digestibility is two fold. Heat inactivates protease inhibitors and cause conformational changes of the proteins. The latter effect is important because peptide bonds become more accessible to enzymes. Native proteins are resistant to hydrolysis by proteases owing to their fairly compact structures in which most of the peptide linkages are buried inside the molecules. Consequently if the closely packed peptide chains are partially unfolded upon denaturation, hydrolysis would be facilitated and in-vitro protein digestibility improved. However, excessive heating causes a reduction in in-vitro protein digestibility. Thus changes in digestibility are not necessarily proportional to the degree of protein denaturation. With prolonged heating the conformations of the protein may refold to give new, enzyme resistant structures, possibly stabilized by S-S polymerization (LIN and LAKIN, 1990). Heat treatment improved the digestibility of rapeseed proteins in vitro MANSOUR et al., 1993).

The non-protein nitrogen (NPN) from post-extraction rapeseed meal contained mainly $\mathrm{N}$ of low-molecular peptides (rich in asparginine, glutamine and basic aminoacids), glucosinolates and free amino acids. The NPN fraction of untoasted rapeseed meal contained peptide-N (about 60\%), glucosinolate-N (19\%) and free NPN (21\%); that of toasted rapeseed meal contained 62,7 and $31 \%$, respectively. About $30 \%$ of NPN in toasted rapeseed meal (including peptides and glucosinolates) were insoluble in water and $80 \%$-ethanol (ROGULSKI, 1989)

\subsubsection{AMINO ACIDS}

The amino acids were variously influenced by different heat treatments. The amino acids of special interest in connection with poultry feeding are methionine, lysine and arginin. Methionine content were $0.7 \%$ in untreated control rapeseed meal sample. Heat treatment resulted in reduction of this amino acid and was 0.56 to $0.58 \%$ in 30 and 60 minutes heated meal samples, respectively. Lysine content also decreased from 2.3 to 1.22 and $1.10 \%$ with these treatments, respectively. Effect of heat treatment on arginin, however was inconsistent. The original arginin content $(2.22 \%)$ 
increased to $3.22 \%$ with 30 minutes treatment but decreased to $1.93 \%$ with 60 minutes treatment time.

The autoclaving treatment seems to have more drastically influenced the amino acid profile of rapeseed meal. The percentage of cystine was reduced from 0.32 to 0.20 with 20 minutes treatment but was increased to 0.42 with 30 minutes autoclaving. Similarly methionine $(0.70 \%)$ remained almost unchanged with 20 minutes treatment but increased to $1.43 \%$ with 30 minutes autoclaving treatment. This trend was reversed with lysine, which was not much affected with the first treatment but showed 52\% decrease with 30 minutes autoclaving. Arginin on the other hand was reduced from 2.22 to $1.60 \%$ with 20 minutes but longer treatment showed practically an increase in its content $(2.50 \%)$.

Effect of irradiation doses on different amino acids in rapeseed meal showed that the sulphur containing amino acids (cystine and methionine) were reduced with both the irradiation doses. Lysine also showed a reduction with irradiation but argentine was increased due to irradiation treatments.

It would be rather unrealistic to expect similar amino acid profiles from any two studies involving different rapeseed meal samples. Large variations in the contents of amino acids of rapeseed meal are to be expected. These variations can be explained on the basis of differences in genetic background, agroclimatic conditions, procedures adopted for oil extraction and analytical techniques FENWICK and CURTIS, 1980). The contents of different amino acids in the untreated control sample of rapeseed meal in present study fall well within the limits of the reported values.

Lysine is reported to be the most heat labile amino acid in rapeseed meal dENSEN et al., 1995). Heat treatments of proteins have been reported to result in losses in the lysine content. Heating the protein with steam and under atmospheric pressure resulted in lysine losses only when the heating time was longer than 40 minutes. During heat treatment the e-amino group of the reactive lysine may react with reducing surgars (Maillard reaction). Alternatively, dehydroalanine (a decomposition product of cystine or serine) may react with the free amino group of lysine to form lysino-alanine. A third possible reaction is that between amide group of glutamine and free amino group of lysine to form a peptide type linkage with the release of ammonia. Any one or all of these reactions could cause significant loss of available lysine (LIN and LAKIN, 1990). The analysed lysine content in canola meal was 
reduced greatly by increased autoclaving time, with little or no effects for other amino acids (ANDERSON-HAEFERMANN et al., 1993).

GRALA et al., (1994) reported that Increasing the toasting temperature from $90^{\circ} \mathrm{C}$ to $95^{\circ} \mathrm{C}$ and $100^{\circ} \mathrm{C}$ decreased total and available lysine contents $(5.20,4.85,4.33$ and $4.28,3.84,3.00 \mathrm{~g} / 16 \mathrm{~g} \mathrm{~N}$, respectively). But other parameters of rapeseed processing such as moisture and duration of heating may also affect the nutritional value of RSM. In whole rapeseed, toasting significantly decreased total and available lysine and glucosinolates compared with untreated seeds. Increasing temperature and time of laboratory heating resulted in a linear decrease in lysine, available lysine and protein value of defatted rapeseed cake in rats. The decrease in lysine content depended more on the increase of temperature than heating time.

\subsection{CHICK BIOASSAYS}

The prospects and potentials in comparison with the hindrances in the use of rapeseed meal as a Poultry feed ingredient are discussed in view of the results obtained from a series of rapeseed meal feeding trials on broiler chicks and are compared to the trends in the literature.

\subsubsection{EFFECT OF FEEDING DIFFERENT LEVELS OF RAPESEED MEAL ON THE PERFORMANCE OF BROILER CHICKS.}

Results of the present study have clearly demonstrated that performance of broiler chicks was influenced with rapeseed meal inclusion at higher levels in the diets. The feed intake and gain in weight was significantly influenced with rapeseed meal feeding. However, changes in feed intake were not proportionate to the changes in weight gain. There are contradictory reports in literature in this regards.LESLIE $e t$ al., (1973) noted that changes in feed consumption due to different dietary treatments were not followed by proportionate changes in weight gain, indicating that the level of consumption was not a major factor in the utilisation of diets containing rapeseed meal. It was suggested that some toxic factor/s or amino acid imbalances were responsible for the depression in performance. KHAN et al., (1996) fed up to $20 \%$ RSM to broiler chicks and noted no significant differences in the weight gain and feed intake among different groups. However, thyroid weight was increased with increasing levels of rapeseed meal in the diet. LEESON and SUMMERS, (1976) noted that depression in weight gain was associated with reduced feed intake and an 
increased feed to gain ratio. SUMMERS and LEESON, (1977a) studied the effects of feeding up to $31 \%$ Span rapeseed meal to broilers on their performance. Significantly $(\mathrm{P}<0.05)$ lower weight gains with rapeseed meal than soybean meal (194 vs. 214g) were noted. Feed intake was not affected but feed : Gain ratio was increased with rapeseed meal.

While diets containing HG-rapeseed meal have a low palatability for pigs and young ruminants, it has generally been assumed (HILL, 1979) that this is not the case with poultry. The influence of flavour on feed intake is probably less important for poultry than for other classes of livestock because the senses of taste and smell are not as well developed in birds relative to those of other species. According toELWINGER et al., (1986) a lower dietary inclusion of HG-rapeseed meal (6 and 12\%) did not affect palatability of feed for broiler chicks. In their experiment the intake of diets with HG- $(109 \mu \mathrm{mol} / \mathrm{g}$ glucosinolates $)$ or LG (31.3 or $19.0 \mu \mathrm{mol} / \mathrm{g})-$-rapeseed meal was similar. LEESON et al., (1987) found that even complete replacement of soybean meal with rapeseed meal did not result in a significant drop of feed intake in broilers and laying hens.

However, in present study a reduction in weight gain was only seen when the inclusion level was above $15 \%$. While there are some indications in the literature that this level of rapeseed meal inclusion is tolerable POKNIAK et al., 1985, SCHÖNE et al., 1990), the general trend is a lower HG-rapeseed meal inclusion. The present results therefore, seem to be against the recommended limit of 6 to $10 \%$ of HG-RSM in the broiler diet. Seen purely from the standpoint of RSM inclusion in the broiler's ration, a rather critical examination of these results in view of literature can help explain the findings.

Quite a large amount of literature has accumulated during the last three decades, dealing with almost every aspect of the subject of including rapeseed meal in the diet of broiler chicks. Depression in weight gain in broilers has been frequently reported with rapeseed meal inclusion in the diet. Many workers have related it to the presence and concentrations of glucosinolates (THOMAS et al., 1983). CLANDININ et al., (1966) studied the effect of goitrin at $0.15 \%$ in the diet of broiler chicks on the growth rate, and observed a depression in performance and thyroid enlargement. VOGT and SCHUBERT, (1969) conducted a series of experiments on feeding rapeseed meal to poultry. In one of their experiments on broilers they fed rapeseed meal up to $35 \%$ of the diet for different lengths of times and noted that negative influence of rapeseed meal increased corresponding to the period of its feeding. 
Weight gain was slightly reduced but feed to gain ratio was increased from 1.85 in control group to 3.40 in group fed rapeseed meal for 8 weeks.

Most of the reports in the literature which describe a depression in the broiler performance due to rapeseed meal feeding relate it to glucosinolates; however, only a few workers have tried to quantify the effect of glucosinolates on performance. VOGT and STUTE, (1974) reported that broiler chicks could tolerate oxazolidinethion (OZT) level 700 to $1500 \mathrm{ppm}(5.4-11.6 \mu \mathrm{mol} / \mathrm{g})$. Several reports (LEESON et al., 1987, ROBBLEE et al., 1978) appearing latter on are consistent with the recommended/permissible levels of glucosinolates in the feed, proposed by these authors. Results of the present study can be explained on the basis of content of total glucosinolates in the feed. Upto 15\% RSM in the diet the glucosinolates content of the diet was $9.12 \mu \mathrm{mol} / \mathrm{g}$. This is well under the threshold fixed byVOGT and STUTE, (1974). On the other hand PEARSON et al., (1983a) reported from a study involving four different broiler strains, that the growth rate with feeding high glucosinolates rapeseed meal was reduced only in one broiler strain although hypertrophic effects in all strain was evident. PROUDFOOT et al., (1983) also concluded that some genotypes exhibit a greater response to RSM diets than others. It has been stressed that growth responses to the feeding of rapeseed meal will depend on cultivar, processing, strain of bird and the nutritional equivalence of test diets as well as glucosinolate contents (MAWSON et al., 1993). Glucosinolate related problems appear to be less severe in broiler birds than in laying hens or turkeys. Due to differences in life span and in the periods of taking diets with RSM inclusion, the goitrogenic activity of glucosinolates is a less significant problem in broiler chicks but can be considerable in laying hens (MAWSON et al., 1993).

Several workers have explained the inclusion of rapeseed meal in the broiler's rations on the basis of protein, energy and amino acid profiles of the diets. Diets in the present study were so formulated that the various experimental diets were almost isonitrogenous and iso-caloric. ANWAR et al., (1971) reported that when the same levels of energy and gross protein values were fed to broilers from 6 day age onwards, soybean meal and rapeseed meal as protein sources produced similar results in weight gains. The amino acid profiles of all the diets in present study were also not much different. LESLIE et al., (1976) demonstrated that when fortified with arginin and methionine, rapeseed meal can be fed to broilers at a level of $40 \%$ to supply the entire protein requirements without any adverse effects on growth.

The lysine-arginin imbalances (seen in the rapeseed meal feeding to broiler chicks), however, were observed by SUMMERS and LEESON, (1978) only when rapeseed meal was used as the sole source of dietary protein in chickens ration and associated 
with supplemental lysine, arginin and methionine. With practical type diets no growth depression was observed. It appeared that the amino acid balance of rapeseed meal was more favourable in practical type diets in which part of the protein came from soybean meal and corn, than that of rapeseed meal alone. Hence a synergistic balancing effect was observed among the three proteins.

OPSTVEDT et al., (1991) reported on the complementary effects of fish meal with soybean meal replacers in broiler diets. Double-zero rapeseed meal (low in glucosinolates and erucic acid) partially replaced soybean meal in diets of broilers with and without fish meal. Inclusion of rapeseed meal, of European origin, in lowenergy unpelleted diets reduced feed intake and growth rate of chicks to 3 weeks old. In contrast, inclusion of rapeseed meal in high-energy diets increased intake and growth rates. Inclusion of 5\% fish meal further improved performance both under isoenergetic conditions, but particularly when inclusion also resulted in an increased energy density of the diet. It was recommended that only part of the soybean meal should be replaced by other plant proteins; it can be beneficial to use a combination of proteins. The diet should include $5 \%$ fish meal to improve the amino acid supply. Soybean meal should only be replaced in high energy diets, and the energy density of the diet should be maintained or increased.

One important point in this connection is that most of the reports suggesting a reduction in broiler performance at lower rapeseed meal inclusion are from studies conducted with soy-corn based diets (THOMAS et al., 1983, PROUDFOOT et al., 1983, SCHÖNE et al., 1990, ANDERSON-HAEFERMANN et al., 1991). On the other hand it was suggested by HULAN and PROUDFOOT, (1978) and IRISH and BALNAVE, (1993) that in combination with a complementary protein source, such as fish meal, rapeseed meal can replace all of the soybean meal in practical type broiler diets. Lack of any adverse effect of rapeseed meal upto $15 \%$ level in the present study can, at least partly, be explained on the grounds that feed used in this experiment contained several animal protein concentrates like fish meal, blood meal and meat meal. This view point is also supported by the work of REDDY and REDDY, (1987), who reported work on utilization of turnip Brassica campestris) meal in the ration of White Leghorn chicks. Male White Leghorn chickens were given to age 3 weeks a control diet containing maize 45 , rice polish 6.5 , groundnut cake 26 , fish meal 10 and wheat bran $10 \%$ or with turnip meal (14.1\% crude protein) replacing $25,50,75$ or $100 \%$ of bran. Turnip meal up to $75 \%$ replacement did not affect weight gain and feed efficiency but values were poorer with $100 \%$ replacement. 
The intensity of adverse effects of glucosinolates in rapeseed meal in broiler chicks feeding is dependent on the length of feeding period. A severe manifestation was seen only when at $35 \%$ level of rapeseed meal in the diet the broilers were fed for times longer than six weeks (VOGT and SCHUBERT, 1969). Since in the present studies the experiment was only of five weeks duration, this can be yet another reason why feeding HG-RSM did not result in reduced performance.

\section{Relationship between growth performance of broiler chicks and glucosinolates content :-}

The glucosinolate contents of different diets were calculated and related to the weight gain data of different groups. Fitting a straight line to the data in the following figure (Fig. 20) gave a regression equation :,

where

$$
Y=972.48-5.8741 X
$$

$\mathrm{Y}$ is the gain in weight and

$\mathrm{X}$ is the glucosinolate contents of the diets.

The straight line (Fig.20), however, does not fit properly to different data points and there is quite a large degree of dispersion. For this purpose a binomial curve (Fig. 21) was tried and the dispersion was less in this case, indicating that the phenomena was not a straight line. The decrease in the performance of broiler chicks did not occur with very low concentrations of total glucosinolates rather the line declined at about $7-8 \mu \mathrm{mol}$ of glucosinolates per gram of feed. Therefore a regression equation for straight line will not properly explain the phenomena, rather the equation of second degree for a binomial curve will suit the situation. The equation is as follows ;

where

$$
Y=948.61+5.90 X-0.77 X^{2}
$$

$\mathrm{Y}$ is the gain in weight and

$\mathrm{X}$ is the glucosinolate contents of the diets.

It may however be kept in mind that this equation is derived from a five week experiment on Hubbard broilers where the desired final weight is about $1000 \mathrm{~g}$. For situations where broiler breed with a relatively slower growth rate and where the desired final weights are higher, this equation may not hold good. Due to longer feeding periods the adverse effects of glucosinolates may be manifested and growth may not follow this equation. 
Fig. 20. Linear relationship between glucosinolate contents of diet and weight gain of broiler chicks.

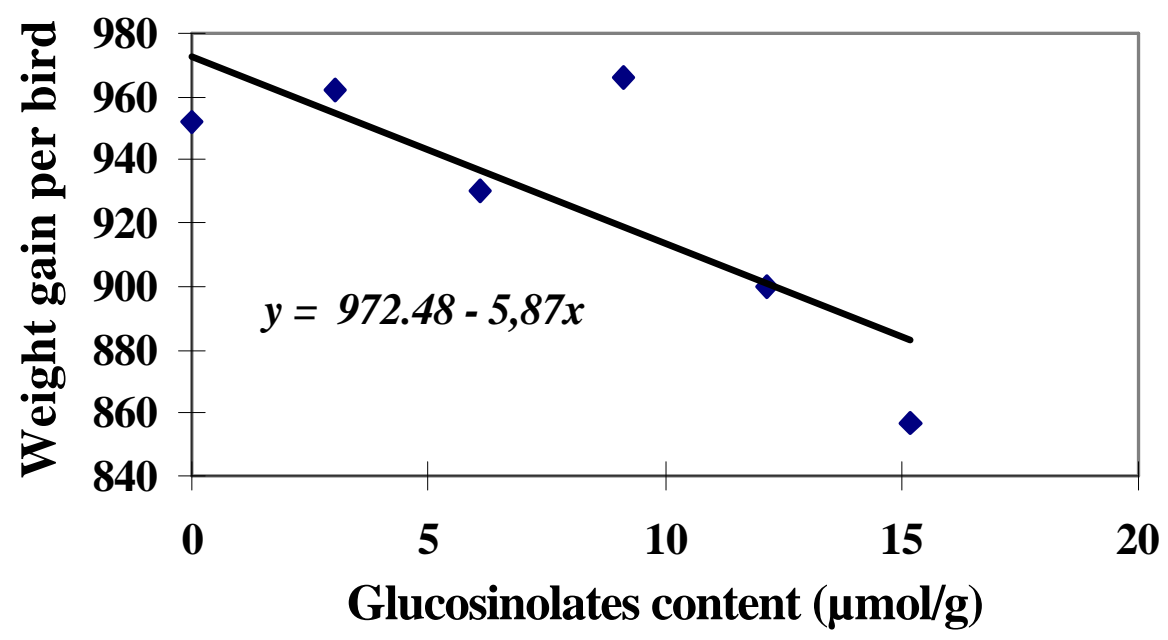

Regression equation for glucosinolates and growth in rates and mice (VERMOREL et al., 1988 ) is available. The relationship for rats was negative curvilinear between growth performance of rats and glucosinolate intake in the diet with the depression in growth starting beyond $4.4 \mu \mathrm{mol} / \mathrm{g}$ of the diet.VOGT and SCHUBERT, (1969) have suggested a straight line regression for broiler chicks but they have related glucosinolate contents to feed efficiency ratio. Generally the literature suggests (MAWSON et al., 1994) that reduced performance of broiler chicks is seen with glucosinolates levels of $2-4 \mu \mathrm{mol} / \mathrm{g}$ of diet, but a significant reduction is evident only when the value exceeded the limit of $10 \mu \mathrm{mol} / \mathrm{g}$ of diet.

Fig. 21. Curvilinear relationship between glucosinolate contents of diet and weight gain of broiler chicks.

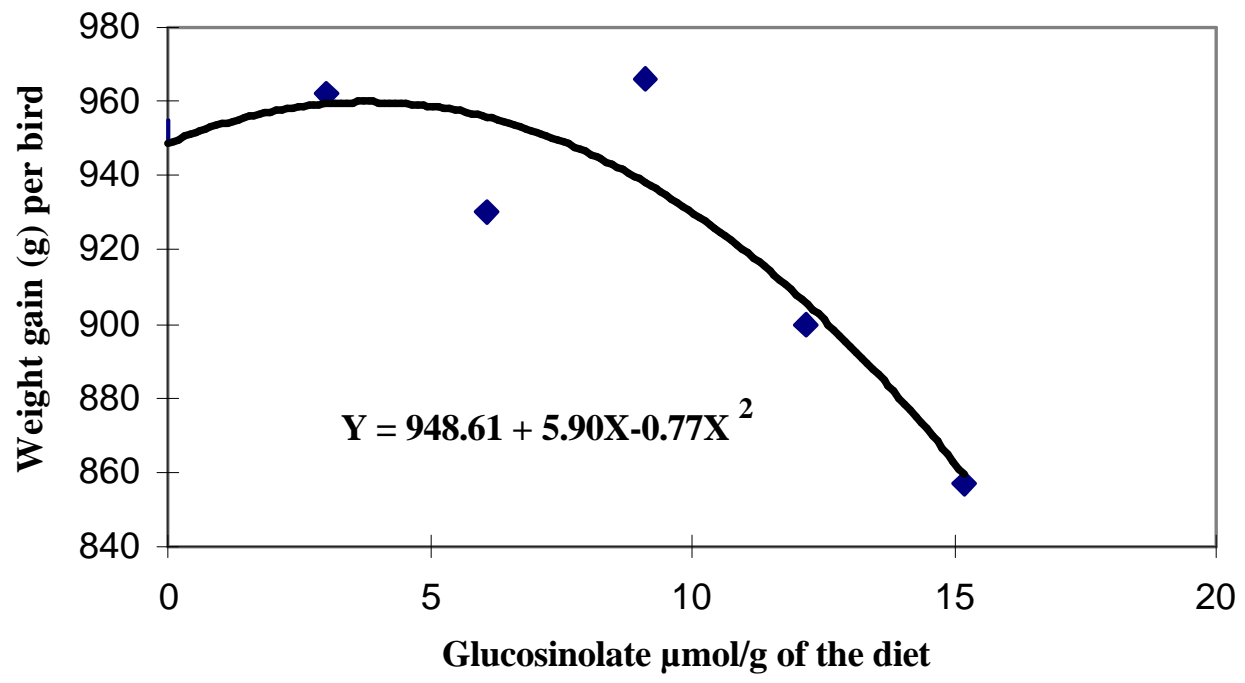




\subsubsection{EFFECT OF IRRADIATION ON THE NUTRITIONAL VALUE OF RAPESEED MEAL FOR BROILER CHICKS.}

Results of this five weeks experiment revealed non-significant differences among different groups regarding total feed intake, total weight gain and final weight. However feed consumption was maximum in 5kGy group and did not improve further with $10 \mathrm{kGy}$ groups, indicating some taste improvement over control and even standard diet. This, however, was not paralleled by a concomitant increase in weight gain and feed to gain ratio was maximum with $5 \mathrm{kGy}$ diet.

As can be seen from Figure 12, feed intake per chick as well as weight gain in control group were lower than standard group. Feed intake improved with 5kGy irradiation and did not further improve with higher dose. Gain in weight on the contrary was highest with $10 \mathrm{kGy}$ dose.

Gamma Irradiation has been frequently considered to have bearing on the nutritional quality of food and feed items. It improves the utilization, digestibility and absorption of large polymeric molecules of proteins and carbohydrates by breaking these into small, easily digestible chains (NENE et al., 1975a, b). Several reports have also indicated its beneficial effects on some antinutritional factors like trypsin inhibitors and phytates in some grains (REDDY et al., 1979, NEELOFAR, 1986). It has also been used to reduce the microbial load of poultry feeds NUGON-BAUDON et al., 1988). In the experiment under report rapeseed meal was irradiated at two different doses and included $(10 \%)$ in the ration of broiler chicks to study its effects on the growth performance of chicks. The results are explainable both in the light of results of first experiment and also on the basis of glucosinolate contents of the diets. In the previous experiment we have seen that rapeseed meal from this variety (Pak-cheen) can be safely incorporated upto $15 \%$ in the broiler's diet. On the other hand irradiation of the rapeseed meal reduced its glucosinolate contents (Table 7). Consequently the contents of glucosinolates in the control $(6.08 \mu \mathrm{mol} / \mathrm{g}), 5 \mathrm{kGy}$ irradiated $(5.5 \mathrm{~mol} / \mathrm{g})$ and $10 \mathrm{kGy}$ irradiated group diet $(3.9 \mu \mathrm{mol} / \mathrm{g})$ were not sufficient to cause reduction in the performance of broiler chicks (NOGT and STUTE, 1974 ). Again the shorter length of the experiment did not allow the glucosinolates to exert adverse effects to any mentionable extent.

\subsubsection{EFFECT OF DRY HEATING AND DEHULLING ON THE NUTRITIONAL VALUE OF RAPESEED MEAL FOR BROILER CHICKS.}


In a five weeks trial effects of heating and dehulling on the nutritional quality of rapeseed meal for broiler chicks was studied. Level of rapeseed meal inclusion was kept so as to provide $25 \%$ of the total protein requirements from the rapeseed meal. This meant $16 \%$ inclusion of meal from whole rapeseed and $11 \%$ from dehulled seeds. All rapeseed meal fed groups consumed significantly $(\mathrm{P}<0.05)$ more feed than the standard diet with no rapeseed meal. Among the rapeseed meal groups heat treatment resulted in the highest feed intake followed by control and dehulled rapeseed meal. This trend was paralleled by gain in weight and maximum gain was recorded in the case of heat treated rapeseed meal fed group, whereas minimum weight gain was noted in standard group without rapeseed meal. This was significantly $(\mathrm{p}<0.05)$ lower than all rapeseed meal groups. Feed to gain ratio ranged from 2.49 to 2.72 among different groups.

\section{Dehulling effect}

Protein digestibility in rapeseed meal is influenced to a large extent by the presence of relatively disproportionate amounts of hulls. Dehulling of the rapeseeds results in meals with 7 to $11 \%$ higher digestibility in different low and high glucosinolates rapeseed meal (LESSIRE and BAUDET, 1986).

Most of the phytate and tannins are concentrated in the seed- coat (hull) and measures aimed at reducing these compounds have included breeding for reduced seed coat thickness or mechanically removing the seed coat (dehulling). The latter process has been profitably used in France where the hulls may be fed to rabbits (CHONE et al., 1986), however processing designed to reduce tannins (in rapeseed meal) are generally ineffective in reducing rapeseed glucosinolates and, in fact dehulling increases the relative proportion of glucosinolates in the remaining meal (MAWSON et al., 1993). This was partially manifested in those studies in which dehusking the seeds significantly increased the energy and protein digestibility of the RSM and the utilization of digestible protein in an indirect nitrogen balance trial, however in the feeding trial the feed efficiency of the dehusked RSM diets was lower than that of the untreated RSM diets. Dehusking the Tandem rapeseed reduced lysine content and availability (VERMOREL and BAUDET, 1987). Mean true digestibility of protein and true digestibility of amino acids in whole and dehulled rapeseed meals was found similar (ZUPRIZAL et al., 1991).

\section{Dry heating effect}

Dry heating is a normal process in the extraction of oil from rapeseed. It facilitates oil extraction. Beneficial effects of this processing step on the quality of resultant meal 
has long been reported. However, the heating temperature and length of heating time has been debated in the literature (WOODLY et al., 1972, HAEFERMANN, 1993). In the present experiment, although non-significantly different among the various rapeseed meal fed groups, the feed consumption and weight gain was higher in heat treated rapeseed meal group. The equal or somewhat better performance of rapeseed meal fed broiler chicks can be explained again on the grounds that the level of inclusion was less or almost equal to $15 \%$ as in the experiment on levels of rapeseed meal.

It has been reported that birds fed rapeseed meal desolventized at $100 \mathrm{C}$ consumed $6 \%$ more feed $(\mathrm{P}<0.01)$ and grew $5 \%$ faster $(\mathrm{P}<0.01)$ than birds fed desolventized at $25^{\circ} \mathrm{C}$. This was attributed to the inactivation of myrosinase with $100^{\circ} \mathrm{C}$ treatment for desolventization. This process , however, had no effect on feed : gain ratio. Also the use of live heat had no further advantage (SHIRES et al., 1983). The heating conditions have to be optimum if enhanced performance is expected. Heating with steam for 30 and $60 \mathrm{~min}$ had no effect on the nutritive value of the meal except that it decreased the digestibility of protein, although this treatment reduced the glucosinolate and sinapine contents in the meal (SIONEK et al., 1994). LEE et al., (1991) reported from their studies on live performance, carcass yield, protein and energy retention of broiler chickens fed canola and flax full-fat seeds and the restored mixtures of meal and oil Heat treatment did not significantly affect performance. DM and protein retention, and bird mortality were not influenced by diet.KOZLOWSKI and FARUGA, (1989) fed Peking ducklings, in 4 groups of 60, of both sexes, from hatch to 8 weeks old on a diet containing 10 and $15 \%$ rapeseed meal (RSM) in starter and finisher diets, respectively in place of soybean meal (SBM). RSM had been steamed at $90^{\circ} \mathrm{C}$ for $90 \mathrm{~min}$, at $105^{\circ} \mathrm{C}$ for $90 \mathrm{~min}$ or at $95^{\circ} \mathrm{C}$ for $60 \mathrm{~min}$. Live weight at 8 weeks was with SBM 2586, with RSM, treatments 1, 2 and 3, 2521, 2653 and $2558 \mathrm{~g}$, respectively. Feed intake/kg gain was similar, from 3.9 to $4 \mathrm{~kg}$. Dressing percentage was 66.4, 64.8, 64.2 and 66.6, respectively. Weight of liver was $20.4 \mathrm{~g}$ with SBM; with RSMs 28, 25.4 and $24.4 \mathrm{~g}$, and weight of thyroid was 221.6, 198.3 and $322.2 \mathrm{mg}$.

\subsubsection{EFFECT OF AUTOCLAVING TIME ON THE NUTRITIONAL VALUE OF RAPESEED MEAL FOR BROILER CHICKS.}

Significant $(\mathrm{P}<0.05)$ differences were observed in the values regarding feed intake, total weight gain and feed to gain ratio among different groups. All the treated and control rapeseed meal diets up to 25 minutes treatment (except the 10 minutes treatment) gave higher values for feed intake than standard diet. With 30 minutes 
treatment the feed intake per bird became almost at par with the standard diet group. The same (30 minutes treatment) gave highest value for weight gain. All other treatments gave equal to or lower values than standard diet group.

The results are interesting and strange, and have a certain degree of contradiction to the results of the previous experiments, but explainable on the basis of published facts and in light of the differences in the experimental conditions to previous experiments. The level of inclusion of rapeseed meal in the experimental diet was $16.7 \%$ (to provide $25 \%$ of the total dietary protein from rapeseed meal). In view of the previous trials this should not have led to reduced weight gain, because even the control diet had glucosinolates content of $10.03 \mu \mathrm{g} / \mathrm{g}$. The reason is that this was the only 8 week trial in this series of experiments. The intensity of adverse effects of glucosinolates is dependent on the duration of feeding, and upto 6 weeks feeding the effects are not well manifested (VOGT and SCHUBERT, 1969). The glucosinolate content of only control, 15 minutes and 30 minutes treatment feeds could be calculated.

Autoclaving time has been reported to influence feed intake. ANDERSON et al., (1993) reported that 10 minutes autoclaving was most suitable, their level of rapeseed meal inclusion in chicks diet, however, was $44 \%$. The pattern of influence of autoclaving time on the feed consumption, however, was not paralleled by that of weight gain. Minimum weight gain was recorded with control rapeseed meal group, while maximum with the longest autoclaving time (30 minutes); and hence resulted in the lowest feed to gain ratio. Inclusion of rapeseed meal in the diet of broilers causes thyroid enlargement (ANDERSON et al., 1993) due to the glucosinolates in the rapeseed meal (HENKLE et al., 1989). These effects have been attributed to the glucosinolates hydrolysis products. The glucosinolate progoitrin (2-hydroxy,3butenyl-glucosinolate) yields on hydrolysis as end product a cyclic compound 5venyl,2-thio oxazolidinthione, called goitrin due to its strong goitrogenic effects (KJAER, 1960). Most of the other glucosinolates hydrolysis products have also been frequently reported to be implicated in the anti thyroidal activity, differing only in the degree of severity and mode of action (BELL, 1984). With the lowest (3.97 $\mu \mathrm{mols} / \mathrm{g}$ ) glucosinolate contents the 30 minutes treatment gave the highest weight gain value in the present study.

Improvement in the biological performance of chicks due to feeding on autoclaved rapeseed meal in the diet could be related to the reduction in glucosinolate (ARONEN and VANHATALO, 1992), soluble tannins and sinapine (FENWICK et al., 1984b) content as a result of moist heat. Thermal treatment of rapeseed meal 
causes the production of a relatively insoluble degradation product of indol glucosinolate in the hind gut of poultry, which is readily excreted CAMPBELL and SLOMINSKI, 1989). Thermal treatment on the other hand reduces the lysine content and dry matter degradability of rapeseed meal. This however, did not decrease protein utilization despite a slight reduction in lysine content NASI and SALJINDER, 1991). Hydrothermally treated rapeseeds also have been found to improve body weights of broilers over controls (KOZLOWSKA et al., 1987). As a result of these studies it can be concluded that autoclaving rapeseed meal improves its overall nutritional worth for broiler chicks by enhancing the gain in weight.

\subsubsection{EFFECT OF PRE- AND POST-EXTRACTION AUTOCLAVING ON THE NUTRITIONAL VALUE OF RAPESEED MEAL FOR BROILER CHICKS.}

Autoclaving of different seed grains has been reported to have beneficial effects on the nutritive value of their protein. In case of rapeseed it was reported to exhibit the additional benefit of deactivating myrosinases in the seed to avoid the hydrolysis of glucosinolates. Another important effect among others is the destruction of glucosinolates in the rapeseed meal. It was, therefore, considered important to study the effects of autoclaving rapeseed for different times before and after extraction of oil on the nutritional quality of the resultant meal for broiler chicks.

None of the reported performance parameters was significantly influenced by any dietary treatment in this experiment of five weeks duration and with rapeseed meal inclusion level of $10 \%$ in the diets. It can, however, be noted from the data that feed intake in general was better in the case of pre-extraction autoclaving.

In case of weight gain maximum total weight gain per chick was recorded with seed autoclaved for 30 minutes, followed by control. It is clear that all the rapeseed meal diets gave better results as compared to standard diet. Feed to gain ratio ranged from 1.94 (control) to 2.08 (SA-30).

Results of this experiment are a confirmation of our previous results. Level of rapeseed meal inclusion was only $10 \%$, depicting glucosinolate levels of the diet to be 2.38 to $6.08 \mu \mathrm{g} / \mathrm{g}$, which is much below the reported threshold NOGT and STUTE, 1974). Duration of the experiment was only five weeks. This feeding period again is short enough to avoid the hazardous effects of the glucosinolates NOGT and SCHUBERT, 1969). Performance results were better with pre-extraction autoclaving than with meal autoclaving. This demonstrates that both the functions of inactivating 
of myrosinases and improvement in the proteins (MANSOUR et al., 1993) are at work. However, since the level of inclusion of rapeseed meal in the chick diet was relatively low (10\%), these effects could not be very clearly demonstrated.

\subsubsection{EFFECT OF FEEDING INCREASED LEVELS OF HEAT PROCESSED RAPESEED MEAL ON THE PERFORMANCE OF BROILER CHICKS.}

Feed consumption was not influenced significantly by the different dietary treatments. Gain in weight on the other hand was significantly $(\mathrm{P}<0.01)$ influenced by different treatments. Highest gain in weight was recorded in standard diet group, but not significantly different from weight gain in $15 \%$ untreated RSM fed group. This trend in the groups fed on untreated rapeseed meal is exactly what was observed in the experiment on different levels of rapeseed meal, and by similar reasoning the trend can be justified. All levels of heat treated rapeseed meal inclusion resulted in inferior performance than in standard diet group and 15\% untreated rapeseed meal group. This seems to be in contradiction to the results of experiment no. 3, where heat treatment of the rapeseed meal resulted in better performance of the broiler chicks. The level of inclusion was almost similar in both the experiments, however, the treatment conditions of rapeseed meal were different in the two cases, the treatment being more severe in the present experiment $\left(105^{\circ} \mathrm{C} / 15\right.$ minutes) as compared to those in the experiment no. $3\left(80^{\circ} \mathrm{C} / 60\right.$ minutes $)$. Beneficial effects of heating on the quality of resultant meal has long been reported. However, the heating temperature and length of heating time has been debated in the literature (WOODLY, et al. 1972, ANDERSON-HAEFERMANN, 1993).

Improvement in the nutritional value of rapeseed meal with desolventization temperature of $100^{\circ} \mathrm{C}$ has been reported and was attribute to the inactivation of myrosinases, the process however, had no effect on the feed efficiency ratio (SHIRES, et al. 1983). The heating conditions have to be optimum if enhanced performance is expected. Heating with steam for 30 and $60 \mathrm{~min}$ had no effect on the nutritive value of the meal except that it decreased the digestibility of protein, although this treatment reduced the glucosinolate and sinapine contents in the meal (SIONEK et al., 1994,). Lack of improvement in the nutritive value of rapeseed meal with higher temperatures has been widely reported (KOZLOWSKI and FARUGA, 1989, LEE et al., 1991). 


\subsubsection{EFFECT OF FEEDING INCREASED LEVELS OF IRRADIATED RAPESEED MEAL ON THE PERFORMANCE OF BROILER CHICKS.}

Differences in feed consumption of different groups were statistically non-significant, indicating similar taste preference of birds for all the feeds. Weight gain of the birds was significantly $(\mathrm{P}<0.01)$ influenced by different feeds. Gain was maximum with $15 \%$ untreated RSM followed by standard diet and were not significantly different from each other. Minimum values for weight gain were recorded for $15 \%$ irradiated RSM and 25\% untreated RSM diet. Feed to gain ratio was highest with irradiated $25 \%$ RSM diet followed by untreated 25\% RSM diet. Feed to gain ratio was minimum for $15 \%$ RSM diet. Results of this experiment again confirm the findings of previous ones. The various factors like the short duration of the experiment (VOGT and SCHUBERT, 1969 ), the lower glucosinolate content of the diet than the threshold (VOGT and STUTE, 1974) ), the formulation of the diet so that plant and animal protein concentrates (PROUDFOOT et al., 1983, HULAN and PROUDFOOT, 1978, SALMON, 1982), and the genotypic resistance (PEARSON et al., 1983a, PROUDFOOT et al., 1983) of the broilers used in this experiment to the adverse effects of glucosinolates may have singularly or in combination/s of any number of these factors may have played a role in obtaining these results.

\section{Irradiation effect}

Although irradiation treatment of RSM does bring some benefits like reducing the contents of glucosinolates (NUGON-BAUDON and co-workers, 1988) and phytic acid (HAFIZ et al., 1989) in rapeseed. Biosynthesis of ascorbic acid in irradiated germinating seeds has also been higher than the unirradiated controls SATTAR et al., 1995). However, in present work this treatment could not improve the nutritional value of rapeseeds for broiler chicks. Rather the chicks fed on diets containing irradiated RSM performed poorer than their respective controls. At $15 \%$ levels of inclusion the untreated RSM gave comparative performance to the standard group. The irradiated RSM could not give similar results. This is supported by the work of NUGON-BAUDON and co-workers, (1988) who reported that irradiation sterilization of the RM diet did not affect the growth of broiler chicks, but the weight of the thyroid was significantly higher if the diet was not irradiated. Irradiation caused partial destruction of progoitrin. This treatment also has been reported to have no effect on the in-vitro protein digestibility of rapeseed (BADSHAH et al., 1993). BARQUE et al., (1982) showed improvement in the feed efficiency, chick growth and cost economics of the ration containing guar meal by gamma irradiation as compared to autoclaving. 


\section{Thyroid Function}

As can be seen from the data, inclusion of rapeseed meal in broiler's diet resulted in increased levels of thyroid hormones. This however, was not related to any of the performance parameters (Table 24). The reason seems to be the short duration of the experiment, during which the changes in thyroid hormone levels could not express themselves in terms of reduced growth or feed intake. It is probably this reason that in general higher levels of rapeseed meal inclusion are recommended for broiler chicks than for layers (CLANDININ et al., 1986). Lack of any relationship between growth and thyroid function in broiler chicks has been reported by several other workers (SCHÖNE et al., 1990), SUMMERS and LEESON, (1977a) suggested that although rapeseed meal fed birds were abnormal with respect to their thyroid activity, it seems probable that factors other than a simple reduction in serum thyroxin concentrations are responsible for the growth depression. MATSUMOTO et al., (1968) confirmed the effects of goitrin on thyroid but failed to record any depression in the weight gain of broiler chickens when goitrin was included in their diet at $0.05 \%$ level. KINAL et al., (1990) reported that compared with the control group the chickens on the different rape diets had $35-90 \%$ thyroid hypertrophy. This however, was irrespective of the weight gain, which was similar in control and rapeseed meal fed group at the end of the experiment. TREFNY et al., (1989) observed significant increases in the liver and slightly increase in thyroid weight. These changes, however, had no effects on their physiological functions, and on broiler productivity. Rapeseed meal was found to have no effect on serum enzymes activities. CLANDININ et al., (1966) included $0.15 \%$ of 5-venyl,2-oxazolidinthione in the diet of chicks and observed depression in growth rate and thyroid enlargement. Initially decreased radio iodine uptake and increased excretion by the thyroid gland was noted. However, a physiological equilibrium was reached after 3-4 weeks.

TREFNY et al., (1990) reported from a similar experiment on fowls and turkeys that at the end of finishing thyroid weights of both fowls and turkeys were increased with rapeseed meal diets and iodine and zinc supplements had no effect. In fowls rapeseed meal decreased blood thyroxine compared with controls but overall had no effect on growth rate. Iodine and zinc supplements had no effect on body weight changes. In turkey poults blood triiodothyronine increased with $\mathrm{Zn}+\mathrm{I}$ and $\mathrm{Zn}$ alone and thyroxine increased with $\mathrm{Zn}+\mathrm{I}$.

The hormones triiodothyronin (T3) and thyroxin (T4) can be synthesised by the thyroid gland only when sufficient iodine is supplied in the diet. Iodine ions are removed from the blood against a concentration gradient, oxidised to elemental 
iodine and inserted into a tyrosine radical (KARLSON, 1969). Isothiocyanates block iodine transport from the blood into the thyroid (KARLSON, 1969, CLANDININ et al., 1966). ANKE et al., (1980) reported that isothiocyanates compete for the available iodine at the site of thyroxin formation in thyroid gland, resulting in a decreased synthesis of thyroxin. Goitrin has been shown to hinder the iodide oxidation, resulting in its decreased availability for organification (binding) to the aromatic ring of tyrosine which serves as the basic structural nucleus for thyroxin formation(GMALIN, 1969, BERGNER and SCHMIDT, 1972) CLANDININ et al., (1966) included $0.15 \%$ of 5-venyl,2-oxazolidinthione in the diet of chicks and observed depression in growth rate and thyroid enlargement. Initially decreased radio iodine uptake and increased excretion by the thyroid gland was noted. However, a physiological equilibrium was reached after 3-4 weeks. The reduced synthesis of thyroid hormones which control, through a negative feed back relationship with pituitary, the production of thyroid stimulating hormones (TSH), results in enhanced production of the later ANKE et al., (1980). The increased physiological activity resulting from competition for iodine leads to increased thyroid size, also to alteration in the ratio of triiodothyronine to thyroxin (T3 : T4) and thyroid histology LO et al., 1971, BERGNER and SCHMIDT, 1972, BELL et al., 1972, LEUNG and MARCH, 1976, NISHIE and DAXENBICHLER, 1980). 


\section{CHAPTER 6}

\section{SUMMARY}

The non-availability of locally produced soybean and soybean meal in Pakistan, compels the poultry feed producer to use protein concentrates from animal sources. These have, not only several technical problems, but also are costly, rendering the cost of feed production, and ultimately that of poultry, very high. Therefore search for cheaper protein sources for use in poultry feeds is necessary.

Rapeseed ranks first among other oilseed crops in Pakistan. The meal left after the extraction contains up to $48 \%$ of good quality protein. The amino acid profile of rapeseed protein compares favourably with that of soybean meal protein, except that it has more sulphur-amino acids and is low in lysine than soybean meal. It has been frequently suggested that in combination with some complementary protein source it can replace part or all of the soybean meal in poultry rations.

Rapeseed meal, however, contains certain antinutritional factors especially glucosinolates, phytic acid, and phenolics which make its utilisation in poultry feeding questionable. It has been possible to reduce the glucosinolates content in rapeseed and hence in rapeseed meal through breeding. The 00-rapeseed varieties, which are called Canola in Canada, contain less than $30 \mu$ moles of glucosinolates. However, in Pakistan the bulk of rapeseed meal available in market is from HGvarieties. Efforts therefore were concentrated to make use of this indigenously available protein source for inclusion in poultry feed.

Seeds from HG- variety (Pakcheen) of rapeseed were treated in different ways and the effect of these treatments was studied on the contents of various nutrients and anti-nutrients. Phytic acid was not reduced significantly by heating time, autoclaving time and irradiation doses. Sinapine was reduced upto $60 \%$ with dry heating at $250^{\circ} \mathrm{C}$ for 30 minutes. Autoclaving the seed for 30 minutes also produced similar results. Total phenol contents could be reduced upto almost $30 \%$ at $100^{\circ} \mathrm{C}$ for 30 minutes. Higher temperatures had no further effects. The 30 minutes autoclaving resulted in over $40 \%$ reduction in total phenol contents. Longer treatments had practically no further effect. Glucosinolates were most drastically reduced with autoclaving treatments (48 and $61 \%$ with 10 and 30 minutes treatments, respectively). Irradiation at $10 \mathrm{kGy}$ dose also reduced it upto $35 \%$, but dry heating treatments did not cause any mentionable reduction.

In-vitro protein digestibility of rapeseed meal increased upto 15 minutes of autoclaving and 60 minutes of dry heat treatments. Amino acids were variously 
influenced by different treatments. Heat treatments for 30 and 60 minutes and irradiation treatment at 5 and $10 \mathrm{kGy}$ doses resulted in losses both in lysine and methionine contents. Autoclaving caused loss of lysine but methionine content practically increased with this treatment.

Seven feeding trials were carried out on broiler chicks using control and variously treated rapeseed meal at different levels in the diets. Rapeseed meal from variety Pakcheen (glucosinolates $60 \mathrm{~mol} / \mathrm{g}$ ) could be safely incorporated in the broiler ration upto $15 \%$ level. Higher levels resulted in significantly reduced performance of the broiler chicks. It was established that the relationship between the glucosinolate contents of the feed and weight gain of broiler chicks was not a linear rather a curvilinear one and the results can best be explained with a regression equation of second degree. Irradiated rapeseed meal at $10 \%$ level did not significantly improve the performance of broiler chicks.

In an experiment using heat treated and dehulled rapeseed meal at a level to provide $25 \%$ of the total protein requirements from rapeseed meal it was concluded that heating at $80^{\circ} \mathrm{C}$ of the seeds and then extracting resulted in enhanced nutritional value of rapeseed proteins. Autoclaving of rapeseed meal for 30 minutes was found suitable in another experiment. Autoclaving of the seeds before extraction was found better than the same treatment given to meal after extraction. Higher levels of heat treated $\left(105^{\circ} \mathrm{C}\right)$ and irradiated $(5 \mathrm{kGy})$ rapeseed meal did not possess any better nutritional value than their respective controls. However a level of $15 \%$ was established again in these trials.

It can be concluded that although the feeding of $15 \%$ rapeseed meal to broiler chicks disturbs the thyroid hormone levels and ratio, this effect is not clearly manifested in terms of growth depression due to their relatively short life span. Also the inclusion of this particular rapeseed meal (glucosinolates $60 \mu \mathrm{mol} / \mathrm{g}$ ) resulted in a total of $9.12 \mu \mathrm{mol} / \mathrm{g}$ of feed, which is well within the reported threshold.

An important point that can be arrived at from these studies is regarding the classification of RSM into LG- and HG-RSM. Where this can be a valid classification from the stand point of breeding and other purposes, keeping in mind the definition of LG-RSM, for the purpose of poultry and particularly for broiler chicks feeding, another class i. e. medium glucosinolates rapeseed will have to be defined. This class, by definition should contain $30-65 \mu \mathrm{mol}$ of glucosinolates per gram of meal. NASI and SILJANDER-RASI, (1991) have already used this terminology by taking the upper limit for medium glucosinolates RSM at $55 \mu \mathrm{mol} / \mathrm{g}$ of meal. With this concentration of glucosinolates in the rapeseed meal, its inclusion at $15 \%$ level in the broiler chicks rations does not cross the glucosinolate threshold in feed. 


\section{CHAPTER 7}

\section{ZUSAMMENFASSUNG}

Wegen der mengenmäßig unzureichenden Produktion von Sojabohnenextraktionsschrot (SBM) in Pakistan sind die Futterhersteller gezwungen, andere Eiweißkonzentrate tierischer- und pflanzlicher Herkunft zu nutzen. Hieraus ergeben sich nicht nur technische Probleme, sondern sie erhöhen auch, durch ihren hohen Preis, die Kosten der Futter- und damit der Geflügelproduktion. Es ist deshalb notwendig, billigere Proteinquellen zur Herstellung von Geflügelfutter zu erschließen.

In Pakistan steht bei der Ölpflanzenproduktion der Raps an erster Stelle. Rapsextraktionsschrot (RSM) enthält bis zu 48\% Protein guter Qualität. Es hat ein vergleichbares Aminosäurenmuster zum Sojaprotein, mit der Ausnahme, daß Raps etwas höhere Gehalte an schwefelhaltigen Aminosäuren und niedrigere Gehalte an Lysin enthält. Es ist daher zu prüfen, inwieweit SBM im Geflügelfutter ganz bzw. teilweise durch andere Proteinquellen bzw. durch die Kombination von anderen Proteinträgern, wie RSM, ersetzt werden kann.

Rapsschrot enthält antinutritive Faktoren wie Glukosinolate, Phytin und Phenole, die den Gebrauch von RSM in der Geflügelfütterung begrenzen können. Es ist möglich, den Glucosinolatgehalt in Raps und RSM durch Züchtung zu vermindern. Die 00Rapssorten, die in Canada als Canola bezeichnet werden, enthalten weniger als $30 \mu \mathrm{mol}$ Glucosinolate je g. Auf dem pakistanischen Markt stammt der größte Anteil an RSM aus glucosinolatreichen (HG) Sorten. Deshalb ist es notwendig, zu prüfen, ob RSM durch geeignete Behandlungsverfahren bearbeitet werden kann, um diese vorhandene Proteinquelle für Geflügelfutter zu nutzen.

Die HG-Rapssorte "Pakcheen" wurde unterschiedlichen Behandlungmethoden unterworfen und der Einfluß dieser Behandlungsmethoden auf verschiedene Inhaltsstoffe untersucht. Der Phytingehalt wurde durch trockenes Erhitzen, Autoklavieren (Dampferhitzung unter Druck) und Gamma-Bestrahlung nicht beeinflußt. Der Sinapingehalt wurde durch trockene Hitze $\left(250^{\circ} \mathrm{C}\right.$ für 30 Minuten) um $60 \%$ vermindert. Die Behandlung im Autoklaven für 30 Minuten hatte den gleichen Effekt. Der Gesamtphenolgehalt konnte durch trockene Hitze $\left(100^{\circ} \mathrm{C}\right.$ für 30 Minuten) um 30\% vermindert werden. Durch 30 minütiges Autoklavieren wurde der Gesamtphenolgehalt um mehr als $40 \%$ vermindert. Eine längere Behandlungsdauer 
zeigte keinen weiteren Effekt. Der Glucosinolatgehalt wurden am stärksten (bis 60\%) bei der Behandlung im Autoklaven vermindert. Die Gamma-Bestrahlung (10kGy) verminderte den Glucosinolatgehalt um 35\%, die Anwendung von trockener Hitze war ohne Einfluß.

Die in-vitro Verdaulichkeit der Proteine im RSM wurde durch 15 minütiges Autoklavieren bzw. 60 minütige trockene Hitze erhöht. Die Aminosäurengehalte wurden durch die angewendeten Behandlungsverfahren unterschiedlich beeinflußt. Trockene Hitze und Gamma-Bestrahlung führten zu einer Verminderung der Lysinund Methioningehalte. Das Autoklavieren verursachte eine Verminderung des Lysingehaltes, wobei der Methioningehalt etwas erhöht wurde.

Es wurden sieben Fütterungsversuche mit Broilern durchgeführt, in denen unterschiedlich behandeltes RSM in verschiedenen Konzentrationen verfüttert wurde. Rapsschrot der Sorte Pakcheen (Glucosinolatgehalt $=60,8 \mu \mathrm{mol} / \mathrm{g}$ RSM) konnte ohne Probleme bis $15 \%$ in Broilerfutter eingemischt werden. Höhere Konzentrationen führten zu einer signifikant erniedrigten Mastleistung. Die Beziehung zwischen dem Glucosinolatgehalt im Futter und der Gewichtszunahme der Broiler verläuft nicht linear sondern curvilinear. Die Bestrahlung von RSM, das zu 10\% in der Ration eingesetzt wurde, ergab keine Leistungsverbesserung.

In einem Versuch mit hitzebehandeltem und geschältem (dehulled) RSM (25\% der Gesamtproteinzufuhr kamen aus diesem RSM) wurde ermittelt, daß die Erhitzung $\left(80^{\circ} \mathrm{C}\right)$ der Rapskörner vor der Extraktion zu einer Erhöhung der Qualität von Rapsprotein bei Broilern führt. In einem weiteren Versuch wurde gefunden, daß die Behandlung im Autoklaven (30 Minuten) vor der Extraktion zu einer besseren Mastleistung führt. Höhere Konzentrationen an erhitztem $\left(105^{\circ} \mathrm{C}\right) \mathrm{bzw}$. bestrahltem (5kGy) RSM ergaben keine Leistungsverbesserungen. Danach läßt sich aus diesen Versuchen schließen, daß RSM (mit bis zu $60,8 \mu$ mol Glucosinolat) bis zu $15 \%$ im Geflügelfütter eingesetzt werden kann.

Obwohl die RSM-Fütterung (bis 15\%) bei den Broilern die Konzentration an Schilddrüsehormon beeinflußt, tritt keine Verminderung der Mastleistung auf. Dies ist wahrscheinlich durch die kurze Lebensdauer der Broiler bedingt. Auch die Beimischung von RSM (mit 60,8 $\mu$ mol Glucosinolatgehalt je g) bis $\mathrm{zu}$ einem Gesamtglucosinolatgehalt von $9,12 \mu \mathrm{mol} / \mathrm{g}$ Futter, liegt innerhalb der in der Literatur beschriebenen Grenzen (threshold). 
Aus diesen Untersuchungen läßt sich eine Klassifizierung von RSM in LG- und HGSorten durchführen. Das bereits geltende System wird wahrscheinlich für die Pflanzenzüchtung ausreichend sein, für die Geflügelernährung müßte eine weitere Klasse als "Medium Glucosinolathaltiges RSM" definiert werden. RSM dieser neuen Klassifizierung sollte definitionsgemäß ca. 30 bis $65 \mu \mathrm{mol}$ an Glucosinolaten nicht überschreiten. NAESI und SILJANDER-RASI (1991) geben für "Medium Glucosinolathaltiges RSM" als Höchstgrenze einen Glucosinolatgehalt von $55 \mu \mathrm{mol} / \mathrm{g}$ an. RSM mit einem Glucosinolatgehalt in dieser Größenordnung kann bis zu 15\% im Broilerfutter eingemischet werden, ohne Leistungseinbußen zu befürchten. 


\section{BIBLIOGRAPHY}

ALLI, I.; HOUDE, R. 1986 : Characterisation of phytates in canola meal., In: 8th progr. Rept. Res on canola seed, oil, meal and meal fractions Canola Council of Canada.

AN, M.S.; PAIK, I.K. 1989 : The effect of ammoniation on the feed value of korean rape-meal. Han'guk Ch'uksan Hakhoechi 31, 20-25.

ANJOU, K.; LÖNNEDRAL, B.; UPPSTRÖM, B.; AMAN, P. 1977 : Composition of seeds from Brassica cultivars. Swed. J. Agric. $\underline{7}, 169-178$.

ANKE, M.; SCHWARZ, S.; HENNIG, A; GROPPEL, B.; GRÜN, M: ZENKER, G.; GLÖS, S. 1980

: Der Einfluß zusätzlicher Zink- und Jodgaben auf rapsextraktionschrotbedingte Schäden beim Schwein. Mh.Veterinärmed. 35, 90-94.

ANWAR, A.; CLANDININ, D.R.; ROBBLEE, A.R. 1971 : Effects of equallizing gross protein value units in isocaloric rations containing rapeseed meals of different quality. Poultry Sci. $\underline{50}, 181-183$.

APPELQVIST, I.; OHLSON, R. 1972 : Rapeseed: Cultivation, composition, processing and utilisation. Elsevier Pub.Co. Amsterdam.

ARENA, S.; PENZ, A.M.Jr. 1988 : Estimation of nutritional quality of rapeseed meal.2. Metabolizable energy of rapeseed meals for broilers, 21 or 42 days old and performance of broilers fed on diets with increasing amounts of rapeseed meals. Rev. Soc. Bras. Zootech. 17, 138-146.

ARONEN, I; VANHATALO, A. 1992: Heat-moisture treatment of rapeseed meal: effect on digestibility of the diet, voluntary grass silage intake and growth rate of Ayrshire bulls. Acta-Agriculturae-Scandinavica.-Section-A,-Animal-Science. 42, 3, 157-166.

BANASKIEWICZ, T. 1996: Effect of using 00-rapeseed meal or rapeseed oil in feed mixtures on nutrient digestibility and performance in broiler chicks. Biuletyn Naukowy Przemystu Paszowego $\underline{35}$, 47-56.

BANASKIEWICZ, T. 1995: Nutritive value of rapeseed -00 and oil for broiler chicks. Biuletyn

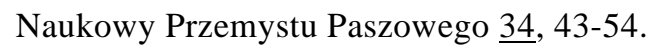


BAO, C.; XU, F.; SUN, Y.; SHAO, C.; LIU, M. 1995: Histological changes in main viscera of broiler chicks fed on different rapeseed meals containing toxic substances. Jiangsu J. Agr. Sci. 11,(4) 34-40.

BARBOUR, G.A.; SIM, J.S. 1991 : True metabolizable energy and true amino acid availability in canola and flax products. Poultry Sci. $\underline{70}, 2154-2160$.

BARRETT. J. E.; KLOPFENSTEIN. C. F.; LEIPOLD. H. W. 1997 : Detoxification of rapeseed meal by extrusion with an added basic salt. Cereal Chem. $\underline{74}, 168-170$

BARQUE A. R.; SATTAR, A.; RAFIQUE, CH. M.; ALAM, M.Z.; QURESHI, J.M. 1982. Effect of gamma irradiation and autoclaving on the nutritive value of guar meal. J. Agric. Sci. $\underline{19}$, 133-139.

BECKER, M.; NEHRUNG, K. 1965 : Handbuch der Futtermittle. Verlag Paul Perey, Hamburg, Berlin.

BELL, J.M.; BELZILE, R.J. 1965 : Goitrogenic properties. In: Bowland, J.P.; Clandinin, D.R., Wetter, I.R. (eds) Rapeseed meal for livestock and poultry- A review. Pub.1257, Canada Dept. Agr.

BELL, J.M.; BENJAMIN, B.R., GIOVANNETTI, P.M. 1972 : Histopathology of thyroid and livers of rats and mice fed diets containing Brassica glucosinolates. Can.J.Anim.Sci. 52, 395406.

BELL, J.M. 1982 : From rapeseed to canola: A brief history of researdh for superior meal and edible oil. World poultry science association sponsored lecture. Poultry Sci. $\underline{61}$, 613-622.

BELL, M. 1984 : Nutrients and toxicants in rapeseed meal.-A review.J. Animal Sci. 58, 996-1010.

BENN, M. 1977 : Glucosinolates. Pure and Appl. Chem. 49, 197-210.

BERGNER, H.; SCHMIDT, W. 1972 : Untersuchungen zur Wirkung von Rapsextraktionsschrot das Kükenwachstum. Arch.Tierernähr. 20, 179-187.

BILlE, N.; EGGUM, B.O.; JACOBSEN, I.; OLSEN,.; SOERENSEN,H.; 1983 : The effects of processing on antinutritional constituents and nutritive value of double low rapeseed meal. Z.Tierphsiol. Tierernähr. Futtermittelkd. 49, 148-163. 
BJERG, B.; SÖRENSEN, H. 1986 : Quantitative analysis of glucosinolates in oil seed rape based on HPLC of desulfoglucosinolates and HPLC of intact glucosinolates. CEC Workshop, Gembloux, Belgium.

BJÖRKLUND, K; OLSSON, A.C.; THOMKA, S. 1990 : Nutritional value of rapeseed meal and expeller for pigs and poultry. Hudjur $\underline{7}, 4$.

BLAIR, R.; BELL, J.M.; CLANDININ, D.R. 1986a : The chemical composition and nutritional value for chickens of meals from recent cultivars of canola. Can.J.Anim.Sci. $\underline{66}$, 821-825.

BLAIR, R.; SCOUGAL, K. 1975 : Chemical composition and nutritive value of rapeseed meals. Feedstuffs $\underline{10}$, 26-27.

BLAIR, R.; AND REICHERT, R.D.; 1984: Carbohydrate and phenolic constituents in a comprehensive rang of rapeseed and canola fractions : nutritional significance for animals. J.Sci.Food Agric. $\underline{35}$, 29-35.

BLAIR, R.; REICHERT, R.D. 1984 : Carbohydrates and phenolic constituents in a comprehensive range of canola fractions: nutritional significance for animals. J.Sci.Food Agri. $\underline{35}$, 2935.

BLAIR, R. 1984 : Nutritional value of ammoniated musterd meal for chickens. Poultry Sci. $\underline{63}$, 754759.

BOGEDANOV, G.A.; ROBAKO, V.N. 1986 : Use of rapeseed oil meal in feeding broiler chickens. Tekhnologiya Polucheniya rapsovogo shrota ego Kormovaya tsennost, veterinarnosanitarnya ostenka 93-113.

BOUGON, M.; BOIXIL, J.; TOMASSONE, L. 1988 : Use of rapeseed oil cakes in chicken. Bullerin d'Information Station Exp.d'Aviculture de Ploufragan, France, 28, 155-162.

BRESSANI, R.; ELIAS, L.G.; WOLZAK, A.; HAGERMAN, A.E.; AND BUTLER, Z.G. 1983 : Tannin in common beans. Methods of analysis and effects on protein quality. J. Food Sci. $\underline{48}$, 1000-1003.

BRESSANI, R.: ELIAS, L.G.; WOLZAK, A.; HAGERMAN, A.E. AND BUTLER ; Z.G. 1983 : Tannin in common beans. Methods of analysis and effects on protein quality. J. Food Sci. $\underline{48}$, 1000-1003. 
BROMIDGE, E.S.; WELLS, J.W.; WIGHT, P.A.L. 1985 : Elevated bile acids in the plasma of laying hens fed rapeseed meal. Res.Vet.Sci. $\underline{39}$, 378-382.

BUCHWALDT, L.; LARSEN, L.M.; PLÖGER, A.; SÖRENSEN, H. 1986 : FPLC isolation and characterization of plant myrosinase, ß-thioglucoside glucohydrolase, isoenzymes. J.Chromatography $\underline{363}, 71-80$.

CAMPBELL, L.D.; SLOMINSKI, B.A.; STENGET, N. 1987 : Influence of cecactomy and antibiotics on the fat of ingested intact glucosinolates in poultry. Proc. 7 th Intern. Conf. Rapeseed, Poznan,Poland ㅍ, 1704-1709.

CAMPBELL, L.D.; SLOMINSKI, B.A. 1987 : Factors influencing the glucosinolate content of commercial canola meal. Poultry Sci. $\underline{66}, 75$ (Abstr).

CAMPBELL, L.D.; SLOMINISKI, B.A. 1989 : Further studies on the source thiocyanyte ions in the excreta of poultry fed low glucosinolate rapeseed (Brassica napus) meal. J. Sci. Food Agric. $\underline{47}, 61-73$.

CAMPBELL, L.D. 1987a : Effect of different glucosinolates on liver haemorrhage in laying hens and the influence of vitamin K. Nutr. Rept. Intern. $\underline{35}$,1221-1227.

CAMPBELL, L.D., PAPAS, A.; CANSFIELD, P.E. 1980 : Glucosinolate analysis of rapeseed meal. In: Research of Canola Seed, oil and Meal Fractions. Pub. 57, Canola Council of Canada.

CAMPBELL, LD; SLOMINSKI, BA 1989 : Further studies on the sources of thiocyanate ion in the excreta of poultry fed low-glucosinolate rapeseed (Brassica napus) meal. Journal-of-theScience-of-Food-and-Agriculture. $\underline{47}, 1,61-73 ; 19$.

CANOLA COUNCIL OF CANADA, 1984 : Canadian Canola Meal, Canola Council of Canada. Winnipeg.

CARLSON, C. W; WAIBEL, P. E; LIU, J. K; BRANNON, J. A; NOLL, S.L 1992 : Performance of male turkeys fed canola, meat, poultry by-product, and feather meals replacing a live quantity of bioavailable protein from soybean meal. 53rd Minnesota Nutrition Conference, Bloomington, Minnesota, USA, 22-23 September, 1992. 1992, 293-302; St. Paul, USA; Minnesota Extension Service, University of Minnesota. 
CHAPPA, V.; STRANZNICK A,H.; PASTUSZEWSKA, B. 1989 : Effect of Czeck or polish 00rapeseed meal on performance of broiler chickens. Zivocisna Vyroba 34, 1037-1046.

CHARLENE, F. B.; LAURENA,A.C.; AND EVELYN MAE T. M. 1985: Polyphenols in mungbean (vigna radiata (L); determination and removal. J. Agric. Food Chem. $\underline{33}$ ,1006-1009.

CHERYAN, M. 1980: PA interactions in food systems. CRC Crit. Rev. food Sci. Nutr. 13, 297-334.

CHIASSON, R.B.; SHARP, P.J. 1979 : Effects of rapeseed meal and methimazole on levels of plasma harmones in growing broiler cockerels. Poultry Sci. $\underline{58}$, 1575-1583.

CHO, C.Y.; BAYLEY, H.S. 1970 : Evaluation of rapeseed and soybean meals as protein source for swine: apparent digestibilities of amino acids. Can. J. Anim. Sci. 50, 521-528.

CHONE, E.; DELAINE, Y.; AND LAPIERRE, O. 1986: Proceedings of World Conference on Emerging Technologies in the Fats and Oil Industry. Ed. Baldwin, A.R. pp. 236-242, American Oil Chemists Society, USA.

CLANDININ, D.R.; BAYLY, L.; CABALlERO, A. 1966 : Rapeseed meal studies. 5: Effects of (_+)-5-venyl-2.oxazolidinthione, a goitrogen in rapeseed meal on the rate of growth and thyroid function in chicks. Poultry Sci. $\underline{45}, 833-838$.

CLANDININ, D.R.; RENNER, R.; ROBBLEE, A.R. 1959 : Rapeseed oil meal studies. 1: Effects of variety of rapeseed, growing environment and processing tempratures on the nutritive value and chemical composition of rapeseed meal. Poultry Sci. $\underline{38}$, 1367-1372.

CLANDININ, D.R.; ROBBLEE,A.R. 1983 : Canola meal can be good source of high quality protein for poultry. Feedstuffs $\underline{55}$, (April), 36-37.

CLANDININ, D.R.; ROBBLEE, A.R.; HARDIN, R.T.; DARLINGKTON, O. 1983 : 7th progress report, research on canola seed oil and meal and meal fractions. Publ. No.61.Canola Council of Canada,

CLANDININ, D.R.; ROBBLEE, A.R.; SLINGER, S.J. 1986 : Canola meal for livestock and poultry. Publ. No. 59. Canola Council of Canada, 
CLASSEN, H.L.; BELL, J.M.; CLARK, W.D. 1991 : Nutritional value of very low glucosinolate canola meal for broilker chickens. Proc. 8th GCIRC Intern. Congr. on rapeseed in a changing world, Saskatoon, Canada.

CORNER, A.H.; HULAN, H.W.; NASH, D.M.; PROUDFOOT, F.G. 1985 : Pathological changes associated with the feeding of soybean oil or oil extracted from defferent rapeseed cultivars to single comb white leghorn cockerels. Poultry Sci. $\underline{64}$, 1438-1450.

COSGROVE, D.J. 1980 : Inositol Phosphates: Their chemistry, biochemistry and physiology. Elsevier Sci. Publ., New York.

COXWORTH, E.; MCGREGOR, I. 1980 : Effect of ammonia treatment on glucosinolates and related isothiocyanates of yellow or oriental mustard seeds. Saskatchewan Res.Council report C-814-K-1-B-80.

DABROWSKI,K. J.; SOSULSKI, F.W. 1984 : Composition of free and hydrolysible phenolic acids in defatted flour of 10 oil seeds. J. Sci. Food Agric. $\underline{32}$, 128-130.

DE BOLAND, A.: GARNER, G.B.; AND O'DELL, B.L. 1975 : Identification and properies of phytates in cereal grains and oilseed products. J.Agric. Food Chem. 23, 186 - 189.

DEAN, W.F.; SCOTT, H.M. 1968 : Ability of arginine to reverse the growth depression induced by supplementing crystilline amino acid diet with excess lysine. Poultry Sci. 47, 341-342.

DECLERCQ, D.R.; AND DAUN, J.K. 1989: Determination of the total glucosinolates content in canola by reaction with thymol and sulfuric acid. JAOCS. $\underline{66}, 788-791$.

DOWNEY, R.K. 1983 : The origenal discription of Brassica oilseed crops. In High and Low Erecic Acid Rapeseed Oils, Kramer,J.K.G.; Sauer,F.D.; Pigden,W.J. (eds).Toronto: Academic Press, 61-83.

DURRANI, F.R.; KHALIL, I.A. 1990 : Chemical composition of Brassica oilseed meal. Pak. J. Sci. Ind. Res. $\underline{33}, 39-41$.

ELIAS, L.G; DEFERMANDZ, D.G.; AND BRESSANI , R. 1979 : Possible effects of seed coat polyphenols on the nutritional quality of pean protein. J. Food Sci. $\underline{44}$, 524-526. 
ELWINGER, K; SATERBY, B. 1986: Continued experiments with rapeseed meal of a Swedish low glucosinolate type fed to poultry. 1. Experiments with broiler chickens. SwedishJournal-of-Agricultural-Research. $\underline{16}, 1,27-34$.

EYRE, M.D.; SMITHARD R.R. 1984. The effect of processing rapeseed upon its anti thyroid activity and the utilization of its protein. J. Sci. Food Agric. $\underline{35}$, 827-832.

EYRE,-M. D.; ROOKE,-J. A. 1983: The effect of solvent extraction upon the utilisation of rapeseed meal protein by rats.Journal-of-the-Science-of-Food-and-Agriculture. 1983, 34, 917920

FARUGA, A.; NABIB, S.I.; KOZLOWSKI, M.; KOZLOWSKA, H. 1987 : Studies on the determination of optimal share of rapeseed meal in the nutrition of broilers. Proc. 7 th Intern.Conf.Papeseed, Poznan,Poland.

FASINA, Y. O.; CAMPBELl,G. L.; TYLER, R.;T. 1997 : Whole canola/pea and whole canola/canola meal blends in diets for broiler chickens. 1. Evaluation of steam-pelleting or expansion processing. Can. J. Anim. Sci. $\underline{77}$, 185-190

FELDHOFER, S.; GORDANA, K.; CURIC, S.; VAKADINOVIC, B.; IVETIC, D.; GALONGA, M. 1996: Cruched rape oilseed and rape oil in feeding of broiler. Veterinarska Stanica, 27, 195-203.

FENWICK, G.R.; CURTIS, R.E. 1980 : Rapeseed meal in rations for laying chickens. A review of the effect on egg quality. J. Sci. Food Agric. $\underline{31,515-525 .}$

FENWICK, G.R.; HEANY, R.K. 1983 : Glucosinolates and thier breakdown products in cruciferus crops, food and feeding-stuffs. Food Chemistry, 11, 249-271.

FENWICK, G.R.; CURL, C.L.; BUTLER, E.J.; GREENWOOD, N.M.; PEARSON, A.W. 1984a : Rapeseed meal and egg taint; effect of low glucosinolate Brassica napus meal, dehulled meal and hull and neomycine. J. Sci. Food Agric. $\underline{35}$, 749-756.

FENWICK, G.R.; CURL, C.L.; PEARSON, A.W.; BUTLER, E.J. 1984b : The treatment of rapeseed meal and its effect on chemical composition and egg tainting potintial. J. Sci. Food Agric. 35, 757-761.

FERNANDEZ, S. R; ZHANG,-Y; PARSONS,. CM 1993 : Determination of protein solubility in oilseed meals using Coomassie blue dye binding. Poultry-Science. $\underline{72}$, 10, 1925-1930. 
FINLAYSON, A.J.; KRZYMANSKI, J.; DOWNY, R.K. 1973 : Comparison of chemical and agronomic characteristics of two Brassica napus cultivars, Bronowski and Target. J. Am. Oil Chem. Soc. 50, 407-410.

FINLAYSON, A.J. 1974 : Note: the amino acid compoaition of rapeseed hulls Can. J. Anim. Sci. $\underline{54}$, 495-496.

FREIG, A.A.H.; CAMPBELL, L.D.; STANGER, N.E. 1987 : Fat of ingested glucosinolates in poultry. Nutr. Rept. Intern. $\underline{36}, 1337-1345$.

FRITZ, Z.; SCHLEICHER, A.;JARESZ, A.; JAMPROZ, D. 1989 : Mixtures supplemented with new variety rapeseed meal, floromycine or tyrosine in broiler chicken feeding. Zootechnica $\underline{31}, 69-77$.

FULLER, H.I.; CHANG, S.I.; POTTER, D.K. 1967 : Detoxification of dietary tannic acid by chicks J.Nutr. $\underline{91}, 477-481$.

GAO, Z.; LI, J.; PETTERSON, H. 1988 : Effects of feeding broilers with rapeseed meal, containing different levels of total glucosinolates and progoitrin. Zhongguo Nongyn Kexue(ch) 21 , 84-90.

GAO, Y.P.; XUE, Y. R.; ZHANG, S.X. 1996: Studies on the nutritional components of double low rapeseed meal and its feeding effects for chickens. J. Southwest Agri. Uni. (China), 18, 281-287.

GAWECKI, K; RUTKOWSKI, A; LIPINSKA, H. 1983: Oilmeal from low-glucosinolate rapeseed Start 00 to replace soyabean meal in diets for broilers Roczniki-Naukowe-Zootechniki. $\underline{10}, 2,117-126$.

GMALIN, R.1969: Glucosinolate (Senfölglucoside). Präp. Pharm. ㅁ, 33-41.

GOH, Y.K.; ROBBLEE, A.R.; CLANDININ, D.R. 1985 : Influence of glucosinolates and free oxazolidinthione in a laying diet containing a constant amount of sinapine on the thyroid size and hepatic trimethyl amine oxidase activity of brown egg layers. Can. J. Anim. Sci. 65, 921-927.

GOH, Y.K.; ROBBLEE,A.R.; CLANDININ, D.R. 1987 : Effect of ammoniation of canol ameal on the fishy odour and trimethylamine contents of egg produced by brown-egg layers. In 8th progress report, research on canola seed oilm meal and meal fractions. Winnipeg: Canola Council of Canada. 79-83. 
GOH, Y.K.; SHIRES, A.; ROBBLEE, A.R.; CLANDININ, D.R. 1982 : Effect of ammoniation of rapeseed meal on the sinapin content of meal. Br. Poultry Sci. $\underline{23}, 121-128$.

GOLDSTEIN J.L.; ANDSWAIN, T. 1963: Changes in tannins in ripening fruits. Phylochem: $\underline{2}$, 1114.

GORRILL, A.D.L., WALKER, D.M., AND JONES, J.D. 1974 : Rapeseed protein source and amino acid supplementation of diets for weanling rats. Can. J. Anim. Sci. 54, 659-667.

GOSSELIN, R.E.; COGHLAN, E.R. 1953 : The stability of complexes between Ca and orthophosphate, polymeric phosphate and phytate. Arch. Biochem. Biophys. $\underline{45}, 301-$ 305.

GRALA, W; BURACZEWSKA, L; GDALA, J; PASTUSZEWSKA, B 1994: Effect of the thermal processing on the protein value of double-low rapeseed products. 1. Effect of toasting temperature on protein value of rapeseed oilmeal for pigs.Journal-of-Animal-and-FeedSciences. $\underline{3}, 33-42$.

GRALA, W; PASTUSZEWSKA, B; SMULIKOWSKA, S; BURACZEWSKA, L; GDALA, J 1994: Effect of thermal processing on the protein value of double-low rapeseed products. 2 . Effect of processing stages in the oil plant and of toasting in laboratory conditions.Journal-of-Animal-and-Feed-Sciences. $\underline{3}$, 43-55.

GRAY, J.A.; HILL, D.C.; BROWN, H.D. 1958 : Effect of autoclaving on nutritive value of Argentine rapeseed for chicks. Poultry Sci. $\underline{37}, 734$.

GREENWOOD, J.S. 1990 : Phytin synthesis and deposition. In: Recent Advances in Development and Germination of Seeds. Tailorson,R.B. (ed), New York Plenum Publ.Corp.

GRIFFITHS, N.M.; FENWICK, G.R.; PEARSON, A.W.; GREENWOOD, N.M.; BUTLER, E.J. 1980 : Effects of rapeseed meal on broilers. Studies of meat flavor, liver haemorrhage and trimethylamine oxidase activity. J. Sci. Food Agric. $\underline{31}$, 188-193.

GRUHN, K.; ZENDER, R. 1989 : Comparision of digestibility of crude nutrients and amino acids from rapeseed oil meal and expeller of varyious origins in colostomised laying hens. Arch. Anim. Nutr. 39, 911-920.

HAFERMANN-ANDERSON, J. C; ZHANG, Y; PARSONS, C. M 1993 : Effects of processing on the nutritional quality of canola meal. Poultry-Science. $\underline{72}$, 326-333. 
HAFIZ, Y. S.; MOHAMMAD, A. I.; PERERA, P. A.; SINGH, G.; AND HUSSAIN, A.S. 1989:

Effects of microwave heatring and irradiation on phytate and phosphlipid contents of soybean. J. Food Sci. 54, 958 - 962.

HARYSH, Z.J.; SAM, R.M.; ROBBLEE, A.R.; HARDIN, R.T. 1980c : Infouence of low glucosinolate rapeseed meal and rapeseed meal screenings meal on the eating quality of broiler chickens. Poultry Sci. 59, 2437-2443.

HAUG, W.; AND LANTZSCH, 1983: Sensitive method for the rapid determination of phytate in cereal products. J.Sci. F,ood Agr. 34, 1423-1426.

HAWRYSH, Z.J.; STEADMAN, D.C.D.; HARDIN, R.T.; SAM, R.M.; 1980a : Influence of low glucosinolate $(\mathrm{Cv}$. Tower) rapeseed meal on the eating quality of broiler chickens. Subjective evaluation by a trained test panel-objective measurement. Poultry Sci. $\underline{59}$, $550-557$.

HAWRYSH, Z.J.; DOUGLAS, D.S.; ROBBLEE, A.R.; HARDIN, A.R.; SAM, R.M. 1980b : Influence of low glucosinolate $(\mathrm{Cv}$. Tower) rapeseed meal on the eating quality of broiler chickens. II. Subjective evaluation by a consumer panel. Poultry Sci. 59, 558562.

HAWRYSH, Z.J.; SAM, R.M.; HARDIN, R.T.; ROBBLEE, A.R. 1980d : A consumer study of the eating quality of broiler chickens fed rations containing low glucosinolate rapeseed meal and rapeseed screenings meal. Poultry Sci. 59, 2444-2448.

HAWRYSH, Z.J.; SAM, R.M.; ROBBLEE, A.R.; HARDIN, R.T. 1982 : Influenceof low glucosinolate canola meal ( $\mathrm{Cv}$. Regent and candle) on the eating quality of broiler chickens. Poultry Sci. 61, 2375-2384.

HEIDENREICH, E; LOWE, R 1993: Rapeseed and rapeseed meal in compound feed. Fett-

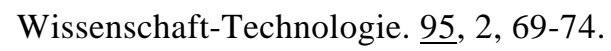

HEINZ, J.; ENGRER, K.H.; SCHÖFFEL, H.-J.1987 : Ernährungphysiologische Bewertung von Rapsextractionsschrot 00-Qualitätssorte in Broilerwachstumversuch. Proc. 7th Intern.Conf.Papeseed, Poznan,Poland.

HENKEL, H.; MOSENTHIN, R.; 1989 : Rapssaat und Rapsprodukte in der Tierernährung. Ubersichten zur Tierernährung $\underline{17}$, 139-190. 
HENKEL, H., KALWEIT, P., 1989 : Comparative feeding experiments with broilers fed 20\% rapeseed in the diet with different content of glucosinolates. Beratender Ausschuß der EEC, Brüssel.

HILL, R. 1979: A review of the toxic effects of rapeseed meal with observations on meal from improved varieties. Br. Vet. J. 135, 3-16.

HSU, H.W.; VAVAK, D.L.; SATTERLEE, L.D.; MILLER, G.A.A. 1977. Multienzyme technique for estimating protein digestibility. J. Food Sci. $\underline{42}$, 1269-1273.

HULAN, H.W.; PROUDFOOT, F.G. 1978 : Nutritional effecacy of rapeseed meal as a source of dietary protein for broiler chickens. Proc. 5th Intern. Rapeseed Conf. Malmo, Sweden.

HULAN, H.W.; PROUDFOOT, F.G. 1980 : The nutritive value of rapeseed meal for layer genotypes housed in pens. Poultry Sci. $\underline{59}$, 585-593.

HULAN, H.W.; PROUDFOOT, F.G.; RAE, K.B. 1980 : The nutritional value of Tower and candle rapeseed meal for turkey broilers housed under different lighting conditions. Poultry Sci. $\underline{59}, 100-109$.

HUYGHEBAERT, G.; FONTAIN, G.; DE-FOOTE, G. 1983 : The feeding value of rapeseed meal with different glucosinolate contents(Brassica sp.) as measured by digestibility experiments with broiler chicks and adult roosters. Arch. Geflügelkd. $\underline{47}, 50-60$.

IRISH, G. G; BALNAVE, D 1993: Poor performance of broilers fed diets containing soyabean meal as the sole protein concentrate. Austra.J.Agri. Res. $\underline{44}, 1467-1481$

J.T.; CHONG, J. 1977 : Ultrastructure and mineral distribution in heat damaged rapeseed. Can. J. Plant. Sci. 57, 21-34.

JAKSON, N. 1969 : Toxicity of rapeseed meal and its use as a protein supplement in the diets of two hybrid strains of caged laying hens. J. Sci. Food Agri. 20, 734-740.

JAMROZ, D 1991: Recent trends in studies on poultry nutrition. Zeszyty-Naukowe-AkademiiRolniczej-we-Wroclawiu,-Weterynaria. No. $\underline{48}$, 47-57.

JENSEN, S. K; LIU, Y. G; EGGUM, B. O 1995: The effect of heat treatment on glucosinolates and nutritional value of rapeseed meal in rats. Animal-Feed-Sci.Tech. $\underline{53}, 17-28$. 
JONNES, J.D.; WALTERS, D.R.; BURNETT, P.C. 1966 : Lysine-Argenine-electrolyte relationshipy in the rat. J. Nutr. $\underline{89}, 171-188$.

KARLSON, P. 1969 : Introduction to modern biochemistry, 3rd ed. Academic Press, New York.

KARUNAJEWA, H., IJAGBUJI, E.G., AND REECE, R.L., 1990: Effect of dietary levels of rapeseed meal and polyethyleneglycole on the performance of male broiler. Poultry Sci. $\underline{31}, 545-$ 555.

KEITH, M. O; BELL, J. M 1984 : Effects of ammoniation of canola (low glucosinolate rapeseed) meal on its nutritional value for the rat. Can.J.Animal Sci. $\underline{64}$, 997-1004.

KENNEDY, T.H.; PURVES, H.D. 1941 : Studies on experimental goitre.1. The effects of Brassica seed diets on rats. Br. J. Exp. Pathol. 22, 241.

KHAN, M.; SARWAR,M.; MAHMOOD,S.; REBAZ, A. 1996 : Effects of various levels of rapeseed meal on the performance of broiler chicks. Pak. Vet. J. 16, 192-195.

KHATTAK, S.; BADSHAH, W.; AND BEGUM, E. 1985: Utilization of persimmon fruit: Investigation of some methods of removal of astringency. Frontier J.Agric. Res. 11, 6671.

KHORASSANI, G.A.; ROBINSON, P.H.; KENNELLY, J.J. 1989 : Effect of chemical treatment on in-vitro and in-situ degradation of canola meal crude protein. J. Dairy Sci. $\underline{72}, 2074-$ 2080.

KIISKINEN,-T 1983: Use of Tower rapeseed meal separately and together with pea meal to replace fish and soybean meal in layers' diet at varying protein concentrations.AnnalesAgriculturae-Fenniae. 22, 195-205

KINAL, S; FRITZ, Z; JAROSZ, L; SCHLEICHER, A. 1990: Rape seeds, partly defatted seeds and rapeseed oil meal from var. Jantar in the feeding of broilers. Roczniki-NaukoweZootechniki,-Monografie-i-Rozprawy. No. 28, 251-260.

KJAER, A. 1960 : Naturally derived isothiocyanates (mustard oil) and their parent glucosides. Fortschr. Chem. Org. Naturstoffe. 18, 122-176.

KOHNHORST, A.L., UEBERSAX, M.A., AND ZABIK, M.E. 1990: Production and functional characteristics of protein concentrates. JAOCS $\underline{67}, 285-291$ 
KONICICKI, A.; KRASNODEBSKA, D.A.; FARUGA, A.; MIKULSKI, D.; KOZLOWSKI, M.; KOZLOWSKA, H,; JANOWSKA,I.; ROTKIEWICKZ, H. 1991 : Effect of concentrated feed containing different rapeseed meals on hematological indices in broiler chicks. Zesz. Nuak. Akad. Roln. Wroclawiu, Weter, 198, 97-105.

KORELSKI, D.; RYS, R. 1987 : The performance of broiler chicks fed double low rapeseed oil meal. Proc. 7th Intern.Conf.Papeseed, Poznan,Poland.

KOSHELEVA, G; VERESHCHAK, V. 1986 : Rapeseed [meal] as a component of a feed mixture. Mukomol'no-elevatornaya-i-Kombikormovaya-Promyshlennost'. No. 2, 43-44.

KOZLOWSKA, H.; NOWAK, H. 1982 : Inactivation of myrosinase of rapeseed. Pol. pl. 118, 747 (U.A.23L1/2030.nov.1982,appl.222,043, 15, Feb,1980.

KOZLOWSKA, H.; NACZ, M.; SHAHIDI, F.; ZADERNOWSKI, R. 1990 : Phenolic acids and Tannins in rapeseed and canola, In: Shahidi, F.(ed):, Canola and rapeseed. Production,chemistry, nutrition and processing technology. Van Nostrand Reinhold : New York.

KOZLOWSKA, H.; DANIELA, R.; KOZLOWSKI, M.; FARUGA, A.; MIKULSKI, D. 1987 : Nutritional value of rapeseed meal obteined from hydrothermally treated seeds. Proc. 7th Intern.Conf.Papeseed, Poznan,Poland.

KOZLOWSKI, M; FARUGA, A 1989: Complete feed with double low (low erucic and low glycosinolate) rapeseed oilmeal in feeding broiler ducklings. Acta-AcademiaeAgriculturae-ac-Technicae-Olstenensis,-Zootechnica. No. 32, 205-219

KOZLOWSKI, M.; FARUGA, A.; MIKULSKI, D.; BOCK, H.D.; KOZLOWSKA, H.; ROTKIEWICZ, D.; KOZLOWSKI, K.; 1987 : Aufzuchtergebnisse bei den mit Futtermittelmischungen mit Rapsschrotanteil poninischer 00-und canadischer Canolasorte geffuterten Broileren. Proc. 7th Intern.Conf.Papeseed, Poznan,Poland.

KOZLOWSKI, M.; FARUGA, A.; MIKULSKI, D.; KOZLOWSKA, H.; ROTKIEWICZ, D.; KOZLOWSK, K. 1989a : Carcass analysis of broiler chickens fed on diets containing various rapeseed meals. Biuletyn Informacyjny Przemyslu Paszowgo 2으, 21-29.

KRALIK, G.; GALONJA, M.; NOVOSELOVIC, A.; FELDHOFER, S.; IVETIC, D.; VUKADINOVIC, B. 1996: Oilrape products in broiler feeding. Kramiva, $\underline{38}, 123-132$. 
KRYGIER, K.; SOSULSKI, F.W., HOGGE, L. 1982 : Free, estrified and insoluble phenolic acids. 2: Composition of phenolic acids in rapeseed flour and hulls. J. Agr. Food Chem. $\underline{30}, 334-$ 336.

KUMAR, K. G.; VENKATARAMAN, L. V.; JAYA, T.V.; AND KRISHNAMURTHY, K. S. 1978 :

Cooking characteristics of some germinated legumes; Changes in phytins, $\mathrm{Ca}^{++}$, $\mathrm{Mg}^{++}$, and pectins. J. Food Sci. $\underline{43}, 85$ - 88 .

LAJOLO, F.M.; ARQUEZ, U.M.; LANFER, F.C.; TULLIA, M.C.C.; MCGREGOR, D.I. 1991 : Chemical composition and toxic compounds in rapeseed(Brassica napus,L.) cultivar grown in Brazil. J. Agric. Food Chem. 푸, 1933-1937.

LARMOND, E.; SALMON, R.E.; KLEIN, K.K. 1980 : Sensory evaluation of turkeys fed diets containing Candle canola meal.In: 6th progr.Rept.Res on canola seed, oil, meal and meal fractions, Canola Council of Canada.

LARSEN, P.O. 1981 : Glucosinolates. In: P.K.Stumpf and E.E.Conn(eds) The chemistry of plants, A comprehensive Treatese. Vol. 7, Secondry Plant Products. Academic Press, New York.

LAURENA, A.C.; VAN, D T.; AND EVELYN MAE, T-M. 1984: The effects of condensed tannins on the in-vitro digestibility of cow pea. J.Agric. food Chem. $\underline{32}$, 1045-1048.

LEASE, J.G. 1966: The effect of autoclavingsesame meal on its phytic acid content and on the availability of its Zn to the chick. Poultry Sci. $\underline{45}, 237$ - 242.

LEE, K. H; OLOMU, J. M; SIM,-JS 1991: Live performance, carcass yield, protein and energy retention of broiler chickens fed canola and flax full-fat seeds and the restored mixtures of meal and oil. Can. J. Animal Sci. $\underline{71}$, 897-903.

LEE, P.A.; PITTAM, S.; HULL, R. 1984 : The voluntaty food intake by growing pigs of diets containing treated rapeseed meals of extracts of rapeseed meals. Br. J. Nutr. $\underline{52}$, 159164.

LEESON, S.; ATTEH, J.O.; SUMMERS, J.D. 1987 : The replacement value of canola meal for soybean meal in poultry diets. Can. J. Anim. Sci. $\underline{67}, 151-158$.

LEESON, S.; SUMMERS, J.D. 1976 : Effects of rapeseed meal on the carcass grading of broilers. Poultry Sci. $\underline{55}, 2465-2467$. 
LESLIE, A.J.; HURNIK, J.F.; SUMMERS. J.D. 1973 : Effect of colour on consumption of broiler diets containing rapeseed meal and rapeseed. Can. J. Anim. Sci. 53, 365-369.

LESLIE, A.J.; SUMMERS, J.D. 1972 : Feeding value of rapeseed meal for laying hens. Can. J. Anim. Sci. 52, 563-566.

LESLIE, A.J.; SUMMERS, J.D. 1975a : Amino acid balance of rapeseed meal. Poultry Sci. ㅁ4, 532538.

LESLIE, A.J.; SUMMERS, J.D.; GRANDHI, R.; LEESON, S. 1976 : Arginine-lysine relationship in rapeseed meal. Poultry Sci. 55, 631-637.

LESSIRE, M.; BAUDET, J.J. 1986 : Nutritional value of high or low glucosinolate rapeseed meal produced from whole or dehulled seeds. Proc. 7th European Poultry Sci Conferfence.

LEUNG, P.; MARCH, B.E. 1976 : The thyroidal response to chronic goitroginic stimulation and persestence of effects of early goitrogenic stimulation Can. J. Physiol. Pharmacol. $\underline{54}$, 583.

LEWIS, D:, SMITH, G.H.; PAYNE, C.G. 1963 : Arginine in poultry nutrition. 1. Dietary requirements for arginine. Br. J. Nutr. $\underline{17}, 415-431$.

LIN,S.; AND LAKIN, A.L. 1990 Thermal denaturation of soy proteins as related to their dye binding characteristics and functionality. JAOCS. $\underline{67}$, 872-878.

LIU, Y. G; ZHOU, M. Q; LIU, M. L 1993: A survey of nutrients and toxic factors in commercial rapeseed meal in China and evaluation of detoxification by water extraction. Anim. Feed.Sci.Tech. $\underline{45}$, 257-270.

LO, M.T.; HILL, D.C. 1971 : Evaluation of protein concentrates prepared from rapeseed meal.J. Sci. Food Agri. 22, 128-130

LOTT, J.N.A. 1985 : Accomulation of deed reserves of P and other minerals, In: Seed physiology, Vol. 1, Murray,d.r.(ed). Academic Press, Sydney, Australia.

MAGA, J.A. 1982 : Phytate: its chemistry, occurance, food interactions, nutritional significance and methods of analysis. J. Agr. Food. Chem. $\underline{30}$, 1-9. 
MANSOUR, EH; DWORSCHAK, E; LUGASI,-A; GAAL, O; BARNA, E; GERGELY, A 1993 :

Effect of processing on the antinutritive factors and nutritive value of rapeseed products. Food-Chem. 47, 247-252.

MARANGOS,A., AND HILL, R. 1974 : The hydrolysis and absorption of thioglycosides of rapeseed meal. Proc. Nutr. Soc. $\underline{33}$, 90A (abstract).

MARCH, B.E.; BRAGG, D.B.; SOONY, R. 1978 : Low erucic acid low glucosinolates rapeseed meal with and without added gums in the layer diet. Poultry Sci. 구, 1599-1604.

MARCH, B.E. 1987 : The inorganic P requirements of white leghorn chicks fed 30\% of dietary canola meal. In : 8th progr.Rept.Res on canola seed, oil, meal and meal fractions, Canola Council of Canada.

MARTLAND, M.F.; BUTLER, E.J.; FENWICK, G.R. 1984 : Rapeseed induced liver hammerage reticulolysis and biochemical changes in laying hens: the effect of feeding high and low glucosinolates meals. Res. Vet. Sci. $\underline{36}$, 298-309.

MATSOMOTO, T.; ITOH, H.; AKIBA, Y. 1968 : Goitrogenic effects of (-)-5-Venyl-2Oxazolidinthione, a goitrogen in rapeseed,in growing chicks. Poultry Sci. $\underline{47}, 1323-$ 1330.

MAWSON, R; HEANEY, RK; PISULA, M; KOZLOWSKA, H. 1993: Rapeseed meal-glucosinolates and their antinutritional effects. Part 1. Rapeseed production and chemistry of glucosinolates. Die Nahrung. $\underline{37}, 131-140$.

MAWSON, R.; HEANY, R.K.; PISKULA, M.; AND KOZLOWSKA, H. 1993 : Rapeseed meal glucosinolates and their antinutritiona effects 1 . Rapeseed production and chemistry of glucosinolates. Die Nahrung $\underline{37}, 131$ - 140.

MAWSON, R.; HEANY, R.K.; ZDUNCZYK, Z.; AND KOZLOWSKA, H. 1994 : Rapeseed meal glucosinolates and their antinutritiona effects 3 . Rapeseed production and chemistry of glucosinolates. Die Nahrung $\underline{38}, 167$ - 177

MAWSON, R.; HEANY, R.K.; ZDUNCZYK, Z. AND KOZLOWSKA, H. 1995 : Rapeseed meal glucosinolates and their antinutritiona effects 7. Processing. Die Nahrung $\underline{39}, 32$ - 41.

MCGREGOR, D.I. 1978 : Thiocyanate, a hydrolysis product of glucosinolates from rape and mustard seed. Can. J. Plant Sci. $\underline{58}, 795$. 
MEEROV, G.; GRIGOR'EVA, V. 1988 : Feed value of rapeseed oilmeal. Ptitserodstvo, $\underline{5}$, 41-43.

MILLER, D.; LEONG, K.C.; SMITH, P.J. 1969 : Effect of feeding and withdrawal of menhaden oil on the 3 and 6 fatty acid content of broiler tissue. J. Food Sci. $\underline{34}$, 136-139.

MONEAM, N.M.A. 1990. Effect of presoaking on faba bean enzyme trypsin inhibitor and polyphenols after cooking. J. Agric. Food Chem. $\underline{38}$, 1479-1482.

MOTHES, R.; SCHWENKE, K.; ZIRWER, D.; GAST, K.; WELFLE, H.1987 : Investigation of rapeseed protein phytic acid complexes. Proc. 7th Intern.Conf.Papeseed, Poznan,Poland.

MUZTAR, A.J.; SLINGER, S.J. 1980a : Apparant amino acid availability and apparant metabolizable energy value of tower and candle rapeseed and rapeseed meal. Poultry Sci. $\underline{59}, 1430-1433$.

MUZTAR, A.J.; SLINGER, S.J.; LIKUSKI, H.J.; DORRELL, J. 1980b : True amino acid availability values for soybean meal and tower and candle rapeseed and rapeseed meal. Poultry Sci. $\underline{59}, 605-610$.

NACZK, M.; SHAHIDI, F.; SULIVAN, A. 1992a : Recovery of rapeseed tannins by various solvent systems. Food Chem. $\underline{45}$, 51-54.

NACZK, M.; SHAHIDI, F.; DIOSDY, L.L.: AND RUBIN.L.J.; 1986 : Removal of glucosinolates from Midas rapeseed and mustard seed by methanol: ammonia. Can. Inst. Food. Sci. Technol. J. $\underline{19}, 75-77$.

NACZK, M.; SHAHIDI, F. 1989 : The effect of methanol-ammonia-water treatment on the content of phenolic acids in canola. Food Chem. $\underline{31}$, 13-16.

NACZK, M.; WANASUNDARA, P.K.P.D.; SHAHIDI, F.1992b: Facile Spectrophotometric quantification method of sinapic acid in hexane extracted and methanole ammonia water treated mustard and rapeseed meal. J. Agric. Food Chem. $\underline{40}$, 444-448.

NASI, M; SILJANDER-RASI, H. 1991 : Effects of thermal processing on digestibility and protein utilization of rapeseed meal of medium and low glucosinolate type in diets for growing pigs. Journal-of-Agricultural-Science-in-Finland. $\underline{63}$, 475-482. 
NASI, M; ALAVIUHKOLA, T; SUOMI, K. 1985 : Rapeseed meal of low- and high-glucosinolate type fed to growing-finishing pigs. Journal-of-Agricultural-Science-in-Finland.57, 263269.

NASSAR, A.R.; ARSCOTT, G.H. 1986a : Canola meal for broilers and the effect of dietary supplement of iodinated casien on performance and thyroid status. Poultry Sci. $\underline{65}$, 97(Abstr).

NASSAR, A.R.; ARSCOTT, G.H. 1986b : Canola meal for broilers and the effects of a dietary supplement of iodinated casien on performance and thyroid status. Nutr. Rept. Int. $\underline{34}$, 791-799

NEELOFAR, 1986: Effect of gamma irradiation and germination on phytate and selected nutrients of soybean. Ph.D thesis, University of Peshawar.

NEN, S.P.; VAKIL, U.K.; SREENIVASAN, A. 1975a : Effect of gamma irradiation on physiochemical characteristics of red gram starch. J.Food Sci. 40, 943-945.

NENE, S.P.; VAKIL, U.K.; SREENIVASAN, A. 1975b : Effect of gamma irradiation on physiochemical characteristics of red gram proteins. J.Food Sci. $\underline{40}, 815-817$

NISHIE, K.; DAXENBICHLER, M.E. 1980 : Toxicology of glucosinolates related compounds (nitriles, R.Goitrin, isothiocyanates) and vitamin found in Cruciferae. Food Cosmet. Toxicol. $\underline{18}, 159$.

NOWKOLO, N.; BRAGG, D.B.; KITS, W.D.1976b : The availability of amino acids from palm kernal, soybean, cotton,seed and rapeseed meal for growinh chickens. Poultry Sci. $\underline{55}$, 2300-2304.

NOWOKOLO, N.; BRAGG, D.B.; KITS, W.D. 1976a : A method for estimating the mineral availability in feedstuff. Poultry Sci. $\underline{55}, 2217-2221$.

NUGON-BAUDON, L; SZYLIT, O; RAIBAUD, P. 1988 : Production of toxic glucosinolate derivatives from rapeseed meal by intestinal microflora of rat and chicken. J. Sci. Food Agri. 43, 299-308.

NWOKOLO, N.; BRAGG, D.B. 1977 : Influence of phytic acid and crude fibre on the availability of minerals from four protein supplements in growing chickens. Can. J. Anim. Sci. $\underline{57}$, 475-477. 
OLIVER, S.L.; MCDONALD, B.E.; OPUSZYNSKA, T.; 1971 : Weight gain, protein utilisation and liver histochemistry of rats fed low and high-thioglucosides content of rapeseed meals. Can. J. Physiol. Pharmacol. $\underline{49}$, 448-456.

OLOGHOBO, A. D. AND FETUGA, B. L. 1984: Distribution of P and phytate in some Nigerian varieties of legumes and some effects of processing. J. Food Sci. $\underline{49}$, 199-203.

OLOMU, J.M.; ROBBLEE, A.R.; CLANDININ, D.R.1974 : Effects of processing and amino acid supplementation on nutritive of rapeseed for broilers. Poultry Sci. $\underline{53}, 175-184$.

OLSEN, O.; SÖRENSEN, H. 1981 : Recent advances in analysis of glucosinolates. J. Am. Oil Chem. Soc. $\underline{58}, 857-865$.

OPSTVEDT, J; MILLER, E. E; PIKE, I. H 1991: Complementary effects of fish meal with soyabean meal replacers in broiler diets. Technical-Bulletin---International-Association-of-FishMeal-Manufacturers. 1991, No. 26, 14 pp.

OPSTVEDT, J. 1974 : Influence of residiual lipids on nutritive value of fish meal. VI: Effect of addition to diets high in fish meal on fatty acid composition and flavour quality of broiler meat. Acta Agric. Scand. 24, 61-75

PAIK, I.K.; ROBBLEE, A.R. 1984 : Influence of feeding canola meal and seed on the level of thoicyanate ions in blood plasma and eggs of laying chickens. Han'guk $\mathrm{Ch}^{\prime}$ uksan Hakhiechi, 26, 541-544.

PAIK, I.K.; SHIRES, A.; ROBBLEE, A.R.; CLANDININ, D.R. 1984 : Amino acids balance of wheat canola meal diet for broiler starter chickens. Han'guk Ch,uksan Hakhoechi 26, 545-554.

PAIK, I.K. 1991: Nutritive value of processed rapeseed meal. Adv. Exp. Med. Biol. 289, 403-414.

PEARSON, A.W.; GREENWOOD, N.M.; BUTLER, E.J.; FENWICK, G.R.; CURL, C.L. 1983a : Rapeseed meal and egg taint; effects of B.compestris meal, progoitrine and potassium thiocyanate on trimethylamin oxidation. J. Sci. Food Agric. $\underline{34}$, 965-972.

PEARSON, A.W.; GREENWOOD, N.M.; BUTLER, E.J.; FENWICK,G.R. 1983b : Biochemical changes in layer and broiler chickens when fed on a high glucosinolates rapeseed meal. Br. Poultry Sci. 24, 417-427. 
PLONKA, S; KIEC, W; KORELESKI, J; PIORKOWSKI, J; STRZETELSKI, J; URBANCZYK, J; WINNICKA, I. 1985 : Extracted rapeseed meal in pig, poultry, cattle and sheep feeding. Biuletyn-Informacyjny,-Instytut-Zootechniki,-Zaklad-Informacji-Zootechnicznej. $\quad \underline{23}$, 31-45.

POKNIAK, J.; CORNEJO, S.; ROMOS, Z.O.; YANES, S.E. 1985 : Evaluation of three levels of rapeseed meal in a commercial broiler starter deit. Arch. Med. Vet. 17, 25-32.

PROUDFOOT, FG; HULAN, HW; MCRAE, KB 1983: Effect of feeding poultry diets suppleented with rapeseed meal as a primary protein source to juvenile and adult meat breeder genotypes. Can.J.Anim.Sci. $\underline{63}$, 957-965.

PUSUTAI, A. 1989 : Antinutritents in rapeseeds. Nutr. Rev. Abstr. 59(B), 427-433.

QUINSAC, A; LESSIRE, M; KROUTI, M; RIBAILLIER, D; COIC, JP; FAUDUET, H; ROLLIN, P 1994: Improvement in the nutritive value of high and low glucosinolate rapeseed meal by aqueous extraction. Anim. Feed Sci.Tech. $\underline{48}, 265-272$

RAMAMURTHI, J.; BUTLER, L.G.; , BANDYOPATHYAY, R.; AND MGHOGHO, L.K.; 1985: Polyphenol concentration in grain, leaf and mold resistant sorghum cultivars. J. Agric. Food Chem. 34, 425-427.

REBLOVA, Z.; PISKACOVA, J.; FARNIKOVA, L.; POKORNI, J.; MOSCICIKI, L.; MATYKA, S.; 1995: Influence of extrusion cooking on antinutritive substances in rapeseed - legume concentrates. Biuletyn Naukowy Przemystu Paszowego 34, 5-19.

REDDY, N.R.; SATHE, S.K.; SALUNKHE, D.K. 1982 : Phytates in legumes and cereals. Adv.Food Res. 28, 1-92.

REDDY, S.J.; PUBOLS, M.N.; MCGINNIS, J. 1979 : Effect of gamma irradiation on nutritional value of dry beans (Phaseolus volgaris) for chicks. J.Nutr. 109, 1307-1310.

REDDY, VR; REDDY, VR. 1987: Utilization of turnip (Brassica campestris) meal in the ration of White Leghorn chicks. Indian-J.Anim.Nutr. $\underline{3}$, 215-217.

REDDY,N.R.; BALAKRISHNAN, C.V. AND SALUNKHE, D.K. 1978: Phytate and mineral changes during germination and cooking of black gram seeds. J. Food Sci. $\underline{43}, 540$ 543.

RÖBBELEN, G. 1976 : Züchtung und Erzeugung von Qualitätsraps in Europa. Fette, Seifen, Anstrichm. 78, 10-17. 
ROBBLEE, A. R., CLANDININ,D.R., SLINGER, S.J., AND SUMMERS, J.D., 1978: in : Canadian rapeseed meal : Poultry and animal feeding Ed. Salmon, R.E. and Biely, J., Rapeseed Association of Canada, Publ. No. 51: 12-17.

ROGULSKI, W. 1989A: Nutritive value of non-protein nitrogen from post-extraction rapeseed meal. Roczniki-Nauk-Rolniczych.-Seria-B,-Zootechniczna. 105, 39-57.

ROGULSKI, W. 1989B: Non-protein nitrogen from post-extraction rapeseed meal. Roczniki-NaukRolniczych.-Seria-B,-Zootechniczna. 105, 7-37.

ROTKIEWICZ, T; KOZLOWSKI, M. 1984 : Morphology of the thyroid gland of broiler ducks fed an all-mash diet supplemented with rapeseed meal. Zeszyty-Naukowe-AkademiiRolniczo-Technicznej-w-Olsztynie,-Weterynaria. 15, 87-93.

ROTKIEWICZ, T; KOZLOWSKI, M; FARUGA, A; WISNIEWSKA SLEDZ, M; IKULSKI, D; KOZLOWSKA, H; ROTIEWICZ, D; KOZLOWSKI, K: 1993: Pathomorphologocal examination of thyroid glands and livers of broiler chickens fed with diets with maximum content of extracted rapeseed oilmeal of the Polish Jantar cultivar and Canadian canola. Acta-Academiae-Agriculturae-ac-Technicae-Olstenensis,-Veterinaria. $\underline{21}, 219-228$.

ROTKIEWICZ, T; RUTA, A; KOZLOWSKI, M; FARUGA, A; MIKULSKI, D; ROTKIEWICZ, D; KOZLOWSKA, H 1990 : Pathomorphology of thyroid glands and liver of broiler chicks fed diets containing rapeseed oilmeal of various cultivars. Acta-AcademiaeAgriculturae-ac-Technicae-Olstenensis,-Veterinaria, 19, 159-174.

ROTKIEWICZ, T., FARUGA, A.; ISSHAK,N.S.; KOZLOWSKI, M. 1988: Pathomorphology of thyroid gland and liver of broiler chickens fed on diets with different rapeseed meals. Acta Academica Agriculturae ac Technicae Olstenensis Veterinaria 17, 131-141.

SALMON, R.E.; GARDINER, E.E.; KLEIN, K.K.; LARMOND, E. 1981 : Effect of canola (low glucosinolate rapeseed ) meal, protein and nutrient density on performance, carcass grade, and meal yield of canola meal on sensory quality of broilers. Poultry Sci. $\underline{60}$, 2519-2528.

SALMON, R.E.;STEVENS, V.I.; LADBROOKE, B.D. 1991 : True amino acid availability of whole or flaked raw or cooked full fat or extracted canola meal. Proc. 8th GCIRC Intern. Congr. on rapeseed in a changing world, Saskatoon, Canada. 
SALMON, R.E., FRÖHICH, D.; BUTTLER, G. 1984 : Effect of canola meal fish meal, and choline plus methionine on the sensory quality of broiler chickens. Poultry Sci. $\underline{63}, 1994-1998$.

SALMON, R.E.1979 : Rapeseed meal in turkey starter diets. Poultry Sci. 58, 410-415.

SALMON, R.E.1982 : Canola meal and fish meal in turkey starter diets. Poultry Sci. $\underline{61}$, 2126-2128.

SANDMANN, M.; SCHÖN, WJ. 1987 : The proteins in rapeseed, composition and characterization. Proc. 7th Intern.Conf.Papeseed, Poznan,Poland.

SATTAR, A.; SHAH, A. B.; AURANGZEB. 1995 : Biosynthesis of ascorbic acid in germinating rapeseed cultivars. Plant Food for Human Nutrition 47, 63 - 70.

SCHADEREIT, R., JEROCH, H.; KESTING, S., KOZLOWSKI, M.; BOCK, H.-D.1987 : Comparison of double low rapeseed meal to soybean meal in feeding experiments on broiler chickens. Proc. 7th Intern.Conf.Papeseed, Poznan,Poland.

SCHÖNE, F; JAHREIS, G; MEIXNER, B 1989: Feeding copper-treated rapeseed meal to broilers by considering supply of iodine - influence on growth and thyroid hormone status. Die Nahrung. 33, 221-223.

SCHÖNE, F; JAHREIS, G; RICHTER, G; LANGE, R 1993: Evaluation of rapeseed meals in broiler chicks: effect of iodine supply and glucosinolate degradation by myrosinase or copper. J. Sci. Food Agri. 61, 245-252.

SCHOENE, F.; GROPPEL. B.; HENNIG. A.; JAHREIS, G.; LANGE. R. 1997: Rapeseed meals, methimazole, thiocyanate and iodine affect growth and thyroid: Investigations into glucosinolate tolerance in the pig. J. Sci. Food and Agr. $\underline{74}$, 69-80

SCHÖNE, F.; HENNIG, A.; GROPPEL, B.; LANGE, R. 1991 : Evaluation of low glucosinolates rapeseed meals in experiments with growing pigs and poultry. Proc. 8th GCIRC Intern. Congr. on rapeseed in a changing world, Saskatoon, Canada.

SCHÖNE, F.; JHARIS,G.; MEIXNER,B. 1989 : Feeding of broilers with rapeseed cake treated with copper ions with reference to the Iodine supply. Effect on growth and thyroid hormone status. Die Nahrung, $\underline{33}, 221-223$.

SCHWENKE, K.D.; MOTHES, R.; BOROWSKA, J.; KOZLOWSKA, H. 1986 : Interaction of phytic acid with $11 \mathrm{~s}$ and 2s protein from rapeseed (Brassica napus) Die Nahrung $\underline{30}$, 397-398. 
SETH, P.C.C.;CLANDININ, D.R.; HARDIN, R.T. 1975 : In-vitro uptake of Zinc by rapeseed meal and soybean meal .Poultry Sci. 54, 626-629.

SHAH, A. B.; AURANGZEB, SATTAR, A. 1993 : Effect of irradiation and other processing methods on the in-vitro digestibility of rapeseed proteins. J.Sci.Food. Agric. $\underline{61}$, 273275.

SHAHIDI, F 1990 : Canola and rapeseed. Production,chemistry, nutrition and processing technology. Van Nostrand Reinhold: New York, pp 355.

SHAHIDI, F.; NACZK, M. 1992 : An overvirw of the phenolics of canola and rapeseed: Chemical sensory and nutritional significance. J. Am. Oil Chem. Soc. $\underline{69}$, 917-924.

SHAHIDI, F.; NACZK, M.; HALL, D.; SYNOWIECKI, J. 1992 : Insensitivity of the amino acids of canola and rapeseed to methanole-ammonia extraction and commercial processing. Food Chem. 44, 283-285.

SHIRES, A.; BELL, J.M.; LAVERTY, W.H.; FEDEC, P.; BLAKE, J.A.; MCGREGOR, D.I. 1983 : Effect of desolventization condition and removal of fibrous material by screening on the nutritional value of canola rapeseed meal for broiler chickens. Poultry Sci. $\underline{62}, 2234-$ 2244.

SIONEK B; HANCZAKOWSKI P; DABROWSKI-K 1994: Effect of different stages of processing of improved rapeseed meal on the content of antinutritional substances and its nutritive value. Roczniki-Naukowe-Zootechniki. 21, 239-245.

SLINGER, S.J.; LEESON, S.; SUMMERS, J.D.; SADIQUE, M. 1978a : Influence of steam pelleting on the feeding value of tower and candle rapeseed products for broiler chickens. Anim. Feed Sci. Technol. $\underline{3}, 251-259$.

SLINGER, S.J.;SUMMERS, J.D.; LEESON, S. 1978b : Utilization of meal from a new rapeseed variety. Brassica compestris cv. candle in layer diets. Can. J. Anim. Sci. 58, 593-596.

SLINGER, S.J. 1977 : Improving the nutritional properties of rapeseed. J. Am. Oil Chem. Soc. $\underline{54}$, 94-99.

SLOMINSKI, B.A.; CAMPBELL, L.D.1985 : Origin of free isothiocyanate ions in the excreta of poultry fed canola meal. Can. J. Anim. Sci. $\underline{65}$, 1198(abstr). 
SLOMINSKI, B.A.; CAMPBELL, L.D. 1989 : The complex carbohydrate content of canola meal: influence on nutritive quality. Poultry Sci. $\underline{68}, 135$ (abstr).

SLOMINSKI, B.A.; CAMPBELL, L.D.; STANGER, N.E. 1983 : Influence of cecactomy and dietary antibiotics on the fate of ingested intact glucosinolates in poultry. Can. J. Anim. Sci. $\underline{67}$, 1117-1124.

SLOMINSKI, B.A.; CAMPBELL, L.D.; STANGER, N.E. 1988 : Extent of hydrolysis in the intestinal tract and potential absorption of intact glucosinolates in laying hens. J. Sci. Food Agri. $\underline{42}, 305-314$.

SMITH, T.K.; CAMPBELL, L.D. 1976 : Rapeseed meal glucosinolates; metabolism and effect on performance on laying hens. Poultry Sci. $\underline{55}, 861-867$.

SMULIKOWSKA, S.; PASTUSZEWSKA, B.; MIECZKOWSKA, A.; OCHTABINSKA, A. 1997 :

Chemical composition, energy value of chickens, and protein utilization in rats of rapeseed expeller cakes produced by different pressing technologies. J.Anim.and Feed Sci. 6, 109-121.

SÖRENSEN, H 1990 : Glucosinolates: Structure-Properties-Function. In: : Canola and rapeseed. Production,chemistry,nutrition and processing technology.ed. SHAHIDI,F.; Van Nostrand Reinhold: New York, pp 355.

STEEDMAN, C.D.; HAWRYSH, Z.J.; HARDIN,R. T.; ROBBLEE, A.R. 1979a : Influence of rapeseed meal on the eating quality of chickens. I. Subjective evaluation by a trained taste panel and objective measurements. Poultry Sci. $\underline{58}, 148-155$.

STEEDMAN, C.D.; HAWRYSH, Z.J.; HARDIN, R.T.; ROBBLEE, A.R. 1979b : Influence of rapeseed meal on the eating quality of chickens. II. Subjective evaluation by a conaumer taste panel. Poultry Sci. $\underline{58}, 337-340$.

STEFANSSON, B.R.; KONDRA, Z.P. 1975 : Tower summer rape. Can. J. Plant Sci. 55, 343-344.

SUMMERS, J.D.;BAILY, H.S.; PEPPER, W.F.; SLINGER, S.J. 1969 : The value of rapeseed meal for growing pullets and laying hens. Can. J. Anim. Sci. $\underline{49}, 97-103$.

SUMMERS, J.D.;BEDFORD, M.; SPRATT, D.1989 : Amino acid supplementation of canola meal. Can. J. Anim. Sci. $\underline{69}$, 469-475. 
SUMMERS, J.D.;BEDFORD, M.; SPRATT, D.1990a : Interaction of calcium and sulfur in canola and soybean meal diets fed to broiler chicks. Can. J. Anim. Sci. 70, 685-694.

SUMMERS, J.D.; LEESON, S. 1977a : Effect of thyroxine and thiouracil addition to the diets containing rapeseed meal on chick growth and carcass composition. Poultry Sci. $\underline{56}, 25-$ 35.

SUMMERS, J.D.; LEESON, S.1978 : Feeding value and amino acid balance of low glucosinolates B.napus (cv. Tower) rapeseed meal. Poultry Sci. 57, 235-241.

SUMMERS, J.D.; LEESON, S.;1985a : Available sodium and potassium in canola and soybean meals. Can. J. Anim. Sci. $\underline{65}$, 211-216.

SUMMERS, J.D.; LEESON, S.1985c : Mineral profile of canola mealand soybean meal. Can. J. Anim. Sci. 65, 913-919.

SUMMERS, J.D.; LEESON, S.1986 : Amino acid supplemmentation of canola and soybean meal. Nutr. Rept. Intern. $\underline{34}$, 447-456.

SUMMERS, J.D.; PEPPER, W.F.; MORAN, E.T.JR. BAILY, H.S. 1967 : Utilisation of rapeseed meal as a source of proteinfor turkeys. Can. J. Anim. Sci. 47, 131-136.

SUMMERS, J.D.; SPRATT, J.D.; BEDFORD, M. 1990b : Factors influencing the response of broiler chickens to calcium supplementation of canola meal. Poultry Sci. $\underline{69}, 615-622$.

SUMMERS, J.D.; SPRATT, J.D.; BEDFORD, M. 1992 : Sulphur and calcium supplementation of soybean and canola meal diets. Can. J. Anim. Sci. $\underline{72}$, 127-133.

SZYMKIEWICZ, M.M.; JAN, N.; STEPINSKA, M. 1988 : Transaminase (ASPT+ALAT), alkaline phosphatase, total protein and cholesterol in blood serum of chicks fed rapeseed meal. Anim. Sci. 21, 61-64.

TAO, R.; BELZILE, R.J.; BRISSON, G.J. 1971 : Amino acid digestibility of rapeseed meal fed to chickens: effect of fat and lysine supplementation. Can. J. Anim. Sci. 51, 507-509.

TAPPER, B.A., READY, P.F. 1973 : Cyanogen glycosides and glucosinolates, In: Chemistry and biochemistry of Herbage Vol. 1. Butler,G.W., Baily,r.W.(eds), Academic Press, London. 
TAYARANIAN, H.; HENKEL, H.1991 : Processing of rapeseed to reduce the content of sinapine and glucosinolates. Proc. 8th GCIRC Intern. Congr. on Rapeseed in a Changing World, Saskatoon, Canada.

THOMAS, V.M.; KATZ, R.J.; AULD, D.A.; PETERSEN, C.F.; SAUTER, E.A.; STEEL, E.E. 1983 : Nutritional value of expeller extracted rapeseed and safflower oil seed meal for poultry. Poultry Sci. $\underline{62}, 882-886$.

THOMPSON, L.U.; CHO, Y. 1984a : Effect of acylation upon extractability of N, minerals, PA in rapeseedflour and protein concentrates. J. Food Sci. 49, 771-776.

THOMPSON, L.U.; CHO, Y. 1984b : Chemical composition and functional properties of acylated low phytate rapeseed protein isolate. J. Food. Sci. $\underline{49}$, 1584-1588.

THOMPSON, L.U. 1987 : Reduction of PA in protein isolates by acylation technique. J. Am. Oil Chem. Soc. $\underline{64}, 712-717$.

THOMPSON, L.U. 1990 : Phytates in canola/rapeseed. In: SHAHIDI,F:, : Canola and rapeseed. Production,chemistry, nutrition and processing technology. Van Nostrand Reinhold: New York.

TIMMS,-LM 1983 :Forms of leg abnormality observed in male broilers fed on a diet containing 12.5 per cent rapeseed meal. Res.Vet.Sci. $\underline{35}$, 182-189.

TITTO, R.. J. 1985: Phenolic constituents on leaves of northern willows: Methods for the analysis of certain phenolics. J.Agric. Food Chem. $\underline{33}$, 213-217.

TKACHUK, R. 1969 : Nitrogen to protein conversion factors for cereals and oilseed meals. Cereal Chem. $\underline{46}, 419-422$.

TREFNY, D; SOVA, Z; PETKOV, S; VODICKOVA, H; FUKAL, L; HOLOUBEK, J. 1990: The possibility of influencing the strumigenic action of rapeseed meal in fattened chickens and turkey poults by adding iodine and zinc to their diets. Biologizace-a-ChemizaceZivocisne-Vyroby,-Veterinaria. 26, 293-302.

TREFNY, D.; SOVA, Z.; PETKOV, S.; FUCIKOVA, A.; FUKAL, L.; VRABEC, P.; VIT, M. 1986 : Biological aspects of using the 00-rape meal or feeding in Czechoslovakia. Proc. 7th Intern.Conf.Papeseed, Poznan,Poland. 
TREFNY, D.; SOVA, Z.; PETKOV, S.; FUCIKOVA, A.; FUKAL, L.; VRABEC, P.; VIT, M.; ZAK, P. 1989 : Physiological aspects of using rapeseed oil meal in fattening broiler chickens. Rada B,Zivocisna Vyroba 51, 17-30.

TZENG, Y.M.; DIOSADY, L.; RUBIN, L. 1988a : Preparation of rapeseed protein isolate using ultrafiltration, precipitation and diafiltration. Can. Inst. Food Sci. Tech. J. 21, 419-424.

TZENG, Y.M.; DIOSADY, L.; RUBIN, L. 1988b : Preparation of rapeseed protein isolate by Nahexametaphosphate extraction, ultrafiltration, diafiltration and ion exchange. J. Food. Sci. $\underline{53}, 1537-1541$.

TZENG, Y.M. 1987 : Process development for production of high quality rapeseed (canola) isolate by memberane technology. Ph.D. thesis Univ. Toronto.

UNDERHILL, E., AND KIRKLAND,D. F., 1980: Glucosinolates in secondary pland products: Encyclopedai of plant physiology, new series, ed. E.A. Bell and Charlwood. Berlin: Springer-Verlag. $\underline{8}, 493-511$.

VALDERRABANO, J; URIARTE, J 1988: Effect of fish meal supplement on the intake and performance of lactating ewes fed on turnips (Brassica campestris var. rapa). ITEAInformation-Tecnica-Economica-Agraria. 19, 12-20.

VAN BAUREN, J.P.; ROBINSON, W.P. 1969 : Formation of complexes betweenprotein and tannic acid. J. Agric. Food Chem. 17, 772-777.

VERMOREL, M; HOCQUEMILLER, R; EVRARD, J. 1987 : Valorization of rapeseed meal. 5. Effects of sinapine and other phenolic compounds on food intake and nutrient utilization in growing rats. Reproduction,-Nutrition,-Developpement. 27, 781-790.

VERMOREL, M; BAUDET, J.J. 1987: Valorization of rapeseed meal. 2. Nutritive value of high or low-glucosinolate varieties and effect of dehulling. Reproduction,-Nutrition,Developpement. 27, (1A) 45-55.

VOGT, H.; SCHUBERT, H.J.; STUTE, K.; RAUCH, W. 1969b : Futterwert und Einsatz von Rapsschrot in der Geflügelfutterung.3 Mitteilung; apsschrot in der Legehennenfütterung. Arch. Geflugelk. $\underline{33}$, 119-124.

VOGT, H.; SCHUBERT, H.J. 1969 : Futterwert und Einsatz von Rapsschrot in der Glügelfutterung.2 Mitteilung Arch. Geflugelk. 33, 42-46. 
VOGT, H.; SCHUBERT, H.J.;STUTE, K. 1967 : Futterwert und Einsatz von Rapsschrot in der Geflügelfutterung.1 Mitteilung. Arch. Geflugelk. 31, 225-244.

VOGT, H.; SCHUBERT, H.J.; STUTE, K.1969a : Futterwert und Einsatz von Rapsschrot in der Geflügelfutterung.4 Mitteilung; Zweiter Legehennen Versuch mit Rapsschrot. Arch. Geflugelk. $\underline{33}$, 392-395.

VOGT, H.; STUTE, K. 1974 : Führt eine Senkung des Venyl-Oxazolidinthion-Gehaltes zu einer Verbesserung des Futterwertes von Rapsextrationsschrote in Geflügel futter. Arch. Geflugelk. $\underline{38}, 127-138$.

VOGT, H.; TORGES, H.G. 1976 : Rapsextractionsschrot aus einer erucasaüre- und glucosinolatarmen Sommerrapssorte in Legehennenfutter. Arch. Geflugelk. $\underline{40}$, 225231.

VYMOLA, J.; KODES, A.; OBEDALEK, J.; 1995: Rapeseed cakes in diets for broiler chicks. Zivocisna Vyroba 40, 407-409.

WAIBEL, P. E; NOLL, S. L; HOFFBECK, S; VICKERS, Z. M; SALMON, R. E 1992 : Canola meal in diets for market turkeys. Poultry-Sci. $\underline{71}, 1059-1066$

WAIBEL, P.E.; NOLL, S.L.; HOFFBECK, S.; VICKERS, Z.M.;SALMON, R.E. 1990 : Canola meal in market Turkey diets. Poultry Sci. $\underline{69}$, 138(abstr).

WASER, J.; WATSON, W.H. 1963 : Crystal structure of sinirgin. Nature 198, 1297-1298.

WETSCHERECK. W.; LETTNER, F.; WÜRZNER, H.1990 : Einsatz von Rapsexpeller in der Geflügelmast. Arch. Geflugelk. 54, 57-60.

WHITING, S.J.; COLE, D.E.C. 1986 : Effect of dietary anion composition on acid-induced hyper calciuria in the adult rat. J. Nutr. $\underline{116}, 388-394$.

WHITING, S:J:, DRAPPER, H.H. 1981 : Effect of chronic acid load as sulfate or lulfur amino acids on bone metabolism in adult rats. J. Nutr. $\underline{111}$ 1721-1726.

WIGHT, P.A.L.; SCOUGEL, R.K.; SHANNON, D.W.F.; WELLS, J.W.; MAWSON, R.1987 : Role of glucosinolates in the causation of liver haemmorrhage in laying hens fed water extracted or heated cakes. Rev. Vet. Sci. $\underline{43}$, 313-319. 
WIGHT, PAL; WELLS, JW; SHANNON, DWF. 1986: Liver haemorrhages induced by rapeseed meal: incidence in adult male and female fowls. British-Poultry-Science. 27: 2, $247-$ 252.

WOODLY, A.; SUMMERS, J.D.; AND BALINSKI, W.K. 1972 : Effect of heat treatment on the nutritive value of rapeseed for poultry. Can.J.Anim. Sci. 52, 189-194.

WÜRZNER, H.; WETSCHEREK, W.; LETTNER, F. 1989 : Rapsextractionsschrot in der Hünermast. Arch. Geflugelk. 53, 6-12.

YAW, O.A.J.; MYLES, M. 1991 : Microwave inactivation of myrosinase in canola seeds; a pilot plant study. J. Food Sci. $\underline{56}$, 1372-1374.

YIU, S.H.; POON, H.; FUCHLER, R.G.; ALTOSAAR, I. 1982 : The microscopic structure and chemistry of rapeseed and its products. Food Microstruct. $1,135.143$.

YOUNG, C. G. 1965: Processing of rapeseed meal for livestock and poultry. Publ. No. 1257, Canadian dept. of agriculture, Canada.

YULE, W.J.; MCBRIDE, R.L. 1976 : Lupin and rapeseed meals in poultry diets.: Effects on broiler performance and sensory evaluation of carcass. Br. Poultry Sci. 17, 231-239.

ZUPRIZAL; LARBIER, M; CHAGNEAU, A. M; LESSIRE, M 1991: Effect of protein intake on true digestibility of amino acids in rapeseed meals for adult roosters force fed with moistened feed. Anim. Feed Sci. Tech. $\underline{34}$, 255-260.

ZUPRIZAL, L.; CHEGNEAU, A.M. 1991 : Bioavailability of lysine in rapeseed and soybean meals determined by digestibility trials in cockerels and chick growth assay. Anim. Feed Sci. Technol. $\underline{35}, 237-246$. 


\section{ACKNOWLEDGEMENTS}

I would like to express my sincere gratitude to my very kind and considerate Ph.D. supervisor Prof. Dr. Udo ter Meulen, for his guidance and advice. He maintained a very friendly atmosphere and I never hesitated to discuss with him any of my problems during the course of my masters and subsequent doctoral studies. I am also thankful to Prof. Dr. K. Eder, my co-supervisor, who, despite his very busy schedule, spared some time to check my thesis. His valuable suggestions and corrections have definitely added value to my work.

I would also like to convey my thanks to Dr. Mohammad Mohsin Iqbal, Director Nuclear Institute for Food and Agriculture (NIFA), Peshawar Pakistan, for his kind support to carry out my doctoral research and in the write-up of this thesis.

I feel greatly indebted to my co-supervisor Dr. Abdus Sattar, Head, Food Science Division, Nuclear Institute for Food and Agriculture (NIFA), Peshawar Pakistan, for his constant encouragement, enthusiastic support, sincere guidance, elderly advice and constructive criticism during the entire course of my research and compilation of this thesis. His pushing support has always been a source of inspiration for me in the pursuit of higher goals.

I owe a great deal to all my colleagues at NIFA Peshawar, who have contributed a lot in terms of good wishes, moral support and practical help. I am thankful especially to Mr. M. Ashraf Chaudry, Mr. Amal Badshah, Mrs. Nizakat Bibi, Mr. Anwar Ahmed, Mr. Saeed Gul, and Mr. Sajjad Ali for their valuable assistance during the research period and writing of this dissertation.

I am also thankful to all my colleagues at the Institute of Animal Physiology and Animal Nutrition at the University of Göttingen for their moral support. Special thanks are due to Mr. Klaus Grow for his help at the institute during my stay in Germany. 


\section{CURRICULUM VITAE}

Name

Nationality

Date of birth

Place of birth

Marital Status

Home address

1965-1968

1969-1974

1975-1976

1977-1980

1981-1983

1984-1990

1991- to date

$1991-1993$
AURANG ZEB

Pakistani

17.08.1957

Akora Khattat, Distt. Peshawar, Pakistan

Married - three children

Nuclear Institute for Food and Agriculture

(NIFA)Tarnab -Peshawar
M.Sc. (Tropical

Agriculture)

Primary education

Secondary education

Higher Secondary

B.Sc.(Hons) Agri.

M.Sc.(Hons) Agri.

Scientific Officer

Senior Scientific Officer

Since1993 Carried out research for obtaining Doctor Degree

Government Primary School Akora Khattak

Government High School Akora Khattak

Government College Nowshera

Faculty of Agriculture, Peshawar University

N.W.F.P. Agricultural University, Peshawar

Nuclear Institute for Food and Agriculture

(NIFA)Tarnab -Peshawar

Nuclear Institute for Food and Agriculture

(NIFA)Tarnab -Peshawar

Faculty of Agriculture,

Georg-August University, Goettingen, Germany 